\title{
Using heated column experiments to investigate the effects of in-situ thermal recovery operations on groundwater geochemistry in Cold Lake, Alberta
}

\author{
by
}

\author{
Andrew T. Craig
}

A thesis submitted to the Faculty of Graduate and Postdoctoral

Affairs in partial fulfillment of the requirements for the degree of

\author{
Master of Science \\ in \\ Earth Sciences \\ Carleton University \\ Ottawa, Ontario, Canada
}

(C) 2017, Andrew T. Craig 


\section{$\underline{\text { Abstract }}$}

Groundwater monitoring studies of the Cold Lake-Beaver River (CLBR) basin in Alberta, Canada have linked increases in arsenic concentration to subsurface heat release caused by insitu thermal recovery operations. In-situ thermal recovery is an extraction technique that is used throughout the CLBR and Athabasca Basins to mine viscous unconventional oil at depths below $80 \mathrm{~m}$ by injecting steam through thermal wells at $200^{\circ} \mathrm{C}$ to $300^{\circ} \mathrm{C}$ into a target reservoir. As the steam is pumped towards the oil deposit, heat is dissipated from the thermal well into the surrounding aquifer layers over the course of one to two-month periods during the steam saturation process.

Aquifer sediments that are exposed to these localized elevated temperature conditions undergo increased rates of water-rock interactions that favour mineral dissolution and desorption of surface complexes. Sulfide and iron oxyhydroxide minerals have been identified in the aquifer sediments as primary carriers of arsenic within the CLBR basin which have the potential to liberate contaminants in potable groundwater sources at near-neutral $\mathrm{pH}$ levels.

Preliminary laboratory experiments have shown an increased rate of reaction at temperatures $>80^{\circ} \mathrm{C}$ with respect to mineral dissolution and the release of constituents, including arsenic and heavy metals, with aquifer sediments from Cold Lake, Alberta. However, previous studies have not incorporated reactive transport processes into their research. To investigate the hydrogeochemical mechanisms of aquifer heating and solute transport in detail, a series of experiments were performed using a novel heated column design. The heated column apparatus is able to simulate the geochemical reactions and physical flow of saturated aquifer materials in contact with a thermal recovery well, while allowing temperature and water geochemistry to be monitored regularly over time at discrete locations. 
In this study, three separate heated column experiments were carried out using different mineralogical compositions of saturated aquifer materials, while maintaining a temperature gradient of $50^{\circ} \mathrm{C}$ to $90^{\circ} \mathrm{C}$, and a constant flow rate of one pore volume per week. Aquifer materials that were used in the three experiments included: (a) 30/40 mesh quartz sand; (b) 30/40 mesh quartz sand with $0.6 \% \mathrm{w} / \mathrm{w}$ pyrite; and (c) sand and gravel sediments collected from the Empress formation aquifer within the CLBR region. For the experiments that had sediments containing sulfide minerals, the column apparatus was kept in an anaerobic chamber and input water was purged using nitrogen gas in order to better simulate anoxic subsurface conditions.

Results from the heated column experiments showed that metal and non-metal constituents were liberated from each of the test materials when subjected to temperatures up to $90^{\circ} \mathrm{C}$. Higher concentrations of these constituents were generally found at locations downgradient of the heating area, while comparatively lower concentrations were observed within and upgradient of the heating area. Furthermore, heated column experiments conducted using sulfidic materials in aerobic conditions showed higher concentrations of oxidized species $\left(\mathrm{SO}_{4}\right)$ and dissolved metals and non-metals, whereas the anaerobic experiments generated higher concentrations of reduced species $\left(\mathrm{HS}^{-}, \mathrm{Fe}^{2+}\right)$ and generally lower concentrations of dissolved metals and non-metals.

Mechanisms for the release of constituents under aerobic conditions are consistent with the oxidative dissolution of sulfide minerals, and rapid oxidation of $\mathrm{Fe}$ and $\mathrm{S}$ species. These processes were found to influence dissolved oxygen, $\mathrm{pH}$, silicate and carbonate buffering, and precipitation of Fe oxyhydroxide minerals. Processes occurring under anaerobic conditions were shown to rely on slower rates of sulfide mineral dissolution and desorption of sulfate and trace metals. 
The heated column experiments have allowed for an improved understanding of the hydrogeochemical reactions that occur under heated aerobic and anaerobic experiments from different material compositions. Overall results of this research indicate that further research involving field and numerical modeling investigations are needed to study and understand the effects of heating within subsurface aquifers. Furthermore, these research outcomes will allow for more informed decisions by energy and environmental policy makers when assessing risks to potable water quality from in-situ thermal oil recovery operations. 


\section{Acknowledgments}

First, I would like to say thank you to my supervisor and mentor Dr. Richard Amos for his genuine support, guidance and encouragement throughout the development of this research project. I am grateful for the time and effort that Richard always made to meet and discuss a wide array of aspects related to the project and share his insights and knowledge. This project was a true collaboration between both of us and I feel privileged to have had such an opportunity.

I would also like to thank my committee members, Dr. Paul Gammon and Dr. Danielle Fortin, for their useful feedback to improve the thesis. In particular, Paul has been extremely helpful with his suggested improvements for the column experiments, as well as providing the resources and equipment necessary to conduct further laboratory experiments and analysis at the Geological Survey of Canada. I would like to thank Paul's colleagues Pierre Pelchat and Isabelle Girard for their valuable expertise and help in developing methods used in Chapter 3.

I was very fortunate to participate in courses at the University of British Columbia, University of Waterloo and University of Quebec (Abitibi-Témiscamingue) over the course of my degree and learn from experts in the fields of hydrogeology, geochemistry and geochemical modelling including Drs. Uli Mayer, Ed Sudicky, Bruno Bussière, Benoit Plante, Isabelle Demers and Carmen Neculita. While attending Carleton, I also had the privilege of learning from extremely knowledgeable professors Dr. Ian Clark and Dr. Tom Al at the University of Ottawa, who I truly admire and respect. It was a collection of knowledge passed down from these experts and their ability to communicate it clearly that helped me to understand more of the complexity associated with hydrogeochemical systems. 
Special thanks are in order to lab assistants Andrew Hicks and Robert Turnbull who helped setup, disassemble and fix the column as needed and perform analytical tasks. I would also like to thank my friends outside of school, at Carleton and at the University of Ottawa for all the good times we shared.

I would especially like to thank my partner Kelsey and my family - Glenn, Laura, Dayle and Robyn, for being a constant source of support and love throughout this journey. I am truly grateful that they have inspired me to pursue my own curiosity and learn more about what I find fascinating. Thank you all so much. 
Table of Contents

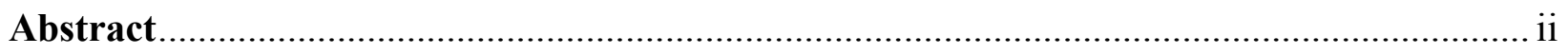

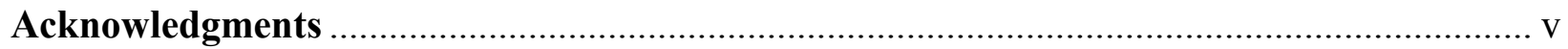

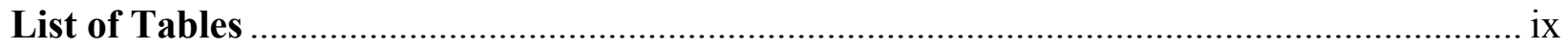

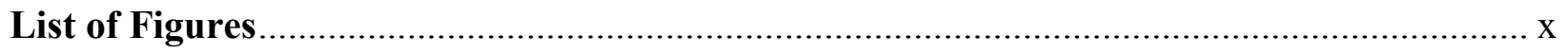

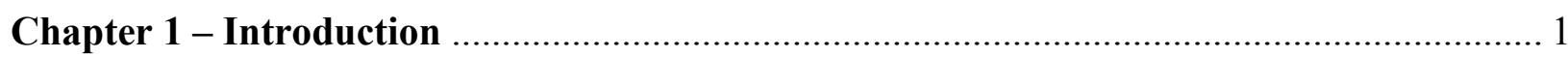

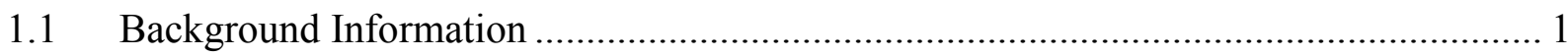

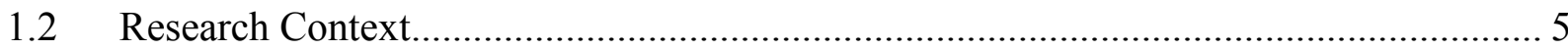

$1.3 \quad$ Experiment Objectives and Purpose …..................................................................... 7

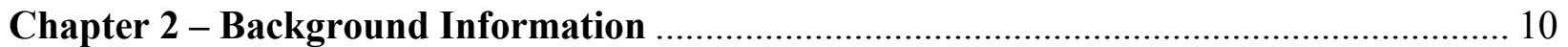

2.1 Geology and Hydrogeology in Cold Lake, Alberta ............................................... 10

2.1.1 Geochemistry of the Cold Lake Sediments and Solid Phase Arsenic .................. 15

2.1.2 Hydrogeochemistry of Groundwater in the CLBR Basin and Dissolved Arsenic . 17

2.2 Temperature Affected Hydrogeochemical Processes ............................................ 21

2.2.1 The Effects of Temperature on Thermodynamic and Kinetic Reactions .............. 21

2.2.2 The Effects of Localized Heating on Groundwater Flow and Mass Transport ...... 25

2.3 Changes to Groundwater Geochemistry from Anthropogenic Aquifer Heating............ 31

Chapter 3 - Materials and Methods.......................................................................... 42

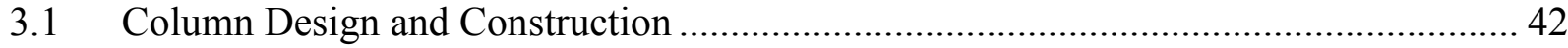

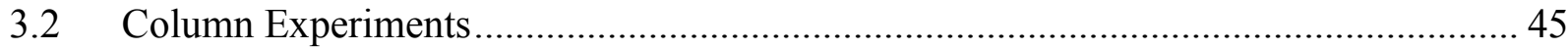

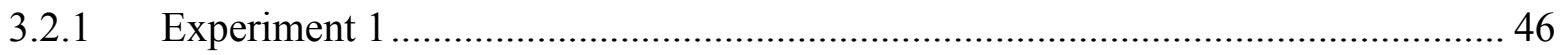

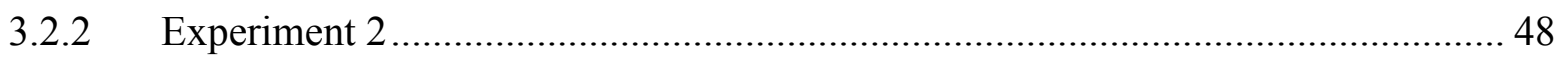

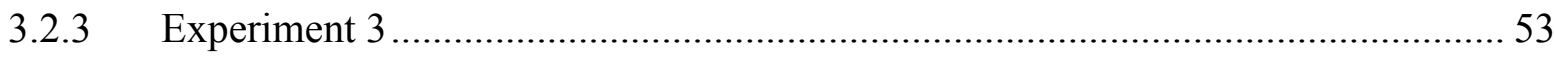

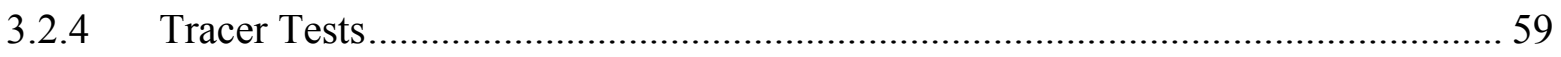

Chapter 4 - Experiment Results and Observations ................................................... 61

4.1 Bromide Tracer Tests and Modeled Data .................................................................. 61

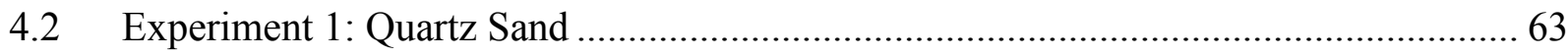

4.2.1 Geochemical Conditions and Physical Characteristics ...................................... 63

4.3 Experiment 2: Quartz Sand and 0.6\% w/w Pyrite................................................ 66

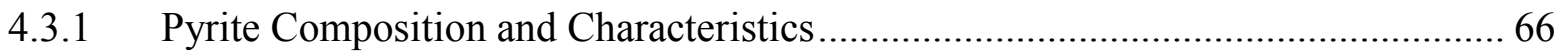

4.3.2 Aerobic Heated Experiment ......................................................................... 68 
4.3.3 Anaerobic Heated Experiment.......................................................................... 70

4.4 Experiment 3: Aquifer Sediments from Cold Lake, Alberta ………………............... 84

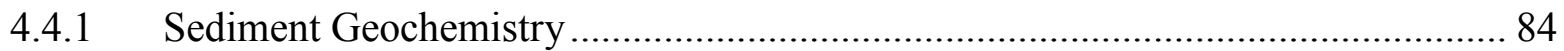

4.4.2 Sulfur Sequential Extractions ........................................................................ 90

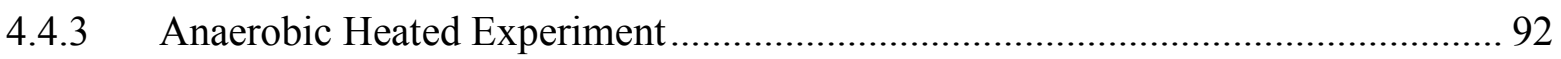

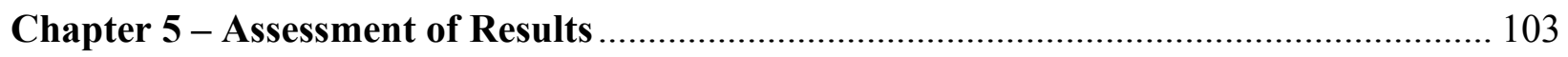

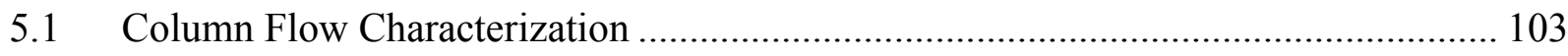

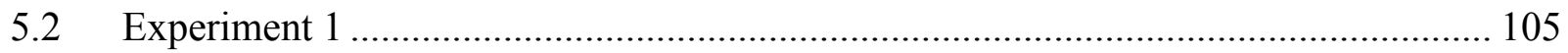

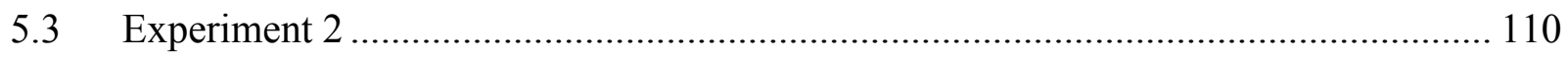

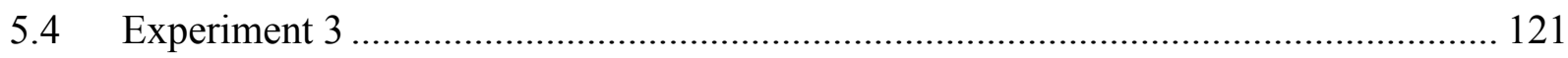

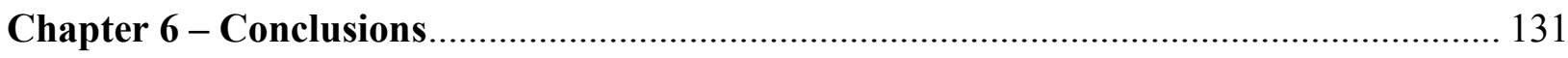

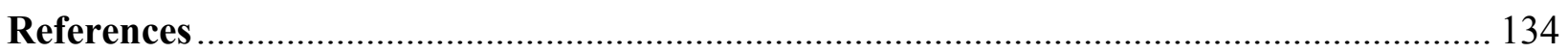

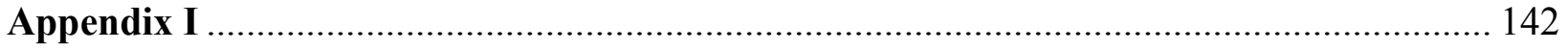




\section{$\underline{\text { List of Tables }}$}

Table 1. A summary of the water sampling and analytical regime used for the aerobic and anaerobic phase of Experiment 2 ............................................................................ 52

Table 2. A summary of the water sampling and analytical regime used during Experiment 3... 54

Table 3. Sulfur sequential extraction process used for the CLBR sediments. 56

Table 4. Hydraulic parameters from the unheated and heated $\mathrm{Br}$ tracer tests and breakthrough curves during Experiment 1 .

Table 5. Hydraulic parameters from the unheated and heated $\mathrm{Br}$ tracer tests and breakthrough curves during Experiment 2.

Table 6. Hydraulic parameters from the unheated and heated $\mathrm{Br}$ tracer tests and breakthrough curves during Experiment 3.

Table 7. LA-ICP-MS results summary of the most abundant trace element concentrations for select pyrite $\left(\mathrm{FeS}_{2}\right)$ grains.

Table 8. Total element concentrations of the digested sediment samples.

Table 9. Sequential extraction results for sulfur in each extraction phase.

Table 10. Phase 1, 2 and 3 a sequential extraction results for elements apart from sulfur. 


\section{List of Figures}

Figure 1. An aerial photo of the thermal operations north of Cold Lake, Alberta. The network of beige square areas indicates the location of the in-situ recovery steam injection well pads (Google Earth, 2017). 3

Figure 2. Schematic diagram of a typical SAGD operation where steam injection causes heat (shown in red) to emitted into the aquifer layers and migrates according to the groundwater flow direction.

Figure 3. The overall stratigraphy and geological formations of the unconsolidated sediments present in the CLBR basin (Andriashek, 2003; Parks et al., 2005; Fennel, 2008).

Figure 4. The five separate groundwater flow systems within the Cold Lake-Beaver River basin. (Parks et al., 2005).

Figure 5. The schematic design of the laboratory set-up used for the aerobic column experiments. Note that the refrigerator was installed following Experiment 1.

Figure 6. A photo of the sediments used in Experiment 2. The bulk material is comprised of $30 / 40$ mesh quartz sand containing $0.6 \% \mathrm{w} / \mathrm{w}$ pyrite (grains circled in red). The scale provided is shown in millimeters. 48

Figure 7. Laboratory set-up used for the anaerobic column experiments (not showing the sealed lid). The clear anaerobic chamber contains the column apparatus and the input water pump.... 50 Figure 8. A photo of the homogenized sediments collected from borehole WR99-1 used in Experiment 3.

Figure 9. The sequential extraction apparatus used in for leaching amorphous and crystalline sulfur fractions from the CLBR sediments.

Figure 10. $\mathrm{pH}$ data collected over the column profile during the unheated ('Baseline') and heated conditions (Weeks 1 to 9) from Experiment 1. The red shaded area from $1.0 \mathrm{~m}$ to $1.9 \mathrm{~m}$ represents the heating section, as well as the area where downgradient temperatures were elevated in comparison to ambient conditions. The blue shaded area from $1.9 \mathrm{~m}$ to $2.4 \mathrm{~m}$ indicates where the cooling section is located.

Figure 11. Concentration profile of dissolved Si throughout the column during unheated ('Baseline') and heated (Week 1 to Week 9) conditions from Experiment 1 65

Figure 12. SEM micrograph of a pyrite grain used in the column material for Experiment 2... 66 Figure 13. $\mathrm{pH}$ profile of the column during aerobic unheated ('Baseline') and heated phase (top) and heated anaerobic phase (bottom) of Experiment 2 .

Figure 14. Dissolved oxygen profile of the column during the aerobic unheated ('Baseline') and heated phase (top) and heated anaerobic phase (bottom) of Experiment 2. 72

Figure 15. Sulfate profile of the column during the aerobic unheated ('Baseline') and heated phase (top) and heated anaerobic phase (bottom) of Experiment 2..... 73

Figure 16. Sulfide profile of the column during Week 2 and Week 8 the aerobic heated phase (top) and Week 1 and Week 7 of the heated anaerobic phase (bottom) of Experiment 2. 74

Figure 17. Ferrous iron profile of the column during the aerobic unheated ('Baseline') and heated phase (top) and Week 3 of the heated anaerobic phase (bottom) of Experiment 2. 76 
Figure 18. Al, $\mathrm{Cu}$ and $\mathrm{Fe}$ concentrations along the profile of the column during the unheated ('Baseline') and heated aerobic phase (Week 1, 3, 5, 7 and 10) shown on the left, and the heated anaerobic phase (Week 2 and Week 8) shown on the right, of Experiment 2......................... 78

Figure 19. $\mathrm{Mn}, \mathrm{Ni}$, and $\mathrm{Zn}$ concentrations along the profile of the column during the unheated ('Baseline') and heated aerobic phase (Week 1, 3, 5, 7 and 10) shown on the left, and the heated anaerobic phase (Week 2 and Week 8) shown on the right, of Experiment 2.......................... 79

Figure 20. $\mathrm{Ca}, \mathrm{K}$ and $\mathrm{Mg}$ concentrations along the profile of the column throughout the unheated ('Baseline'), heated aerobic (Week 1, 3, 5, 7 and 10), and heated anaerobic phase (Week 2 and Week 8) from Experiment 2.

Figure 21. $\mathrm{Na}, \mathrm{S}$, and Si concentrations along the profile of the column throughout the unheated ('Baseline'), heated aerobic (Week 1, 3, 5, 7 and 10), and heated anaerobic phase (Week 2 and Week 8) from Experiment 2.

Figure 22. SEM micrograph of a fine gravel size grain (a), and the surface texture of the sediment grain (b). 85

Figure 23. SEM micrograph of a coarse sand sized grain (a), and the area of a secondary precipitate (circled in orange) on surface of the sediment grain (b).

Figure 24. Total alkalinity profile of the column during the heated (Week 3, 5 and 7) phase of Experiment 3.

Figure 25. Dissolved oxygen profile of the column during the unheated ('Baseline') and heated

(Week 1, 3, 5, 7 and 9) phase of Experiment 3.

Figure 26. $\mathrm{pH}$ profile of the column during the unheated ('Baseline') and heated (Week 1, 3, 5, 7 and 9) phase of Experiment 3.

Figure 27. Sulfate profile of the column during the unheated ('Baseline') and heated phase of (Week 1, 3, 5, 7 and 9) Experiment 3. 96

Figure 28. Ferrous iron profile of the column during the unheated ('Baseline') and heated (Week 3 and 7) phase of Experiment 3.

Figure 29. Sulfide profile of the column during the unheated ('Baseline') and heated (Week 1, 5 and 9) phase of Experiment 3. 98

Figure 30. Fe, Mn, Ni, and $\mathrm{Zn}$ concentrations along the profile of the column throughout the unheated ('Baseline') and heated anaerobic phase (Week 1, 3, 5 and 7) from Experiment 3..... 99 Figure 31. $\mathrm{Ca}, \mathrm{K}, \mathrm{Mg}, \mathrm{Na}, \mathrm{S}$, and $\mathrm{Si}$ concentrations along the profile of the column throughout the unheated ('Baseline') and heated anaerobic phase (Week 1, 3, 5 and 7) from Experiment 3.

Figure 32. Modelled quartz saturation indices over the length of the column during unheated ('Baseline') conditions and heated (Week 1 to Week 9) conditions of Experiment 1. 106 Figure 33. Modelled $\mathrm{SiO}_{2(\mathrm{am})}$ saturation indices over the length of the column during unheated ('Baseline') conditions and heated (Week 1 to Week 9) conditions of Experiment 1. 109

Figure 34. Modelled ferrihydrite saturation indices over the length of the column during aerobic unheated ('Baseline') conditions and heated (Week 1 to Week 10) conditions of Experiment 2.

Figure 35. Modelled quartz and $\mathrm{SiO}_{2(\mathrm{am})}$ saturation indices over the length of the column during heated aerobic (Week 10) and anaerobic (Week 8) conditions of Experiment 2. 


\section{Chapter 1 - Introduction}

\subsection{Background Information}

The global amount of technically recoverable oil resources is forecasted at 5.9 trillion bbl (International Energy Agency, 2012). Of this total, approximately 30\% of the resource is contained in conventional oil deposits while the remaining $70 \%$ is found as unconventional oil, which encompasses oil sands and bitumen, oil shales, as well as heavy and extra-heavy oil (Chopra et al., 2011; Thakur and Rajput, 2013; Færgestad, 2016). Canada is known to contain one of the world's largest quantities of unconventional oil with an estimated 171 billion bbl of proven reserves (Dusseault, 2001; Lines, 2008; McGlade, 2012). Approximately 20\% of Canada's oil reserves are found as oil sands and natural bitumen close to the surface while the additional $80 \%$ is comprised of heavy and extra-heavy oil located at depth. Natural bitumen and heavy oil often varies in hydrocarbon composition and physical characteristics; however, they are both categorized as unconventional deposits because of the advanced methods needed for their extraction.

Strip mining and open pit mining are common techniques used to access oil sands deposits located within surficial layers that extend down to $60 \mathrm{~m}$ depth. After the oil sands material is excavated, it is brought to a processing facility where it can be treated with hot water and solvents to remove bitumen and oil from the sediment. In contrast, heavy and extra-heavy oils can be mined in-situ from unconsolidated, low-permeability sedimentary units below $70-80 \mathrm{~m}$ depth with a steam aided extraction process (Fennel, 2008; Chopra et al., 2011). This technique is broadly referred to as in-situ thermal recovery, and refers to the process of injecting pressurized steam through steel pipes into a target oil reservoir. By applying this method, the 
injected steam is able to infiltrate into the permeable substrate and raise the temperature of the oil, thereby lowering its viscosity and allowing it to be pumped to surface.

Oil companies have been commercially using in-situ thermal recovery methods in the Cold Lake regions of Alberta, Canada since the late 1980's, and have since continued these practices to the Peace River, and Athabasca basins (Figure 1). The continued development of these projects is generally considered to be a critical factor for the long-term success of the Canadian oil industry given the magnitude of unconventional resources. In 2014 alone, $\sim 42 \%$ of the Annual Crude Oil production from the Alberta Oil Sands was produced from in-situ thermal operations (Holly et al., 2016). As of February 2017, a total of 36 thermal recovery projects were operating in Alberta, while another 18 projects were approved for operation or in construction (Government of Alberta, 2017).

Two of the most extensively used thermal recovery methods include steam assisted gravity drainage (SAGD) and cyclic steam stimulation (CSS). Although both methods operate on the same principle, SAGD differs from CSS in both construction and efficiency. In the case of SAGD, the injection well is drilled horizontally in-line above the production well, and pressurized steam is injected at a temperature of $200^{\circ} \mathrm{C}$ to $250^{\circ} \mathrm{C}$ into the reservoir (Fennel, 2008). This process causes a steam chamber to build within the pore space and diffuse upwards and outwards from the injection well, eventually resulting in the less viscous oil to flow downwards via gravity to the production well. With both wells working in tandem, SAGD is able achieve a recovery factor of approximately $60 \%-70 \%$ original oil-in- place (OOIP) (Alvarez and Han, 2013). 


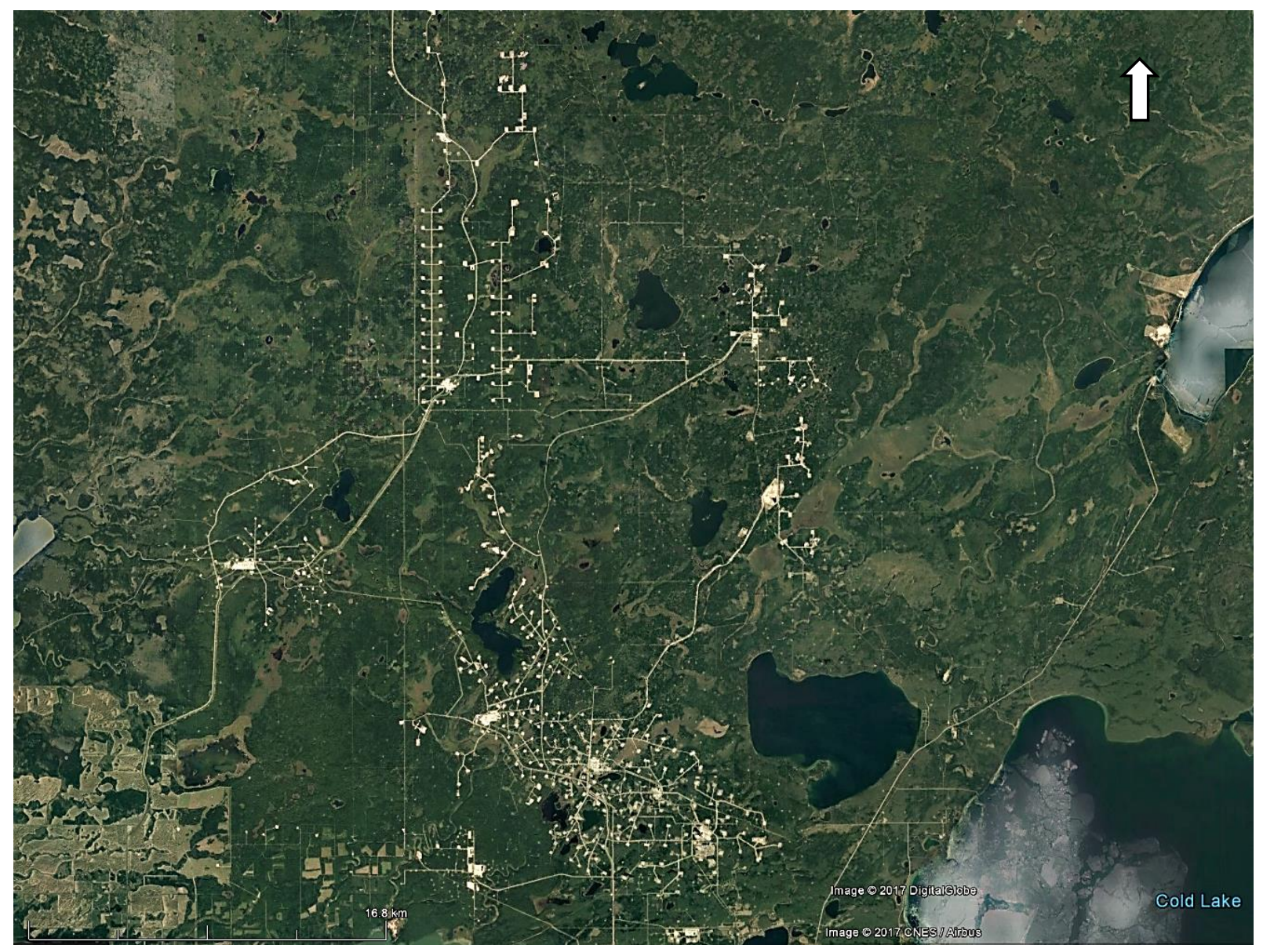

Figure 1. An aerial photo of the thermal operations north of Cold Lake, Alberta. The network of beige square areas indicates the location of the in-situ recovery steam injection well pads (GoogleEarth $\left.{ }^{\mathrm{TM}}, 2017\right)$.

The technique employed by CSS makes use of a single well that carries out both steam injection and oil extraction. The process for extracting oil from a CSS well is accomplished by implementing a three-phase cycle, which includes: a high-pressure steam injection at $200^{\circ} \mathrm{C}-$ $300^{\circ} \mathrm{C}$ lasting several weeks to several months; a steam soak-in period; and lastly, pumping and production of mobile oil (Alvarez and Han, 2013).

This cycle is typically repeated 20 or more times to optimize production. The recovery factor from a single CSS well usually ranges from $15-20 \%$ OOIP, but can increase up to $30 \%$ OOIP if a pattern of multiple wells is utilized in the same operations pad (Alvarez and Han, 2013). 
In comparison to surface mining, thermal recovery methods have the capacity to satisfy higher environmental standards by producing significantly lower amounts of solid waste and operating on a smaller surface footprint. However, public health concerns have been raised over the potential impacts to groundwater quality caused by the release of heat from steam injection wells into the surrounding aquifers (Fennel, 2008; Moncur et al., 2015a; Javed and Siddique, 2016). In the areas where in-situ thermal operations are situated, regional non-saline aquifers provide an abundant supply of potable groundwater to the agricultural industry, and municipal and rural residents (Fennel, 2011).

Although the thermal recovery pipes are encased in cement to minimize heat loss, they are still capable of transferring heat into aquifer sediments during the steam injection phase (Figure 2). When this process occurs over an extended period of time, high temperature water-rock interactions will cause compositional changes in the groundwater geochemistry (Fennel, 2008 Moncur et al., 2015a; Javed and Siddique, 2016). Higher temperatures have the ability control the thermodynamic and kinetic conditions of the local aquifer systems by increasing mineral solubility which leads to a proportional increase in dissolved constituents. The constituents can become mobilized under the physical transport of the thermal and natural groundwater flow regimes while their ultimate fate is dictated by the chemical nature of the individual species, and the downgradient geochemical conditions. 


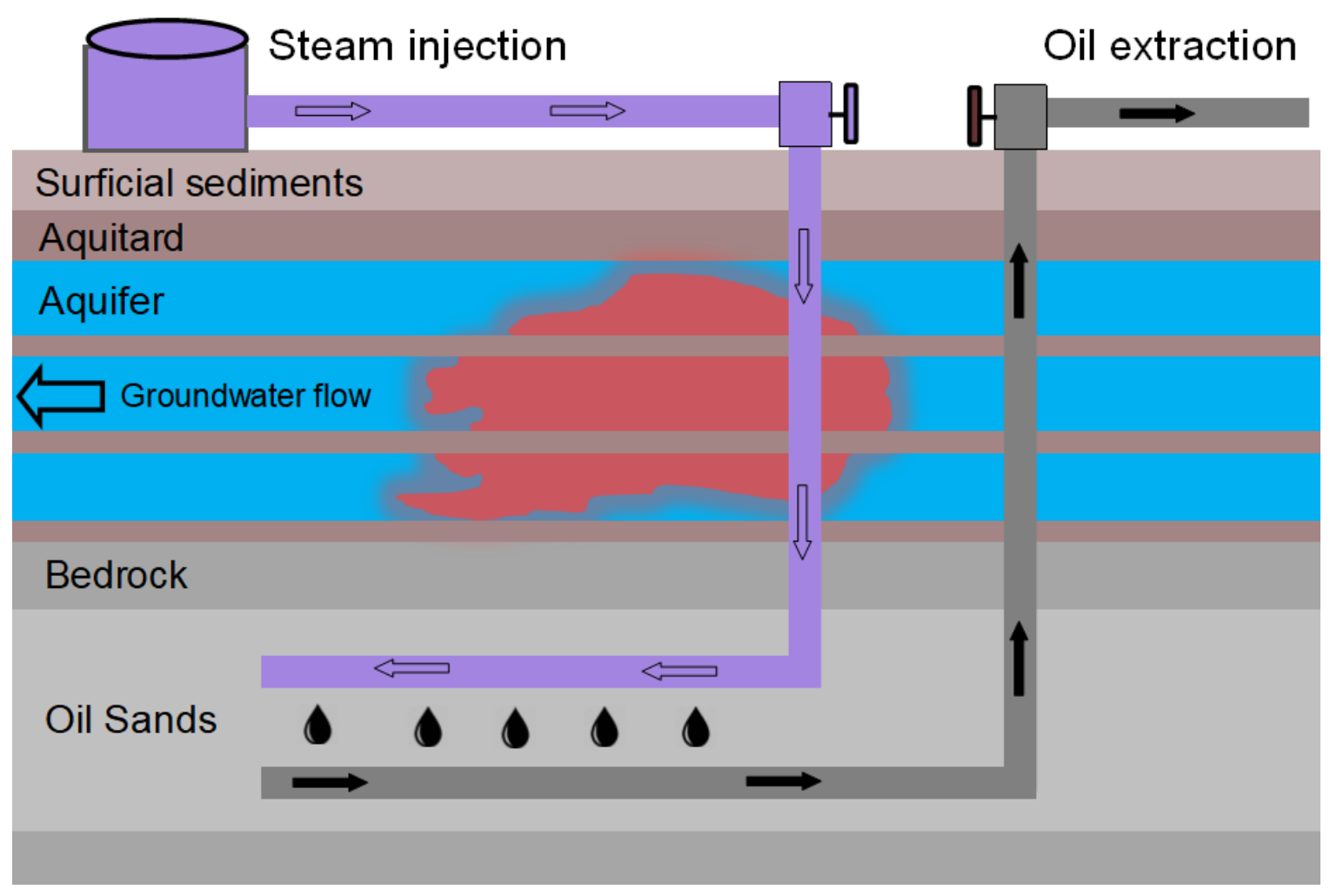

Figure 2. Schematic diagram of a typical SAGD operation where steam injection causes heat (shown in red) to emitted into the aquifer layers and migrates according to the groundwater flow direction.

\subsection{Research Context}

Arsenic (As) is highly toxic metalloid that is often found as a naturally occurring element incorporated into primary minerals such as metal-sulfides, as well as Fe and Mn oxides and oxyhydroxides. Some of the most common As bearing minerals include: arsenopyrite (FeAsS); arsenian pyrite $\left(\mathrm{FeS}_{2}\right)$; cobaltite $(\mathrm{CoAsS})$; enargite $\left(\mathrm{Cu}_{3} \mathrm{AsS}_{4}\right)$; and gersdorffite (NiAsS). Through the oxidative-dissolution of these minerals, arsenic is released in the form of oxyanions, arsenite, As(III) and arsenate, $\mathrm{As}(\mathrm{V})$, which can readily move into the aqueous phase and undergo transport by surface or groundwater flow. Alternatively, if the geochemical conditions of these systems undergo change, these oxy-anions can move back into the solid phase by 
sorption and/or secondary mineral precipitation reactions with metal cations (Drahota and Filippi, 2009).

Characteristically high concentrations of As greater than the $10 \mu \mathrm{g} / \mathrm{L}$ limit set by the World Health Organization (WHO) have been well documented in geothermal waters, and groundwater from Bangladesh and West Bengal, India (Nickson et al., 2000; Stöben et al., 2003; Webster and Nordstrom, 2003; Zheng et al., 2004; Nath et al., 2008; Dhar et al., 2008). In Canada, natural exceedances of As greater than Health Canada's $10 \mu \mathrm{g} / \mathrm{L}$ minimum acceptable concentration (MAC) in drinking water have also been identified in groundwater from every province (Moncur et al., 2015a). These high concentrations are generally attributed to the local abundance of arsenian minerals in the aquifer and aquitard units, in addition to subsurface reducing conditions.

Anthropogenic activities can also act as a vehicle to introduce As into groundwater systems. Such releases have been recorded in areas surrounding industrial sites including gold mines and tailings ponds; surface releases of geothermal waste fluids; aquifer thermal energy storage systems; pressure-treated wood facilities; and in-situ thermal recovery operations (World Health Organization, 2011; Ilgen et al., 2011; Bonte et al., 2013b; Moncur et al., 2015a). Since beginning commercial operations of in-situ thermal recovery in Alberta, Canada, there have been two publicly recognized instances where groundwater collected downgradient from these operations has contained levels of arsenic that exceeded both the WHO and Health Canada MAC limit, while also surpassing background concentrations by an order of magnitude.

The first case was identified by Imperial Oil in the early 1990's during a groundwater monitoring program conducted in proximity to their Cold Lake CSS well pad (Fennel, 2008). Examiners had initially suspected that arsenic concentrations were consistent with background levels, but upon 
further investigation these elevated levels were found to be linked to the company's in-situ thermal operations. A similar instance was also recorded from a groundwater monitoring program conducted by Canadian Natural Resources Ltd. (CNRL) which found elevated levels of arsenic $\sim 360 \mathrm{~m}$ downgradient from a CSS well pad at one of their Cold Lake facilities (CNRL, 2006). Results from this program defined both the arsenic and thermal plumes which were found to originate as a point source from the thermal recovery site. Both of these examples indicate that there are environmental and water quality related risks associated with the thermal extraction method of unconventional oil, particularly in the region of Cold Lake, Alberta.

Several geochemical based studies have examined high temperature dissolution of aquifer sediments and arsenian minerals under various conditions and settings; however, there remains a gap in understanding the hydrogeochemical and reactive transport mechanisms that are responsible for producing these effects from SAGD and CSS operations. To further this area of knowledge, this report will provide a synthesis of previous research and related works, and present the outcomes from a series of experiments designed to elucidate major geochemical reactions and transport behavior between aquifer sediments and the liberation of mobile dissolved constituents under elevated temperature conditions.

\subsection{Experiment Objectives and Purpose}

In order to distinguish the temperature dependent hydrogeochemical reactions and transport mechanisms caused by in-situ thermal recovery this investigation will consist of three heated column experiments to simulate the thermodynamic and kinetic interactions between aquifer sediments and groundwater under heated conditions. 
In similar areas of research, column experiments have been shown to offer several advantages when reproducing natural conditions, and monitoring changes in water geochemistry and solute migration. Generally, the geochemical results of the column effluent and/or water samples are a function of the sediment properties, composition, input water chemistry, flow rate, temperature and time. A strong understanding of these variables is critical when evaluating the geochemical results. As such, the column experiments from this project will aim at characterizing the same variables as mentioned above, while at the same time subjecting a section of the column to high temperatures $\left(<95^{\circ} \mathrm{C}\right)$.

To provide a thorough assessment of the heated heterogeneous system, the column research will be guided by the following objectives:

1. Characterize and compare the groundwater geochemistry and physical flow profile of saturated materials under heated and non-heated conditions;

2. Examine and compare the geochemical reactions between the sediment mineralogy and groundwater geochemistry; and,

3. Establish the dominant mechanisms of reactive mineral dissolution, solute release, physical transport, and attenuation.

The purpose of this research will aim at providing the background information that will be necessary to forecast the water quality effects from thermal recovery on potable groundwater resources and suggest the extent to which remediation efforts are necessary. Particular focus will be directed towards investigating the processes of solute release, migration, and fate in saturated media influenced by temperature and groundwater flow. Cumulative outcomes from this project combined with future field work and reactive transport modelling could aid in distinguishing normal solute concentrations from impacted potable groundwater resources within western 
Canada. Overall, this research could be applied to the heavy oil industry to help mitigate environmental risks from in-situ thermal recovery practices as well as other industries that utilize to subsurface heating methods. 


\section{Chapter 2 - Background Information}

\subsection{Geology and Hydrogeology in Cold Lake, Alberta}

The regional geology and hydrogeology of the Cold Lake-Beaver River (CLBR) basin has comprehensively examined and characterized by Andriashek and Fenton (1989), Andriashek (2000), Lemay et al. (2005), and Parks et al. (2005). Stratigraphic logs in these studies indicate that the upper $\sim 200 \mathrm{~m}$ is comprised of Quaternary to Tertiary glacial, glacio-fluvial and fluvial unconsolidated sediments. The vertical stratigraphy of this section generally follows a cyclical sequence of sands and gravels which form the saturated permeable aquifer units, separated by intervals of till which tend to form low permeability aquitards. From oldest and deepest to youngest and shallowest, these units in this area include: the Empress Formation, the Bronson Lake Formation, the Muriel Lake Formation, the Bonnyville Formation, the Ethel Lake Formation, the Marie Creek Formation, the Sand River Formation, and the Grand Centre Formation (Figure 3). 


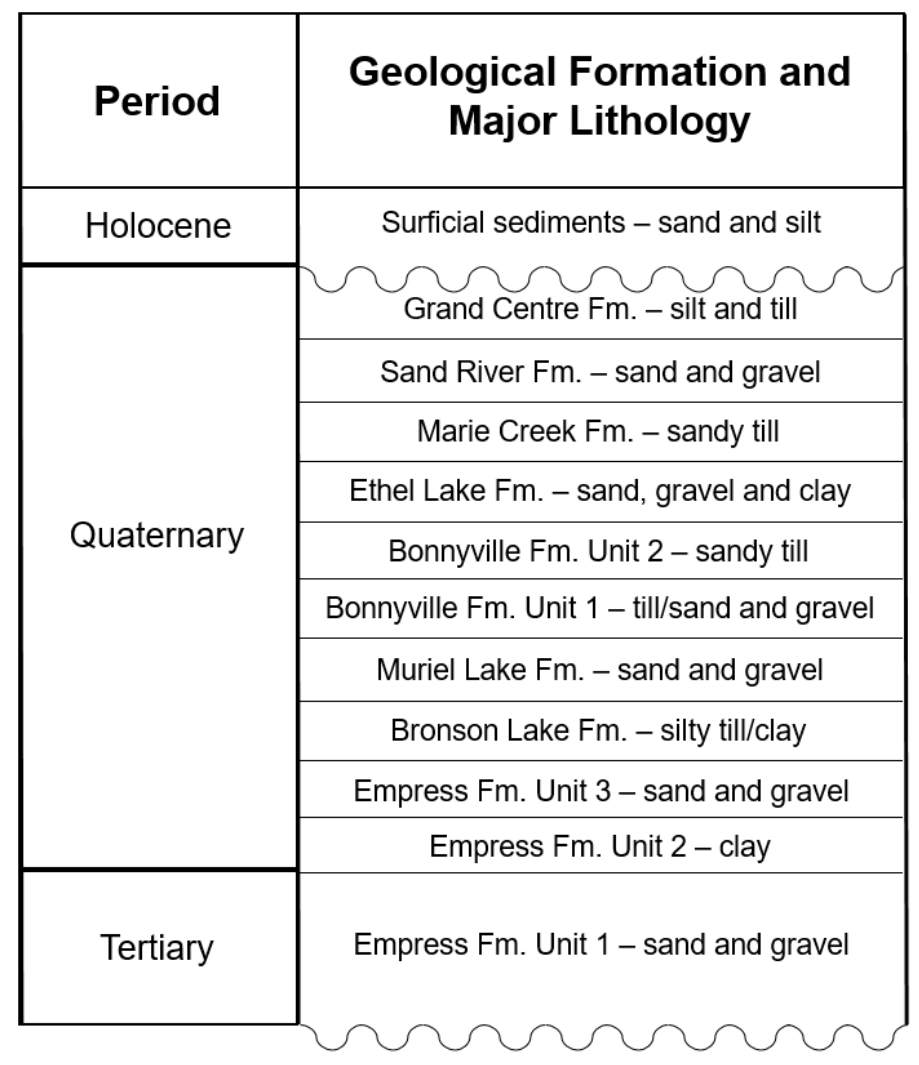

Figure 3. The overall stratigraphy and geological formations of the unconsolidated sediments present in the CLBR basin (Andriashek, 2003; Parks et al., 2005; Fennel, 2008).

The base of the sedimentary drift package overlies a sequence of Cretaceous shales and sandstones, as well as Precambrian igneous and metamorphic bedrock. Preglacial, interglacial and glacial erosional events have shaped the bedrock surface topography and as a corollary, have sourced and distributed of the overlying sediments. Evidence of the preglacial eroded bedrock surface is represented well by the location of the basal Empress Formation, which was deposited along the confines of fluvial paleo-channels. Subsequent coverage of the area by the Laurentide Ice Sheet resulted in the glacial deposition of units above the Empress Formation. During periods of glacier advance and retreat, deposition was controlled by glacio-fluvial processes and formed the sand and gravel units, while intervals of till were deposited during complete glacial cover (Johnsen et al., 2015). 
The combination of glacial and glacio-fluvial erosional and depositional events within the Quaternary is often associated with locally complex hydrostratigraphic relationships between units sometimes described as a three-dimensional labyrinth (Andriashek, 2003; Parks et al., 2005; Johnsen et al., 2015). The term implies that the depositional structure of each formation can vary in thickness and have a tendency to unpredictably cross-cut, and pinch-out (Parks et al., 2005). As a consequence, localized inter-layer hydraulic connectivity and cross formational flow can occur.

Another outcome from the complex network of aquifer units has been observed in the local fluctuations of the regional groundwater flow patterns. For the purpose of simplification, Parks (2005) and Lemay (2005) describe that flow in the CLBR can be separated into five regional networks - the Southwest Beaver River (SWBR), the Southeast Beaver River (SEBR), the Northwest Beaver River (NWBR), the Northeast Beaver River (NEBR), and the Wiau (Figure 4). These broad flow systems illustrate that recharge occurs in locations of higher elevation, or uplands, while discharge sites typically include the lowlands, rivers and lakes. Alternative flow directions and local irregularities can be influenced by geology, surficial and bedrock topography and water well pumping (Parks et al., 2005).

Although flow direction is mostly well understood and recorded for the Cold Lake area, data for groundwater transport and velocity has been less documented. A passive tracer test conducted by Fennel (2008) used deuterium to investigate site specific average flow velocity within the Muriel Lake Formation and found that the average velocity varied between $113 \mathrm{~m} /$ year to $72 \mathrm{~m} /$ year over a $45 \mathrm{~m}$ and $99 \mathrm{~m}$ spacing, respectively. Discrepancies between these values were suggested to arise from changes in the hydraulic conductivity over the travel distance as well as thermal influences to flow. Lemay (2005) also suggests that flow velocities within these aquifers can 
change within the same area due to sediment heterogeneities in conjunction with cross formational flow.

The mineralogy of the Quaternary sediments is generally consistent with that of the underlying Precambrian and Paleozoic bedrock. Previous tests by Fennell (2008) and Moncur et al. (2015b) have characterized the sediment mineralogy from different units above the bedrock surface. Fennell (2008) explains that XRD and XRF analysis from three sediment samples at discrete depth intervals within the Muriel Lake formation revealed an abundance of quartz; lower amounts of plagioclase, potassium feldspars and Fe-rich montmorillonite; and trace quantities of metallic minerals (i.e. magnetite, goethite coated grains, and pyrite), carbonates, illite, kaolinite, chlorite, and garnet. Sulfide minerals primarily in the form of pyrite were found to exist as inclusions within Na-K and $\mathrm{Ca}$ feldspars, and as individual euhedral and framboidal grains. The euhedral crystals and mineral inclusions are likely sourced from the granitic Precambrian bedrock, while the framboidal variety is more likely to have originated from microbial processes within the aquitard or aquifer layers. 


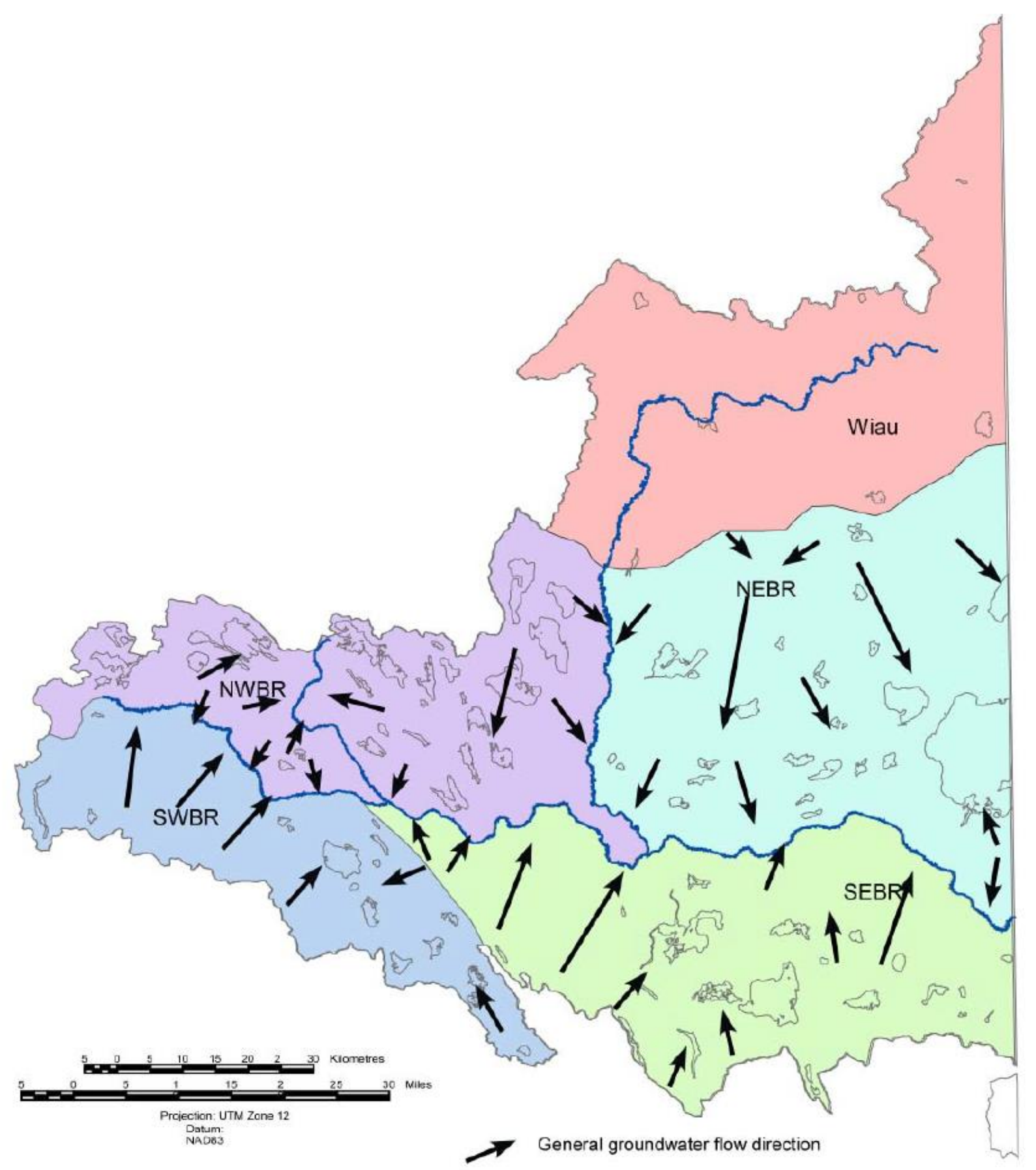

Figure 4. The five separate groundwater flow systems within the Cold Lake-Beaver River basin. (Parks et al., 2005).

In a similar study, Moncur et al. (2015b) characterized sediment mineralogy from the Grand Centre, Sandy River and Bonnyville formations. Findings showed that sediment from all three 
formations mainly consisted of quartz, Ca-plagioclase, K-feldspar, carbonates (calcite and ankerite-dolomite), trace pyrite (as semi-aggregate and framboidal grains), as well as trace siderite found in the Bonnyville Formation sediments. Again, framboidal pyrite was suggested to form from post depositional processes based on its textural features.

\subsubsection{Geochemistry of the Cold Lake Sediments and Solid Phase Arsenic}

Comprehensive geochemical investigations have aided in understanding the composition of the sedimentary units in the CLBR basin (Andriashek, 2000; Fennell, 2008; Javed et al., 2014; and Moncur et al., 2015a). Specific focus has also been directed towards defining the nature and subsurface conditions of solid phase arsenic associated with these sediments and minerals. Results have shown that there are indeed certain minerals that exhibit higher concentrations of As, both as an adsorbed constituent and contained within mineral structures.

In a study by Andriashek (2000), elemental analysis using atomic absorption (AA) spectrometry and neutron activation (NA) analysis was completed on 177 fine grained till and clay sediment samples from five different boreholes. Arsenic concentrations ranged from 3 to $20 \mathrm{ppm}$ in all samples, and generally displayed an increase with depth and a similar trend with vanadium. Average As concentrations in the Marie Creek and Grand Centre Formation sediments were found to be about $5 \mathrm{ppm}$, while Bonnyville sediments were $9 \mathrm{ppm}$, and appeared to be independent of clay content. Although Andriashek notes that the higher values in the Bonnyville Formation could be due to an observed oxidized horizon, the study did not indicate whether the clay or till samples contained sulfide minerals which are often associated with a higher As content. It should also be mentioned that sand and gravel materials from saturated layers were not analyzed. 
Fennell (2008) performed elemental analysis using inductively coupled plasma mass spectrometry (ICP-MS) on sand and clay samples collected from the Muriel Lake Formation aquifer. Results showed that the sediment composition was dominated by $\mathrm{Ca}, \mathrm{Fe}, \mathrm{Mg}, \mathrm{Al}, \mathrm{K}, \mathrm{Mn}$, $\mathrm{P}$ and Na. Sulfur was also abundant in the sand fraction, but was not discussed. Other trace elements in the sand included $\mathrm{Ti}, \mathrm{Ba}$ and $\mathrm{Sr}$, while As ranged from $1.0-1.45 \mathrm{ppm}$. In the clay material, average concentrations of $\mathrm{Zn}, \mathrm{V}, \mathrm{Cr}, \mathrm{Ni}, \mathrm{Cu}, \mathrm{Co}$, and $\mathrm{Pb}$ concentrations were all greater than $13 \mathrm{mg} / \mathrm{kg}$, followed by As which was found to be $8.0 \mathrm{mg} / \mathrm{kg}$. Fennell (2008) did not present individual results from these samples nor mention the presence of sulfide minerals. The concentration profile of As with depth indicated lower values $(0.3 \mathrm{mg} / \mathrm{kg})$ in the shallower section and higher values $(1.6 \mathrm{mg} / \mathrm{kg})$ in the deeper section over a thickness of approximately 11 m. Additionally, Fennell (2008) analyzed clay minerals using Synchrotron Light (SL) in conjunction with X-ray absorption near edge structure (XANES) spectroscopy to show that $\operatorname{As}(V)$ was the dominant species, but that there were also a faint signature indicative of a smaller amount of $\mathrm{As}(\mathrm{III})$.

In a similar investigation, Javed et al. (2014) used X-ray diffraction (XRD) and $\mu$-XRD to characterize the geochemistry of sediment cores with particular attention to solid phase As fractionation in aquifer and aquitard materials. Results revealed that high As concentrations (7 $35 \mathrm{mg} / \mathrm{kg}$ ) were found in deeper marine shale units; unoxidized clays in the Grand Centre and Bonnyville Formation; as well as in unoxidized sediments from the Empress Formation. Statistical analysis indicated that these high levels were attributed to a greater abundance of adsorbed As onto sulfide minerals ( $\mathrm{p}<0.05 ; \mathrm{r}=0.66$ ); however, coprecipitation of As into $\mathrm{FeS}_{2}$ and $\mathrm{As}_{2} \mathrm{~S}_{3}$ was also identified as a major source. Higher levels of As found in the unoxidized sediments was suggested to occur from the integration of sulfide marine shale material, possibly 
caused by glacio-tectonic events or depositional mixing, which is often known to contain sulfide minerals (Muloin and Dudas, 2005). In the samples with lower concentrations of As ( $<7 \mathrm{mg} / \mathrm{kg})$, close to $40 \%$ of the total As was associated with crystalline Fe, Al and Mn oxyhydroxides. Javed et al. (2014) also clarified that As(III) was the dominant species $(60-90 \%)$ in the both high and low As level sediments with the exception of four samples of oxidized till that favored As(V) (60 $-90 \%)$

Subsequent research completed by Moncur et al. (2015a) distinguished the primary sources and geochemical controls of arsenic in CLBR basin sediments. Findings from this study found that deeper ( $>6 \mathrm{~m}$ depth) unoxidized sediments contained framboidal pyrite, while shallower $(\sim 1 \mathrm{~m}$ depth) oxidized sediments contained spheroidal Fe oxyhydroxide with average As concentrations of $530 \mathrm{ppm}$ and $485 \mathrm{ppm}$, respectively. The average As concentration of whole rock samples was stated to be $6 \mathrm{ppm}$, with values ranging from $0.3 \mathrm{ppm}$ to $17 \mathrm{ppm}$. XANES of the sediments showed a dominance of the As(V) species which comprised over $75 \%$ of the solid phase As concentration. Spectral features of the oxidized sediments were found to be similar to those of goethite and/or ferrihydrite with adsorbed As. This data led to the notion that along with sulfides, Fe oxyhydroxides could also act as a primary As bearing mineral.

\subsubsection{Hydrogeochemistry of Groundwater in the CLBR Basin and Dissolved Arsenic}

Regional hydrogeochemistry is a concept that refers to the chemical characteristics of a groundwater as a function of both physical and geochemical parameters controlled by the local geology, hydrogeology, and hydrology. In essence, this means that the concentration of dissolved chemical constituents in groundwater is governed by water - rock interactions as the physical flow of water moves from zones of recharge to discharge. However, understanding the 
hydrogeochemistry of a natural system can become complex when additional factors susceptible to variation such as groundwater velocity, inter-unit mixing, rock/sediment composition, redox conditions, dissolution/precipitation reactions, sorption, and anthropogenic influences are cumulatively taken into account. As such, it is important to consider the role and extent of each of these factors when critically analyzing hydrogeochemical data.

Detailed hydrogeochemical research of the CLBR basin groundwater has been undertaken by Lemay et al. (2005), Parks et al. (2005), Fennell (2008), the Government of Alberta (2014), and Moncur et al. (2015a) through extensive sampling and water geochemistry monitoring programs.

In the report by Lemay et al. (2005), groundwater of the CLBR was found to be consistent with the Freeze and Cherry (1979) Type III classification of water composition in glacial deposits. Generally, the criteria for this classification includes waters that contain total dissolved solids (TDS) values ranging between $1,000 \mathrm{mg} / \mathrm{L}$ to $10,000 \mathrm{mg} / \mathrm{L}$ and primary constituents that include $\mathrm{Na}, \mathrm{Mg}, \mathrm{Ca}, \mathrm{HCO}_{3}$, and $\mathrm{SO}_{4}$ ions. The dominant reactions responsible for producing this chemical make-up include the dissolution of carbonate minerals and minor amounts of gypsum, as well as cation-exchange of $\mathrm{Ca}$ for $\mathrm{Na}$ and $\mathrm{Mg}$ with clay minerals.

Lemay et al. (2005) and Parks et al. (2005) confirm this notion with cation and anion water chemistry piper plot diagrams, which is also supported by Fennel (2008). The cation data indicates that there is a shift from $\mathrm{Ca}$ and $\mathrm{Mg}$ to $\mathrm{Na}$ dominated groundwater often associated with a natural ion-exchange trend along the water flow path. A similar trend is also shown for anions, bicarbonate and sulfate, in the groundwater. Young groundwater in proximity to recharge zones typically contains an abundance of bicarbonate which is later consumed over time in geochemical reactions, while older groundwater gradually increases in sulfate concentration. 
In localized areas of the southern CLBR basin, chloride also appears as a dominant anion. Natural mechanisms that could produce these effects may involve the upward diffusion of deeper groundwater that had interacted with igneous and metamorphic bedrock. Generally, a $\mathrm{Cl}$ dominated signature is often associated with older waters that have experienced longer residence times (Fennel, 2008). The major dissolved constituents discussed above are generally congruent with what would be expected from the mineralogy of the Quaternary sediments and, bedrock presented in Section 2.1.

With respect to minor constituents and geochemical parameters, Fennell (2008) reports less abundant concentrations of: $\mathrm{K}, \mathrm{Si}, \mathrm{Cl}, \mathrm{Fe}$ and $\mathrm{DOC}$, while $\mathrm{pH}, \mathrm{EC}, \mathrm{Eh}$, and temperature have average values of $7.4 \pm 0.2,847 \mu \mathrm{S} / \mathrm{cm} \pm 73,-53 \mathrm{mV} \pm 35$, and $7.0^{\circ} \mathrm{C} \pm 0.8$, respectively. Eh values are shown to align with Fe reducing conditions. Species with trace concentrations $(<1$ $\mathrm{mg} / \mathrm{L}$ ) include $\mathrm{Mn}, \mathrm{Sr}, \mathrm{S}^{2-}, \mathrm{B}, \mathrm{P}$ and As. Noteworthy species $\mathrm{S}^{2-}$ and As were found to have natural average concentrations of $0.13 \mathrm{mg} / \mathrm{L} \pm 0.21$, and $0.021 \mathrm{mg} / \mathrm{L} \pm 0.004$, respectively, and agree with the results presented by Lemay et al. (2005) from the Muriel Lake aquifer.

Lemay et al. (2005) explains that CLBR basin groundwater contains concentrations of As and dissolved metals that sometimes exceed national water quality guidelines. However, as a whole, median arsenic concentrations have been consistently below the national drinking water quality guidelines $(<0.01 \mathrm{mg} / \mathrm{L})$ in all of the flow systems ( $95 \%$ confidence). Mechanisms for the production of dissolved arsenic can occur from a variety of naturally and anthropogenically controlled geochemical reactions involving arsenic bearing and arsenic sorbed minerals. The report notes that dissolved arsenic caused by anthropogenic activities has been presented as a public concern in Cold Lake, but the specific source or mechanisms of how it is produced in this area were not discussed. 
In addition, Lemay et al. (2005) completed a distribution analysis of freshly collected groundwater samples from the eight CLBR basin aquifers to investigate the possible spatial patterns of arsenic. The authors state that there was no evident spatial relationship with the elevated arsenic concentrations in the Empress, Bronson Lake, Muriel Lake, Bonnyville and Ethel Lake formations yet, a higher percentage of samples (>26\%) exceeding $0.025 \mathrm{mg} / \mathrm{L}$ were collected from the Bronson Lake, Muriel Lake and Ethel Lake aquifers. Samples from all aquifer formations with As concentrations $>0.025 \mathrm{mg} / \mathrm{L}$ were located primarily in the NEBR flow system. Subsequent work by Moncur et al. (2015a) noted that Lemay et al (2005) did not indicate the number of wells that showed exceedances of the CDWG.

Further characterization of possible spatial patterns of dissolved As was performed by Moncur et al. (2015a) by compiling new and old groundwater geochemistry data from of the Cold Lake region. Sources of information included fresh sample data from thirteen wells; database records from the Government of Alberta and the Beaver River watershed authority; and, data collected from industry reports. Geochemical data was selected when it contained an explicit depth, location, low geochemical charge balance error $(<10 \%)$, and outside the zone of influence from thermal recovery operations. Criteria used to determine if a well had the potential to be impacted by an in-situ thermal recovery operation was not discussed.

Of the records collected by Moncur et al. (2015a), data from 816 wells was utilized to investigate trends on As distribution. The report states that no obvious patterns were observed with the exception of an area west of Cold Lake that displayed high As values in all but the shallowest aquifer unit (i.e. the Grand Centre Formation). The average As concentration in groundwater samples was found to be $0.015 \mathrm{mg} / \mathrm{L}$ and $50 \%$ of the wells had exceeded the CDWG, generally showing an increase in As concentration with depth within the unconsolidated sediments. With 
respect to vertical distribution, high As concentrations $(>0.010 \mathrm{mg} / \mathrm{L})$ were found in $70 \%$ of the wells within the deepest Quaternary formation (Empress), while 17\% of the wells in the shallowest unit showed exceedances of the CDWG. Additionally, all seven wells sampled from the underlying pyritic shale units contained less than $0.010 \mathrm{mg} / \mathrm{L}$ suggesting that they are not contributing to higher As levels.

In terms of geochemical relationships associated with As, Moncur et al. (2015a) found that As(III) was the dominant dissolved As species in $80 \%$ of the sampled groundwater, and generally showed an increase in percentage with depth thereby suggesting that there is a strong reducing environment in the deeper units of the CLBR basin. Comparatively lower percentages of As(III) were found in the shallow Grande Centre formation and aquitard units, with the exception of the Bonnyville till. Increasing As concentrations were also observed in conditions with lower Eh values; lower concentrations of $\mathrm{SO}_{4}{ }^{2-}$ and $\mathrm{Fe}(\mathrm{II})$; circumneutral $\mathrm{pH}$; alkalinities of $\sim 600 \mathrm{mg} / \mathrm{L} \mathrm{CaCO}_{3}$; and with DOC concentrations of approximately $5 \mathrm{mg} / \mathrm{L}$ (mean: $3.1 \mathrm{mg} / \mathrm{L}$ ). A report by the Government of Alberta (2014b) also found that As (III) species concentrations were generally higher than $\mathrm{As}(\mathrm{V})$ in both raw and treated water samples.

\subsection{Temperature Affected Hydrogeochemical Processes}

\subsubsection{The Effects of Temperature on Thermodynamic and Kinetic Reactions}

The laws of thermodynamics govern the transfer of energy and mass in chemical reactions between constituents in a system and define whether the reaction proceeds in a direction towards products, reactants or has achieved equilibrium. In a hydrogeochemical system, a state of thermodynamic equilibrium is considered to be reached when the difference in Gibbs free energy 
$(\Delta G)$ of the components (i.e. groundwater solution, organic matter, and minerals) is at a minimum (Clark, 2015). The term $\Delta G_{r}^{0}$ refers to the standard Gibbs free energy of individual geochemical reactions, and can be described in the following equation:

$$
\Delta G_{r}^{0}=\Sigma \Delta G_{f \text { products }}^{0}-\Sigma \Delta G_{f \text { reactants }}^{0}
$$

Where, $\Sigma \Delta G_{f}^{0}$ is the sum of the free energy of formation for aqueous phase, solid phase, and gas phase substances. If we then apply the general reaction below as an example:

$$
a A+b B \leftrightarrow c C+d D
$$

It is possible to substitute the reaction into the standard Gibbs free energy equation as:

$$
\Delta G_{r}=\Delta G_{r}^{0}+R T \ln \frac{a_{C}^{c} \times a_{D}^{d}}{a_{A}^{a} \times a_{B}^{b}}
$$

Where, $a$ denotes the activity of the products and reactants, superscript letters represent moles of substance, $R$ is the universal gas constant $\left(8.314 \times 10^{-3} \mathrm{~kJ} / \mathrm{mol} \cdot \mathrm{K}\right), T$ is the absolute temperature (Kelvin), and $\Delta G_{r}$ is the change in Gibbs free energy of the reaction. Calculations of the $\Delta G_{r}$ value indicate the direction of the reaction. This means that if the $\Delta G_{r}$ value is greater than 0 , the reaction will proceed towards the reactants; if the value is less than 0 , the reaction proceeds towards the products; and, if the value is 0 , the reaction is considered to be at equilibrium (Appelo and Postma, 2005). In the case of reactions that have reached equilibrium, the equation above can be simplified to:

$$
\Delta G_{r}^{0}=-R T \ln \frac{a_{C}^{c} \times a_{D}^{d}}{a_{A}^{a} \times a_{B}^{b}}
$$

Because the activity expression in equation 2.4 describes the thermodynamic reaction constant (or mass action constant), $K$ can be substituted into the equation as: 


$$
\Delta G_{r}^{0}=-R T \ln K
$$

Equation 2.5 is perhaps the most important when evaluating chemical equilibrium, and is useful when determining the mineral solubility product, $K_{s p}$, or equilibrium reaction constant, $K_{e q}$, from Gibbs free energy data. Generally, these terms apply when quantifying mineral solubility and determining if minerals or gasses will remain dissolved or precipitate out of solution under constant conditions.

However, the conditions of natural waters can vary regionally, particularly with respect to temperature and pressure. As these geochemical systems undergo change, so too will the state of equilibrium and the reaction constants. In most cases, pressure has a limited effect on reaction constants while temperature plays a fundamental role (Appelo and Postma, 2005). Therefore, it is critical to consider the relationship of $K$ and temperature at different temperatures of a system. Using the Van't Hoff equation (2.6), it is possible to demonstrate the dependence of the reaction constant on temperature:

$$
\frac{d \ln K}{d T}=\frac{\Delta H_{r}}{R T^{2}}
$$

Where, $\Delta H_{r}$ refers to the reaction enthalpy of the system and is used to quantify the amount of heat gained (endothermic) or lost (exothermic) from the reaction. In the same fashion as the calculation for $\Delta G_{r}^{0}$, the reaction enthalpy at equilibrium, $\Delta H_{r}^{0}$, can be derived from formation enthalpy, $\Delta H_{f}^{0}$, of the individual reaction substances.

It is clear from the above equations that temperature has an effect on thermodynamic reaction constants and the state of equilibrium for a given system. At the same time, it is important to consider how temperature influences kinetically driven reactions and the rate at which a system 
reaches equilibrium. The relationship between temperature and reaction rate is often described by the Arrhenius equation (2.7), which can take the same form as the Van't Hoff equation (2.6):

$$
\frac{d \log k}{d T}=\frac{-E_{a}}{2.303 R T^{2}}
$$

Where, $k$ refers to the rate constant (or specific rate) of the reaction, and $E_{a}$ is the activation energy $(\mathrm{kJ} / \mathrm{mol})$. In the Arrhenius equation, the activation energy of a reaction is a measure that relates to the transition state theory, which describes how reactant species must gain energy from the system in order to form an intermediate (or transition state) activated complex before products are created. The activation energy required for the reaction to proceed varies depending on the type of chemical reaction and transport mechanisms involved (Appelo and Postma, 2005).

The amount of time that it takes for a reaction to proceed is linked to the rate constant, $k$, which is equal to the rate of reaction when all reactants in the system have defined unit concentrations (Appelo and Postma, 2005). As such, the units of $k$ are dependent on the units of the reactants and the overall order of the reaction. In some cases, the presence of a catalyst can reduce the $E_{a}$ needed to form an activated complex, thereby increasing the rate of reaction. However, in most situations, the rate is heavily dependent on temperature and will increase at higher temperatures. This has been shown to be particularly evident in the context of mineral dissolution, sorption and precipitation reactions (White et al.,1999; Appelo and Postma, 2005; Payne and Abdel-Fattah, 2005; Kim, 2014). 


\subsubsection{The Effects of Localized Heating on Groundwater Flow and Mass Transport}

\section{Groundwater Flow}

Although the relationship between temperature and groundwater flow has been somewhat well established in hydrothermal and geothermal environments, the flow behavior in saturated porous medium influenced by localized high temperature zones has yet to be comprehensively described. The majority of natural aquifer units are characteristic of low temperature environments $\left(5-25^{\circ} \mathrm{C}\right)$ and as a result, there is little documentation on this particular hydrogeological focus. Nevertheless, several studies have examined aspects of physical hydrogeology at elevated temperatures, which provides a foundation for understanding the mechanisms that take place in heated aquifer systems.

At the time of writing this report, the most prominent field investigation on localized groundwater heating has been carried out by Fennel (2008), who demonstrated how the physical parameters of aquifer sediments and groundwater underwent changes after being heated from a series of CSS wells. At the aquifer depth in the study, it was found that groundwater temperatures could theoretically reach above the boiling point $\left(152^{\circ} \mathrm{C}\right)$ at a hydraulic head of approximately $50 \mathrm{~m}$, assuming that the porous medium was exposed to the average operating temperature of $170^{\circ} \mathrm{C}$. In turn, the additional heat contributed to a reduction in the groundwater fluid density and viscosity, and a subsequent increase in the hydraulic conductivity. Fennel (2008) illustrated that when the temperature of the groundwater increased by $100^{\circ} \mathrm{C}$, a change to these physical properties will proportionally increase the hydraulic conductivity by about one order of magnitude, thereby allowing groundwater to transmit through the aquifer pore-space more quickly. The equation that defines how these variables are linked can be shown as: 


$$
K=\frac{k \rho g}{\mu}
$$

Where, $K$ represents hydraulic conductivity $(\mathrm{cm} / \mathrm{s}), k$ is the substrate permeability $\left(\mathrm{cm}^{2}\right), \rho$ refers to the fluid density $\left(\mathrm{g} / \mathrm{cm}^{3}\right), g$ is the gravitational acceleration $\left(\mathrm{cm} / \mathrm{s}^{2}\right)$, and $\mu$ represents the dynamic fluid viscosity (g/cm's).

The significant effect that elevated temperatures can have particularly with respect to the hydraulic conductivity, groundwater viscosity, and permeability will also have a corresponding influence on the isotropy of groundwater flow path. Using results from a MODFLOW numerical simulation where an increased $K$ value was assigned to reflect a "heated zone" in a typical porous medium, Fennel (2008) illustrated that groundwater flow lines converged towards the heated zone as water entered, and diverged outwards as water exited. The anisotropic behavior occurs as the groundwater flow refracts towards a medium with a higher $K$, and will conversely refract outwards as groundwater travels from the high $K$ zone back to a lower $K$ zone. When considering the law of conservation of mass in this example, it is possible to justify that there will be higher volume of localized groundwater flow to enter and exit through the heated zone in comparison to the adjacent lower $\mathrm{K}$ area, thus creating preferential flow paths. In addition, this demonstrates that the aquifer material is increasing in temperature due to the conduction of heat directly from the source.

Groundwater that continues to flow through a localized high temperature zone will subsequently transport the thermal energy away from the source, as well as the mass of the mobile solutes. The two processes responsible for conveying heat in an aquifer are referred to as convective and conductive transport, and are defined as the movement of thermal energy via groundwater flow, and via thermal conductivity, respectively (Freeze and Cherry, 1979). Due to the combination of 
both effects, the propagation of the thermal front is much slower than groundwater flow; however, the controlling process in a system can be ascertained by calculating a Peclet number $\left(N_{P E}\right)$ from the equation:

$$
N_{P E}=\frac{\rho_{w} c_{w} q L}{k_{e}}
$$

Where, $\rho_{w}$ refers to the fluid density $\left(\mathrm{kg} / \mathrm{m}^{3}\right), c_{w}$ is the specific heat capacity $\left(\mathrm{kcal} / \mathrm{kg}{ }^{\circ} \mathrm{C}\right), q$ is the Darcy velocity $(\mathrm{m} / \mathrm{s}), L$ denotes the length of the distance in which the change in temperature is measured (m), and $k_{e}$ refers to the effective thermal conductivity of both fluids and solids (m/s). In this formula, a high Peclet number generally means that there is a convection driven system and conversely, a low number indicates that conduction is the dominant transport mechanism (Domenico and Schwartz, 1990).

In the CSS field investigation, Fennel (2008) demonstrated that convective transport was the primary mechanism at this site after finding a Peclet number of 13.8. The study showed that significant heat was transported away from the injection well creating a thermal gradient. With the results of a regression line from a distance versus temperature plot, Fennel (2008) forecasted that groundwater flow produced a 'cooling effect' on the injection well, such that the maximum temperature could theoretically reach up to $94^{\circ} \mathrm{C}$, and that the maximum temperature travel distance (i.e. to cause an observed increase) could reach approximately $500 \mathrm{~m}$ from the injection well. This calculated distance is generally in agreement with the field test data which show that several observation wells were experiencing a temperature influence from a CSS well pad roughly $600 \mathrm{~m}$ upgradient that had been in operation for 17 years. Similar results were also obtained from a groundwater monitoring program by $\mathrm{CNRL}$, which found a $4^{\circ} \mathrm{C}$ increase in 
water temperature from an observation well that was $\sim 360 \mathrm{~m}$ downgradient from the thermal well pad (CNRL, 2006).

However, contrasting results were presented from a thermal transport numerical simulation by Giraldo and MacMillan (2016). Simulation data was obtained using the finite element code FEFLOW and showed that the thermal plume was transported $150 \mathrm{~m}$ after 10 years of heating. The model parameters for groundwater flow velocity were significantly lower than those described by Fennel (2008), although a higher temperature was assigned to the area surrounding the steam injection well $\left(>100^{\circ} \mathrm{C}\right)$. The results of the FEFLOW model differ from those of Fennel (2008) likely due to the simulation giving greater emphasis on conductive transport from slower groundwater velocities, which at the same time, highlights the challenges that can be encountered when coupling thermal and groundwater flow in instances of localized heating.

Under most natural conditions, conservative solutes such as $\mathrm{Cl}, \mathrm{Br}$, and $\mathrm{I}$ are able to trace groundwater flow due to their relatively low retardation and attenuation. By measuring their concentration in space and over time, the flow parameters of the groundwater and hydraulic properties of the aquifer can be characterized, thereby allowing for interpretations to be made with respect to other non-conservative constituents. In the research conducted by Fennel (2008), the velocity of the groundwater influenced by aquifer heating was determined using chloride as a conservative solute, and deuterated water $\left({ }^{2} \mathrm{H}_{2} \mathrm{O}\right)$ as a passive tracer. The tracer test results were then compared to the calculated velocity from the groundwater flow equation which made use of constant yield aquifer test derived values for hydraulic conductivity, hydraulic gradient (i), and effective porosity $\left(n_{e}\right)$. Findings from this comparison showed that the calculated flow rate (123 $\mathrm{m} /$ year) was higher than what was ascertained from the chloride $(48-63 \mathrm{~m} /$ year $)$ and deuterium 
$(57-113 \mathrm{~m} /$ year) tracer tests. It was suggested that the cause of this discrepancy could be due to the effect of heat has on the alteration of the hydraulic conductivity.

\section{Mass Transport}

Much like the processes involved with heat flow, the movement of solutes in groundwater is known to propagate by similar transport mechanisms. Mass transport is typically described using the advection-dispersion equation below, which is analogous to the convective transport equation applied for the motion of thermal energy by a moving fluid:

$$
\frac{\partial C}{\partial t}+\bar{v}_{i} \frac{\partial C}{\partial x_{i}}-\frac{\partial}{\partial x_{i}} D_{i, j} \frac{\partial C}{\partial x_{j}} \pm \frac{G}{n}=0 \quad i, j=x, y, z
$$

In Equation 2.10, $\frac{\partial C}{\partial t}$ refers to the storage term, the advective transport term is represented by $\bar{v}_{i} \frac{\partial C}{\partial x_{i}}$, while $D_{i, j}$ is the dispersive/diffusive transport term described by Fick's law as a function of the solution concentration gradient $\frac{\partial C}{\partial x_{j}}$, followed by the final source/sink term $\frac{G}{n}$, which represents sorption, dissolution and precipitation processes that can take place along a given flow path. Therefore, it is important to consider the term $\frac{G}{n}$ when evaluating the additional water rock interactions during transport that can result from increases in temperature.

When groundwater flow is subject to localized high temperature conditions, constituents in the solid and aqueous phases of an aquifer system can be released via desorption and/or dissolution, or they may be adsorbed onto mineral surfaces. In contrast, when heated groundwater returns to lower background temperature levels, it is possible for the species to exhibit the opposite behavior which is consistent with reversible reactions. Aside from temperature influences, these 
processes are very much dependent on the chemical nature of the species and the surface control of the aquifer materials. For example, arsenic and boron have been shown to be released/desorbed from sediments in heated conditions, however, after being mobilized in groundwater, they had re-adsorbed onto mineral surfaces downgradient in low temperature zones (You et al., 1995; Fennel, 2008). On the other hand, nickel and copper have been found to undergo greater adsorption onto organic and inorganic materials at increasing temperatures which would reduce their mobility (Scheekel and Sparks, 2001; Argun et al., 2007).

The change in activity between an ion moved from the mineral surface to the bulk solution can be calculated using the Boltzman expression which describes this ability as a function of temperature:

$$
\left(X_{S}^{Z}\right)=\left(X^{Z}\right)\left[e^{\left.-\frac{\varphi_{F}}{R T}\right]^{z}}\right.
$$

Where, $\left(X_{s}^{z}\right)$ is the activity of the ion $X$ of charge $z$ near the mineral surface, $\left(X^{z}\right)$ refers to the corresponding activity of $X$ in the bulk solution unaffected by the surface, $e^{-\frac{\Psi_{F}}{R T}}$ is the unitless Boltzman factor, where $\Psi$ is the potential in volts at the plane of adsorption, and $F \quad(96,480$ $\mathrm{C} / \mathrm{mol}), R(8.314 \mathrm{~J} / \mathrm{mol} \mathrm{K})$, and $T(\mathrm{~K})$ are the Faraday constant, ideal gas constant and temperature of the system, respectively (Langmuir, 1997).

The Boltzman equation can be used to exemplify how the electrical potential of a charged mineral surface decreases as temperature increases, which consequently reduces the ability for sorption at the mineral surface. Although this expression can adequately explain sorption mechanisms with respect to some sorbed species such as arsenic, it does not necessarily apply for all dissolved species, as demonstrated by the studies involving nickel. As an alternative to using the formula above, temperature-dependent surface complexation modelling (TD-SCM) is an 
emerging method to better understand sorption mechanisms, which has demonstrated its success when simulating surface interactions with arsenic and some cations over a range of temperatures (Bonte et al., 2014; Van Breukelen and Bonte, 2016).

Minerals that are not actively involved in sorption processes, however, can instead exhibit a temperature dependent solubility. It is possible to observe this behavior in particular with quartz, where higher temperatures cause greater mineral dissolution. This means that at the localized heat source, a higher concentration of silica can be dissolved in groundwater from the quartz grains, where it will then be transported downgradient into lower temperature isotherms and precipitated as the solubility decreases (Wood and Hewett, 1982). Unlike adsorption-desorption processes, mineral dissolution and precipitation in natural systems is generally considered to involve irreversible reactions where the final product(s) remain stable.

\subsection{Changes to Groundwater Geochemistry from Anthropogenic Aquifer Heating}

\section{$\underline{\text { In-Situ Thermal Recovery }}$}

The steam injection process in SAGD and CSS thermal recovery operations is used to extract viscous unconventional oil deposits at depths below $80 \mathrm{~m}$, and in order to reach the target bitumen reservoir, the injection wells must pass through multiple shallow and confined freshwater aquifer units. The wells are often incased in thermal-grade cement which acts as an insulator and adds structural stability. However, due to the duration of the steam injection process that can last up to several months, in conjunction with the decades of operation that are necessary to extract oil reserves at each site, it is evident that significant amounts of heat energy are emitted from the steam injection wells and result in localized high temperature zones within 
the adjacent aquifer systems. In turn, this causes increased interactions between the groundwater and minerals immediately surrounding the injection well, as well as along the groundwater flow path where the heat has been carried away from the source.

Publicly available results from environmental monitoring programs carried out by the oil mining companies CNRL and Imperial Oil have identified increased concentrations of arsenic compared to background levels from groundwater monitoring wells in proximity to operating thermal recovery facilities (CNRL, 2006; Imperial Oil, 2017). Statements by both companies indicate that they are aware of the risks associated with the thermal liberation of arsenic from their in-situ operations in the Cold Lake, Alberta area where heat is able to interact with multiple aquifer layers containing Quaternary sediments. Arsenic is known to be trace component within the sulfide minerals that comprise the aquifer sediments, and although natural aqueous concentrations can exceed the $0.010 \mathrm{mg} / \mathrm{L}$ limit of drinking water guidelines (Moncur et al., 2015a), the groundwater concentrations recorded near thermal recovery operations can reach up to an order of magnitude greater than background levels.

Further to this issue, the results from a detailed field program completed by Fennel (2008) demonstrated that the heat production from a series of CSS injection wells operated by Imperial Oil in Cold Lake caused marked changes in the geochemical composition of the surrounding groundwater. This particular research site was designed with groundwater observation wells that were installed adjacent to and downgradient from a new CSS pad, and an older CSS operation that had been in in use for roughly 17 years. The observation wells were positioned at various locations from the steam injection well sites with a minimum distance of $15 \mathrm{~m}$ and maximum distance of $960 \mathrm{~m}$ along the groundwater flow path. Temperature records and geochemical data 
was collected over the course of a $\sim 5$ year period where the steam cycling process was scheduled to occur approximately 4 times at the newly installed CSS facility.

Over the duration of the field study, groundwater samples collected along the flow path from the new CSS facility showed an overall increase in concentration of $\mathrm{As}, \mathrm{B}, \mathrm{Ba}, \mathrm{Cl}, \mathrm{K}, \mathrm{Mo}, \mathrm{Na}, \mathrm{Si}$ and $\mathrm{Sr}$, and to a lesser degree, $\mathrm{Ca}, \mathrm{Mg}, \mathrm{SO}_{4}$, total alkalinity (as $\mathrm{HCO}_{3}$ ) and DOC. The increase in concentration of these species was coincident with the temporal response from aquifer heating, in conjunction with the migration of the groundwater and the thermal plume. After the steam cycles of the CSS wells had ceased and the temperature conditions in the test aquifer began to cool, the geochemical composition of the groundwater was marked by a general decreasing trend of these constituents.

Conversely, parameters such as $\mathrm{pH}$, redox, Fe and $\mathrm{Mn}$, generally displayed a decreasing trend during the arrival of heat from the thermal wells and subsequent increases when the heat cycles had ceased and aquifer cooling began to take place. The overall decrease in Fe and Mn was suggested to be as a result of precipitation of secondary minerals, which was observed on the inside of observation well casing located at $15 \mathrm{~m}$ from the CSS pad. Further analysis showed that this precipitate primarily contained $\mathrm{Fe}, \mathrm{S}, \mathrm{Cu}$ and trace As. The presence of $\mathrm{S}$ at this observation well was also characterized by a notable decrease in $\mathrm{SO}_{4}$ concentration. However, both the decrease in $\mathrm{SO}_{4}$ and the presence of secondary minerals was not observed at other well locations.

Fennel (2008) also demonstrated that the relationship between $\mathrm{pH}$ and total alkalinity was useful for understanding temperature influenced geochemical reactions at this study site. This was evident as the data showed a decline in $\mathrm{pH}$, and a slight increase in total alkalinity, $\mathrm{Ca}$, and $\mathrm{Mg}$ during aquifer heating. After the heating had stopped, there was a subsequent increase in $\mathrm{pH}$, which strongly suggests that buffering reactions had occurred due to thermodynamic processes. 
The maximum distance of the well with recorded geochemical changes was $675 \mathrm{~m}$ from the old CSS pad. At this location, there was a general increase in $\mathrm{SO}_{4}, \mathrm{As}, \mathrm{B}, \mathrm{Mo}$, and $\mathrm{Si}$, and temperature while $\mathrm{pH}$ and redox conditions generally remained consistent with the background levels. It should also be noted that this observation well was intended to monitor the long-term changes produced from the old CSS pad, however, its location was approximately $200 \mathrm{~m}$ downgradient from the newly installed CSS facility, so minor influences should not be ruled out.

Increasing concentrations of arsenic in the groundwater downgradient from the new CSS facility was evident over the course of the study. In contrast, some of the wells used to examine the effects of As release from the old CSS pad showed gradually declining As concentrations, although they were still notably in excess compared to background levels. To explain the behavior of these trends, Fennel (2008) states that aquifer heating during the steam cycling of both facilities is able to liberate As, while the concentration downgradient is a function of both heat advection as well as natural attenuation. Fennel (2008) explains that declining trends are indicative of adsorption, attenuation, and/or a trailing end of the plume, whereas increasing trends are the result of elevated temperatures, groundwater transport, and/or re-mobilization. Various cycles of heating within both CSS pads are therefore able to cause spatial and temporal variability with respect to temperature, As and other consistent concentrations within the aquifer units.

In addition to the geochemical investigation completed during the field study, Fennel (2008) also conducted laboratory experiments to examine the liberation of As from aquifer sediments under heated and cooled conditions and simulate water - rock interactions that take place by CSS wells. Batch heating tests were completed by subjecting sediments and aquifer water to average temperatures of $5^{\circ} \mathrm{C}, 27^{\circ} \mathrm{C}, 50^{\circ} \mathrm{C}, 82^{\circ} \mathrm{C}, 130^{\circ} \mathrm{C}$, and $200^{\circ} \mathrm{C}$, while extracting water samples and 
adding fresh water replacements. Reactions were left to occur for 3 weeks with the test at $5^{\circ} \mathrm{C} ; 6$ days for the test at $27^{\circ} \mathrm{C} ; 7$ weeks for the tests at $50^{\circ} \mathrm{C}$ and $82^{\circ} \mathrm{C}$; and for 7 days with the tests at $130^{\circ} \mathrm{C}$ and $200^{\circ} \mathrm{C}$.

Results from the experiments showed that there was strong evidence supporting the liberation of As from CLBR basin aquifer sediments into the aqueous phase starting at temperatures of $50^{\circ} \mathrm{C}$. However, there is also an indication that As release could be occurring at $27^{\circ} \mathrm{C}$. Due to the limited duration of the test, no definitive reaction rate constant or activation energy constant was attained, but nevertheless, the relative increasing trend shown by the data over the 7 day period does suggest that As is released at this temperature. In addition to As, elements that were also found to increase in concentration during the $200^{\circ} \mathrm{C}$ experiment included $\mathrm{Al}, \mathrm{Ca}, \mathrm{K}, \mathrm{Mo}, \mathrm{Na}, \mathrm{Sb}$, and $\mathrm{Zn}$, while elements $\mathrm{Cu}, \mathrm{Mg}, \mathrm{Mn}, \mathrm{Sn}, \mathrm{Sr}$, and Ti exhibited a decrease. The overall outcomes from these batch heating tests indicate that the rate at which As release occurs is largely dependent on the temperature of the system and the time that is given for the sediments and water to equilibrate (Fennel, 2008). However, it should also be noted that additional mechanisms relating to $\mathrm{pH}$ and redox conditions can be strong controls for constituent solubility and release.

Similar sediment - groundwater heating experiments have also been conducted by Moncur et al. (2015b) and Javed and Siddique (2016) to investigate the thermal effects on groundwater geochemistry over time. The study carried out by Moncur et al. (2016) exposed aquifer sediments and groundwater collected from the Grand Centre, Sand River and Bonnyville units of the CLBR basin to temperatures of $4^{\circ} \mathrm{C}, 60^{\circ} \mathrm{C}$ and $120^{\circ} \mathrm{C}$ over 188 days in sealed pressure vessels. Routine water samples were collected from the vessels throughout the course of the experiment, and final results showed that As concentrations reached up to 16 and 150 times higher than the initial concentration, at $60^{\circ} \mathrm{C}$ and $120^{\circ} \mathrm{C}$ respectively. The oxidation state of 
dissolved As in the $120^{\circ} \mathrm{C}$ experiments also showed that As(III) was the dominant species. Although the abundance of the As(III) indicates that the experiments were subjected to reducing conditions, secondary goethite and depleted $\delta^{34} \mathrm{~S}$ and $\delta^{18} \mathrm{O}-\mathrm{SO}_{4}$ values were also observed, which suggests that oxidation of sulfide minerals may have taken place. In addition to As, increased concentrations of $\mathrm{Al}, \mathrm{Ba}, \mathrm{Li}, \mathrm{Mo}, \mathrm{DOC}$ were detected after the $120^{\circ} \mathrm{C}$ experiment along with $\mathrm{CO}_{2}$ and methane gas, however, there was no data presented on the release of these constituents from the $60^{\circ} \mathrm{C}$ test.

Javed and Siddique (2016) performed a comparable study to the preceding experiments by heating saturated sediment samples in an autoclave reactor for 1 hour at $\sim 200^{\circ} \mathrm{C}$ and $20-30$ bar pressure to simulate average CSS well conditions. After this phase of the experiment, the samples were centrifuged once temperatures decreased to $\sim 90^{\circ} \mathrm{C}$ for 40 minutes. Analysis of the water and sediments was then completed within the following 24 hours. Sediments that were used in this experiment had been collected from the Mary Creek, Ethel Lake, Bonnyville and Empress formations, ground to $<121 \mu \mathrm{m}\left(\mathrm{D}_{90}\right)$, and saturated using 1.4:1 and 3.4:1 liquid-solid ratios of synthetic and deionized water. Results from the heating experiments revealed that significant amounts of As $(\sim 500-2200 \mu \mathrm{g} / \mathrm{L}$ and $\sim 1200-5000 \mu \mathrm{g} / \mathrm{L})$ were leached into the aqueous phase when saturated to liquid-solid ratios of $1.4: 1$ and $3.4: 1$, respectively. Additionally, it was found that deionized water was more capable at extracting As from the sediments. Although the experiments were useful in illustrating the release of As from aquifer sediments during thermal treatments, this study did not discuss the liberation of other dissolved constituents.

The cumulative findings from these studies indicate that there is sufficient evidence to support the release of As from saturated aquifer sediments when exposed to increased temperatures 
above $50^{\circ} \mathrm{C}-60^{\circ} \mathrm{C}$. While the batch heating tests performed by Fennel (2008), Moncur et al. (2015b), and Javed and Siddique (2016) provide insight into the reaction mechanisms of elemental release from sediments, the ultimate fate of these constituents in an aquifer is primarily governed by their mobility and solid-phase interactions during transport. Fennel (2008) demonstrated that most species increase in their downgradient concentration over time as a response from localized aquifer heating and groundwater transport. These combined processes are known to cause specific reactions including sorption, precipitation, and (re)mobilization as they influence the conditions of the aquifer system. Although the results of the field program illustrate the geochemical changes caused by these driving mechanisms, there was little data on the groundwater geochemistry at locations between $0 \mathrm{~m}$ and $10 \mathrm{~m}$ from the CSS injection well. Some of this data could be elucidated from the results of the batch heating tests; however, reactive transport was not adequately represented in these experiments nor was the complete discussion on the geochemical species aside from arsenic.

\section{Aquifer Thermal Energy Storage}

Aquifer thermal energy storage (ATES) is an emerging method that is being used increasingly in parts of Europe and Asia to regulate the temperature of buildings by utilizing the heat capacity characteristics of aquifers. When buildings are heated due to warm outside temperatures, the ATES system operates by removing the warm water from conduits within the infrastructure and injecting into a subsurface aquifer while simultaneously pumping and recirculating cool groundwater $\left(\sim 11^{\circ} \mathrm{C}\right)$ throughout the building, thereby causing an overall decrease in building temperature. Conversely, when outside temperatures are cooler, the warm water that had been stored within aquifer is pumped back up and circulated through the infrastructure while the cool 
water from the building is injected into the aquifer. The system makes use of 'cold' and 'hot' wells to source cool and warm water, and the cycle is typically repeated according to the seasonal variability and overall building temperatures.

The temperature of the warm water from hot wells ATES injection typically averages $\sim 16^{\circ} \mathrm{C}$ during operation with a maximum allowable yearly average temperature of $25^{\circ} \mathrm{C}$ in European countries, but can reach up to $40^{\circ} \mathrm{C}$ to $80^{\circ} \mathrm{C}$ when high temperature systems are employed. Because these thermal wells are commonly constructed within aquifer units containing potable groundwater resources, localized heating of shallow freshwater aquifers can occur. As such, it is possible to recognize that ATES can affect groundwater conditions similarly to that of in-situ thermal recovery. Although obvious differences do exist in terms of the temperature range between the two systems, the results from ATES investigations could allow for additional insight to be gained with respect to the liberation and mobility of geochemical species caused by increases in groundwater temperature from in-situ thermal recovery operations.

Several studies have recently examined and reviewed the geochemical effects from ATES systems in Belgium and the Netherlands through a combination of field programs, column experiments, and geochemical modelling. Bonte et al. (2011, 2013a, 2013b, 2013c, 2014) has published extensively on this subject and the effects of ATES on the evolution of groundwater geochemistry. Over the course of a 4-year field monitoring period, the observed concentrations of $\mathrm{Cl}, \mathrm{SO}_{4}, \mathrm{NO}_{3}, \mathrm{NH}_{4}, \mathrm{Fe}, \mathrm{Mn}$, and DOC from groundwater at shallow and deep ATES warm well locations showed a cyclical behavior which generally followed the increasing and decreasing trends in temperature and pumping/injection rate (Bonte et al., 2013a). Temperature fluctuations of the warm well were on the order of $12^{\circ} \mathrm{C}$ to $22^{\circ} \mathrm{C}$, while pumping and injection rates were approximately $80,000 \mathrm{~m}^{3} /$ month and $20,000 \mathrm{~m}^{3} /$ month, respectively. Overall increases 
in concentration were observed for $\mathrm{SO}_{4}, \mathrm{Cl}, \mathrm{Na}$, and $\mathrm{K}$, while $\mathrm{Fe}$ was shown to decrease with respect to background levels (Bonte et al., 2013a). The field results are comparable to those attained by Fennel (2008) who reported similar increases and decreases in these elements from wells surrounding a thermal recovery facility. In addition, Bonte et al. (2013a) suggested similar mechanisms to those of Fennel (2008) with respect to the mobilization of trace metals and DOC due to changes in redox conditions caused by temperature effects.

In conjunction with the field program, laboratory column experiments were also performed by Bonte et al. (2013a, 2013b, 2013c, 2014) to assess the impact of temperature on groundwater quality and geochemical changes. The tests were conducted at $5^{\circ} \mathrm{C}, 11^{\circ} \mathrm{C}, 25^{\circ} \mathrm{C}$ and $60^{\circ} \mathrm{C}$ in anoxic conditions using three different aquifer sediment cores and carried out over a period of 24 pore volumes (equal to one pore volume per day). Effluent samples collected from the columns were analyzed for geochemical species and parameters of interest. Results from the $5^{\circ} \mathrm{C}$ and $11^{\circ} \mathrm{C}$ experiments generally showed no significant changes in the effluent concentrations over time in all three sediments. In contrast, there were obvious differences with the results from the $25^{\circ} \mathrm{C}$ tests which showed a significant increase in As concentration over time that exceeded 10 $\mu \mathrm{g} / \mathrm{L}$ in two of the sediments cores. Increased concentrations were also noted for $\mathrm{K}$ and $\mathrm{Si}$ indicating the dissolution of silicate minerals, such as K-feldspar which had been identified. Additionally, test data showed that a redox shift from Fe-reducing to $\mathrm{SO}_{4}$-reducing had occurred when temperatures increased from $11^{\circ} \mathrm{C}$ to $25^{\circ} \mathrm{C}$, respectively (Bonte et al., 2013c).

Geochemical species and parameters that were significantly influenced $(\mathrm{p}<0.05)$ by temperature in the $60^{\circ} \mathrm{C}$ tests included As, B, DOC, F, K, Mo, P, Si, V and pH (Bonte et al., 2013b). The general trend of these constituents was dictated by a sharp initial increase in concentration followed by a gradual decrease with the progressive number of pore volumes. Mechanisms that 
were attributed to the release and of mobilization of oxyanions As, B, Mo, P, and V were suggested to be from desorption and possibly reductive dissolution of iron (hydr)oxides. The release of DOC on the other hand, was suggested to be from a combination of desorption and dissolution of sedimentary organic matter.

A similar initial increasing trend was also observed for $\mathrm{SO}_{4}$ concentrations, however, the subsequent decrease was much more abrupt than the previous species and was suggested to be consistent with sulfate-reduction processes. In both the $25^{\circ} \mathrm{C}$ and $60^{\circ} \mathrm{C}$ tests, there were also no temperature effects that were evident for $\mathrm{Al}, \mathrm{Ba}, \mathrm{Ca}, \mathrm{Co}, \mathrm{Cu}, \mathrm{Fe}, \mathrm{Mg}, \mathrm{Mn}, \mathrm{Na}, \mathrm{Ni}, \mathrm{Pb}, \mathrm{Zn}, \mathrm{Sb}, \mathrm{Sr}$, Eu, Ga, Ho, La, Sc, Th, and Yb which were identified in the sediments (Bonte et al., 2013b).

After reviewing the collective data produced from the column experiments designed to study the effects of ATES systems, there are apparent and interesting patterns when compared to the batch heating tests performed by Fennel (2008) and Moncur et al. (2015b). Generally, there was agreement between the results in all batch and column heating tests where arsenic concentrations had increased at temperatures of $50^{\circ} \mathrm{C}$ to $60^{\circ} \mathrm{C}$. Data from the $27^{\circ} \mathrm{C}$ test by Fennel (2008) did not conclusively show that As was released; however, Bonte et al. (2013a, 2013c) demonstrated that an increase in As concentration was indeed linked to temperature at $25^{\circ} \mathrm{C}$. The results between all tests also matched well regarding the low temperature experiments. Data from these tests showed that there were little to no changes between the concentration of As and other species at temperatures $<11^{\circ} \mathrm{C}$.

Discrepancies between the results of the heating tests primarily exist due to the absence of supplementary geochemical information for the $27^{\circ} \mathrm{C}, 50^{\circ} \mathrm{C}$ and $60^{\circ} \mathrm{C}$ batch heating experiments. In the reports by Bonte et al. (2013a, 2013c), a detailed discussion of geochemical species aside 
from As was included for tests at all temperatures, whereas Fennel (2008) and Moncur et al. (2015b) only presented this data for tests performed at $>120^{\circ} \mathrm{C}$.

When comparing the results, it is also important to note that the batch heating and column experiments are inherently different tests due to the added function of mass transport that is applied in the column, in addition to the fact that both tests make use of different aquifer sediments, thereby affecting the overall mineralogy and geochemical outcomes. Nevertheless, similar conclusions were evident between the two tests, which include Mo, K, and DOC as constituents that were consistently released and mobilized due to heating, as well as the dissolution and sorption processes that are principle mechanisms for controlling the dissolved species concentrations. 


\section{Chapter 3 - Materials and Methods}

\subsection{Column Design and Construction}

All heat experiments were performed using a polytetrafluoroethylene (PTFE) column enclosed with PTFE threaded end caps. Unlike polyvinylchloride (PVC), PTFE is stable at temperatures of up to $200^{\circ} \mathrm{C}$ and was selected as the column material for its enhanced thermal tolerance. The column had overall dimensions of $3.0 \mathrm{~m}$ in length, with a $5 \mathrm{~cm}$ outer diameter, and $4.6 \mathrm{~cm}$ inner diameter. Each of the end caps were fitted with $1 / 2$ " hose barb by $1 / 2$ " Male NPT Swagelok fittings to allow for the attachment of inflow and outflow tubing. Inflow water to the column was controlled using a Cole-Parmer four channel micro-peristaltic pump and sourced from a $25 \mathrm{~L}$ Nalgene carboy of deionized water.

Twenty-nine water sampling ports were installed at $10 \mathrm{~cm}$ intervals along the length of the column using bored-through stainless steel Swagelok tube fittings with a 1/8" Male NPT. Each of the fittings held a $10 \mathrm{~cm}$ length of $1 / 8$ " PTFE tubing, which had been perforated along a $4 \mathrm{~cm}$ section and filled with glass wool to act as a non-reactive filter. The perforated ends of the tubes were set inside the column while the outer ends were connected to one-way Luer lock valves on the outside of the column.

A $0.6 \mathrm{~m}$ section of the column located between $1.0 \mathrm{~m}$ and $1.6 \mathrm{~m}$ from the input end was designed to heat the water and sediments using six $120 \mathrm{~V}$ two-wire stainless steel Marathon cartridge heaters positioned at $10 \mathrm{~cm}$ intervals and staggered radially (herein referred to as "the heating section"). The cartridge heaters were $4.4 \mathrm{~cm}$ in length and fitted with a $1 / 8$ " Male NPT.

The column was also designed with a cooled section located between $1.9 \mathrm{~m}$ and $2.4 \mathrm{~m}$ from the input end, which consisted of two $1 / 4$ " diameter cooling lines that ran inside the column to 
circulate cold water (herein referred to as "the cooling section"). Cooling lines were installed using bored-through stainless steel Swagelok fittings with a $1 / 2$ " Male NPT that connected a loop of PTFE tubing. The cooling loop was run from the interior of the column down to a Masterflex Console Drive, Model 7017-20 peristaltic pump, which then fed inside a reservoir to allow for the water to be recirculated. A small refrigerator was later added to this set-up, and housed the water reservoir and a 25' length of coiled PVC tubing to allow for lower temperatures to be attained. The end of the coiled cooling line was made to exit the refrigerator and feed back into the column by foam insulated tubes to minimize heat gain.

A total of twelve thermistors and three RTD's were installed along the entire length of the column to provide a temperature profile. Thermistors and RTD's were positioned at $10 \mathrm{~cm}$ intervals in the heated section; at $20 \mathrm{~cm}$ spacing from both ends of the heated section; and at 30 $\mathrm{cm}$ intervals in all other sections of the column. The thermistors were manufactured by U.S. Sensor and were constructed using a two-wire thermistor element contained within a 1.5" stainless steel probe housing and fitted to a 1/8" Male NPT. RTD sensors were constructed from a $1000 \Omega$ DIN 0.00385 Class A element coupled with a 1/8" Male NPT fitting manufactured by Watlow.

To ensure a water tight seal during the experiments, all fittings and instrumentation were threaded into the column using PTFE tape. Cartridge heaters, Swagelok fittings and thermistors in the heated section were also sealed with silicon caulking to help prevent leaks after being subjected to high temperatures over long periods of time. Insulation tape was also wrapped around the heated and cooled sections to allow for more accurate readings from the thermistors and greater precision from the heat cartridge output temperatures. 
A Campbell Scientific CR1000 Data Logger coupled with the 16-channel control port module and 16/32 channel multiplexer was used to control the six cartridge heaters, and record measurements from all thermistors and RTD's. To ensure that measurements were recorded during possible power outages, the Data Logger was equipped with a $12 \mathrm{~V}$ power supply and an 8.5 Amp sealed rechargeable battery. A computer was hard-wired to the Data Logger to program and control the column instrumentation.

Complex flow regimes due to fluctuations in water density during the heating experiments were taken into account when considering the orientation of the column. A horizontal alignment was thought to minimize these effects due to the controlled flow gradient and minimized water density effects during heating. The end of the column outflow tubing was positioned $50 \mathrm{~cm}$ higher than the column input water to achieve a forward gradient. Effluent water was collected from the output tubing to monitor water geochemistry, flow rate and pore volumes.

Aerobic experiments were carried out using the experimental set-up illustrated in Figure 5, while anaerobic experiments were performed in anoxic conditions by removing dissolved and atmospheric oxygen. A detailed description of the additional equipment used in the anaerobic experimental set-up is described in Section 3.2.2. 


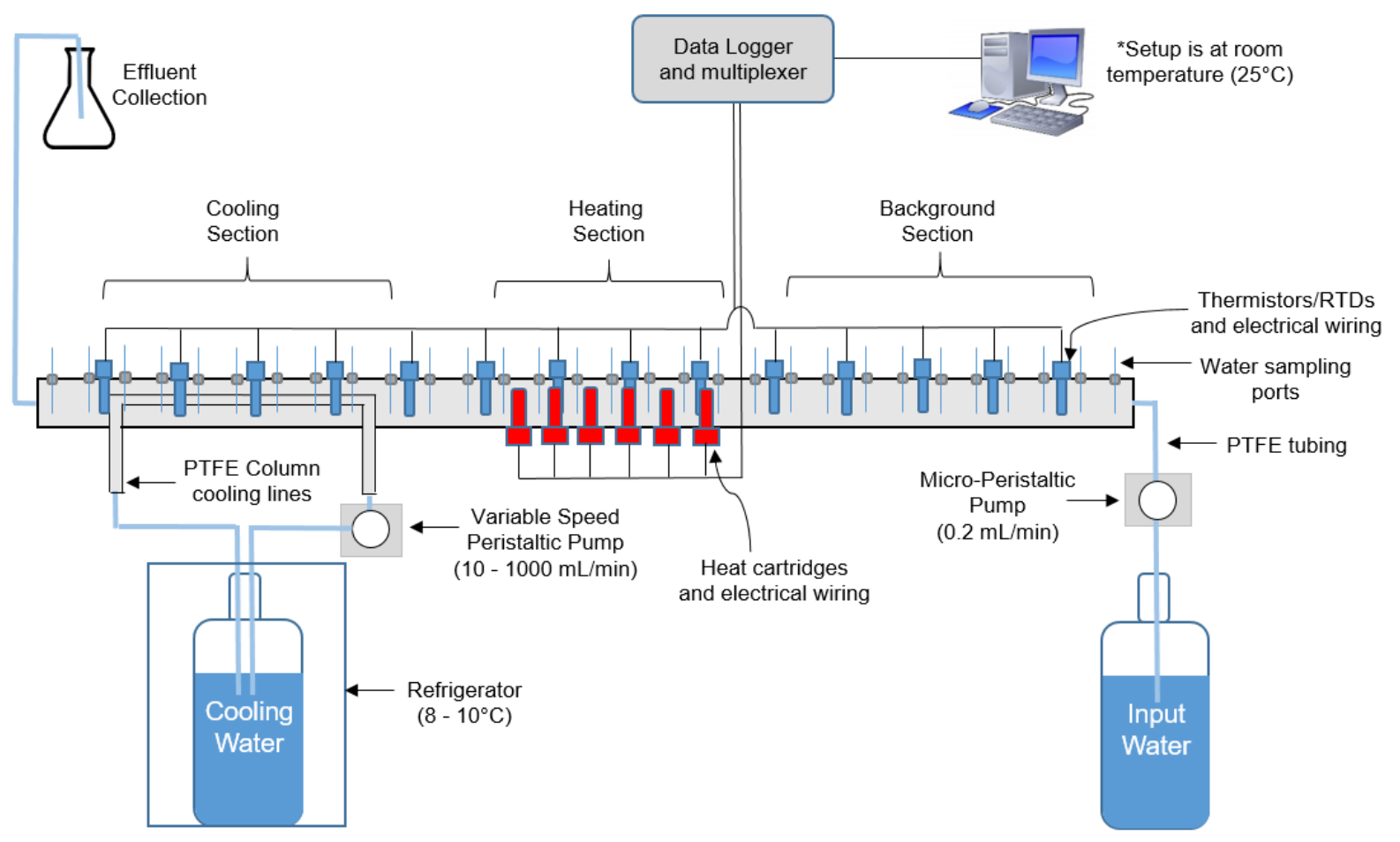

Figure 5. The schematic design of the laboratory set-up used for the aerobic column experiments. Note that the refrigerator was installed following Experiment 1.

\subsection{Column Experiments}

In this research study, unheated and heated column experiments were conducted to characterize and compare the effects of ambient and high temperature $\left(\sim 90^{\circ} \mathrm{C}\right)$ conditions on water quality from different substrate materials. Overall, these experiments were designed to mimic a fully saturated aquifer unit in contact with an in-situ thermal recovery well. The duration of the experiments were constrained to a two-month period, typical of a SAGD heating cycle, and the intention of the results were to allow for comparisons with existing field and laboratory data.

The first column experiment (Experiment 1) was performed in aerobic conditions with quartz sand and ran for two-months at room temperature, followed by two-months at high temperature. The second experiment (Experiment 2) was performed in both aerobic and anaerobic conditions 
with quartz sand containing $0.6 \% \mathrm{wt} / \mathrm{wt}$ pyrite. Experiment 2 consisted of an unheated aerobic phase which was run for half a month, in addition to heated aerobic and anaerobic experiments, each lasting approximately two-months. The final experiment (Experiment 3) made use of aquifer sediments collected from Cold Lake, Alberta and was conducted entirely in anaerobic conditions. Similarly to Experiment 2, the unheated phase of Experiment 3 was run for half a month, while the heated phase was run for approximately two months.

Inverse geochemical modelling of the column experiment results was carried out using PHREEQC Version 3 (Parkhurst and Appelo, 2013) coupled with the MINTEQ database (Allison et al., 1991). Modelling was performed to determine the saturation indices of particular minerals in each experiment and investigate the likelihood of precipitation and/or dissolution reactions. The MINTEQ database was specifically selected based on its correct reaction enthalpy and demonstrated accuracy for calculating quartz solubility at high temperatures (Appelo and Postma, 2005).

\subsubsection{Experiment 1}

Prior to commencing Experiment 1, the column was gradually filled with $30 / 40$ mesh quartz sand and was tapped gently before being capped to promote sediment settling and avoid damage to the sensors. Previous efforts to characterize the physical parameters of the sand have been completed by Williams and Oostrum (2000), and Sequeira (2014). Once the column was filled with dry sediment, it was flushed with $\mathrm{CO}_{2}$ gas to remove other atmospheric gases. After flushing, deionized water was pumped continuously at a rate of $0.2 \mathrm{~mL} /$ minute (approximately one pore-volume per week) into the column to dissolve and remove the gaseous $\mathrm{CO}_{2}$, while fully saturating the pore space. Because the solubility of $\mathrm{CO}_{2}$ is much higher than most other 
atmospheric gases, it readily dissolves in water at room temperature which reduces the potential to form gas bubbles and allows for uniform flow. De-ionized water (DIW) was used to simulate a low ionic strength porewater during heated conditions, and mimic the geochemistry of a relatively young groundwater after recharge. Output flow volumes were measured regularly to establish steady-state conditions and confirm that the system was completely saturated.

Water was sampled once a week at $0.2 \mathrm{~m}$ intervals along the column during the unheated and heated experiments to establish baseline concentrations and to distinguish data acquired during the heated phase of the experiment. Dissolved silica was analyzed with a Hach DR 2800 spectrophotometer using the silicomolybdate method (Knudson et al., 1940). The pH was analyzed at the time of sampling using a double-junction Cole Parmer ATC $\mathrm{pH} /$ temperature probe connected to an Oakton Ion 700 meter. Individual samples were collected at a frequency of 1 hour to allow enough time for the pumping rate to replace the volume of water that was extracted. This frequency was also employed in Experiment 2 and 3.

The heated experiment began by programing a temperature gradient from $50^{\circ} \mathrm{C}$ to $90^{\circ} \mathrm{C}$ within the heated section of the column. This temperature range was also implemented in subsequent experiments and tracer tests as it does not produce a phase change within the column, and because SAGD field observations have shown that temperatures reach approximately $100^{\circ} \mathrm{C}$ in the aquifer units adjacent to the steam injection well (Giraldo and MacMillan, 2016). All temperatures within the column were recorded every minute for the duration of the baseline conditions and during the two-month heated experiment. 


\subsubsection{Experiment 2}

The second column experiment began by first thoroughly cleaning the inside of the column from the previous experiment. Sediments were removed and the internal volume was flushed five times with deionized water. After being flushed, the column was left to dry, and later refilled with quartz sand containing $0.6 \% \mathrm{w} / \mathrm{w}$ pyrite (Figure 6 ). The pyrite grains were prepared from a $9 \mathrm{~cm} \times 8 \mathrm{~cm} \times 6 \mathrm{~cm}$ crystal of pyrite sourced from Weinrich Minerals Inc., that was fed into a Braun Chipmunk rock chipper and sieved to $30 / 55$ mesh size. The amount of pyrite used in the material was based on the average percentage of sulfides present in Alberta aquifer sediments which had been characterized by Javed et al. (2014). Once the column was refilled with the mixed material and capped, the column pore space was flushed using $\mathrm{CO}_{2(\mathrm{~g})}$ and deionized input water was pumped continuously to fully saturate the material.

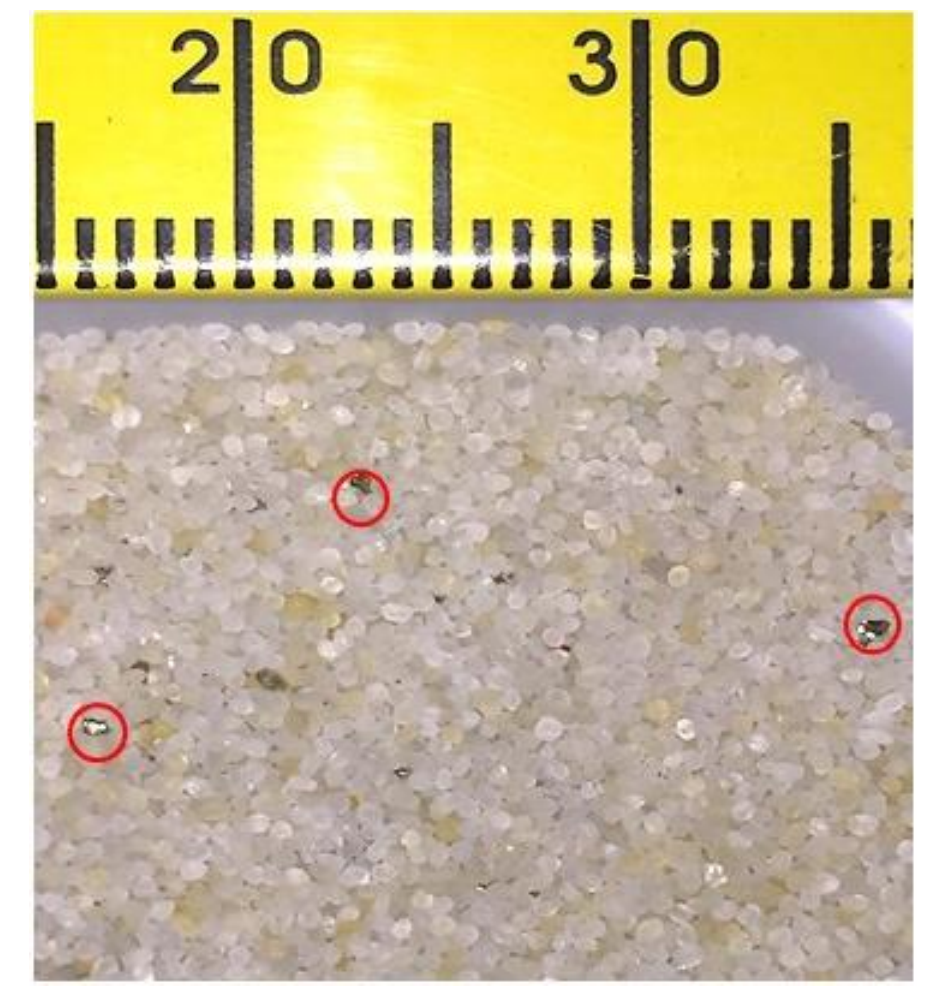

Figure 6. A photo of the sediments used in Experiment 2. The bulk material is comprised of $30 / 40$ mesh quartz sand containing $0.6 \% \mathrm{w} / \mathrm{w}$ pyrite (grains circled in red). The scale provided is shown in millimeters. 
In an effort to reduce the amount of dissolved oxygen (DO) entering the column from the input water and better mimic subsurface conditions, a PermSelect ${ }^{\mathrm{TM}}$ TinyModule microporous membrane module with a KNF diaphragm pump running at 15 psi vacuum pressure was attached in-line to the inflow tubing. As an additional measure, the column and input water pump were placed inside a custom built anaerobic chamber purged with ultra-pure $\mathrm{N}_{2(\mathrm{~g})}$ to prevent diffusion of $\mathrm{O}_{2(\mathrm{~g})}$ through the column walls (Figure 7). Nitrogen gas was constantly flushed through the chamber to maintain anoxic conditions, and the $\mathrm{O}_{2(\mathrm{~g})}$ concentration within the anaerobic chamber was monitored using an Apogee Instruments Inc. SO-210 fast response thermistor reference oxygen sensor. The $\mathrm{O}_{2(\mathrm{~g})}$ sensor was connected to the Campbell Scientific data logger and calibrated in an $\mathrm{N}_{2(\mathrm{~g})}$-filled container prior to installation in the anaerobic chamber.

The anaerobic chamber was constructed using 0.5 " thick clear acrylic panels welded together with a removable lid. The interface between the lid and the chamber walls was clamped together and sealed with a combination of a $1 / 4 "$ butyl rubber gasket and silicon caulking to ensure a gas tight fit along the perimeter edge. Input and output water and gas tubing was connected to the chamber using bored-through Swagelok threaded fittings sealed with PTFE tape. Holes that were drilled to house electrical wiring were sealed using silicon caulking.

Deionized input water was also kept in a glass carboy and regularly purged with ultra-pure $\mathrm{N}_{2(\mathrm{~g})}$ $1-2$ times a week with a microporous gas bubbler for $4-5$ hours. Purging water with $\mathrm{N}_{2(\mathrm{~g})}$ has been shown to be an effective method for DO removal when compared to the performance of alternative techniques (Butler et al., 1994). Prior to purging, the carboy was sealed using a PTFE lined cap with a fitted $\mathrm{N}_{2(\mathrm{~g})}$-filled Mylar ${ }^{\circledR}$ balloon and a connection to the output gas line to reduce the interaction of the input water with atmospheric oxygen. 


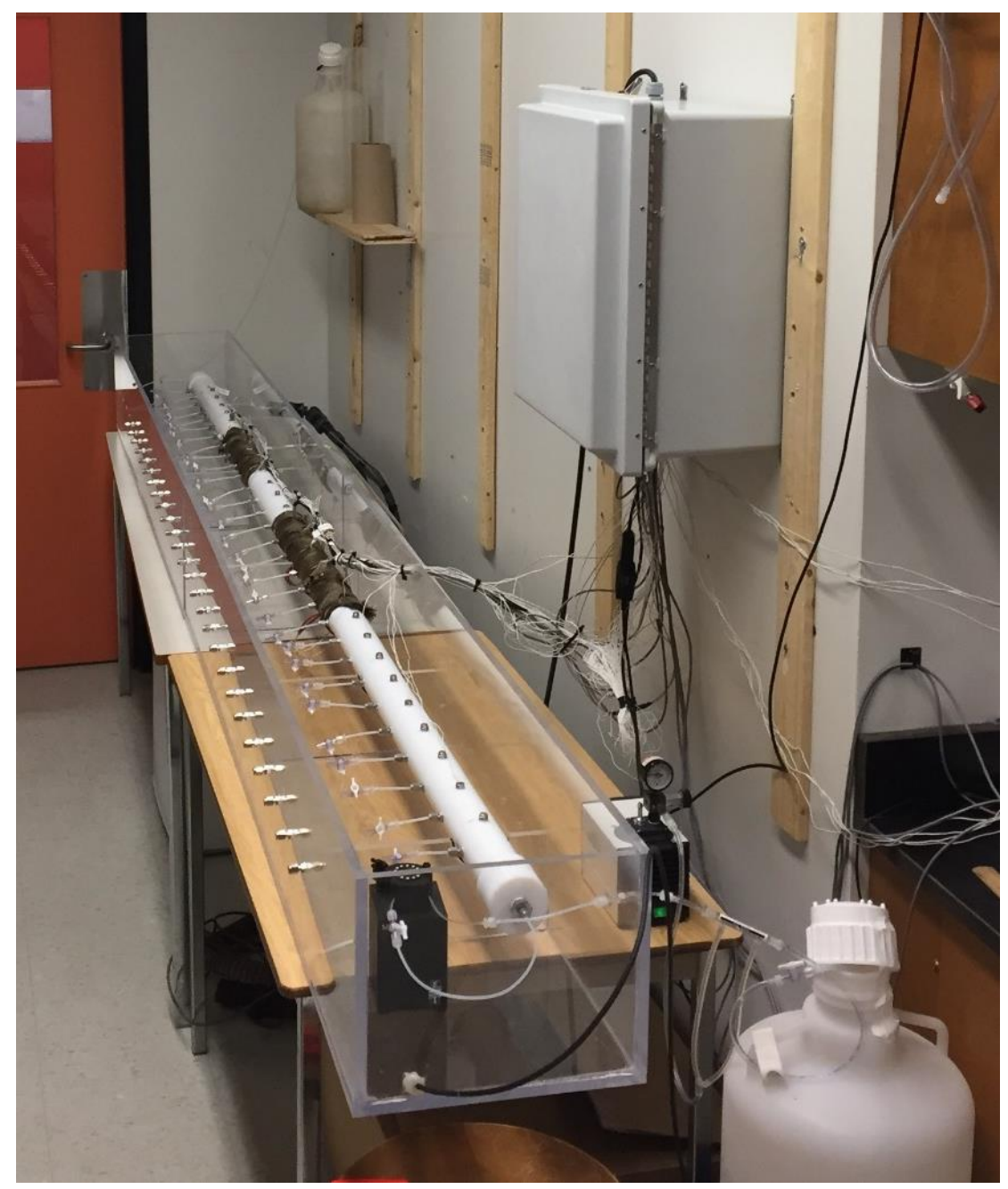

Figure 7. Laboratory set-up used for the anaerobic column experiments (not showing the sealed lid). The clear anaerobic chamber contains the column apparatus and the input water pump.

Water samples were collected on a weekly basis in unheated (baseline) and heated conditions at $0.3 \mathrm{~m}$ intervals along the column. A summary of the sampling regime is provided in Table 1 . Sample collection was performed by first purging $2 \mathrm{~mL}$ from the sample port to allow for a representative sample to be acquired. Afterwards, two $5 \mathrm{~mL}$ aliquots were collected from the port, filtered to $0.45 \mu \mathrm{m}$, and analyzed for $\mathrm{pH}$, $\mathrm{DO}$, and redox species $-\mathrm{SO}_{4}{ }^{2-}, \mathrm{S}^{2-}$, and $\mathrm{Fe}^{2+}$. Dissolved oxygen was measured with an Oakton DO 6+ meter and DO probe, while sulfate, sulfide and ferrous iron concentrations were measured using the Hach USEPA SulfaVer 4, 
methylene blue, and 1,10-phenanthroline methods, respectively. Because both $\mathrm{DO}$ and $\mathrm{pH}$ measurements are relatively sensitive to time after sample collection, these readings were completed immediately before proceeding to redox species analysis. Sulfate was also measured during every sampling period while sulfide and ferrous iron analysis was alternated due to water volume limitations.

Sampling periods for $\mathrm{DO}, \mathrm{pH}$ and redox ion analysis were also alternated with those for total element concentrations using inductively coupled plasma-optical emission spectroscopy (ICPOES). Water samples for ICP-OES submission were collected as a full $10 \mathrm{~mL}$ aliquot, filtered to $0.45 \mu \mathrm{m}$, and kept in sealed, $2 \% \mathrm{HNO}_{3}$-washed $15 \mathrm{~mL}$ tubes. A series of blank samples were also submitted to test the potential for contamination from the sample syringe, filter, sample tube, the tube cap, as well as the deionized water. Upon sample submission, the water samples were acidified and analyzed using ICP-OES. 
Table 1. A summary of the water sampling and analytical regime used for the aerobic and anaerobic phase of Experiment 2.

\begin{tabular}{|c|c|c|}
\hline Sampling Time & Volume (mL) & Analytical Parameters \\
\hline \multirow{2}{*}{$\begin{array}{l}\text { Baseline Week 1, } 2 \\
\text { (Aerobic) }\end{array}$} & $5^{1}$ & $\mathrm{pH}, \mathrm{SO}_{4}$ \\
\hline & $5^{2}$ & $\mathrm{DO}, \mathrm{Fe}^{2+}$ \\
\hline $\begin{array}{l}\text { Baseline Week } 1 \\
\text { (Aerobic) }\end{array}$ & $10^{3}$ & $\begin{array}{l}\text { Al, As, Ca, Cu, Fe, K, Mg, Mn, Ni, Na, S, Si, } \\
\text { Zn }\end{array}$ \\
\hline \multirow{2}{*}{$\begin{array}{l}\text { Heated Week 1, 2, } 6 \\
\text { (Aerobic) }\end{array}$} & $5^{1}$ & $\mathrm{pH}, \mathrm{SO}_{4}$ \\
\hline & $5^{2}$ & $\mathrm{DO}, \mathrm{Fe}^{2+}$ \\
\hline \multirow{2}{*}{$\begin{array}{l}\text { Heated Week } 4,8 \\
\text { (Aerobic) }\end{array}$} & $5^{1}$ & $\mathrm{pH}, \mathrm{SO}_{4}$ \\
\hline & $5^{2}$ & $\mathrm{DO}, \mathrm{S}^{2-}$ \\
\hline $\begin{array}{l}\text { Heated Week 1, 3, 5, 7, } 9 \\
\text { (Aerobic) }\end{array}$ & $10^{3}$ & $\begin{array}{l}\text { Al, As, Ca, Cu, Fe, K, Mg, Mn, Na, Ni, S, Si, } \\
\text { Zn }\end{array}$ \\
\hline \multirow{2}{*}{$\begin{array}{l}\text { Heated Week 1, } 7 \\
\text { (Anaerobic) }\end{array}$} & $5^{1}$ & $\mathrm{pH}, \mathrm{SO}_{4}$ \\
\hline & $5^{2}$ & $\mathrm{DO}, \mathrm{S}^{2-}$ \\
\hline \multirow{2}{*}{$\begin{array}{l}\text { Heated Week } 3 \\
\text { (Anaerobic) }\end{array}$} & $5^{1}$ & $\mathrm{pH}, \mathrm{SO}_{4}$ \\
\hline & $5^{2}$ & $\mathrm{DO}, \mathrm{Fe}^{2+}$ \\
\hline $\begin{array}{l}\text { Heated Week 2, } 8 \\
\text { (Anaerobic) }\end{array}$ & $10^{3}$ & $\begin{array}{l}\text { Al, As, Ca, Cu, Fe, K, Mg, Mn, Na, Ni, S, Si, } \\
\text { Zn }\end{array}$ \\
\hline
\end{tabular}

Geochemical characterization of the sediments was carried out using a tungsten filament Tescan Vega-II XMU scanning electron microscope equipped with an Oxford X-ray detection system capable of energy dispersive X-ray spectrometry (SEM-EDX). The SEM was used to provide qualitative analysis and observe the condition of the quartz and pyrite grains before the heated experiments, while the EDS enabled quantitative trends to be identified with respect to elemental composition of the minerals and secondary precipitates. To ensure high resolution images from the SEM, the samples were dried at $75^{\circ} \mathrm{C}$, then mounted on an aluminum stub using double-sided carbon tape and coated in gold. 
As an additional measure to identify trace metals, elemental analysis of the pyrite grains was performed by laser ablation (LA) ICP-MS using a $40 \mu \mathrm{m}$ spot size and $\sim 60$ seconds of ablation at a $10 \mathrm{~Hz}$ repetition rate. Before undergoing analysis, pyrite grains were also ultrasonicated in deionized water to remove surface contamination.

\subsubsection{Experiment 3}

The third column experiment applied the same procedure used for cleaning and preparing the column in the previous experiment. Similarly, the column was place inside the anaerobic chamber and both the column and input water were purges as previously described.

Similarly to the procedure used during second experiment, water samples were collected on a weekly basis during unheated (baseline) and heated conditions and analyzed for $\mathrm{DO}, \mathrm{pH}, \mathrm{SO}_{4}{ }^{2-}$,

$\mathrm{S}^{2-}$, and $\mathrm{Fe}^{2+}$, as well as total elemental concentrations using ICP-OES (Table 2). Total Alkalinity was also measured bi-weekly during heated conditions using a Hach TNTplus 870 Colorimetric method. Prior to submission and analysis, ICP-OES samples were stored in a refrigerator at $\sim 4^{\circ} \mathrm{C}$. 
Table 2. A summary of the water sampling and analytical regime used during Experiment 3.

\begin{tabular}{|c|c|c|}
\hline Sampling Time & Volume (mL) & Analytical Parameters \\
\hline \multirow{2}{*}{ Baseline Week 1, 3} & $5^{1}$ & $\mathrm{pH}, \mathrm{SO}_{4}$ \\
\hline & $5^{2}$ & $\mathrm{DO}, \mathrm{S}^{2-}$ \\
\hline \multirow{2}{*}{ Baseline Week 2} & $5^{1}$ & $\mathrm{pH}, \mathrm{SO}_{4}$ \\
\hline & $5^{2}$ & $\mathrm{DO}, \mathrm{Fe}^{2+}$ \\
\hline \multirow{2}{*}{ Heated Week 1, 5, 9} & $5^{1}$ & $\mathrm{pH}, \mathrm{SO}_{4}$ \\
\hline & $5^{2}$ & $\mathrm{DO}, \mathrm{S}^{2-}$ \\
\hline \multirow{2}{*}{ Heated Week 3, 7} & $5^{1}$ & $\mathrm{pH}, \mathrm{SO}_{4}$ \\
\hline & $5^{2}$ & $\mathrm{DO}, \mathrm{Fe}^{2+}$ \\
\hline Heated Week 3, 5, 7 & 1 & Total Alkalinity (as $\mathrm{CaCO}_{3}$ ) \\
\hline Heated Week 2, 4, 6, 8 & $10^{3}$ & $\begin{array}{l}\mathrm{Al}, \mathrm{As}, \mathrm{B}, \mathrm{Ca}, \mathrm{Cu}, \mathrm{Fe}, \mathrm{K}, \mathrm{Mg}, \mathrm{Mn}, \mathrm{Ni}, \mathrm{S}, \mathrm{Si} \\
\mathrm{Zn}\end{array}$ \\
\hline
\end{tabular}

- Refers to the first aliquot collected.

${ }^{2}$ - Refers to the second aliquot collected.

${ }^{3}$ - Refers to the sample collected for ICP-MS analysis.

The sediments used in Experiment \#3 were provided by the Alberta Geological Survey from borehole WR99-1 (Coordinates: $55.7143794^{\circ} \mathrm{N} 112.1879148^{\circ} \mathrm{W}$ ) located within the CLBR basin (Andriashek, 2003). The core material was collected between depth intervals 400 to $439 \mathrm{ft}$ and 682 to $700 \mathrm{ft}$, from the Empress Formation Unit 3. Before being poured into the column, the aquifer material was mixed thoroughly using equal volumes of sediments from both depth intervals. A photo of the homogenized sediment mixture is shown in Figure 8, and reflects the borehole log description described in Section 4.3.1.

A combination of X-ray diffraction (XRD), X-ray fluorescence (XRF) was used to characterize the bulk mineralogy and total elemental composition of the sediments, respectively. A total of three samples were dried, ground and sieved to $40 \mu \mathrm{m}$ before being submitted for analysis. Two of the samples contained material from the individual depth intervals, and one was comprised of 
mixed material. Bulk XRD was performed in two trials with a Rigaku Ultima IV Diffractometer using $\mathrm{Cu} \mathrm{K} \alpha$ radiation at an accelerating voltage of $40 \mathrm{kV}$ and $40 \mathrm{~mA}$, and range of $4-100^{\circ} 2 \theta$. In the first trial, samples were scanned continuously at a step-width of $0.02^{\circ} 2 \theta$ and $3.00^{\circ} /$ minute, while samples in the second trial were scanned at a step-width of $0.05^{\circ} 2 \theta$ and $0.75^{\circ} /$ minute. The parameters in the first trial were used to identify major silicate and nonsilicate minerals, while the slower step-width of the second trial was used to identify less abundant minerals which were emulated from Javed et al. (2014) to allow for comparisons to be made.

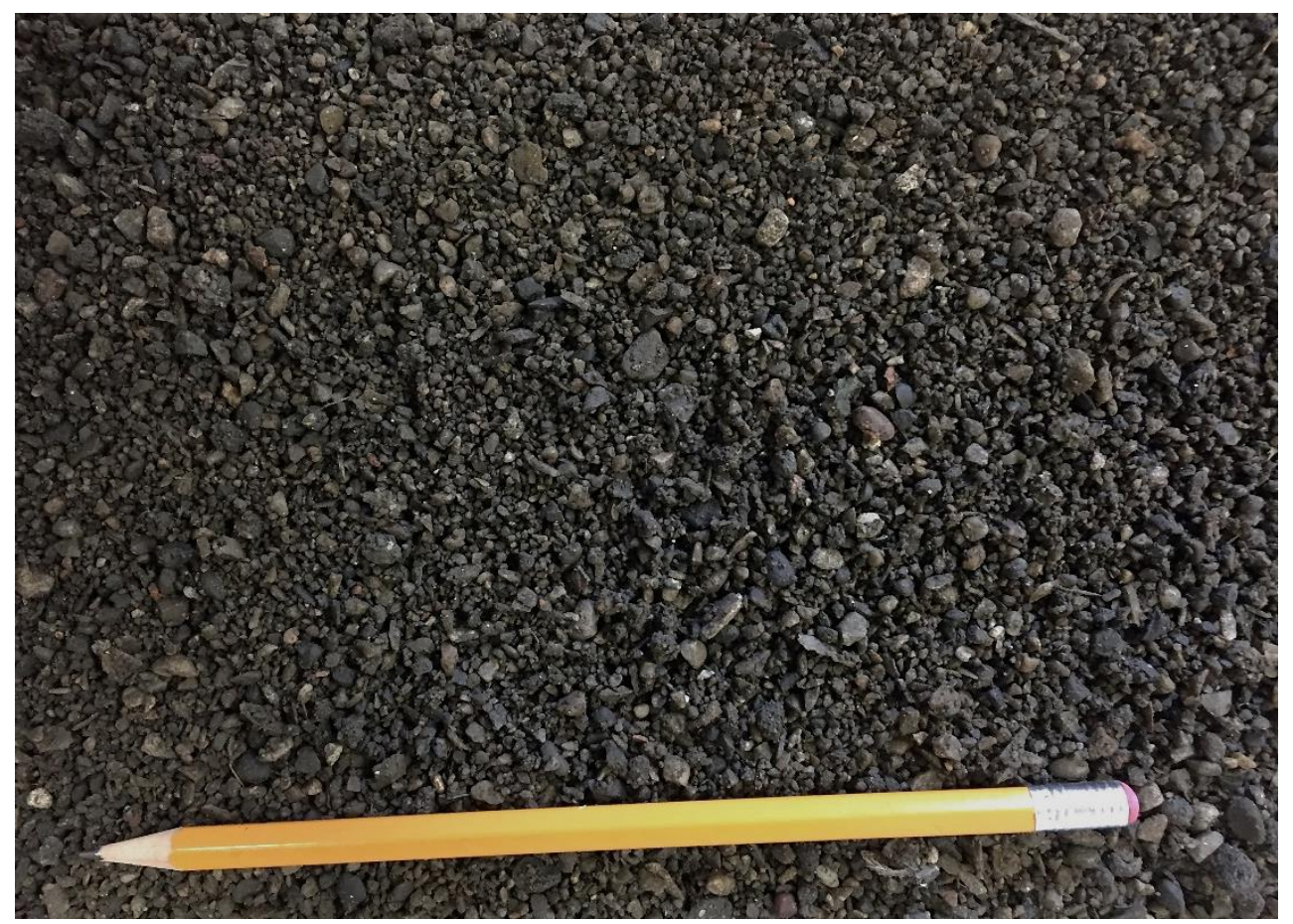

Figure 8. A photo of the homogenized sediments collected from borehole WR99-1 used in Experiment 3.

XRF was completed by first melting the samples into fused glass beads with a Claisse M4 fluxer, followed by analysis using a Rigaku Supermini200 spectrometer. SEM-EDX was also performed 
on the sediments to identify elemental quantitative trends. Sediments were prepared for SEMEDX using the same procedure as described in Experiment 2.

In addition to the use of XRF, XRD, and SEM-EDX techniques, sediment samples were also analyzed for different sulfur fractions using a modified sequential extraction method established by Xiao-quan et al. (1992) and Chen et al. (1997). The tests were performed to identify the sources of $\mathrm{S}$ associated with the sediments and to better understand the mechanisms by which sulfide and sulfate are liberated. A summary of the four-phase sulfur extraction procedure is detailed in Table 3.

Table 3. Sulfur sequential extraction process used for the CLBR sediments.

\begin{tabular}{|c|c|c|c|c|}
\hline Phase & Extractant & $\begin{array}{l}\text { Extraction } \\
\text { Method }\end{array}$ & $\begin{array}{l}\text { Reaction } \\
\text { Time }\end{array}$ & Sulfur Fraction \\
\hline 1 & $\begin{array}{l}\text { 1.0 M Ammonium } \\
\text { Acetate }\left(\mathrm{NH}_{4} \mathrm{CH}_{3} \mathrm{CO}_{2}\right) \\
\text { pH } 7.0\end{array}$ & $\begin{array}{l}\text { Mechanical } \\
\text { shaker and } \\
\text { centrifuge }\end{array}$ & 2 hours & $\begin{array}{l}\text { Water soluble and surface } \\
\text { bound (adsorbed) }\end{array}$ \\
\hline 2 & $\begin{array}{l}1.0 \mathrm{M} \text { Ammonium } \\
\text { Acetate }\left(\mathrm{NH}_{4} \mathrm{CH}_{3} \mathrm{CO}_{2}\right) \\
\text { pH } 5.0\end{array}$ & $\begin{array}{l}\text { Mechanical } \\
\text { shaker and } \\
\text { centrifuge }\end{array}$ & 2 hours & $\begin{array}{l}\text { Water soluble and surface } \\
\text { bound (adsorbed), and } \\
\text { carbonate bound }\end{array}$ \\
\hline $3 \mathrm{a}$ & $1.0 \mathrm{M} \mathrm{HCl}$ & Boiling flask & \multirow{2}{*}{1 hour } & $\begin{array}{l}\text { Dilute } \mathrm{HCl} \text { soluble (organic } \\
\text { and amorphous minerals) }\end{array}$ \\
\hline $3 b$ & $0.05 \mathrm{M} \mathrm{NaOH}$ & Distillation trap & & $\begin{array}{l}\mathrm{HCl} \text { volatile (i.e. amorphous } \\
\text { sulfide minerals) }\end{array}$ \\
\hline $4 a$ & $\begin{array}{l}6.0 \mathrm{M} \mathrm{HCl} \text { and } \\
\text { granular } \mathrm{Zn}\end{array}$ & Boiling flask & \multirow{2}{*}{1 hour } & Residual \\
\hline $4 b$ & $0.05 \mathrm{M} \mathrm{NaOH}$ & Distillation trap & & Crystalline sulfide minerals \\
\hline
\end{tabular}

Sequential extraction of sulfur was carried out using three, $1.00 \mathrm{~g}$ samples of air-dried sediment in pre-washed $50 \mathrm{~mL}$ centrifuge tubes. The four-phase procedure began with the removal of adsorbed and exchangeable sulfur by adding $30 \mathrm{~mL}$ of $1.0 \mathrm{M}$ ammonium acetate solution buffered at $\mathrm{pH} 7.0$ to the sediment sample, which was then mechanically shaken for 2 hours. 
Afterwards, the sediment-solution mixture was centrifuged at $3800 \mathrm{rpm}$ for 10 minutes. The supernatant was then removed, and the sediment residue was rinsed with $5 \mathrm{~mL}$ of deionized water. This extraction method was repeated using $40 \mathrm{~mL}$ of $1.0 \mathrm{M}$ ammonium acetate buffered to pH 5.0.

Once the surface bound S had been removed, the sediment residue was poured into a 3-neck boiling flask. The flask was connected to a distillation-reflux apparatus and a dropping funnel, which was used to add $10 \mathrm{~mL}$ of $2.0 \mathrm{M} \mathrm{HCl}$ and dilute the overall solution to $1.0 \mathrm{M} \mathrm{HCl}$. The solution was brought to a gentle boil for 1 hour while a stream of $\mathrm{N}_{2(\mathrm{~g})}$ was passed through the flask to carry the volatile $\mathrm{S}$ fraction into $10 \mathrm{~mL}$ of $0.05 \mathrm{M} \mathrm{NaOH}$. Dilute $\mathrm{HCl}$ was used to attain the soluble S fraction associated with carbonate and organic compounds, as well as the volatile sulfur fraction from the reaction with amorphous sulfide minerals. The volatile $\mathrm{S}$ released as $\mathrm{H}_{2} \mathrm{~S}_{(\mathrm{g})}$ can then be captured in an alkaline solution (i.e., $0.05 \mathrm{M} \mathrm{NaOH}$ ). After the one-hour reaction, $0.1 \mathrm{~mL}$ of $30 \% \mathrm{H}_{2} \mathrm{O}_{2}$ was added to the $\mathrm{NaOH}$ solution to oxidize any trapped sulfide to sulfate. The overall apparatus used in the sequential extractions for Phase 3 and 4 is shown in Figure 9. 


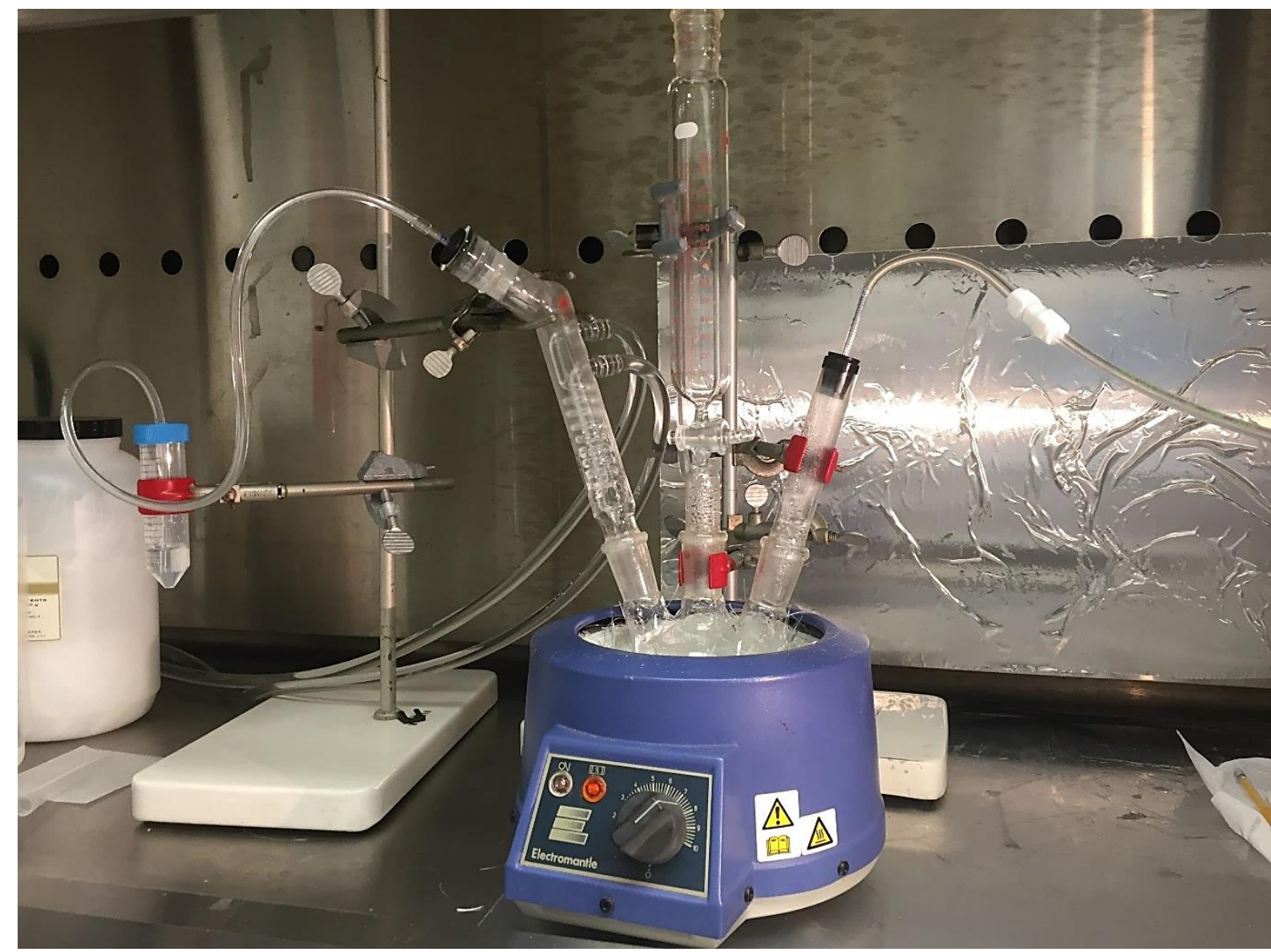

Figure 9. The sequential extraction apparatus used in for leaching amorphous and crystalline sulfur fractions from the CLBR sediments.

After removing the $1.0 \mathrm{M} \mathrm{HCl}$ from the boiling flask, $3.0 \mathrm{~g}$ of granular $\mathrm{Zn}(\mathrm{BDH})$ was added to the sediment residue in the boiling flask and the system was purged with $\mathrm{N}_{2(\mathrm{~g})}$ for several minutes. A dropping funnel was used to add $20 \mathrm{~mL}$ of $6.0 \mathrm{M} \mathrm{HCl}$ slowly. The solution was heated to a gentle boil for 1 hour while the $\mathrm{H}_{2} \mathrm{~S}_{(\mathrm{g})}$, produced from reaction with crystalline sulfide minerals, passed through the distillation-reflux apparatus and collected in $10 \mathrm{~mL}$ of $0.05 \mathrm{M}$ $\mathrm{NaOH}$. Similarly to the procedure used in Phase 4, once the 1-hour leach had been completed, $0.1 \mathrm{~mL}$ of $30 \% \mathrm{H}_{2} \mathrm{O}_{2}$ was added to the $\mathrm{NaOH}$ solution. The final residue and solution in the boiling flask was not collected for analysis. Lastly, three fresh sediment samples were also 
digested in aqua regia at $90^{\circ} \mathrm{C}$ for three hours and analyzed using ICP-OES to determine the total concentration of sulfur.

Quality assurance and control methods employed during the sequential extraction tests were

carried out using Teflon ${ }^{\mathrm{TM}}$ boiling chips as the blank, as well as a known till material for the standard which had been previously characterized by sequential extraction tests performed by Hall et al. (1996). During each phase of the extraction test, the sediment, blank and standard samples were run in triplicate to validate reproducibility of the extraction test and investigate the distribution of results.

\subsubsection{Tracer Tests}

Hydraulic properties of the quartz sand, quartz sand with $0.6 \% \mathrm{w} / \mathrm{w}$ pyrite, and aquifer material were obtained by conducting tracer tests in both heated $\left(80^{\circ} \mathrm{C}\right)$ and unheated $\left(25^{\circ} \mathrm{C}\right)$ conditions using bromide as the conservative solute. The tracer solution was prepared using a known weight of $99.9 \% \mathrm{NaBr}$ salt dissolved in deionized water and pumped into the column at the same flow rate as the column experiments.

Water samples were collected from the sampling ports at $0.5 \mathrm{~m}, 1.7 \mathrm{~m}$, and $2.5 \mathrm{~m}$ along the column during the estimated time of arrival for the bromide solution. To reduce possible impacts caused by water withdrawals during sampling, $5-6 \mathrm{~mL}$ of water $(<0.5 \%$ of the total porevolume) was collected to encourage a steady flow of the Br plume. Flow rate measurements were recorded regularly using a graduated cylinder positioned at the output of the column.

Bromide concentration was analyzed using a double-junction Cole Parmer Bromide Ion Selective Electrode (ISE) and an Oakton Ion 700 meter. The Br ISE was calibrated using 100 
ppm, $10 \mathrm{ppm}$ and $1 \mathrm{ppm} \mathrm{Br}$ standards. Before measuring bromide concentration, samples and standards were given aliquots of $5 \mathrm{M} \mathrm{NaNO}_{3}$ Ionic Strength Adjustor (ISA) and mixed well. Samples that had been collected at $1.7 \mathrm{~m}$ during the heated tracer tests were also given time to cool down to room temperature before analysis due to the temperature sensitivity of the ISE.

Characterization of the hydraulic parameters - average linear velocity, hydrodynamic dispersion, and longitudinal dispersivity, for each material was carried out by fitting data to a modeled curve using equation 5.1 below:

$$
\frac{C}{C_{0}}=(0.5) \operatorname{erfc}\left[\frac{x-v t}{2 \sqrt{a v t}}\right]
$$

Where $\frac{C}{C_{0}}$ represents the normalized concentration of the solution, $x$ refers to the location at which the solution is measured, $v$ refers to the average linear velocity of the fluid, $a$ is the longitudinal dispersivity, and $t$ is time. Each breakthrough curve was modeled by applying the least squares method, while using the Microsoft Excel Solver function to determine an optimal value for $a$. 


\section{Chapter 4 - Experiment Results and Observations}

\subsection{Bromide Tracer Tests and Modeled Data}

Modeled breakthrough curves and $\mathrm{Br}$ concentrations for tracer tests conducted with aquifer materials used in Experiments 1,2 and 3 were collected at $0.5 \mathrm{~m}, 1.7 \mathrm{~m}$ and $2.5 \mathrm{~m}$ from the column input location. Breakthrough curves for the unheated and heated tracer tests at $0.5 \mathrm{~m}, 1.7$ $\mathrm{m}$ and $2.5 \mathrm{~m}$ from each experiment align well with measured data $\left(\mathrm{R}^{2}=0.9755-0.9958\right)$ and are presented in Appendix I.

Unheated $\left(25^{\circ} \mathrm{C}\right)$ tracer measurements were collected at $0.5 \mathrm{~m}, 1.7 \mathrm{~m}$ and $2.5 \mathrm{~m}$ for Experiment 1, while heated results $\left(80^{\circ} \mathrm{C}\right)$ were collected at $1.7 \mathrm{~m}$ and $2.5 \mathrm{~m}$ as they were located downgradient from the heating section. Results from the heated tracer test demonstrate that $\mathrm{Br}$ arrives earlier than that of the unheated test, which is also made evident by the respective values of dispersivity and the coefficient of hydrodynamic dispersion that increase by approximately one order of magnitude (Table 4).

Table 4. Hydraulic parameters from the unheated and heated $\mathrm{Br}$ tracer tests and breakthrough curves during Experiment 1.

\begin{tabular}{|c|c|c|c|c|c|c|}
\hline \multirow{2}{*}{$\begin{array}{c}\text { Location } \\
(\mathbf{m})\end{array}$} & \multicolumn{2}{|c|}{$\begin{array}{c}\text { Average Linear } \\
\text { Velocity } \\
\mathbf{v}_{\text {avg }}(\mathbf{m} / \mathbf{s})\end{array}$} & \multicolumn{2}{c|}{$\begin{array}{c}\text { Coefficient of } \\
\text { Hydrodynamic Dispersion } \\
\mathbf{D}_{\mathbf{L}}\left(\mathbf{m}^{2} / \mathbf{s}\right)\end{array}$} & \multicolumn{2}{|c|}{$\begin{array}{c}\text { Longitudinal } \\
\text { Dispersivity } \\
\mathbf{\alpha}_{\mathbf{L}}(\mathbf{m})\end{array}$} \\
\cline { 2 - 7 } & Unheated & Heated & Unheated & Heated & Unheated & Heated \\
\hline 0.5 & $4.89 \times 10^{-6}$ & - & $2.12 \times 10^{-8}$ & - & $4.34 \times 10^{-3}$ & - \\
\hline 1.7 & $4.93 \times 10^{-6}$ & $4.63 \times 10^{-6}$ & $1.45 \times 10^{-8}$ & $1.38 \times 10^{-7}$ & $2.95 \times 10^{-3}$ & $2.99 \times 10^{-2}$ \\
\hline 2.5 & $4.72 \times 10^{-6}$ & $4.23 \times 10^{-6}$ & $2.22 \times 10^{-8}$ & $1.54 \times 10^{-7}$ & $4.71 \times 10^{-3}$ & $3.65 \times 10^{-2}$ \\
\hline
\end{tabular}

Bromide tracer tests with material used in Experiment 2 were conducted after completing the anaerobic experiment. In this tracer test, unheated results were collected at $0.5 \mathrm{~m}$ while the 
heated results were collected at $1.7 \mathrm{~m}$ and $2.5 \mathrm{~m}$ (Table 5). Overall trends indicate that longitudinal dispersivity and the coefficient hydrodynamic dispersion increased by one to two orders of magnitude when temperatures changed from $25^{\circ} \mathrm{C}$ to $80^{\circ} \mathrm{C}$, while the average linear velocity only showed slight variation $\left(4.1 \times 10^{-6} \mathrm{~m} / \mathrm{s}-4.5 \times 10^{-6} \mathrm{~m} / \mathrm{s}\right)$.

Table 5. Hydraulic parameters from the unheated and heated $\mathrm{Br}$ tracer tests and breakthrough curves during Experiment 2.

\begin{tabular}{|c|c|c|c|c|c|c|}
\hline \multirow{2}{*}{$\begin{array}{c}\text { Location } \\
(\mathbf{m})\end{array}$} & \multicolumn{2}{|c|}{$\begin{array}{c}\text { Average Linear } \\
\text { Velocity } \\
\boldsymbol{v}_{\text {avg }}(\mathbf{m} / \mathbf{s})\end{array}$} & $\begin{array}{c}\text { Coefficient of } \\
\text { Hydrodynamic Dispersion } \\
\boldsymbol{D}_{\boldsymbol{L}}\left(\mathbf{m}^{\mathbf{2}} \mathbf{s}\right)\end{array}$ & \multicolumn{2}{c|}{$\begin{array}{c}\text { Longitudinal } \\
\text { Dispersivity } \\
\boldsymbol{\alpha}_{\boldsymbol{L}}(\mathbf{m})\end{array}$} \\
\cline { 2 - 7 } & Unheated & Heated & Unheated & Heated & Unheated & Heated \\
\hline 0.5 & $4.17 \times 10^{-6}$ & - & $8.20 \times 10^{-9}$ & - & $1.96 \times 10^{-3}$ & - \\
\hline 1.7 & - & $4.45 \times 10^{-6}$ & - & $2.79 \times 10^{-7}$ & - & $6.26 \times 10^{-2}$ \\
\hline 2.5 & - & $4.18 \times 10^{-6}$ & - & $2.92 \times 10^{-7}$ & - & $6.98 \times 10^{-2}$ \\
\hline
\end{tabular}

Similarly to Experiment 2, the unheated tracer test was performed at $0.5 \mathrm{~m}$ and heated tests were conducted at $1.7 \mathrm{~m}$ and $2.5 \mathrm{~m}$ in Experiment 3. Breakthrough curves indicate that the average linear velocity at the test locations ranges between $4.4 \times 10^{-6} \mathrm{~m} / \mathrm{s}-5.0 \times 10^{-6} \mathrm{~m} / \mathrm{s}$ (Table 6). In contrast, the hydrodynamic dispersion and longitudinal dispersivity at $1.7 \mathrm{~m}$ and $2.5 \mathrm{~m}$ are two orders, and one order of magnitude larger than the values from $0.5 \mathrm{~m}$, respectively.

Table 6. Hydraulic parameters from the unheated and heated $\mathrm{Br}$ tracer tests and breakthrough curves during Experiment 3.

\begin{tabular}{|c|c|c|c|c|c|c|}
\hline \multirow{2}{*}{$\begin{array}{c}\text { Location } \\
(\mathbf{m})\end{array}$} & \multicolumn{2}{|c|}{$\begin{array}{c}\text { Average Linear } \\
\text { Velocity } \\
\boldsymbol{v}_{\text {avg }}(\mathbf{m} / \mathbf{s})\end{array}$} & \multicolumn{2}{c|}{$\begin{array}{c}\text { Coefficient of } \\
\text { Hydrodynamic Dispersion } \\
\mathbf{D}_{\boldsymbol{L}}\left(\mathbf{m}^{2} / \mathbf{s}\right)\end{array}$} & \multicolumn{2}{c|}{$\begin{array}{c}\text { Longitudinal } \\
\text { Dispersivity } \\
\boldsymbol{\alpha}_{\boldsymbol{L}}(\mathbf{m})\end{array}$} \\
\cline { 2 - 7 } & Unheated & Heated & Unheated & Heated & Unheated & Heated \\
\hline 0.5 & $4.96 \times 10^{-6}$ & - & $4.54 \times 10^{-7}$ & - & $9.17 \times 10^{-2}$ & - \\
\hline 1.7 & - & $4.91 \times 10^{-6}$ & - & $1.73 \times 10^{-6}$ & - & $3.53 \times 10^{-1}$ \\
\hline 2.5 & - & $4.48 \times 10^{-6}$ & - & $1.39 \times 10^{-6}$ & - & $3.11 \times 10^{-1}$ \\
\hline
\end{tabular}


Flow rate measurements from each test were found to be $\sim 0.17 \mathrm{~mL} /$ minute, or approximately one pore flush per 7 days, which approximately reflects the digital pumping rate of $0.2 \mathrm{~mL} / \mathrm{minute}$. Calculated porosity from flow rate and model-derived parameters showed that aquifer material used in Experiment 1, 2 and 3 had values of 0.34, 0.35 and 0.31 , respectively.

\subsection{Experiment 1: Quartz Sand}

\subsubsection{Geochemical Conditions and Physical Characteristics}

Average weekly in-situ temperature records at points within the background, heating and cooling sections of the column were generally consistent over the course of the heated experiment (Appendix I). Maximum temperatures within the heating section (from $1.0 \mathrm{~m}$ to $1.6 \mathrm{~m}$ ) are maintained at approximately $97^{\circ} \mathrm{C}$ throughout the 9-week heated period and decrease to roughly $35^{\circ} \mathrm{C}$ over the following $0.2 \mathrm{~m}$ distance leading up to the cooling section. In comparison to baseline levels, slightly higher temperatures are observed at points within and after the cooling section during the heated experiment, which is likely due to the migration of heat in the direction of water flow as well as the absence of the refrigerated water reservoir.

The $\mathrm{pH}$ measurements and $\mathrm{Si}$ concentrations of the water samples collected bi-weekly throughout the first column experiment are presented in Figure 10 and Figure 11, respectively. Over the course the course of the experiment, both parameters show notable differences between unheated and heated conditions. Baseline $\mathrm{pH}$ of the input solution begins at $\sim 5.5$ and increases to around 8 at $1.2 \mathrm{~m}$, which then reaches to $\sim 9$ towards the end of the column at $2.4 \mathrm{~m}$ (Figure 10). Similarly, the observed baseline Si concentrations also show a gradual increasing trend that 
ranges from approximately $1 \mathrm{mg} / \mathrm{L}$ to $5 \mathrm{mg} / \mathrm{L}$ over the span of $0.3 \mathrm{~m}$ to $2.7 \mathrm{~m}$ along the column (Figure 11).

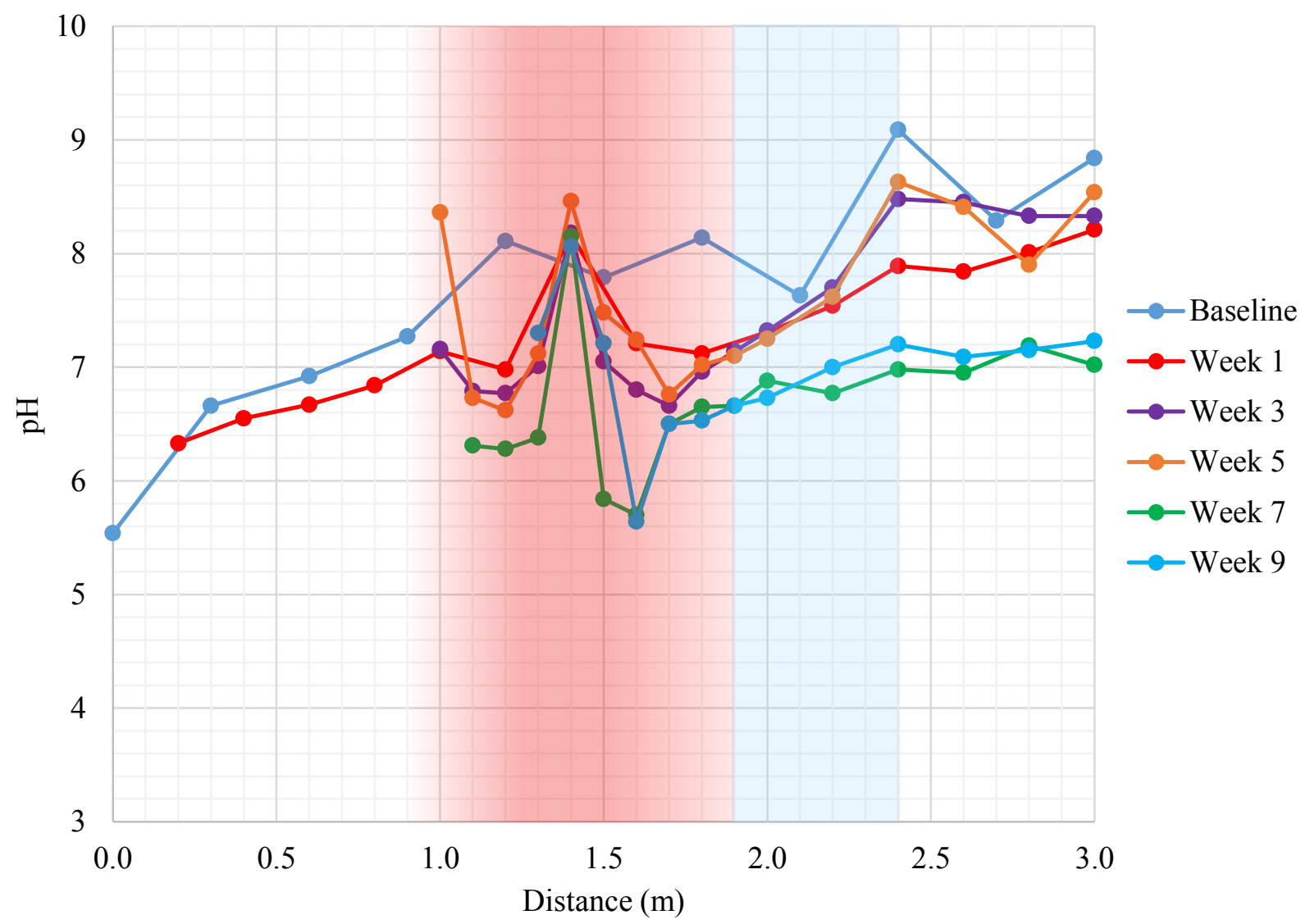

Figure 10. $\mathrm{pH}$ data collected over the column profile during the unheated ('Baseline') and heated conditions (Weeks 1 to 9) from Experiment 1. The red shaded area from $1.0 \mathrm{~m}$ to $1.9 \mathrm{~m}$ represents the heating section, as well as the area where downgradient temperatures were elevated in comparison to ambient conditions. The blue shaded area from $1.9 \mathrm{~m}$ to $2.4 \mathrm{~m}$ indicates where the cooling section is located.

After the first week of heating, there is a noticeable spike in Si concentration that increases up to $\sim 20 \mathrm{mg} / \mathrm{L}$ in the $97^{\circ} \mathrm{C}$ area of the heating section which then rapidly decreases as temperature dissipates to $\sim 35^{\circ} \mathrm{C}$ moving further across the column. Data from Week 1 also shows an increase in Si concentration throughout the cooling section that is maintained at approximately $22 \mathrm{mg} / \mathrm{L}$ between $2.0 \mathrm{~m}$ and $2.4 \mathrm{~m}$, following a gradual decrease to about $18 \mathrm{mg} / \mathrm{L}$ leading up to the 
column output. As the heated phase of the experiment continues from Week 1 to Week 9, there is an overall decrease in Si concentration by approximately $10 \mathrm{mg} / \mathrm{L}$ at points within the heating and cooling sections, while last $0.5 \mathrm{~m}$ of the column displays a more subtle decrease of $\sim 5 \mathrm{mg} / \mathrm{L}$.

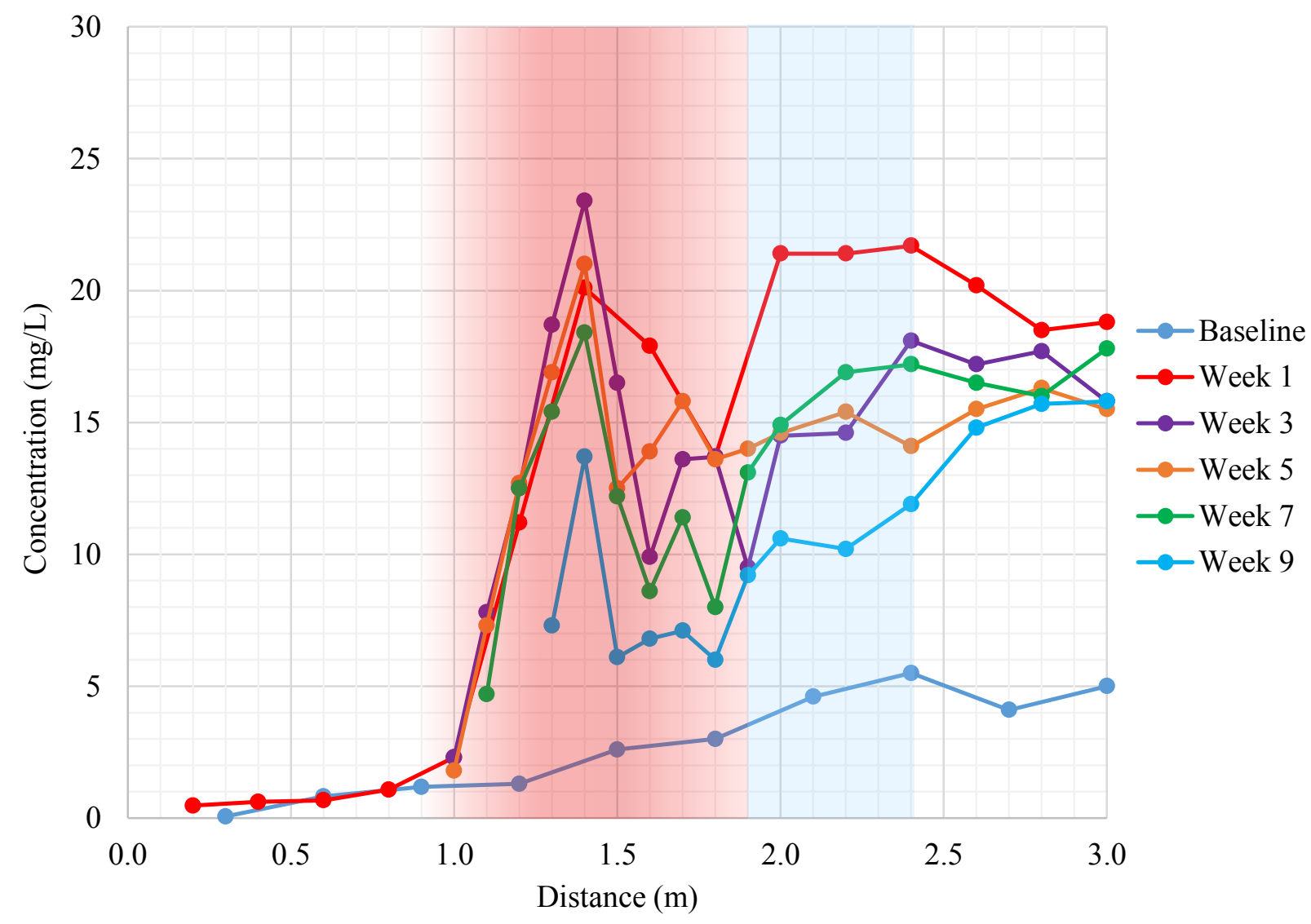

Figure 11. Concentration profile of dissolved $\mathrm{Si}$ throughout the column during unheated ('Baseline') and heated (Week 1 to Week 9) conditions from Experiment 1.

The $\mathrm{pH}$ levels during the heated phase of the experiment also exhibit a general decrease over time in comparison to the baseline conditions, and display a similar spike in the heating section as noted with Si. During Week 1 to Week 5, pH appears to increase from roughly 7 to 8.4 between $1.7 \mathrm{~m}$ to $3.0 \mathrm{~m}$ as temperature decreases from $\sim 35^{\circ} \mathrm{C}$ to $28^{\circ} \mathrm{C}$. In Week 7 to Week $9, \mathrm{pH}$ 
levels are lower than those from Week 5 and instead show a gradual increasing trend from $\sim 6.5$ to just above 7 over the same section of the column.

\subsection{Experiment 2: Quartz Sand and 0.6\% w/w Pyrite}

\subsubsection{Pyrite Composition and Characteristics}

An SEM micrograph illustrating the overall condition of pyrite grains used in Experiment 2 indicates that surfaces are angular with fresh conchoidal fracture edges, which is consistent with the method used to break apart the larger pyrite crystal (Figure 12). From these images, there also appears to be smaller fragments on the surface that are likely finer surface bound particles $(<$ $50 \mu \mathrm{m})$ produced during the crystal fragmentation.

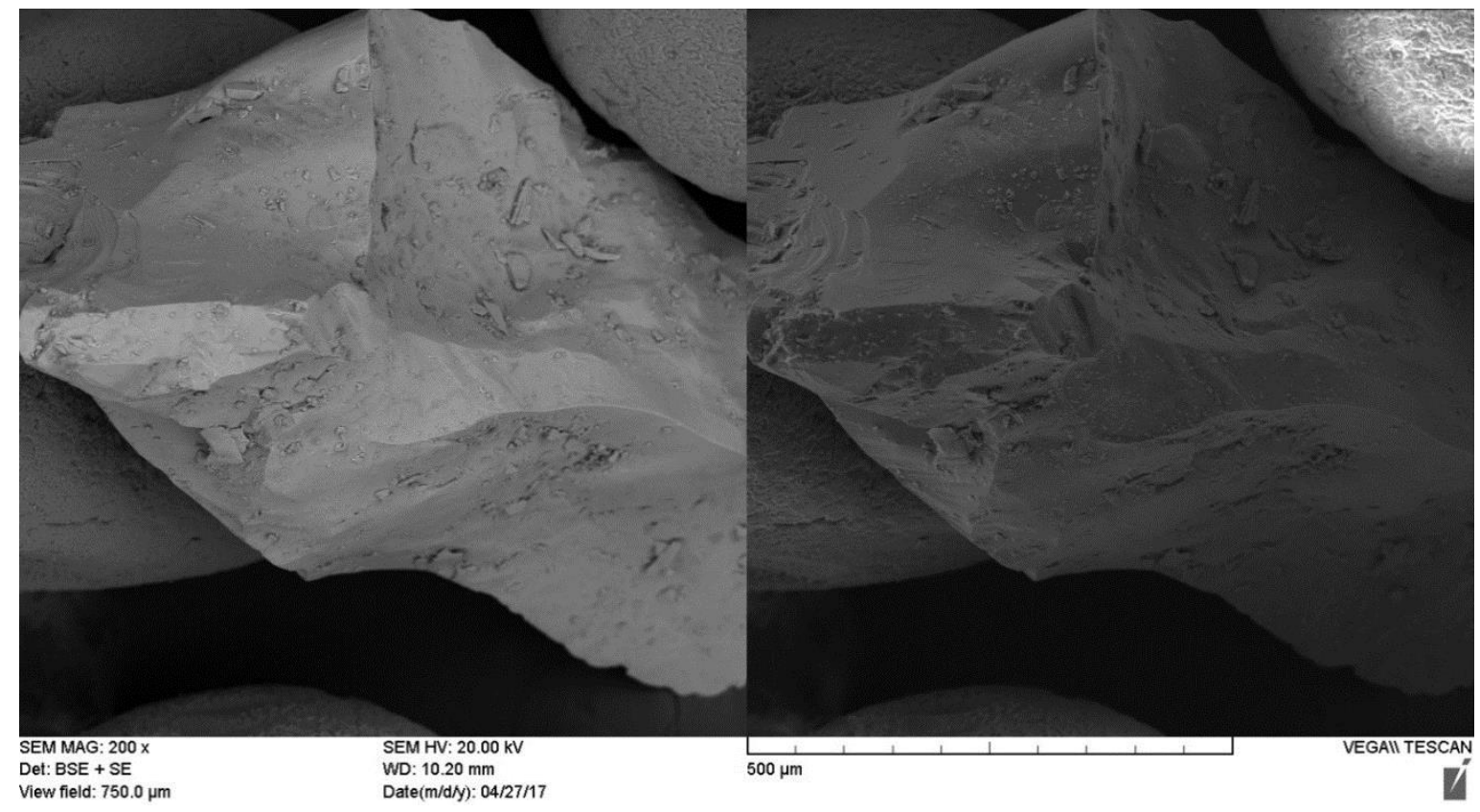

Figure 12. SEM micrograph of a pyrite grain used in the column material for Experiment 2.

LA-ICP-MS results of the nine pyrite grain samples demonstrate that concentrations for the most abundant trace elements display a high degree of variability after undergoing two rounds of 
analysis (Table 7). In turn, these discrepancies lead to a greater distribution of values as noted by the standard deviation of average trace element concentrations. Generally, this data suggests that the original pyrite crystal had substantial inclusions and/or crystal zoning features and forms an added challenge when assessing how these possible factors influenced column results.

Table 7. LA-ICP-MS results summary of the most abundant trace element concentrations for select pyrite $\left(\mathrm{FeS}_{2}\right)$ grains.

\begin{tabular}{|l|c|c|c|c|}
\hline \multicolumn{1}{|c|}{ Parameter } & $\begin{array}{c}\text { Average (n= 9) } \\
(\mathbf{p p m})\end{array}$ & $\begin{array}{c}\text { Median } \\
(\mathbf{p p m})\end{array}$ & $\begin{array}{c}\text { Minimum } \\
\mathbf{( p p m )}\end{array}$ & $\begin{array}{c}\text { Maximum } \\
(\mathbf{p p m})\end{array}$ \\
\hline Aluminum $(\mathrm{Al})$ & $0.47 \pm 0.85$ & 0.23 & 0.08 & 3.9 \\
\hline Arsenic $(\mathrm{As})$ & $251.5 \pm 131.0$ & 296.2 & 7.16 & 448.82 \\
\hline Copper $(\mathrm{Cu})$ & $0.84 \pm 1.03$ & 0.33 & 0.12 & 4.3 \\
\hline Lead $(\mathrm{Pb})$ & $0.99 \pm 1.39$ & 0.18 & 0.0075 & 3.69 \\
\hline Manganese $(\mathrm{Mn})$ & $0.35 \pm 0.42$ & 0.14 & 0.045 & 1.48 \\
\hline Titanium (Ti) & $0.50 \pm 0.18$ & 0.54 & 0.08 & 0.91 \\
\hline Selenium $(\mathrm{Se})$ & $1.72 \pm 0.57$ & 1.89 & 0.77 & 2.83 \\
\hline Vanadium $(\mathrm{V})$ & $0.14 \pm 0.25$ & 0.05 & 0.035 & 1.07 \\
\hline Zinc $(\mathrm{Zn})$ & $0.90 \pm 0.60$ & 0.77 & 0.37 & 3.24 \\
\hline
\end{tabular}

Note: \pm indicates standard deviation.

Aside from Fe and $\mathrm{S}$, As was found to have the highest concentration in all nine samples, with median, minimum, and maximum values of $296.2 \mathrm{ppm}, 7.16 \mathrm{ppm}$, and $448.82 \mathrm{ppm}$, respectively (Table 7). The highest concentration of As was also two orders of magnitude larger than the next most abundant trace element, $\mathrm{Cu}$ which had a maximum concentration of $4.3 \mathrm{ppm}$. Interestingly, Se had the second highest average concentration, but had a lower maximum concentration than $\mathrm{Al}, \mathrm{Cu}, \mathrm{Pb}$ and $\mathrm{Zn}$. In the case of the less abundant trace elements, Ti, Mn, and $\mathrm{V}$ contained the lowest average concentrations $(<0.5 \mathrm{ppm})$, and the lowest maximum concentrations $(<1.5 \mathrm{ppm})$. Although Ni concentrations generally remained below detection limits $(0.08 \mathrm{ppm})$, several exceedances were observed in the dataset, which reached as high as $3.5 \mathrm{ppm}$. 


\subsubsection{Aerobic Heated Experiment}

Baseline measurements indicate that a temperature of $\sim 25^{\circ} \mathrm{C}$ was maintained throughout the length of the column, apart from the cooling section (Appendix I). Cooled water $\left(\sim 10^{\circ} \mathrm{C}\right)$ which was circulated internally in the cooling section lowered the temperature to $\sim 14^{\circ} \mathrm{C}$ except during Week 1 and Week 9 of the heated experiment when a pump malfunction had occurred. During the heated experiment, temperatures within the heating section of the column gradually increased from $25^{\circ} \mathrm{C}$ to $90^{\circ} \mathrm{C}$ over the $0.6 \mathrm{~m}$ distance. This temperature gradient had been programmed to closely resemble the heating regime during the Br tracer experiments. Discrepancies in weekly temperatures were determined to be a result of heat loss, and in some instances, heat cartridge failure. Although components of the heating and cooling sections experienced minor failures, the overall temperature trends remained relatively constant over the course of the experiment.

The $\mathrm{pH}$ of the water during unheated conditions was shown to stay consistent at approximately 5.8 throughout the length of the column (Figure 13). Following initiation of the heated phase, the $\mathrm{pH}$ trend exhibited obvious changes over the course of the eight-week period. In the heating section of the column, $\mathrm{pH}$ decreased to 4.4 at $1.2 \mathrm{~m}$ from Week 1 to Week 6 while contemporaneously fluctuating between 6.8 and 5.8 at $1.5 \mathrm{~m}$. Substantial differences were observed in Week 8 as $\mathrm{pH}$ decreased to $\sim 4.0$ at sampling locations throughout the heating section. In contrast to these patterns, $\mathrm{pH}$ in the cooling section fluctuated between 5.2 and 5.8 from Week 1 to Week 8 and generally remained within these bounds after $2.4 \mathrm{~m}$.

Although the concentration of the input water was measured to be $8.0 \mathrm{mg} / \mathrm{L}$, dissolved oxygen in the first meter of the column was on the order of $4.2 \mathrm{mg} / \mathrm{L}$ to $5.5 \mathrm{mg} / \mathrm{L}$ during both the heated and unheated phase of the experiment due to the installation of the dissolved gas membrane filter 
(Figure 14). After $1.0 \mathrm{~m}$ from the column input, concentrations increase gradually up to approximately $6.0 \mathrm{mg} / \mathrm{L}$ at the column output during unheated conditions.

During the heated phase of the experiment, DO concentrations within the heating section decrease sharply to $\sim 3.0 \mathrm{mg} / \mathrm{L}$ in Week 1 to Week 6 , and rise to $4.2 \mathrm{mg} / \mathrm{L}$ during Week 8 . Following this abrupt decline, dissolved oxygen increases steadily and plateaus as water exits the cooling section. In Week 1 to Week 4 , the DO concentration at $3.0 \mathrm{~m}$ is $\sim 4.8 \mathrm{mg} / \mathrm{L}$, while in Week 6 and Week 8, the concentration reaches up to $\sim 6.7 \mathrm{mg} / \mathrm{L}$.

During unheated conditions, sulfate concentrations gradually increase over the length of the column and reach a final output concentration of $20 \mathrm{mg} / \mathrm{L}$ at $3.0 \mathrm{~m}$ (Figure 15). After commencing the heated experiment, numerous spikes in sulfate concentration are observed at locations within and following the heating section. Maximum concentrations during the heated phase reach $\sim 105 \mathrm{mg} / \mathrm{L}$ during Week 1 and Week 4 , while comparatively lower sulfate concentration spikes of $30 \mathrm{mg} / \mathrm{L}$ to $40 \mathrm{mg} / \mathrm{L}$ are observed in Week 8 .

The overall concentration of both sulfide and ferrous iron is consistently $(<0.15 \mathrm{mg} / \mathrm{L})$ throughout the duration of the heated experiment and is indicative of oxidized conditions (Figure 16 and Figure 17). In the case of sulfide, an inverse pattern was observed such that the highest concentrations were consecutively recorded at points between $0.0 \mathrm{~m}$ to $1.0 \mathrm{~m}$ of the column during Week 4 and were subsequently measured at points between $2.0 \mathrm{~m}$ to $3.0 \mathrm{~m}$ during Week 8.

Ferrous iron concentrations were generally at or slightly above detection limits $(0.02 \mathrm{mg} / \mathrm{L})$ for the duration of the aerobic heated experiment. Overall concentrations were highest during the 
unheated phase of the experiment, reaching up to $0.12 \mathrm{mg} / \mathrm{L}$, and exhibited a decrease following commencement of the heated phase.

\subsubsection{Anaerobic Heated Experiment}

The heating gradient from $25^{\circ} \mathrm{C}$ to $\sim 90^{\circ} \mathrm{C}$ closely resembles that of the aerobic experiment; however, the data appears to be more uniform over time (Appendix I). Fluctuations in temperature are noted at $1.4 \mathrm{~m}$ and $1.6 \mathrm{~m}$ within the heating section due to malfunctioning heat cartridges, and also at $2.4 \mathrm{~m}$ in the cooling section which was known to be caused by temporarily frozen tubing. 

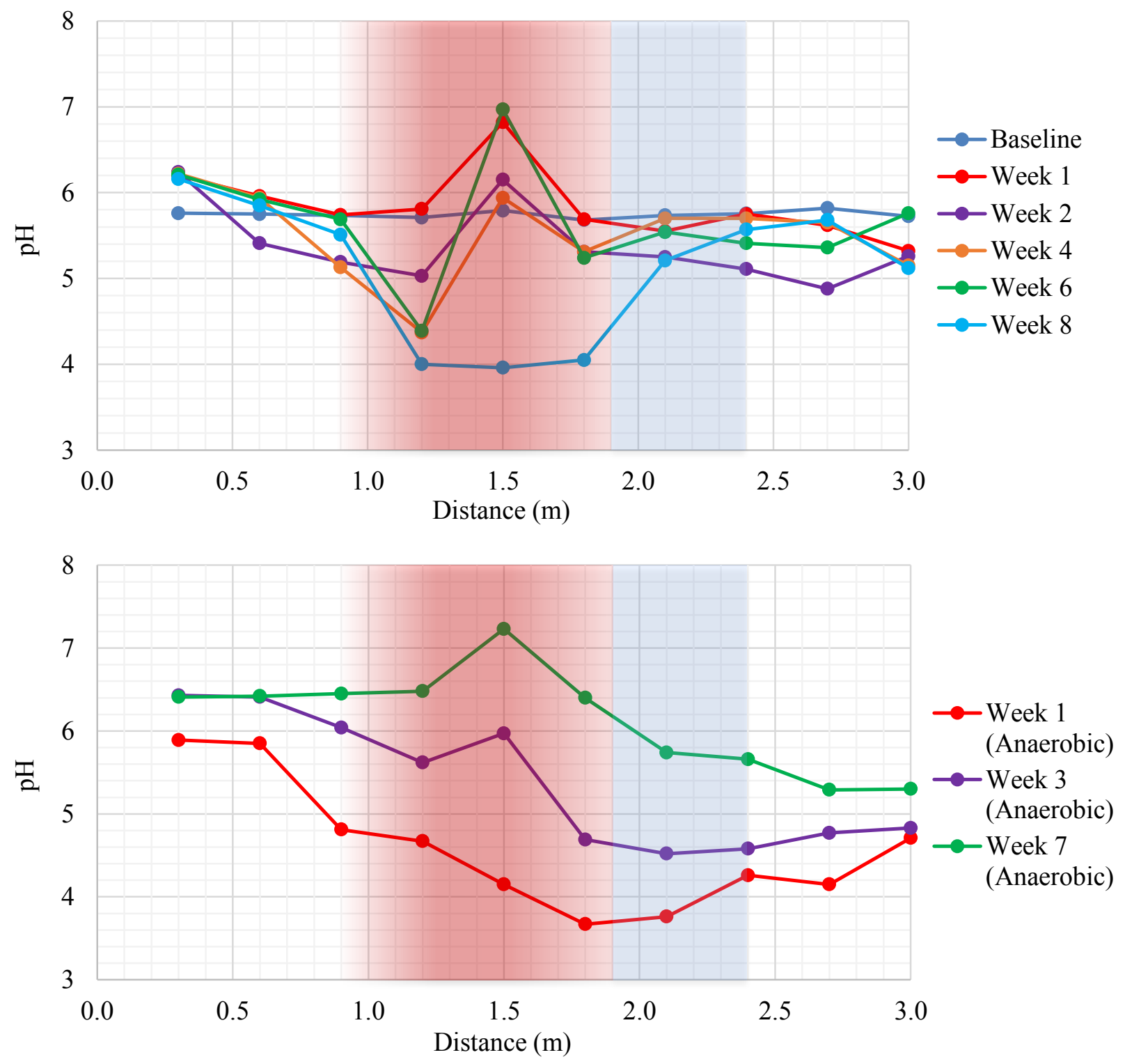

Figure 13. $\mathrm{pH}$ profile of the column during aerobic unheated ('Baseline') and heated phase (top) and heated anaerobic phase (bottom) of Experiment 2.

The general trend in Week 1 indicates that low $\mathrm{pH}(\sim 4)$ conditions persisted since Week 8 of the aerobic experiment (Figure 13). In addition, this moderately acidic front was shown to advance to the end of the column. Following Week 1, the $\mathrm{pH}$ was found to increase at locations along the column after $0.6 \mathrm{~m}$ and was particularly evident at $1.5 \mathrm{~m}$ within the heating section where $\mathrm{pH}$ 
rose to 5.9 and 7.2 during Week 3 and Week 7, respectively. It was also observed that the rate of $\mathrm{pH}$ increase was slower at points downgradient of the heating section between $2.2 \mathrm{~m}$ and $3.0 \mathrm{~m}$.
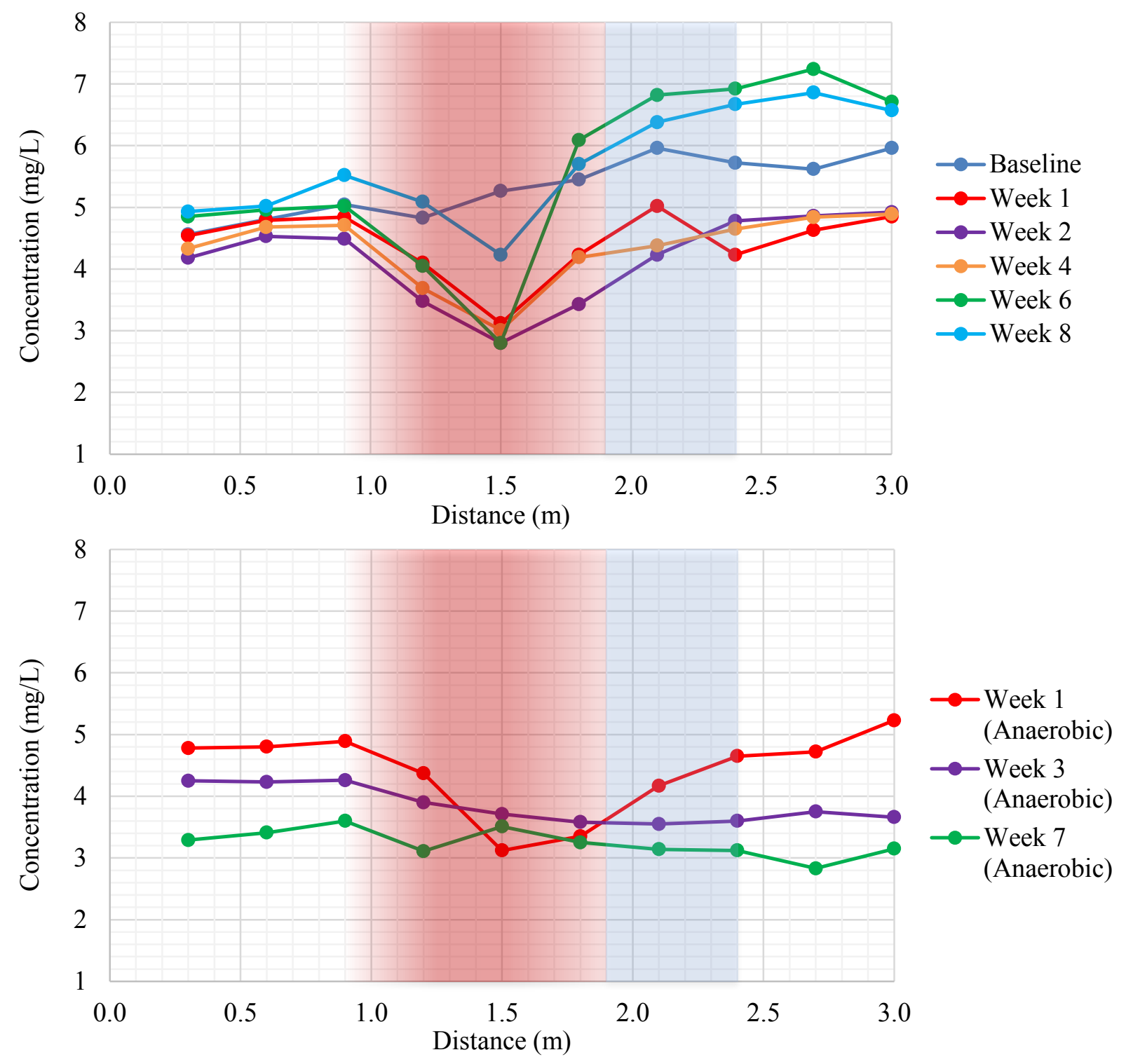

Figure 14. Dissolved oxygen profile of the column during the aerobic unheated ('Baseline') and heated phase (top) and heated anaerobic phase (bottom) of Experiment 2.

The DO pattern in Week 1 resembles that of Week 8 during the aerobic experiment where concentrations of $\sim 5 \mathrm{mg} / \mathrm{L}$ are found in the first $1.0 \mathrm{~m}$, and are followed by a decline in the heating section (Figure 14). It was noted that concentrations in the latter section of the column 
between $2.0 \mathrm{~m}$ to $3.0 \mathrm{~m}$ were not as high as those in Week 8 of the aerobic experiment and differ by $\sim 1.5 \mathrm{mg} / \mathrm{L}$. DO trends in Week 3 and Week 7 change from those in Week 1, and instead of sharply decreasing in the heating section, concentrations exhibit a gradual decline over the length of the column. Additionally, data from Week 7 shows the shallowest decline where input and output concentrations shift from $3.25 \mathrm{mg} / \mathrm{L}$ to $3.10 \mathrm{mg} / \mathrm{L}$, respectively; however, minor fluctuations are evident at some points along the column.
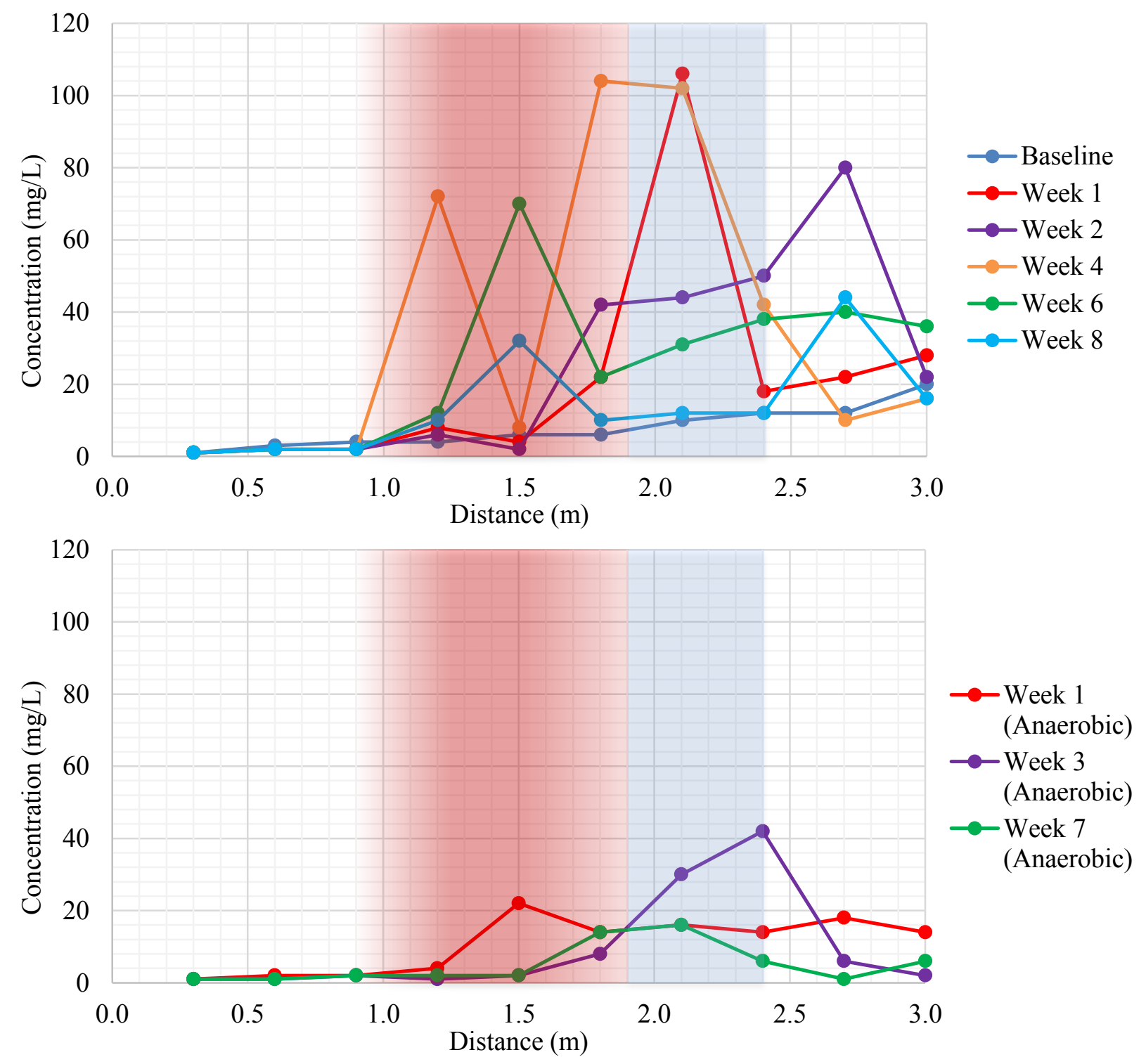

Figure 15. Sulfate profile of the column during the aerobic unheated ('Baseline') and heated phase (top) and heated anaerobic phase (bottom) of Experiment 2. 
As available oxygen is removed from the column, it is evident that the oxidation products from reactions with pyrite decrease considerably (Figure 15). Observed trends from Week 1 to Week 7 indicate an overall decrease in sulfate concentration. However, sulfate does peak within the cooling section during Week 3 and is approximately $15 \mathrm{mg} / \mathrm{L}$ to $25 \mathrm{mg} / \mathrm{L}$ higher than in Week 1 . By Week 7, concentrations throughout the column are greater than $16 \mathrm{mg} / \mathrm{L}$.
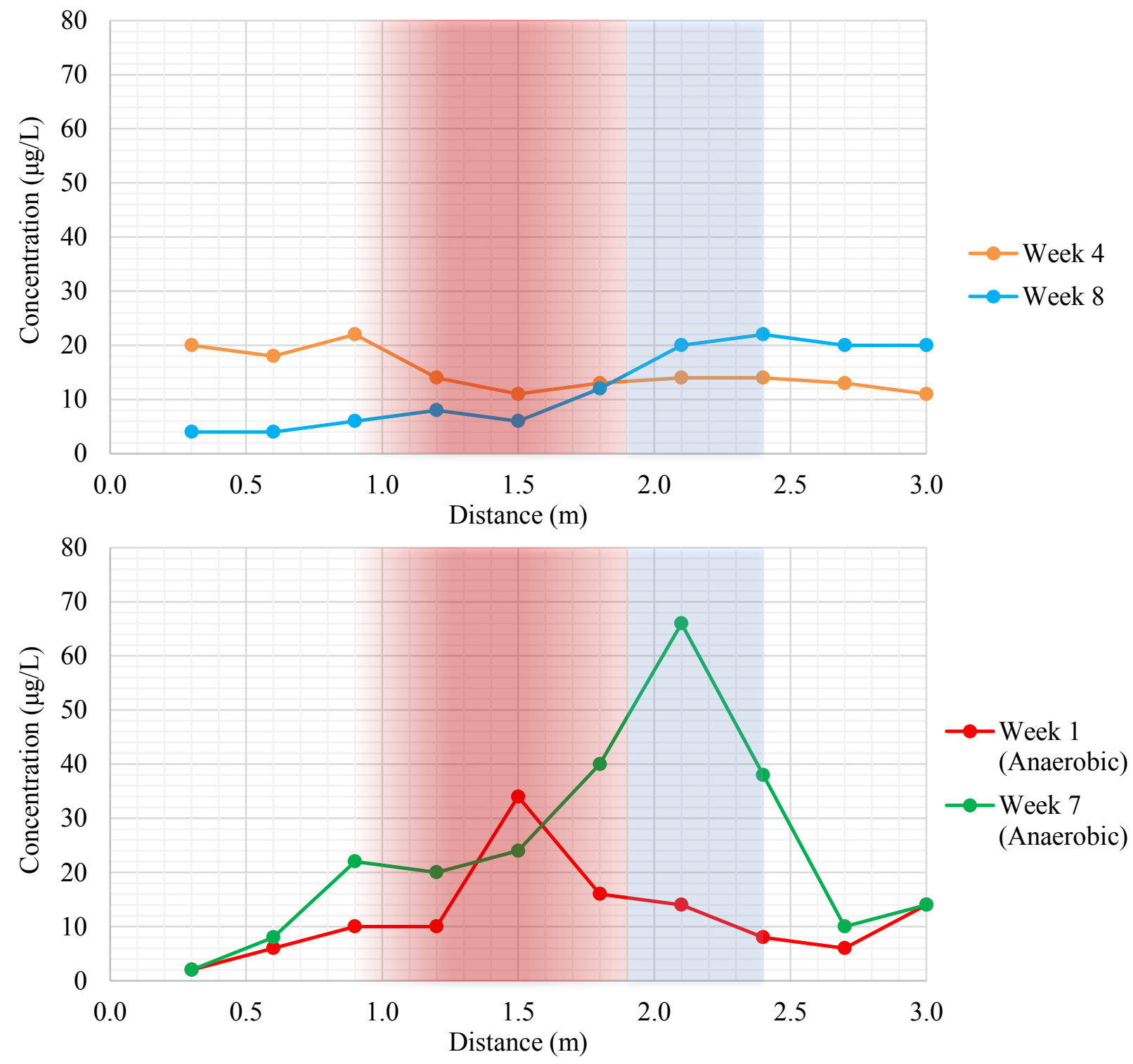

Figure 16. Sulfide profile of the column during Week 2 and Week 8 the aerobic heated phase (top) and Week 1 and Week 7 of the heated anaerobic phase (bottom) of Experiment 2. 
In comparison to the results at the end of the aerobic experiment, both ferrous iron and sulfide show a substantial increase in concentration when the column is contained in a nitrogen environment (Figure 16 and Figure 17). During Week 7 of the anaerobic experiment, sulfide concentration peaks within the cooling section at $\sim 65 \mu \mathrm{g} / \mathrm{L}$ and is approximately four times higher than Week 1. However, in other areas of the column aside from the cooling section, concentrations are less variable. A similar peak in concentration is shown in the trend for ferrous iron in the cooling section during Week 3 . The maximum concentration reaches $1.44 \mathrm{mg} / \mathrm{L}$ and is approximately two orders of magnitude higher than the concentration in the same location in Week 8 of the aerobic experiment (Figure 17). In areas of the column outside of $1.8 \mathrm{~m}$ to $2.4 \mathrm{~m}$, ferrous iron concentrations were unchanged after anaerobic conditions were established. 

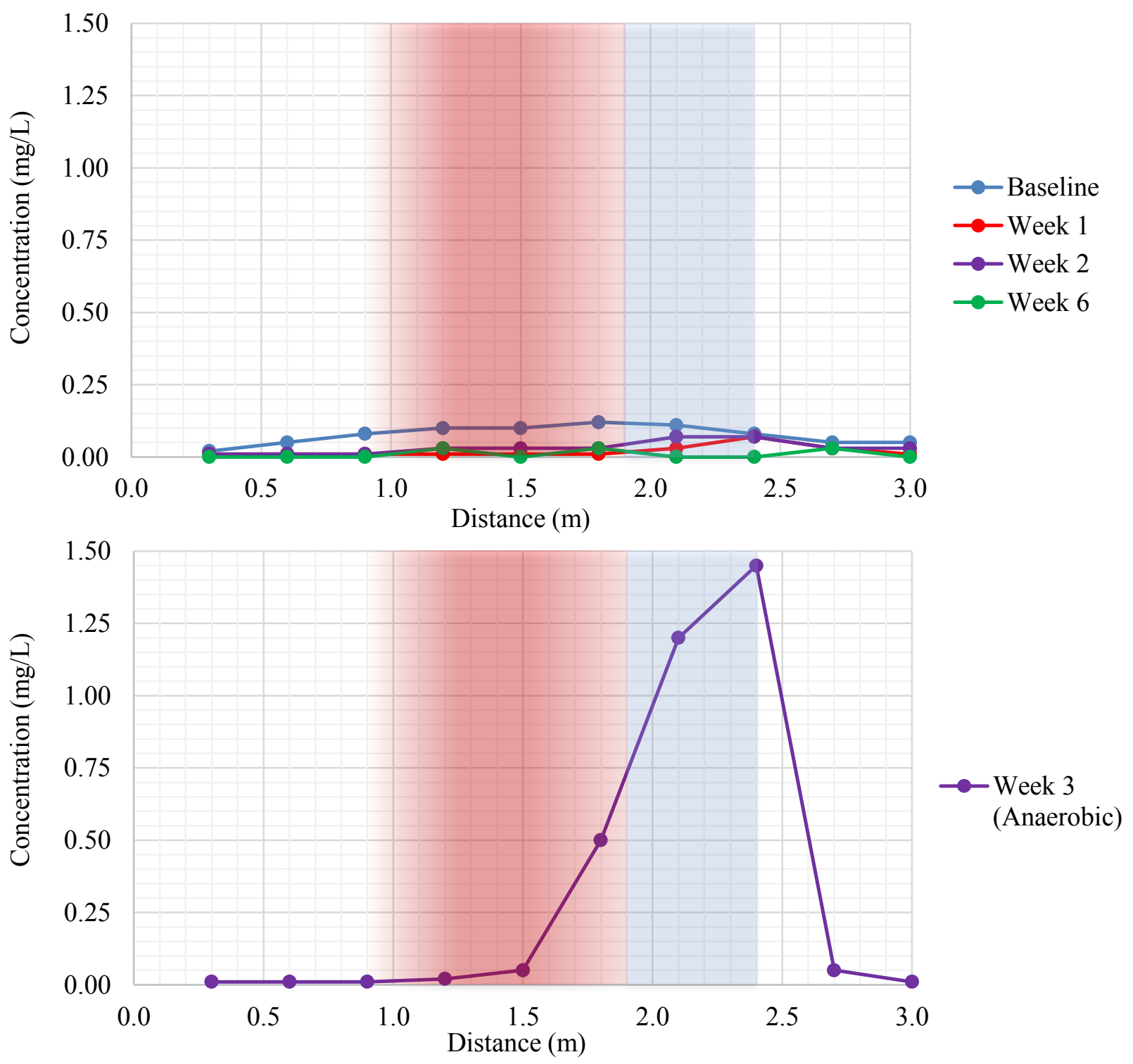

Figure 17. Ferrous iron profile of the column during the aerobic unheated ('Baseline') and heated phase (top) and Week 3 of the heated anaerobic phase (bottom) of Experiment 2.

Overall trends for $\mathrm{Al}, \mathrm{Cu}, \mathrm{Ni}$ and $\mathrm{Zn}$ indicate that these metals are gradually liberated over the course of the aerobic phase within the heating section and reach maximum concentrations of 0.4 $\mathrm{mg} / \mathrm{L}, 0.5 \mathrm{mg} / \mathrm{L}, 2.1 \mathrm{mg} / \mathrm{L}$ and $0.8 \mathrm{mg} / \mathrm{L}$, respectively (Figure 18 and Figure 19). Conversely, there was an overall decline in concentration for $\mathrm{Cu}, \mathrm{Ni}$, and $\mathrm{Zn}$ during the anaerobic phase of the experiment, which eventually drops below the detection limit $(0.005 \mathrm{mg} / \mathrm{L})$ by Week 8 . 
Additionally, data for $\mathrm{Al}$ was not available in the anaerobic phase, while $\mathrm{As}, \mathrm{Pb}$ and $\mathrm{Se}$ concentrations did not reach above detection limits $(0.01 \mathrm{mg} / \mathrm{L})$ for the duration of Experiment 2 .

Patterns in $\mathrm{Fe}$ and $\mathrm{Mn}$ display a gradual increase in concentration throughout the aerobic experiment and their concentrations generally continue to grow until Week 2 of the anaerobic phase (Figure 18 and Figure 19). Peak concentrations for Fe and Mn reached during Week 2 of the anaerobic phase were $3.6 \mathrm{mg} / \mathrm{L}$ and $0.2 \mathrm{mg} / \mathrm{L}$, respectively. Similarly to the trends observed for $\mathrm{Cu}, \mathrm{Ni}$ and $\mathrm{Zn}$, concentrations of $\mathrm{Fe}$ and $\mathrm{Mn}$ were $<0.005 \mathrm{mg} / \mathrm{L}$ throughout the column by Week 8 of the anaerobic phase.

Two distinct peaks in concentration are displayed for $\mathrm{Al}, \mathrm{Mn}, \mathrm{Ni}$ and $\mathrm{Zn}$ in Week 5 and for all dissolved metals in Week 10 of the aerobic phase at $3.0 \mathrm{~m}$ in the column. In the first peak, $\mathrm{Zn}$ had the highest concentration at $2.9 \mathrm{mg} / \mathrm{L}$, while $\mathrm{Ni}, \mathrm{Zn}$ and $\mathrm{Fe}$ had concentrations greater than $2.0 \mathrm{mg} / \mathrm{L}$ during the second peak. The concentration for Ni observed during the second peak appeared to be anomalously high, which reached $8.7 \mathrm{mg} / \mathrm{L}$. Although Ni shows concentrations above $1.0 \mathrm{mg} / \mathrm{L}$ during Week 2 of the anaerobic experiment, concentrations for all metals exhibited a gradual decline during the anaerobic experiment and were generally less than 0.01 $\mathrm{mg} / \mathrm{L}$ by then end of Experiment 2. 
$\rightarrow$ Baseline

$\rightarrow$ Week 7
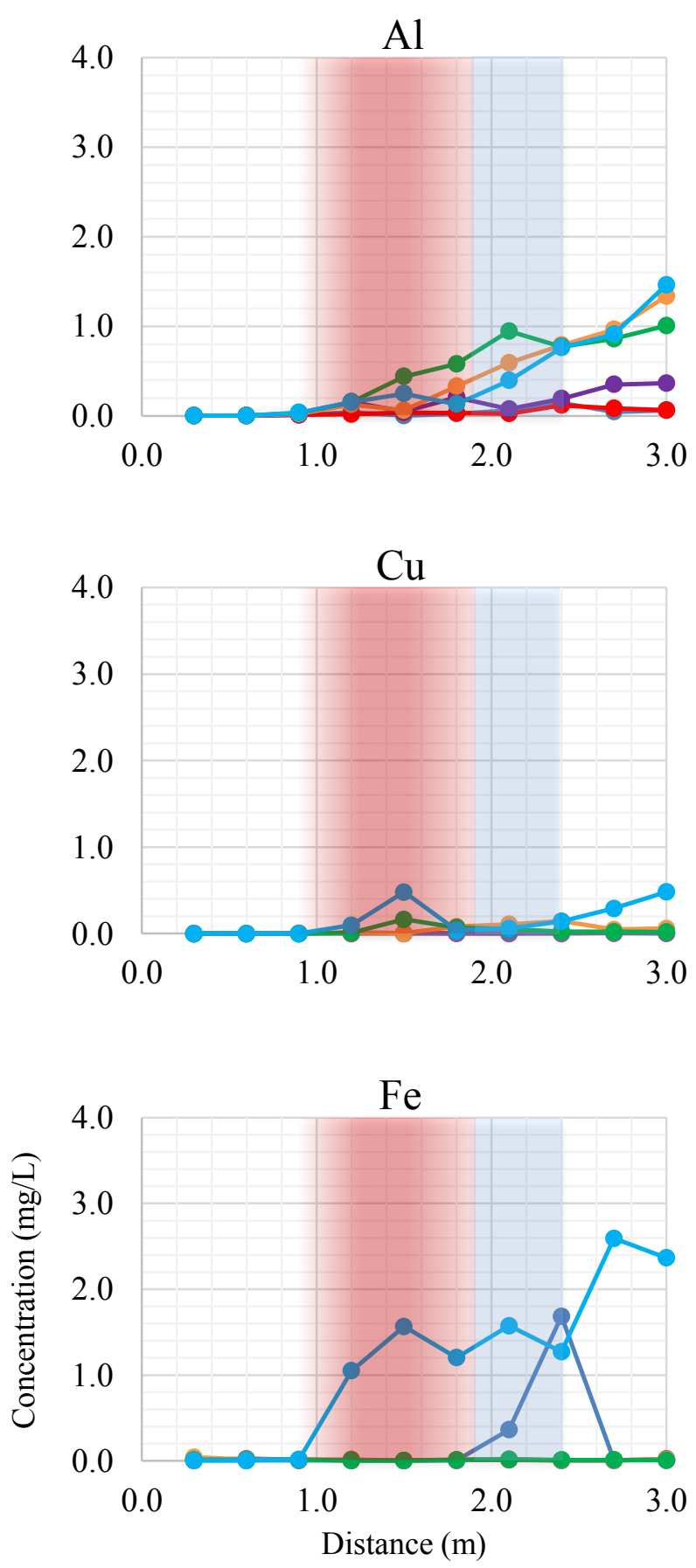

$\rightarrow$ Week $3 \quad \rightarrow$ Week 5

$\rightarrow$ Week 2 (Anaerobic) $\rightarrow$ Week 8 (Anaerobic)
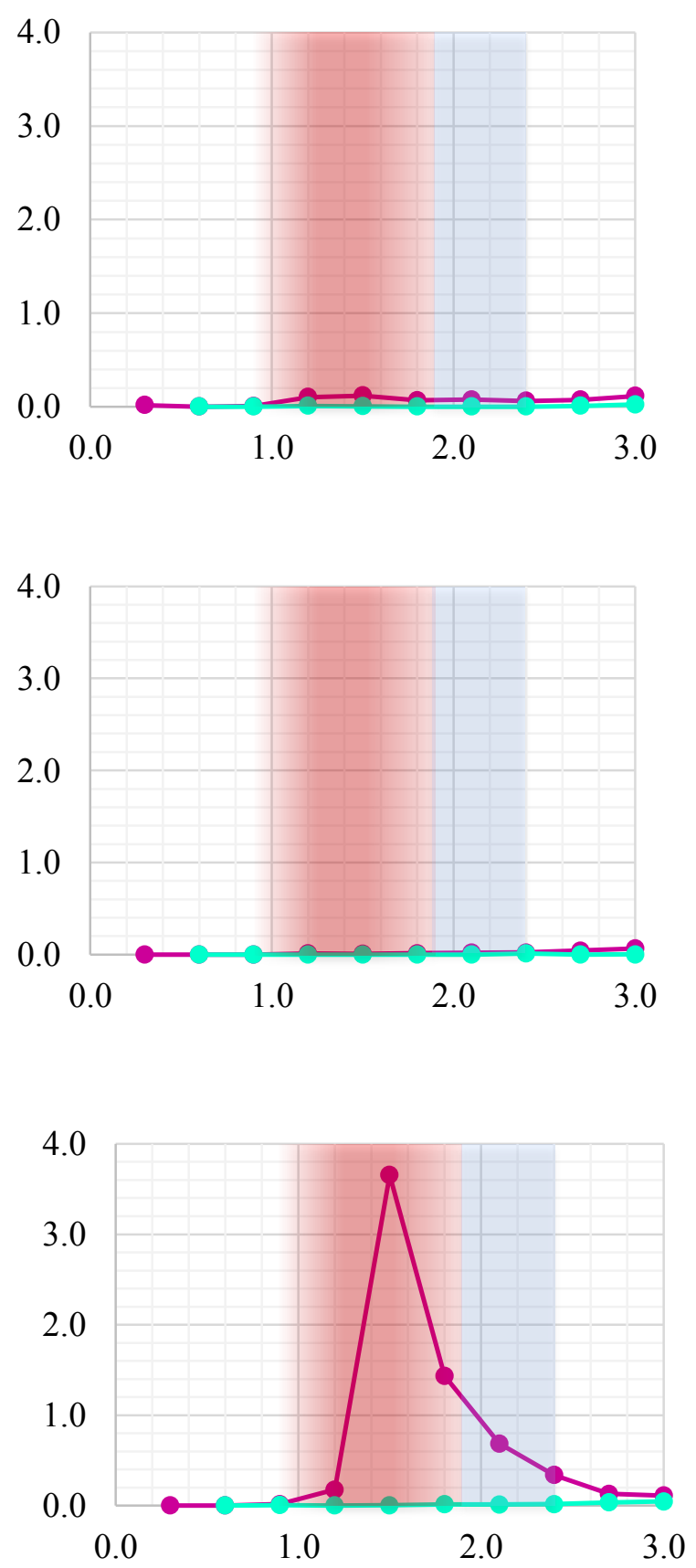

Figure 18. $\mathrm{Al}, \mathrm{Cu}$ and $\mathrm{Fe}$ concentrations along the profile of the column during the unheated ('Baseline') and heated aerobic phase (Week 1, 3, 5, 7 and 10) shown on the left, and the heated anaerobic phase (Week 2 and Week 8) shown on the right, of Experiment 2. 


$$
\begin{array}{ll}
\rightarrow \text { Baseline } & \rightarrow \text { Week } 1 \\
\multimap \text { Week } 7 & \rightarrow \text { Week } 10
\end{array}
$$

$\rightarrow$ Week 3

$\rightarrow$ Week 5

$\rightarrow$ Week 2 (Anaerobic)

$$
\rightarrow \text { Week } 8 \text { (Anaerobic) }
$$
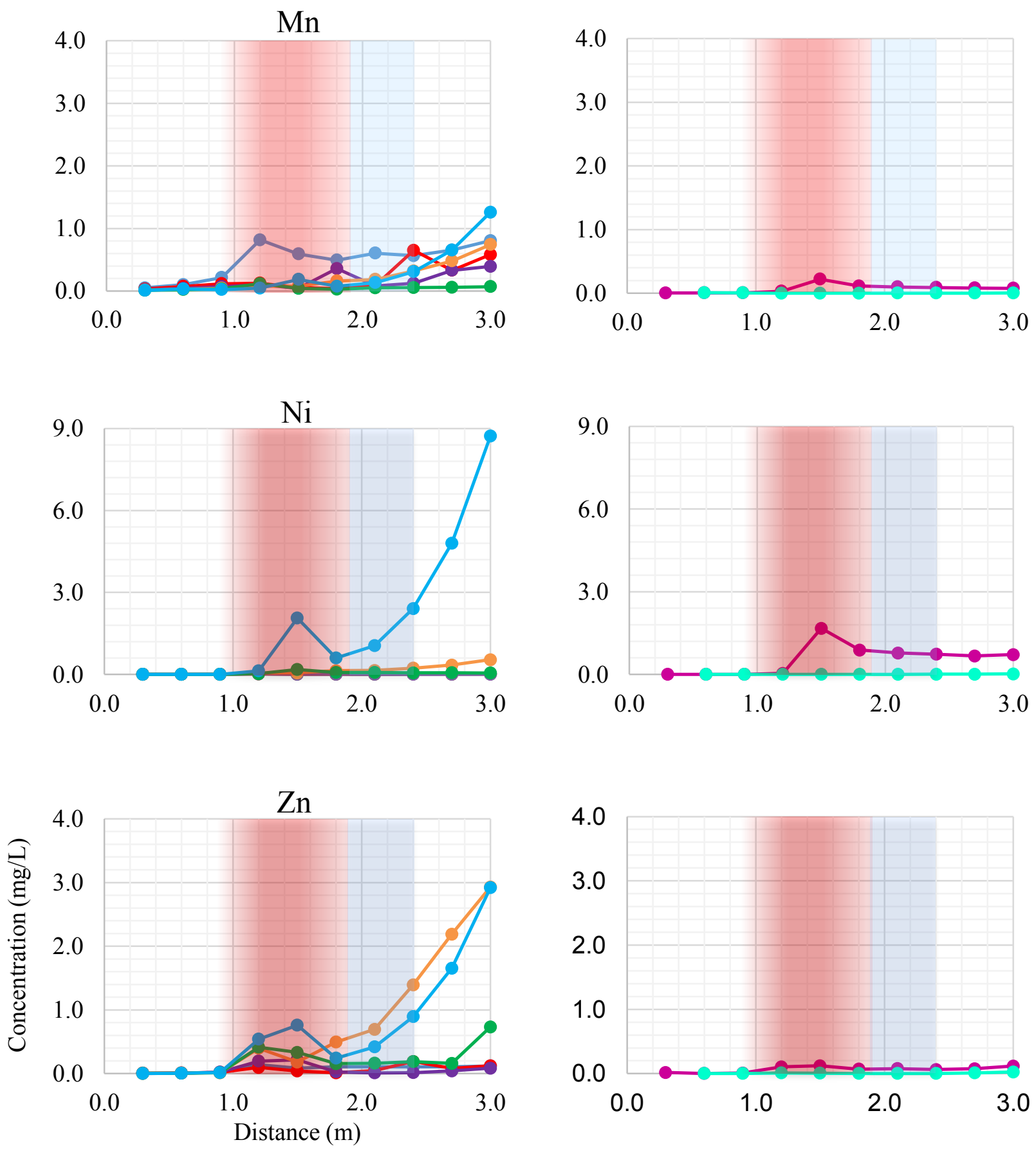

Figure 19. $\mathrm{Mn}, \mathrm{Ni}$, and $\mathrm{Zn}$ concentrations along the profile of the column during the unheated ('Baseline') and heated aerobic phase (Week 1, 3, 5, 7 and 10) shown on the left, and the heated anaerobic phase (Week 2 and Week 8) shown on the right, of Experiment 2. 
An initial decline was observed for $\mathrm{Ca}, \mathrm{K}, \mathrm{Mg}$ and $\mathrm{S}$ concentrations within the heating section between the shift from unheated conditions to Week 1 of the heated aerobic phase, while $\mathrm{Na}$ increased by a factor of five from $0.6 \mathrm{mg} / \mathrm{L}$ to $3.1 \mathrm{mg} / \mathrm{L}$ (Figure 20 and Figure 21). At locations within the heating section of the column, peak concentrations for $\mathrm{Ca}, \mathrm{K}, \mathrm{Mg}, \mathrm{S}$ and $\mathrm{Si}$ were simultaneously observed during Week 5 of the aerobic phase, with $\mathrm{S}$ reaching the highest concentration of $37 \mathrm{mg} / \mathrm{L}$. These peak values exhibited a two to four fold decrease following Week 5 and remained consistent for the duration of the aerobic experiment. Following this trend, a gradual decrease was observed for $\mathrm{Ca}, \mathrm{K}, \mathrm{Mg}, \mathrm{Na}$, and $\mathrm{S}$ during the anaerobic phase of the experiment while Si displayed an overall increase from between Week 2 and Week 8. 


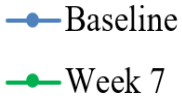

$\rightarrow$ Week 1

$\rightarrow$ Week 10
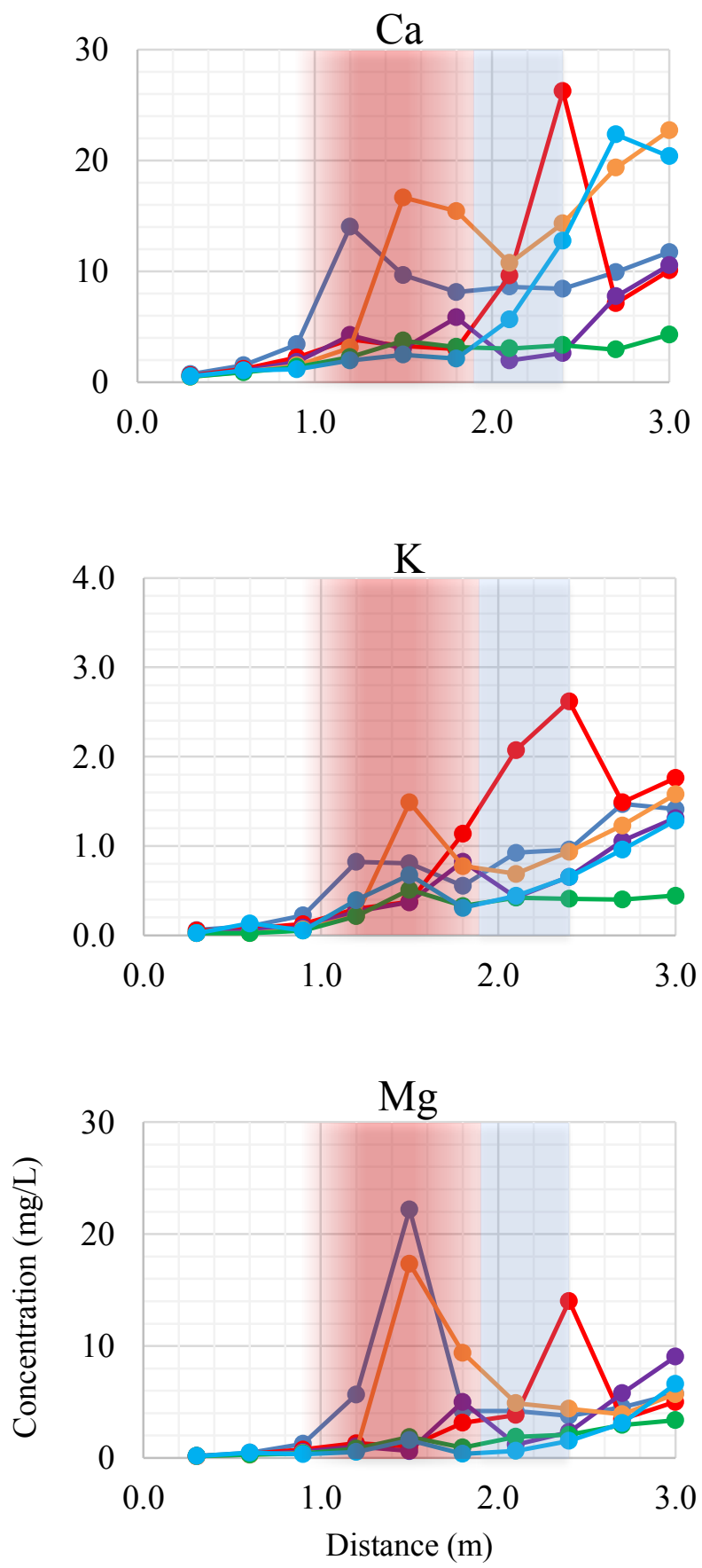

$\rightarrow$ Week $3 \quad \rightarrow$ Week 5

$\rightarrow$ Week 2 (Anaerobic) $\rightarrow$ Week 8 (Anaerobic)
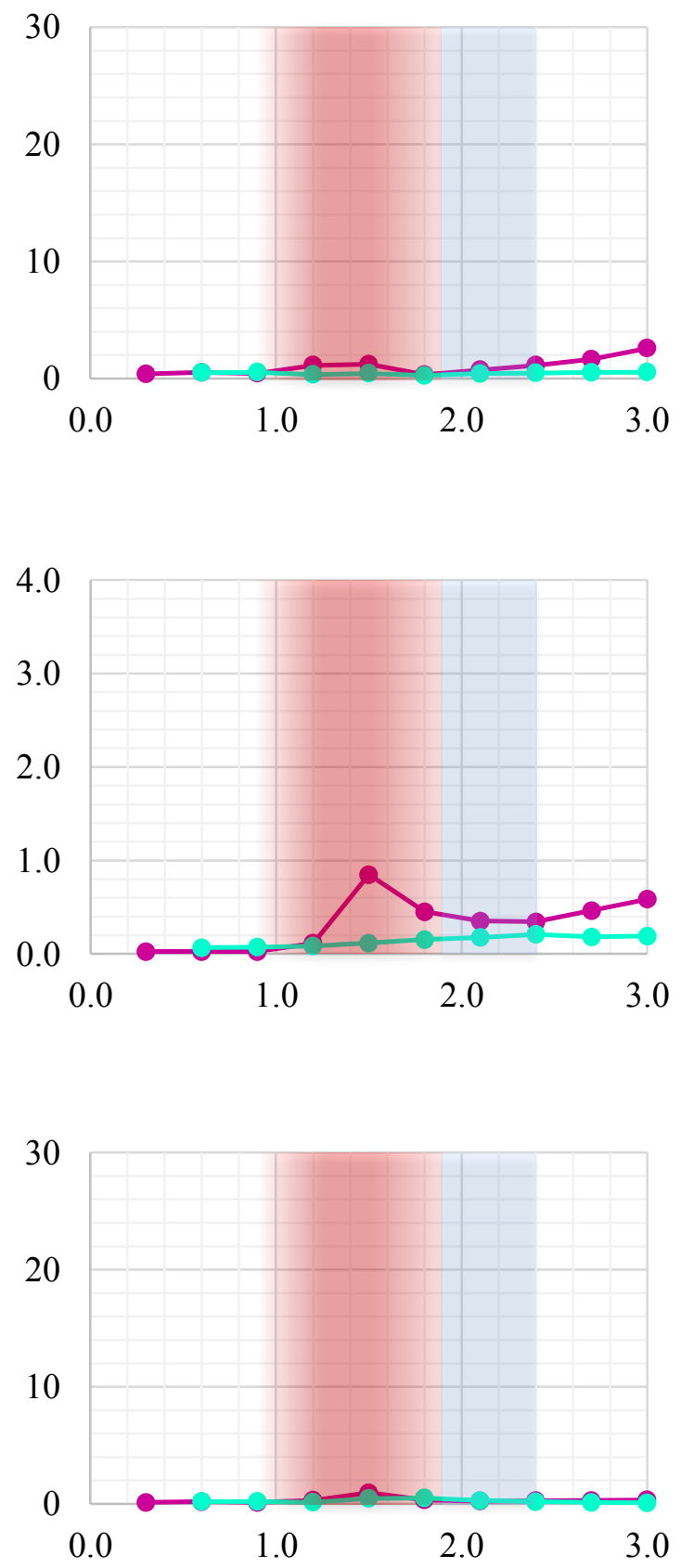

Figure 20. $\mathrm{Ca}, \mathrm{K}$ and $\mathrm{Mg}$ concentrations along the profile of the column throughout the unheated ('Baseline'), heated aerobic (Week 1, 3, 5, 7 and 10), and heated anaerobic phase (Week 2 and Week 8) from Experiment 2. 
At locations downgradient of the heating section of the column, $\mathrm{Ca}, \mathrm{K}, \mathrm{Mg}, \mathrm{Na}, \mathrm{S}$ and $\mathrm{Si}$ display distinct peaks in concentration during the heated aerobic phase of the experiment, with the exception of $\mathrm{K}$ and $\mathrm{Na}$ which appear to show more subtle increases at specific points (Figure 20 and Figure 21). Generally, these peaks occur on Week 1 at $2.4 \mathrm{~m}$; Week 5 at $3.0 \mathrm{~m}$; and Week 10 at $3.0 \mathrm{~m}$. Sulfur exhibits the highest concentrations during these peaks with values for Weeks 1 , 5 and 10 reaching $46 \mathrm{mg} / \mathrm{L}, 30 \mathrm{mg} / \mathrm{L}$ and $37 \mathrm{mg} / \mathrm{L}$, respectively.

When considering the abundance of these species, successively lower concentrations are observed in the order: $\mathrm{S}>\mathrm{Ca}>\mathrm{Mg} \approx \mathrm{Si}>\mathrm{Na}>\mathrm{K}$. Not shown on the plots are concentrations of $\mathrm{B}$, which reaches a maximum value of $0.5 \mathrm{mg} / \mathrm{L}$ on Week 3, and $\mathrm{P}$, which remains below detection limits $(0.05 \mathrm{mg} / \mathrm{L})$ for majority of the aerobic experiment and increases slightly to 0.07 $\mathrm{mg} / \mathrm{L}$ on Week 10.

During the anaerobic phase of the experiment, concentrations for $\mathrm{Ca}, \mathrm{K}, \mathrm{Mg}, \mathrm{Na}$ and $\mathrm{S}$ decrease to below $1.0 \mathrm{mg} / \mathrm{L}$ by Week 8 . In contrast, concentrations for $\mathrm{Si}$ and $\mathrm{P}$ increase from $1.7 \mathrm{mg} / \mathrm{L}$ to $4.0 \mathrm{mg} / \mathrm{L}$, and from $0.8 \mathrm{mg} / \mathrm{L}$ to $1.1 \mathrm{mg} / \mathrm{L}$ between Week 2 and Week 8 , respectively. Interestingly, these trends indicate that both $\mathrm{Si}$ and $\mathrm{P}$ are the primary constituents at the end of anaerobic experiment. 


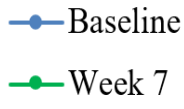

$\rightarrow$ Week 1

$\rightarrow$ Week 10
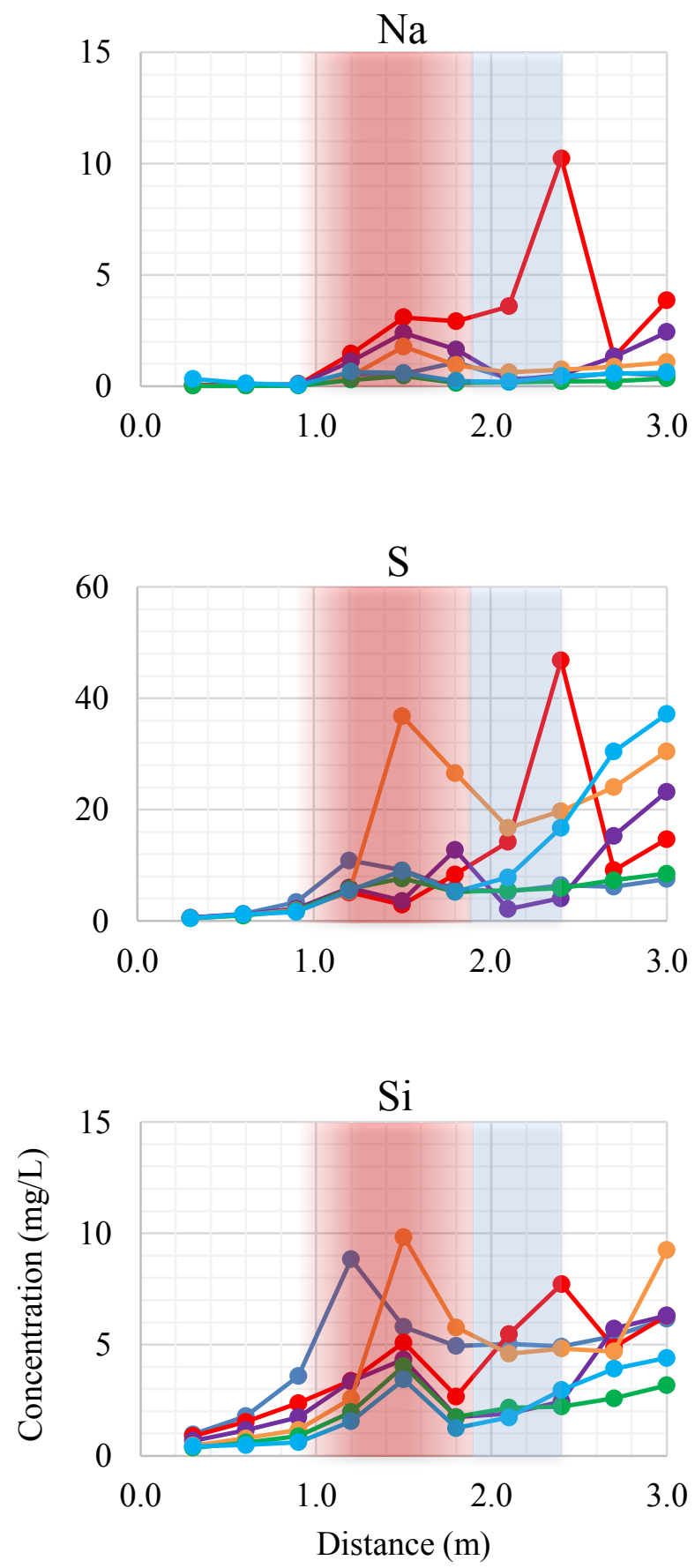

$\rightarrow$ Week $3 \quad \rightarrow-$ Week 5

$\rightarrow$ Week 2 (Anaerobic) $\rightarrow$ Week 8 (Anaerobic)

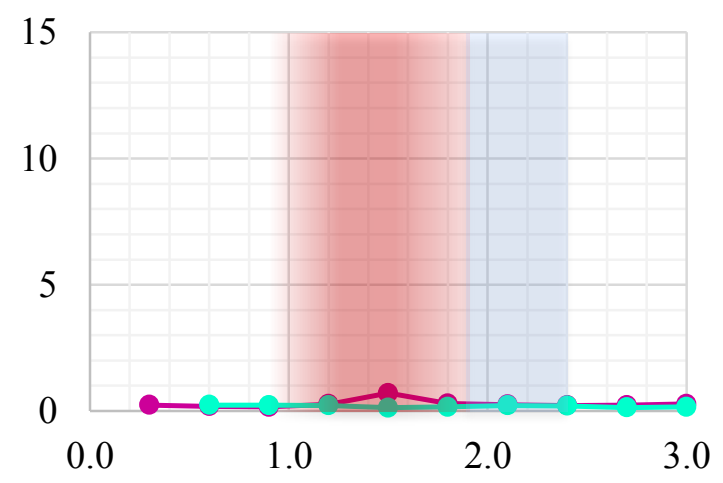

Figure 21. Na, S, and Si concentrations along the profile of the column throughout the unheated ('Baseline'), heated aerobic (Week 1, 3, 5, 7 and 10), and heated anaerobic phase (Week 2 and Week 8) from Experiment 2. 


\subsection{Experiment 3: Aquifer Sediments from Cold Lake, Alberta}

\subsubsection{Sediment Geochemistry}

Aquifer material used in Experiment 3 was first characterized by Andriashek (2003), who classified the sediment core sections as sand, and sand and fine gravel deposits from the Empress Formation. Visual observations of the homogenized sediments indicate that the grains are subangular to subrounded, and moderately sorted.

Bulk XRD and XRF analysis of the samples indicate that the sediments are primarily composed of quartz $\left(\mathrm{SiO}_{2}\right)$ and calcite $\left(\mathrm{CaCO}_{3}\right)$, with moderate amounts of albite $\left(\mathrm{Na}\left(\mathrm{AlSi}_{3} \mathrm{O}_{8}\right)\right)$ and muscovite $\left(\mathrm{KAl}_{2}\left(\mathrm{AlSi}_{3} \mathrm{O}_{10}\right)(\mathrm{F}, \mathrm{OH})_{2}\right)$. Test results also show that minor enstatite $\left((\mathrm{Fe}, \mathrm{Mg}) \mathrm{SiO}_{3}\right)$ and sericite $\left(\mathrm{KAl}_{2}\left(\mathrm{AlSi}_{3} \mathrm{O}_{10}\right)(\mathrm{OH})_{2}\right)$ is also present. Although specific methods were employed to determine if clay minerals within the samples were present, none were detected from this analysis. XRD analysis also did not detect the secondary mineral precipitates; however, visual observations and quantitative SEM trends suggest that they are present.

Figure 22 presents SEM micrographs of a gravel grain sample showing small and large-scale surface textures. Quantitative trends indicate that the grain primarily contains $\mathrm{Si}, \mathrm{Al}, \mathrm{Ca}$ and $\mathrm{Fe}$. Although the presence of Fe could be associated with enstatite, the occurrence is suggested to be a result of Fe-oxyhydroxide precipitates, which had been visually observed on numerous sediment surfaces. 


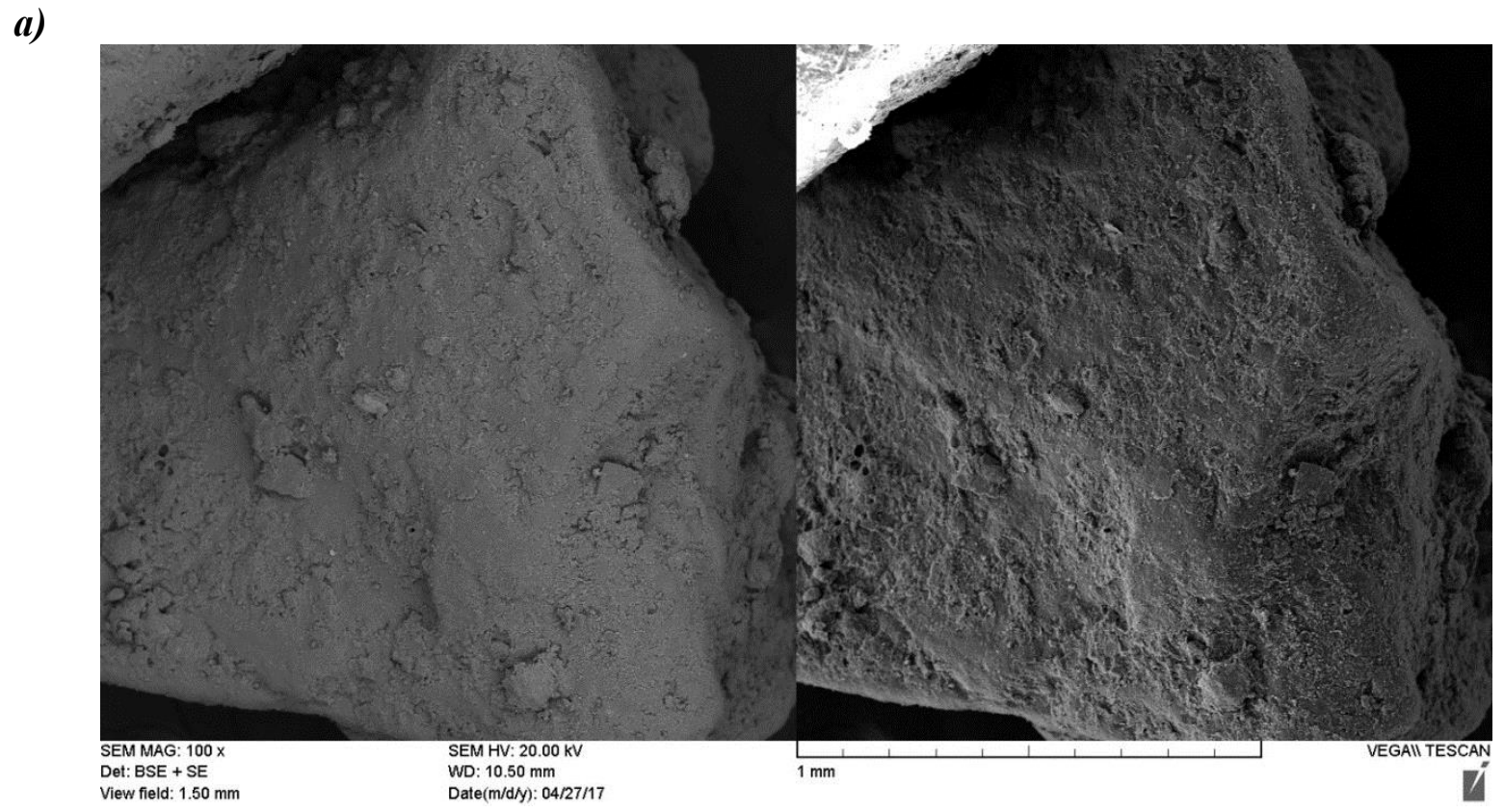

b)

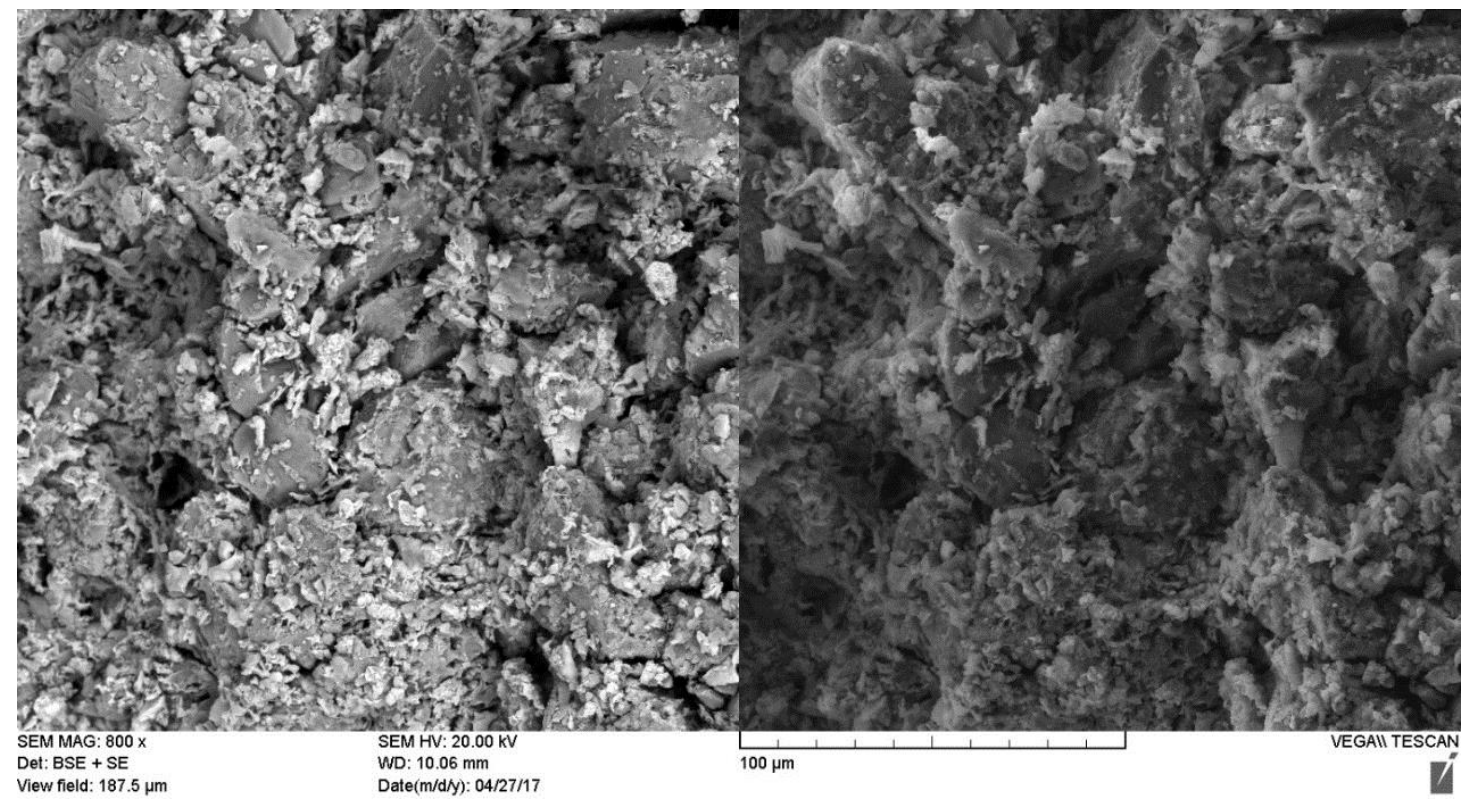

Figure 22. SEM micrograph of a fine gravel size grain (a), and the surface texture of the sediment grain (b).

Figure 23 present SEM micrographs of a sand grain sample showing the surface texture of small and large-scale features. Evidence of a secondary mineral precipitate is shown in Figure 23(b), which is approximately $100 \mu \mathrm{m}$ in length. Quantitative trends indicate that the precipitate is 
largely composed of $\mathrm{Fe}$ with minor amounts of $\mathrm{Si}, \mathrm{Al}, \mathrm{Ca}$ and trace As. Qualitative analysis could not confirm whether this mineral was crystalline or amorphous; however, this trend in composition suggests that it could be Fe-oxyhydroxide. Supplementary quantitative data for SEM analysis of this sample is provided in Appendix I. 
a)

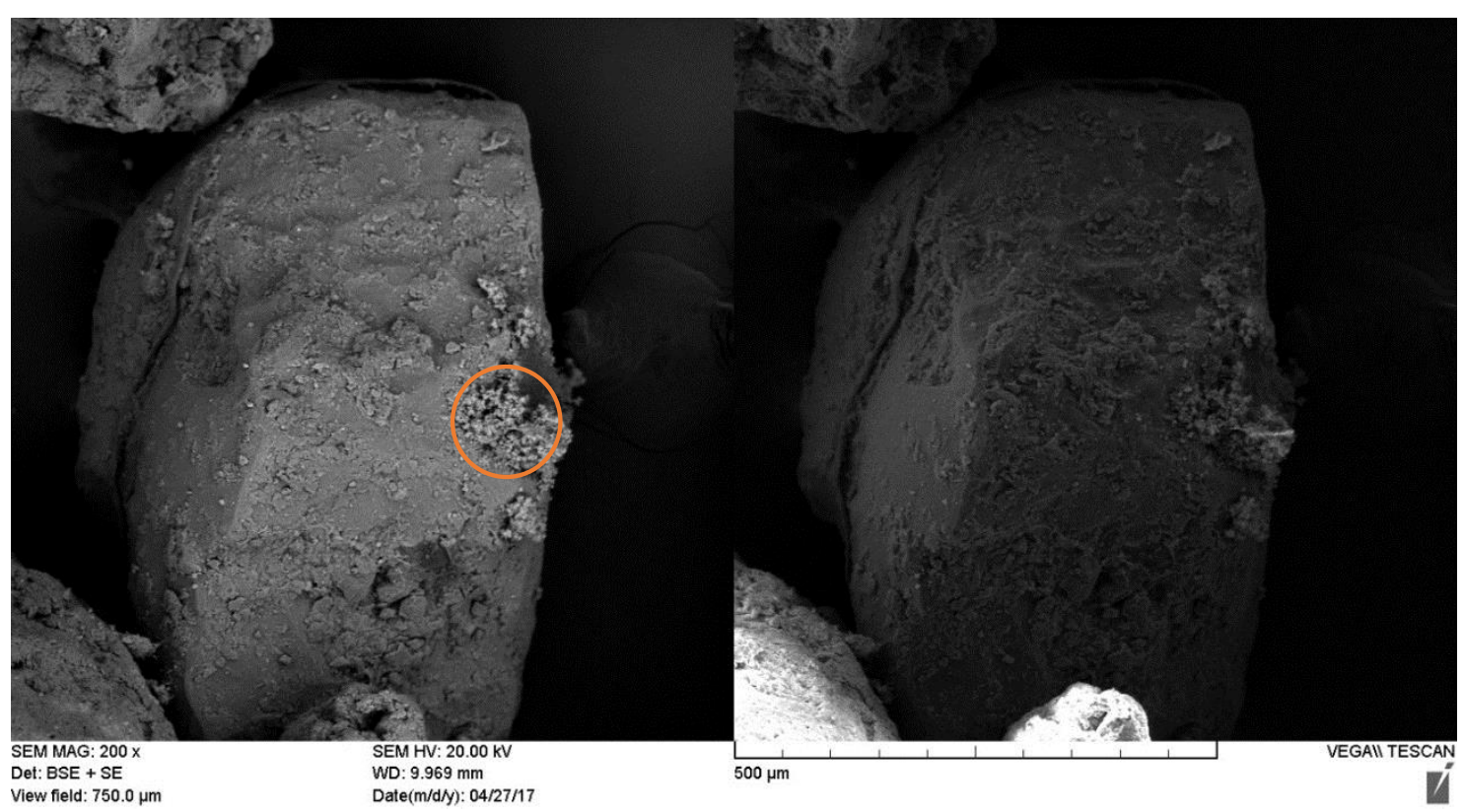

b)

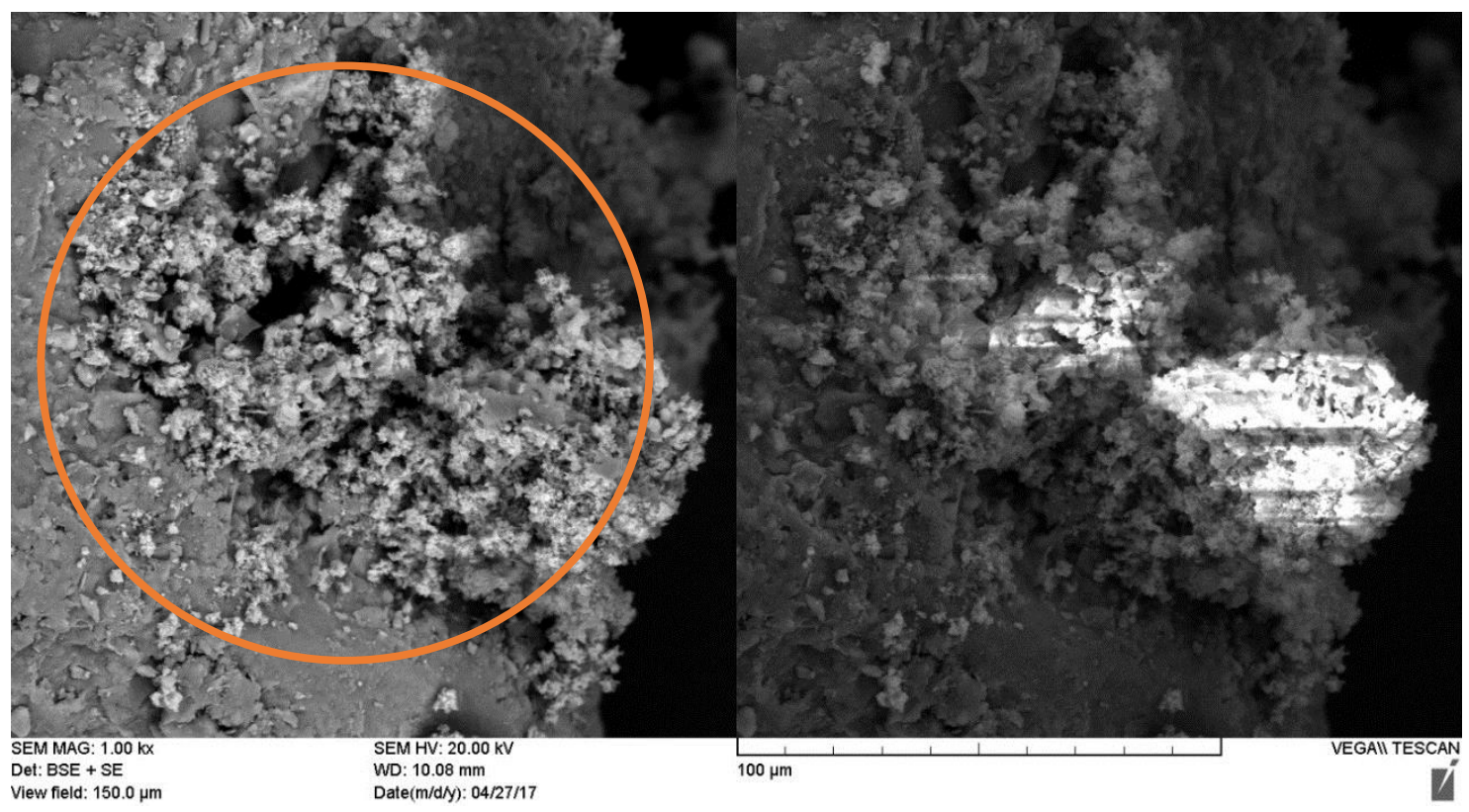

Figure 23. SEM micrograph of a coarse sand sized grain (a), and the area of a secondary precipitate (circled in orange) on surface of the sediment grain (b).

Results from ICP-OES analysis after aqua regia digestion of sediment samples indicate concentrations of Fe greater than $7400 \mathrm{ppm}$ and S greater than $380 \mathrm{ppm}$ in all three samples and could suggest the presence of sulfide minerals not detected using the employed characterization 
techniques (Table 8). Additionally, the larger quantity of Fe further supports the occurrence of Fe-oxyhydroxide minerals on grain surfaces. Concentrations of $\mathrm{Al}, \mathrm{Ca}, \mathrm{Mg}$ and $\mathrm{K}$ were also found to be primary constituents of the sediments, which is consistent with the dominant mineralogy. Moderately high Mn concentrations (148 ppm - 394 ppm) were also observed in all three samples and could reflect the occurrence of a less abundant Mn oxyhydroxide precipitate. 
Table 8. Total element concentrations of the digested sediment samples.

\begin{tabular}{|c|c|c|c|}
\hline Element & $\begin{array}{c}\text { Sample } 1 \\
(\text { ppm) }\end{array}$ & $\begin{array}{c}\text { Sample } 2 \\
\text { (ppm) }\end{array}$ & $\begin{array}{c}\text { Sample } 3 \\
\text { (ppm) }\end{array}$ \\
\hline Aluminum (Al) & 1313 & 1429 & 1548 \\
\hline Arsenic (As) & 8 & $<5$ & $<5$ \\
\hline Boron (B) & $<3$ & $<3$ & $<3$ \\
\hline Barium $(\mathrm{Ba})$ & 27.5 & 41.2 & 33.0 \\
\hline Calcium $(\mathrm{Ca})$ & 2913 & 3203 & 1733 \\
\hline Cadmium (Cd) & $<0.5$ & $<0.5$ & $<0.5$ \\
\hline Cobalt (Co) & 3.3 & 2.9 & 3.7 \\
\hline Chromium (Cr) & 5.0 & 4.4 & 4.7 \\
\hline Copper $(\mathrm{Cu})$ & 5 & 5 & 5 \\
\hline Iron $(\mathrm{Fe})$ & 7015 & 9522 & 7409 \\
\hline Potassium (K) & 253 & 387 & 258 \\
\hline Lithium (Li) & 2.3 & 2.6 & 3.0 \\
\hline Magnesium $(\mathrm{Mg})$ & 756 & 1400 & 1019 \\
\hline Manganese $(\mathrm{Mn})$ & 148 & 394 & 204 \\
\hline Molybdenum (Mo) & $<3$ & $<3$ & $<3$ \\
\hline Sodium $(\mathrm{Na})$ & 105 & 175 & 102 \\
\hline Nickel (Ni) & 9 & 5 & 8 \\
\hline Phosphorus (P) & 216 & 247 & 141 \\
\hline Lead $(\mathrm{Pb})$ & 6 & 5 & $<5$ \\
\hline Sulfur (S) & 1492 & 509 & 386 \\
\hline Selenium $(\mathrm{Se})$ & $<5$ & $<5$ & $<5$ \\
\hline Silicon $(\mathrm{Si})$ & 194 & 189 & 191 \\
\hline Strontium (Sr) & 10.8 & 14.5 & 8.3 \\
\hline Titanium (Ti) & 33 & 46 & 46 \\
\hline Vanadium $(\mathrm{V})$ & 7 & 6 & 7 \\
\hline Zinc (Zn) & 12 & 11 & 16 \\
\hline
\end{tabular}

Results from sediment digestions indicate that arsenic was above detection limit (5 ppm) in only one of the three samples with a concentration of $8 \mathrm{ppm}$, while metals $\mathrm{Cr}, \mathrm{Cu}, \mathrm{Pb}$, and $\mathrm{Ni}$ were 
found in similar amounts between roughly $5 \mathrm{ppm}$ to $10 \mathrm{ppm}$. In contrast, Ti and $\mathrm{Zn}$ exhibited slightly higher concentrations, which reached up to $46 \mathrm{ppm}$ and $16 \mathrm{ppm}$, respectively.

\subsubsection{Sulfur Sequential Extractions}

Supernatant samples collected during the four-phase sulfur sequential extraction process were used to assess the concentration of sulfur from each separated fraction, as well as to identify the abundance of associated constituents (Table 9). The ammonium acetate solution at $\mathrm{pH} 7.0$ used in the Phase 1 removed an average of $252 \pm 68.2 \mathrm{ppm} \mathrm{S}$ from the sediment surfaces. In relation to the total $\mathrm{S}$ concentration, this indicates that the primary $\mathrm{S}$ fraction is surficially bound. The results also show that the extractant used in Phase 1 was successful in removing the adsorbed $\mathrm{S}$, as the fraction in Phase 2 was below detection limits $(10 \mathrm{ppm})$. Furthermore, the data from Phase 2 indicates that $\mathrm{S}$ was not associated with the carbonate fraction, which should have dissolved in the $\mathrm{pH} 5.0$ solution.

Table 9. Sequential extraction results for sulfur in each extraction phase.

\begin{tabular}{|c|c|c|c|c|}
\hline Phase & $\begin{array}{c}\text { Sample 1 } \\
\text { (S ppm) }\end{array}$ & $\begin{array}{c}\text { Sample 2 } \\
\text { (S ppm) }\end{array}$ & $\begin{array}{c}\text { Sample 3 } \\
\text { (S ppm) }\end{array}$ & $\begin{array}{c}\text { Mean } \\
(\mathbf{S ~ p p m})\end{array}$ \\
\hline 1 & 180 & 232 & 343 & $252 \pm 68.2$ \\
\hline 2 & $<10$ & $<10$ & $<10$ & $<10$ \\
\hline $3 \mathrm{a}$ & 44 & 25 & 29 & $33 \pm 8.1$ \\
\hline $3 \mathrm{~b}$ & 32.8 & 17.4 & 19.4 & $23.2 \pm 6.8$ \\
\hline $4 \mathrm{~b}$ & 97.7 & 24.9 & 34.7 & $52.5 \pm 32.2$ \\
\hline Subtotal & $\mathbf{3 5 4 . 5}$ & $\mathbf{2 9 9 . 3}$ & $\mathbf{4 2 6 . 1}$ & $\mathbf{3 5 9 . 9} \pm 51.9$ \\
\hline
\end{tabular}

Generally, the sulfur concentrations in Phase $3 \mathrm{a}, 3 \mathrm{~b}$ and $4 \mathrm{~b}$ show that there are relatively low quantities present in the carbonate/organic, amorphous sulfide, and crystalline sulfide mineral 
fractions, respectively. In Sample 2 and Sample 3, these fractions represent approximately 4\% $8 \%$ of the total S; however, data from Sample 1 indicates that Phase $3 \mathrm{a}$ and $3 \mathrm{~b}$ account for $9 \%-$ $12 \%$ of the total $\mathrm{S}$, while Phase $4 \mathrm{~b}$ made up to $27 \%$. Average results also indicate that amorphous and crystalline sulfide minerals (Phase $3 \mathrm{~b}$ and $4 \mathrm{~b}$ ) contribute approximately $20 \%$ of the total S. Supernatant samples for Phase 4a were not analyzed due to the addition of granular $\mathrm{Zn}$ and therefore, results for residual $\mathrm{S}$ and other elements are not presented.

Table 10. Phase 1, 2 and 3a sequential extraction results for elements apart from sulfur.

\begin{tabular}{|l|c|c|c|}
\hline \multicolumn{1}{|c|}{ Element } & $\begin{array}{c}\text { Phase 1 } \\
(\mathbf{p p m})\end{array}$ & $\begin{array}{c}\text { Phase 2 } \\
\mathbf{( p p m )}\end{array}$ & $\begin{array}{c}\text { Phase 3a } \\
(\mathbf{p p m})\end{array}$ \\
\hline Aluminum $(\mathrm{Al})$ & $8.2 \pm 2.4$ & $18 \pm 2.2$ & $1570 \pm 434$ \\
\hline Arsenic $(\mathrm{As})$ & $<2$ & $<2$ & $2 \pm 0.8$ \\
\hline Calcium $(\mathrm{Ca})$ & $1511 \pm 428$ & $2586 \pm 1923$ & $2449 \pm 1960$ \\
\hline Copper $(\mathrm{Cu})$ & $<0.4$ & $0.7 \pm 0.49$ & $3.6 \pm 0.9$ \\
\hline Iron $(\mathrm{Fe})$ & $5.0 \pm 1.2$ & $26 \pm 12.8$ & $4186 \pm 712$ \\
\hline Potassium $(\mathrm{K})$ & $55 \pm 2.8$ & $<10$ & $229 \pm 71$ \\
\hline Magnesium $(\mathrm{Mg})$ & $102 \pm 2.8$ & $91 \pm 50$ & $749 \pm 244$ \\
\hline Manganese $(\mathrm{Mn})$ & $2.92 \pm 0.96$ & $18.7 \pm 9.3$ & $128.3 \pm 36.3$ \\
\hline Sodium $(\mathrm{Na})$ & $113.6 \pm 3.9$ & $<10$ & $40.5 \pm 3.6$ \\
\hline Nickel $(\mathrm{Ni})$ & $<0.4$ & $<0.4$ & $5.47 \pm 0.93$ \\
\hline Lead $(\mathrm{Pb})$ & $<2$ & $<2$ & $3.06 \pm 1.4$ \\
\hline Silicon $(\mathrm{Si})$ & $33.5 \pm 6.2$ & $45.1 \pm 5.1$ & $1558 \pm 376$ \\
\hline Zinc $(\mathrm{Zn})$ & $<0.9$ & $1.6 \pm 1.5$ & \\
\hline Ni & & & \\
\hline
\end{tabular}

Note: average values reflect the number of samples (n) equal to 3 .

Average element concentrations in supernatant samples from Phase 1, 2 and 3a sequential extractions indicate an overall increase during the extraction phases (Table 10). Calcium, $\mathrm{Mg}$, and $\mathrm{Na}$ exhibited the highest concentrations in Phase 1, and reached average values of $1511 \pm$ $428 \mathrm{ppm}, 102 \pm 2.8 \mathrm{ppm}$, and $113.6 \pm 3.9 \mathrm{ppm}$, respectively. In comparison to Phase $1, \mathrm{Ca}$ concentration showed an increase when subjected to more acidic solutions $(\mathrm{pH} \leq 5)$ in Phase 2 
and Phase 3a, while Mg maintained a similar concentration in Phase 2 before increasing to $749 \pm$ $244 \mathrm{ppm}$ in Phase 3a. Na and K showed a decreasing trend from Phase 1 to Phase 2 indicating that the surface bound fraction was removed in the first extraction. Mean Ca concentrations were consistently $>1511 \mathrm{ppm}$ throughout the experiment, while $\mathrm{Al}$ and $\mathrm{Si}$ displayed peak concentrations of $1570 \pm 434 \mathrm{ppm}$ and $1558 \pm 376 \mathrm{ppm}$ in Phase 3a, respectively.

Fe and Mn also exhibit peak concentrations of $4186 \pm 712 \mathrm{ppm}$ and $128.3 \pm 36.3 \mathrm{ppm}$, in Phase 3a, respectively. In addition, $\mathrm{As}, \mathrm{Cu}, \mathrm{Ni}$, and $\mathrm{Pb}$ show the highest concentrations in Phase $3 \mathrm{a}$, which were below or only slightly above their respective detection limits in Phase 1 and 2. This indicates that these metals were generally not present in the adsorbed or surface bound fraction, and were associated with the amorphous mineral phase. Analysis for $\mathrm{Zn}$ was not possible in Phase 3a due to potential contamination resulting from granular $\mathrm{Zn}$ being used in the sequential extraction as a reagent. Furthermore, the residual fraction from Phase $4 \mathrm{~b}$ did not undergo analysis as a consequence of the extremely high $\mathrm{Zn}$ concentrations produced by the granular reagent used to extract $\mathrm{S}$ in Phase 4a.

\subsubsection{Anaerobic Heated Experiment}

The partial pressure of $\mathrm{O}_{2(\mathrm{~g})}$ in the anaerobic chamber during the unheated and heated phase of Experiment 3 was kept below $2 \mathrm{kPa}$. During the heated phase, temperatures within the heating section were controlled using a temperature gradient from $50^{\circ} \mathrm{C}$ to $90^{\circ} \mathrm{C}$ between 1.0 and $1.6 \mathrm{~m}$ which remained relatively consistent throughout the nine-week period (Appendix I). Temperatures within the cooling section exhibited gradual decrease over the course of the heated experiment after improvements were made to the circulation of cooling fluid. However, the thermistor located within the cooling section at $2.0 \mathrm{~m}$ malfunctioned during Week 2 and 
subsequent temperatures from this location were not recorded. Despite this loss, data from the thermistor at $2.3 \mathrm{~m}$ was still able to indicate the approximate temperature throughout the cooling section.

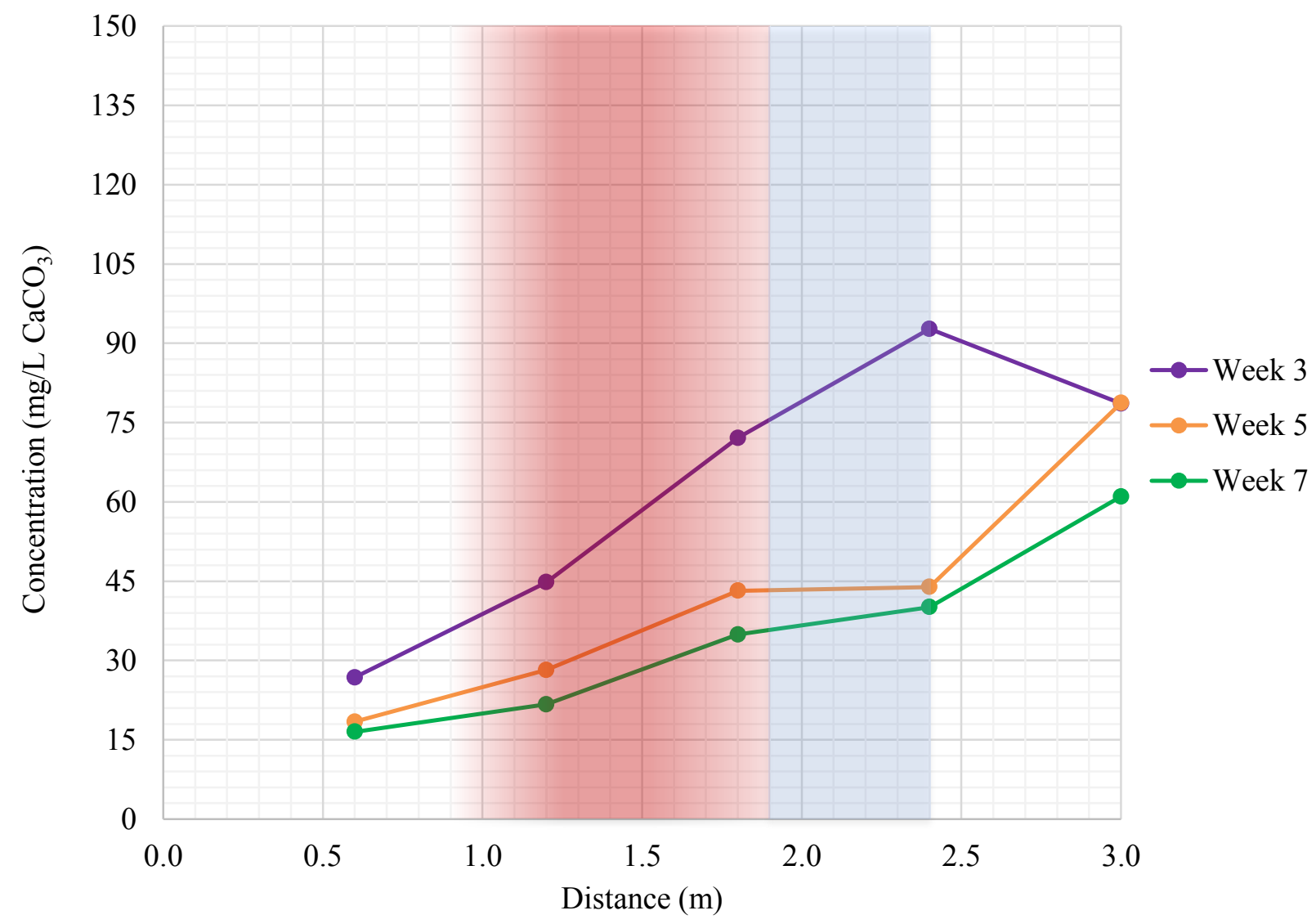

Figure 24. Total alkalinity profile of the column during the heated (Week 3, 5 and 7) phase of Experiment 3.

Although there was not data available for the total alkalinity (expressed as $\mathrm{mg} / \mathrm{L} \mathrm{CaCO}$ ) during unheated conditions, the general trend during heated experiment shows an overall increase from the input to the output location along the column (Figure 24). Between Week 3 to Week 7, total alkalinity decreases by $10 \mathrm{mg} / \mathrm{L}$ to $15 \mathrm{mg} / \mathrm{L} \mathrm{CaCO}_{3}$ at $0.6 \mathrm{~m}$ and $3.0 \mathrm{~m}$ along the column and 
output locations whereas concentrations in the cooling section at $2.4 \mathrm{~m}$ are reduced by approximately $42 \mathrm{mg} / \mathrm{L} \mathrm{CaCO}_{3}$.

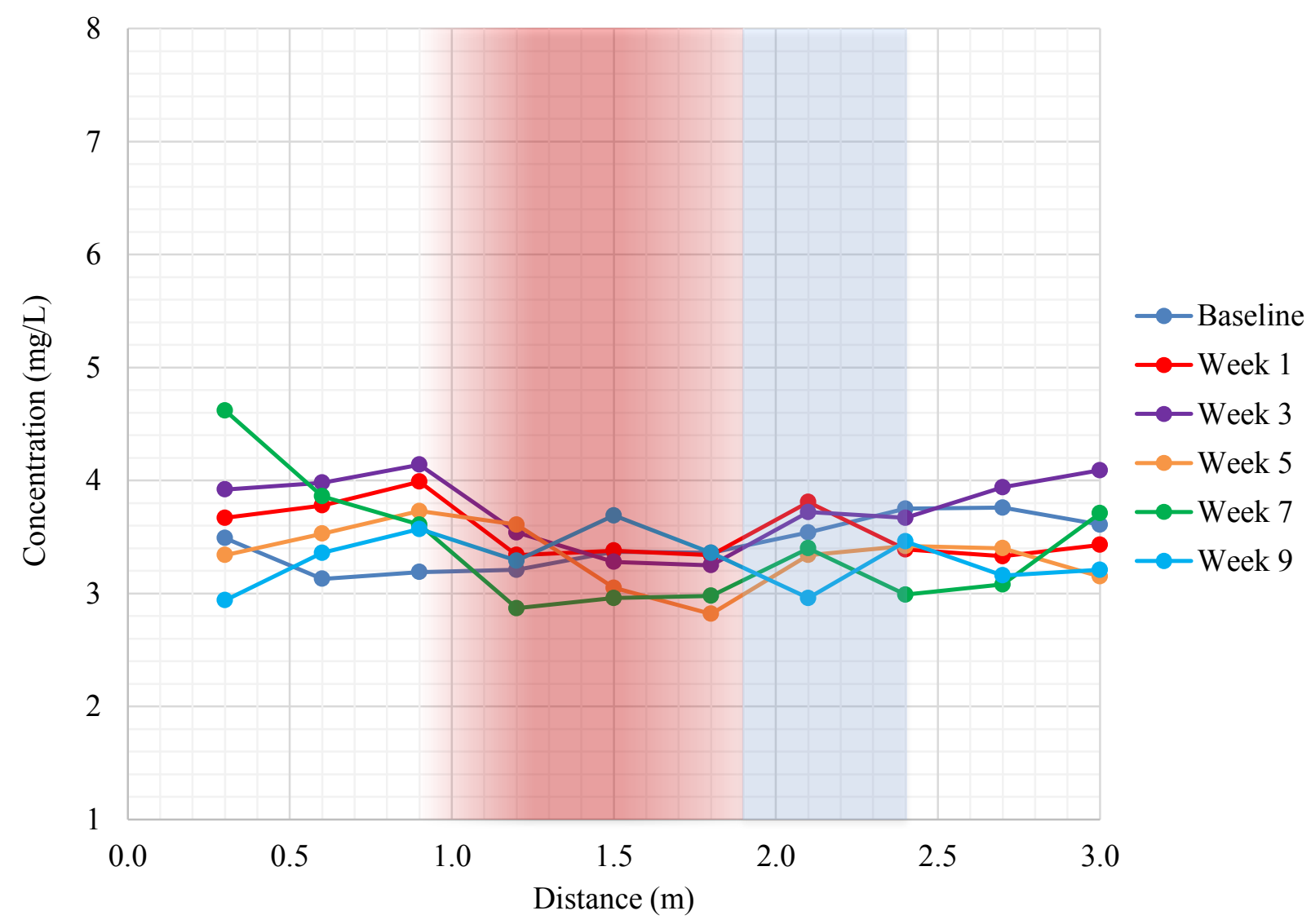

Figure 25. Dissolved oxygen profile of the column during the unheated ('Baseline') and heated (Week 1, 3, 5, 7 and 9) phase of Experiment 3.

The majority of the data points for DO fall between $3 \mathrm{mg} / \mathrm{L}$ and $4 \mathrm{mg} / \mathrm{L}$ during both the unheated and heated conditions, which indicates there was minimal change in the overall flux within the column (Figure 25). Subtle trends in the weekly data during the heated conditions are observed and include a slight decrease as input water moves from the background section to the heated section, which then remains relatively constant downgradient in the column. However, data from unheated conditions exhibits the opposite trend as initial concentrations are approximately 3 
$\mathrm{mg} / \mathrm{L}$ in the first metre of the column and gradually increase to $\sim 3.8 \mathrm{mg} / \mathrm{L}$ in final metre of the column.

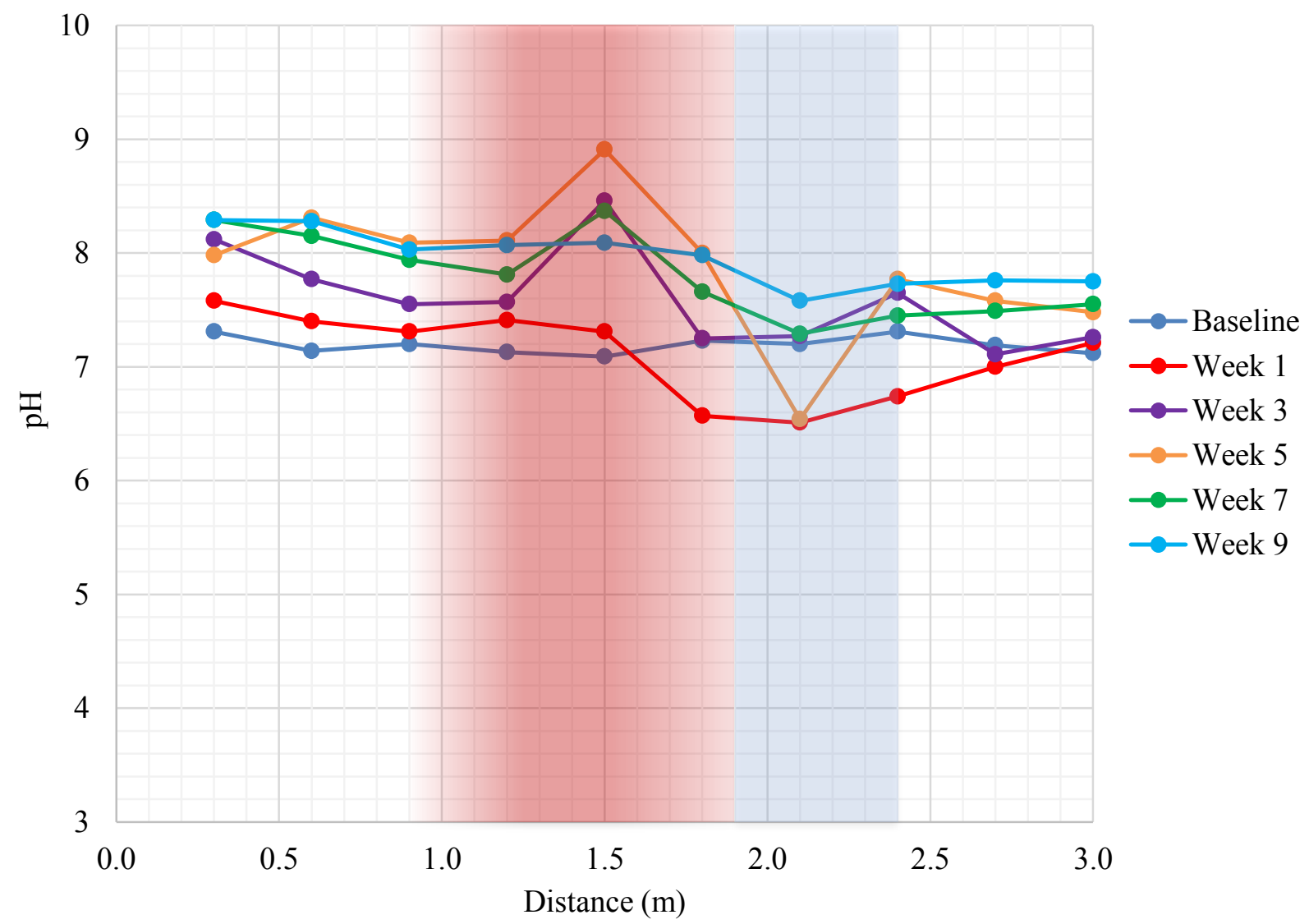

Figure 26. $\mathrm{pH}$ profile of the column during the unheated ('Baseline') and heated (Week 1, 3, 5, 7 and 9) phase of Experiment 3.

The baseline trend for $\mathrm{pH}$ is steady throughout the column at $\sim 7.2$ and undergoes several transformations over the nine-week heated period (Figure 26). Within the background section, $\mathrm{pH}$ increases from $\sim 7.4$ in Week 1 to $\sim 8.2$ in Week 5 and remains relatively constant until Week 9. Concurrent changes are exhibited within the heating section where $\mathrm{pH}$ increases from the Baseline level up to a peak of $\sim 9$ during Week 5, which then appears to flatten to approximately 8 by Week 9 . In the section of the column between $1.5 \mathrm{~m}$ and $3.0 \mathrm{~m}, \mathrm{pH}$ exhibits an overall 
decrease apart from Week 1. In Week 5, this decrease in $\mathrm{pH}$ is marked by a sharp decline while in Week 9, there is a more gradual reduction.

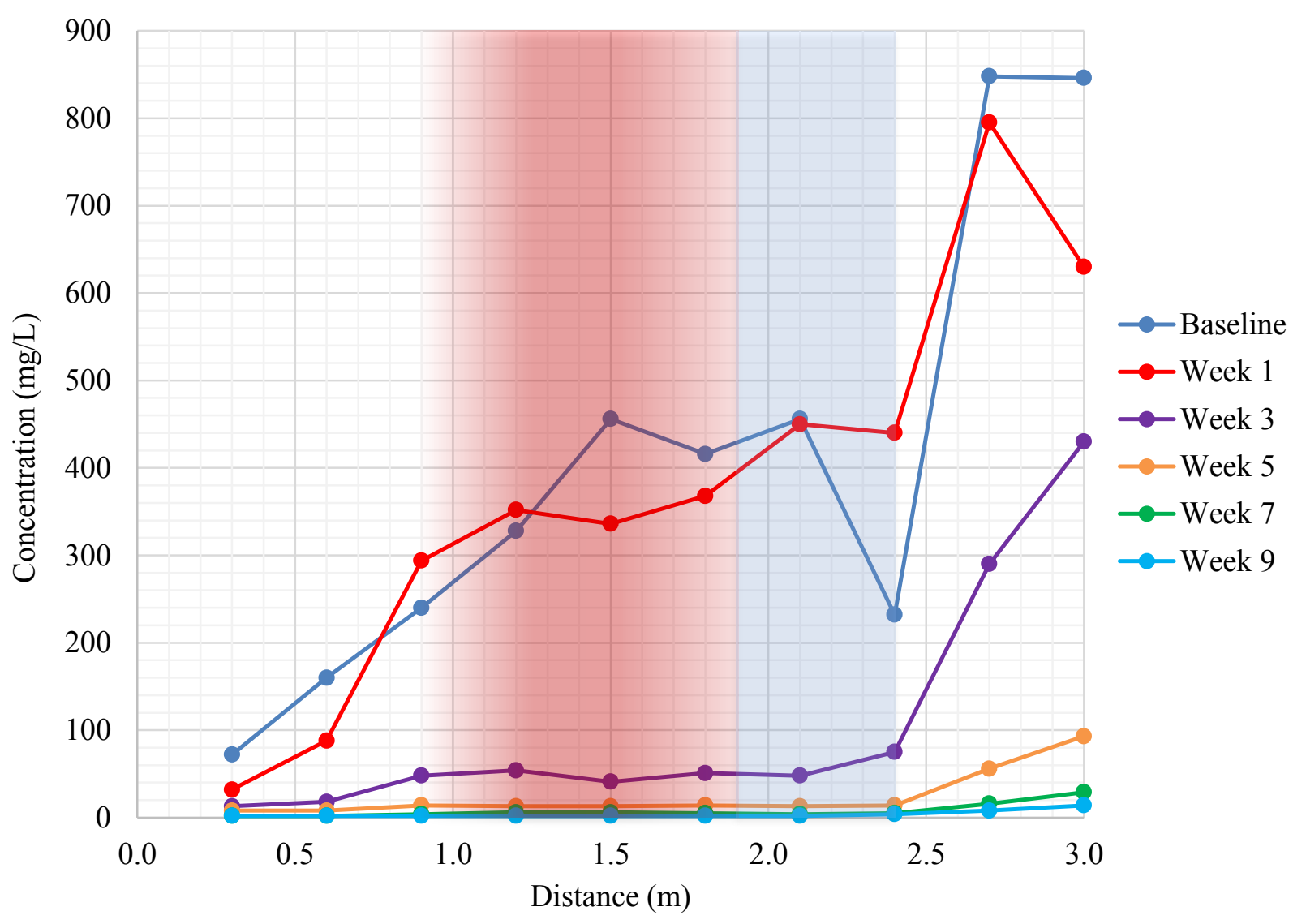

Figure 27. Sulfate profile of the column during the unheated ('Baseline') and heated phase of (Week 1, 3, 5, 7 and 9) Experiment 3.

During the baseline phase and Week 1 of the heated phase, overall sulfate concentrations increase throughout the length of the column at a moderately similar rate, and both reach 800 $\mathrm{mg} / \mathrm{L}$ or above in the last $0.5 \mathrm{~m}$ (Figure 27). A noteworthy peak in concentration is observed within this increasing trend from $2.4 \mathrm{~m}$ to $2.7 \mathrm{~m}$ where values appear to increase by a factor of approximately 2 to 3 . In Week 3 to Week 9 , sulfate concentration rapidly declines between $0.3 \mathrm{~m}$ to $2.4 \mathrm{~m}$ along the column and eventually reaches $\sim 2 \mathrm{mg} / \mathrm{L}$ in Week 9 . However, during this time 
sulfate consistently exhibits an increase from $2.4 \mathrm{~m}$ to $3.0 \mathrm{~m}$ by a factor of 4 to 6 , similarly to the pattern observed for baseline conditions and in Week 1.

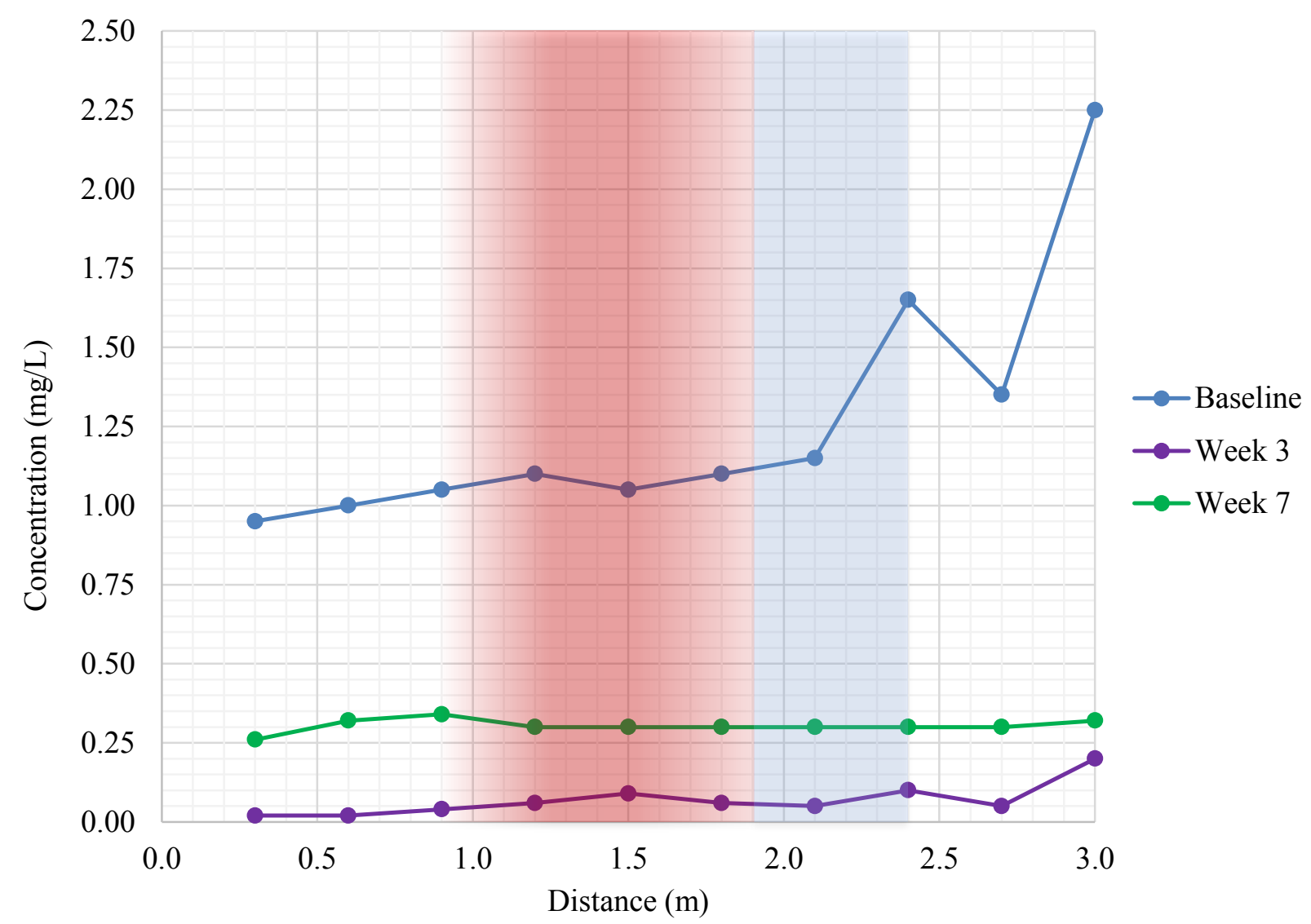

Figure 28. Ferrous iron profile of the column during the unheated ('Baseline') and heated (Week 3 and 7) phase of Experiment 3.

Baseline concentrations in ferrous iron increase gradually from $0.95 \mathrm{mg} / \mathrm{L}$ to $1.16 \mathrm{mg} / \mathrm{L}$ between $0.3 \mathrm{~m}$ to $2.1 \mathrm{~m}$ and proceed to increase rapidly up to $2.25 \mathrm{mg} / \mathrm{L}$ at $3.0 \mathrm{~m}$ (Figure 28). Data from Week 3 shows that concentrations have diminished to below $0.2 \mathrm{mg} / \mathrm{L}$ throughout the column. Despite this trend, ferrous iron exhibits an increase up to $\sim 0.3 \mathrm{mg} / \mathrm{L}$ throughout the column in Week 7 with respect to Week 3 . 


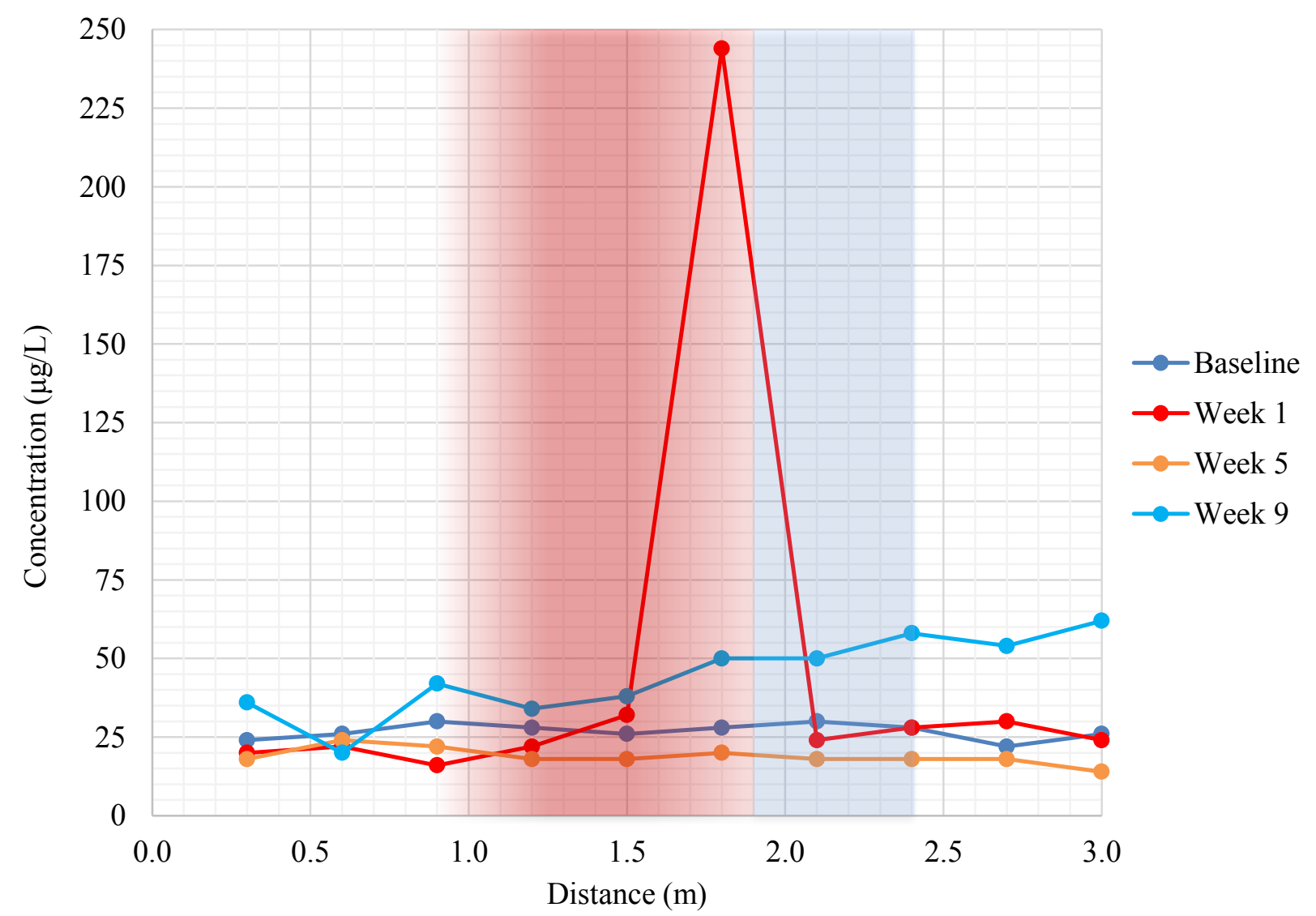

Figure 29. Sulfide profile of the column during the unheated ('Baseline') and heated (Week 1, 5 and 9) phase of Experiment 3.

Baseline sulfide concentrations remain consistent at approximately $25 \mu \mathrm{g} / \mathrm{L}$ and remain somewhat similar to those in Week 1 of the heated experiment, with the exception of the point at $1.7 \mathrm{~m}$ following the heated section, which displays a concentration that is one order of magnitude larger (Figure 29). Sulfide concentrations in Week 5 are lower than the baseline trend and remain relatively constant at $\sim 20 \mu \mathrm{g} / \mathrm{L}$ throughout the column. The observed trend for sulfide in Week 9 exhibits an overall increase from $1.2 \mathrm{~m}$ in the heated section to $3.0 \mathrm{~m}$, which gradually doubles in concentration to $62 \mu \mathrm{g} / \mathrm{L}$. 

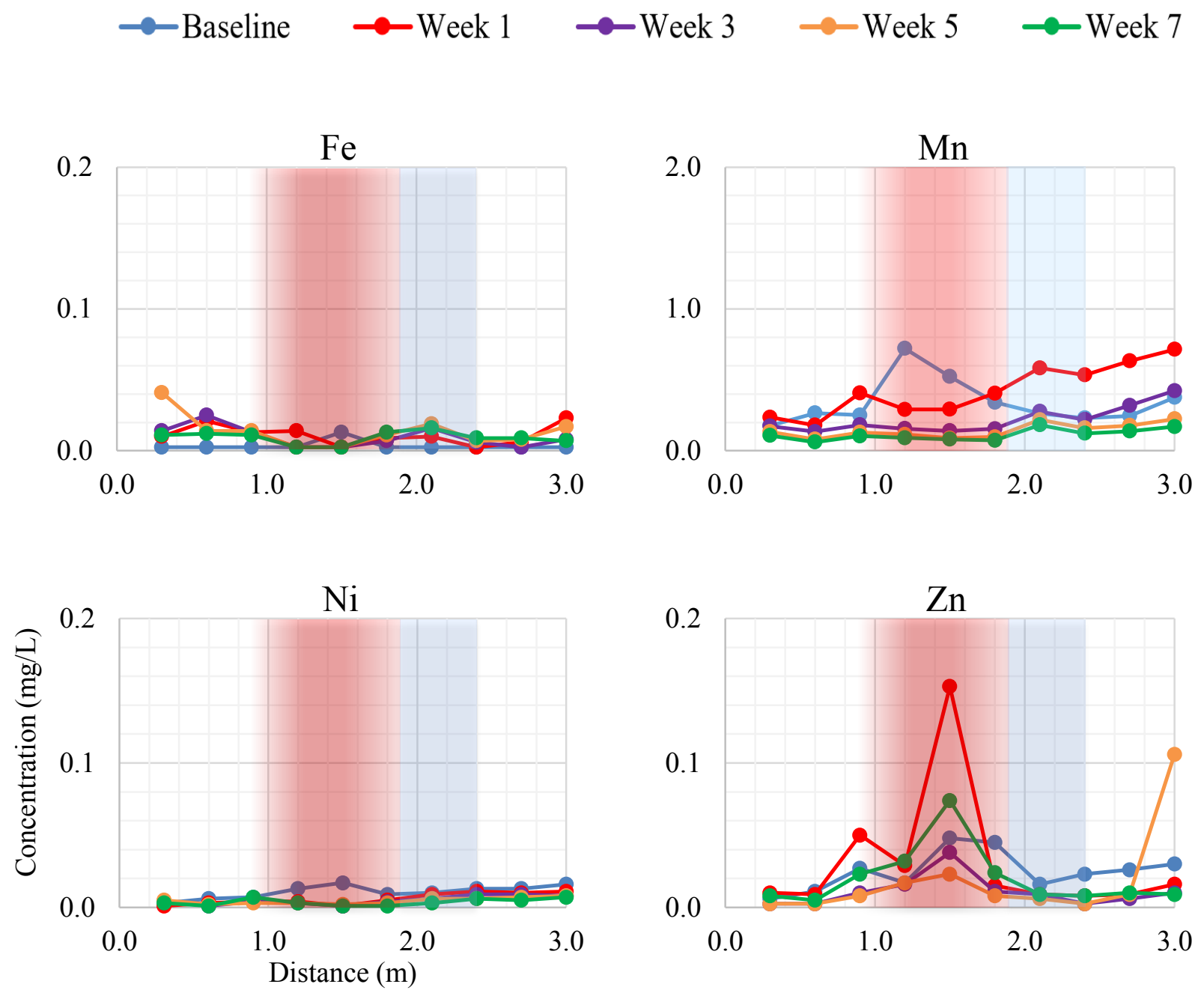

Figure 30. $\mathrm{Fe}, \mathrm{Mn}, \mathrm{Ni}$, and $\mathrm{Zn}$ concentrations along the profile of the column throughout the unheated ('Baseline') and heated anaerobic phase (Week 1, 3, 5 and 7) from Experiment 3.

Following the baseline phase, concentrations in Fe and $\mathrm{Ni}$ decrease to below $0.01 \mathrm{mg} / \mathrm{L}$ for the duration of the heated experiment (Figure 30). In the case of Fe, data indicates that two subtle increases occurred on Week 1 and Week 5 at $3.0 \mathrm{~m}$, which reached $0.023 \mathrm{mg} / \mathrm{L}$ and $0.017 \mathrm{mg} / \mathrm{L}$, respectively. Concentrations for $\mathrm{Mn}$ increases briefly in Week 1 to above $0.5 \mathrm{mg} / \mathrm{L}$ following the heated section, and then rapidly decreases leading up to Week 3. In Week 5 and Week 7, Mn exhibits a more gradual decline and eventually falls below $0.2 \mathrm{mg} / \mathrm{L}$. 
After the unheated phase, $\mathrm{Zn}$ increases during Week 1 of the heated experiment and reaches up to $0.16 \mathrm{mg} / \mathrm{L}$ within the heated section. This overall concentration subsequently decreases in Week 3 and Week 5, but increases once more in Week 7 to $\sim 0.07 \mathrm{mg} / \mathrm{L}$. Throughout Week 1 to Week 7 of the heated experiment, none of the metals reach a concentration above $0.3 \mathrm{mg} / \mathrm{L}$ at 1.5 $\mathrm{m}$ within the heating section. In addition, As and $\mathrm{Pb}$ concentrations did not reach above detection limits $(2 \mathrm{mg} / \mathrm{L})$ for the duration of Experiment 3 . 
$\multimap$ Baseline $\rightarrow$ Week $1 \rightarrow$ Week $3 \rightarrow$ Week $5 \rightarrow$ Week 7
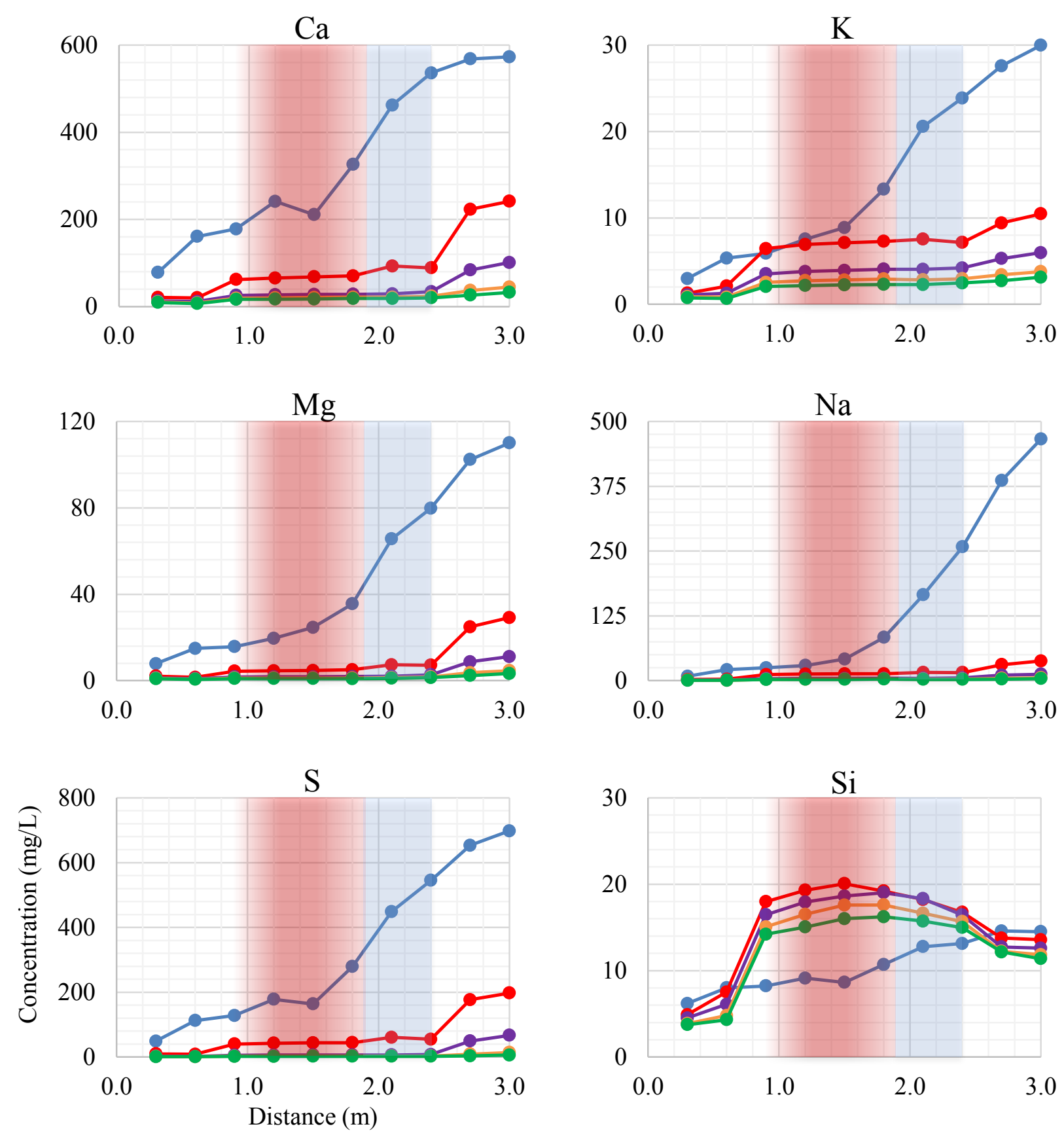

Figure 31. $\mathrm{Ca}, \mathrm{K}, \mathrm{Mg}, \mathrm{Na}, \mathrm{S}$, and $\mathrm{Si}$ concentrations along the profile of the column throughout the unheated ('Baseline') and heated anaerobic phase (Week 1, 3, 5 and 7) from Experiment 3. 
Baseline results for $\mathrm{Ca}, \mathrm{K}, \mathrm{Mg}, \mathrm{Na}$ and $\mathrm{S}$ show that there is a substantial increase in concentration with distance along the column (Figure 31). Concentrations of $\mathrm{Ca}, \mathrm{Na}$ and $\mathrm{S}$ show particularly high values at the end of the column, and reach up to $572 \mathrm{mg} / \mathrm{L}, 466 \mathrm{mg} / \mathrm{L}$, and 697 $\mathrm{mg} / \mathrm{L}$, respectively. After initiating the heated phase of the experiment, there is a rapid decrease for all constituents throughout all locations along the column.

Results from within the heating section during Week 1 indicate that $\mathrm{Ca}$ and $\mathrm{S}$ continue to be the most abundant constituents with concentrations of $70 \mathrm{mg} / \mathrm{L}$ and $44 \mathrm{mg} / \mathrm{L}$, respectively. Moderate amounts of $\mathrm{Na}$ and $\mathrm{Mg}$ are also observed, and are followed by lower quantities $(\sim 8 \mathrm{mg} / \mathrm{L})$ of $\mathrm{K}$. Over the course of the heated experiment, trends for $\mathrm{Ca}, \mathrm{K}, \mathrm{Mg}, \mathrm{Na}$ and $\mathrm{S}$ display a steady decrease from Week 1 to Week 7, and reach a final concentration of less than $3 \mathrm{mg} / \mathrm{L}$, with the exception of $\mathrm{Ca}$ which plateaus at $17 \mathrm{mg} / \mathrm{L}$. In contrast to these trends, Si displays an overall increase from baseline conditions to Week 1 of the heated phase (Figure 31). Concentrations of Si increase from $8 \mathrm{mg} / \mathrm{L}$ to $20 \mathrm{mg} / \mathrm{L}$ within the heating section which decrease slightly to $\sim 16$ $\mathrm{mg} / \mathrm{L}$ by Week 7.

Concentrations of $\mathrm{Ca}, \mathrm{K}, \mathrm{Mg}, \mathrm{Na}$ and $\mathrm{S}$ at locations down gradient of the heating section have similar decreasing trends throughout the heated experiment with final concentrations in Week 7 that are approximately 1 to 2 orders of magnitude smaller than those from baseline conditions. In contrast to the other constituents, Si displays a subtle decrease from $14 \mathrm{mg} / \mathrm{L}$ to $11 \mathrm{mg} / \mathrm{L}$ over the duration of the heated experiment. 


\section{Chapter 5 - Assessment of Results}

\subsection{Column Flow Characterization}

Unheated and heated tracer tests demonstrate that $\mathrm{Br}$ generally acted as a conservative solute in materials used in all three experiments as peak concentrations were found to match the concentration of the input solution in most instances. Minor discrepancies were likely caused by inherent error from the ISE probe readings. Overall observations between the unheated and heated tracer test results during Experiment 1,2 and 3 show that dispersivity and dispersion increase as a function of temperature by one to two orders of magnitude. This reoccurring trend in all three materials strongly suggests that the properties of the fluid flow change with increasing temperature.

Fennel (2008) noted that similar increases in temperature caused proportional increases in calculated hydraulic conductivity. Results from tests in this study show that the velocity and column outflow rate remain relatively constant $( \pm 6 \%-10 \%)$ during unheated $\left(25^{\circ} \mathrm{C}\right)$ and heated $\left(80^{\circ} \mathrm{C}\right)$ conditions. However, the flow rate through the column is primarily controlled by the pumping rate set on the peristaltic pump. It is possible that the early arrival of $\mathrm{Br}$ during the heated tracer tests results from changes in the hydraulic conductivity, which is due to its dependency on water temperature. As temperature is known to control both water density and viscosity, the relationship between temperature and hydraulic conductivity can be expressed as:

$$
K=\frac{\rho k g}{\mu}
$$

Where $K$ denotes the hydraulic conductivity, $\rho$ refers to the fluid density, $k$ is the absolute permeability, $\mathrm{g}$ is the acceleration due to gravity, and $\mu$ is the viscosity. In the temperature range of most groundwater systems between $5^{\circ} \mathrm{C}$ to $25^{\circ} \mathrm{C}$, water has a similar density and viscosity, 
and hydraulic conductivity is often assumed to be a property of the material. However, in higher temperature systems, water viscosity and density are reduced considerably while hydraulic conductivity increases (Levy et al., 1989; Cho et al., 1999). Through this comparison, it becomes evident that hydraulic conductivity is a function of both the fluid and the material.

Based on the permeability of Ottawa sand measured by Williams and Oostrum (2000) and assuming this remains constant within the observed temperature range, $K$ within heating section is approximately 2.5 times higher than unheated section. Although this change in hydraulic conductivity can be conceptually presented as a controlling factor in this system, the overall results of these tests clearly demonstrate that greater dispersion is a primary characteristic of flow behavior under heated conditions. Possibly, the contrast in temperature within the unheated and heated sections of the column would also introduce additional mixing that would contribute to a wider distribution of $\mathrm{Br}$ concentration with continued transport.

Another factor to consider with flow in higher temperature environments is the effect of eddying as viscosity is reduced. Generally, this can be determined by calculating a Reynolds number (Re), which indicates if the flow regime behaves according Darcy's Law and produces laminartype flow $(\operatorname{Re}<1)$ or deviates to produce non-Darcy flow $(\operatorname{Re}>1)$ where eddy-type flow becomes significant (Chaundhary et al., 2011). Results from this experiment suggest that the Re is still less than 1 likely due to the low flow rate, and therefore flow throughout the column still behaves according to Darcy's Law. 


\subsection{Experiment 1}

The trends observed for $\mathrm{pH}$ and $\mathrm{Si}$ during the unheated baseline and heated experiment from Week 1 to Week 9 are generally in agreement with respect to the process of quartz dissolution and the co-dependency on $\mathrm{pH}$ conditions and temperature (Figure 10 and Figure 11). The relationship between these parameters is evident by the relatively proportional patterns in the data and appears to follow the hydrolysis reaction:

$$
\mathrm{SiO}_{2 \text { (quartz) }}+2 \mathrm{H}_{2} \mathrm{O} \rightarrow \mathrm{Si}(\mathrm{OH})_{4}
$$

Baseline concentrations of Si recorded at the end of the column align moderately well with the $\sim 6 \mathrm{mg} / \mathrm{L}$ solubility for quartz at $25^{\circ} \mathrm{C}$ (Morey et al., 1962; Rimstidt and Barnes, 1980). However, in other sources of literature, Rimstidt (1997) argues that the true value of quartz solubility is 11 $\mathrm{mg} / \mathrm{L}$, which is roughly half of the value attained in this experiment. Although there is some ambiguity between the accepted value, results of geochemical modelling using PHREEQC Version 3 (Parkhurst and Appelo, 2013) and the MINTEQ database (Allison et al., 1991) indicate the saturation index (SI) values for quartz increase with distance in the column and demonstrate an overall agreement with quartz solubility at $6 \mathrm{mg} / \mathrm{L}$ (Figure 32). 


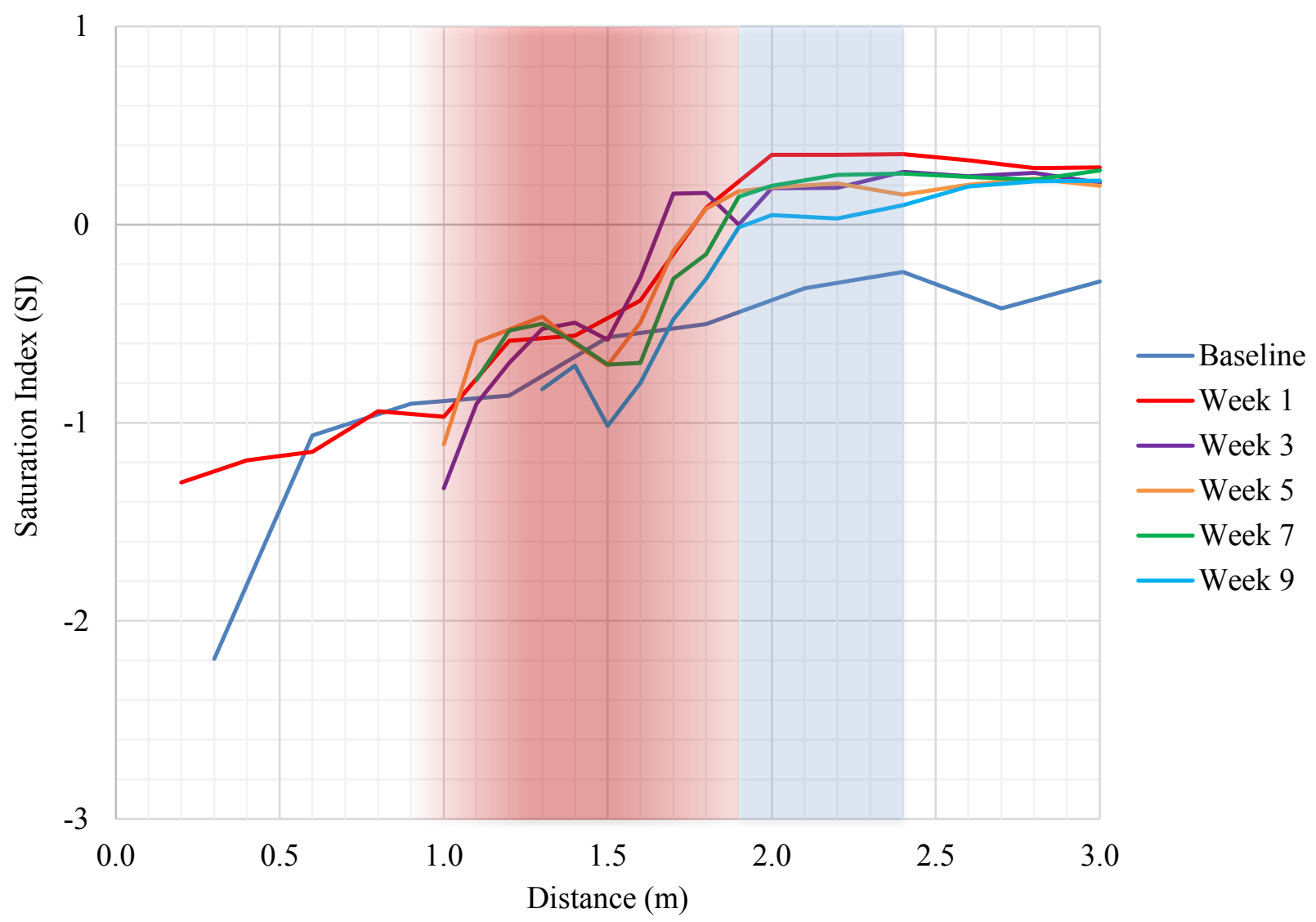

Figure 32. Modelled quartz saturation indices over the length of the column during unheated ('Baseline') conditions and heated (Week 1 to Week 9) conditions of Experiment 1.

Discrepancies between the data attained during Baseline conditions and the $11 \mathrm{mg} / \mathrm{L}$ value could be attributed to the system not yet reaching equilibrium with respect to quartz solubility due to differences in reaction enthalpy. This can also be justified as the maximum Si concentration in Experiment 1 was attained with a residence time of approximately 1 week at $\sim 25^{\circ} \mathrm{C}$, while the value by Rimstidt (1997) was the result of a 4917 day experiment at $\sim 21^{\circ} \mathrm{C}$. Although residence time in the column was one week, baseline data was collected after a four-week period (equivalent to $\sim 4$ pore volume flushes) to achieve steady state conditions. The difference in the baseline results and those presented by Rimstidt (1997) highlights the variation that is obtained from batch tests and column experiments where transport becomes an influential variable. 
During the heated experiment, the increase in $\mathrm{Si}$ and decline in $\mathrm{pH}$ within the heating section was attributed to the increase in temperature. This relationship can be explained as rising temperature is known to affect the thermodynamic equilibrium of the quartz dissolution rate above $\mathrm{pH} 6-7$, which breaks covalent bonds of the mineral surface during hydrolysis (Knauss and Worley, 1988; Brady and Walther, 1989; Brady and Walther, 1990). During this reaction, there is a subsequent increase in the production of $\mathrm{Si}(\mathrm{OH})_{4}$ which leads to an increase in $\mathrm{pH}$, as hydrolysis involves adsorption of protons (Blake and Walter, 1999). The maximum observed $\mathrm{pH}$ is also in agreement with $\mathrm{Si}$ dissolution to form $\mathrm{Si}(\mathrm{OH})_{4}$ at $\mathrm{pH} \leq 9$ (Sjöberg, 1996).

Furthermore, the mean Si concentration within the heating section of the column was found to be roughly $20 \mathrm{mg} / \mathrm{L}$ which approximately half of the reported literature value that was derived from a 108 day batch test study at $96^{\circ} \mathrm{C}$ (Rimstidt, 1997). The discrepancy strongly suggests that thermodynamic equilibrium was not reached within the heating section over the course of the heated experiment. PHREEQC model results from data in the heated experiment indicate that the SI for quartz reaches saturation at downgradient locations from the heating section (Figure 32). Overall, this trend demonstrates that the solution is near the limit of quartz solubility in these temperature and $\mathrm{pH}$ conditions.

Although quartz hydrolysis was likely the primary reaction occurring the heating section, silica concentrations were also potentially controlled by surface bound Si from the quartz with the exposure to high temperatures. Since grains were not pre-treated with acid to clean the surfaces, there is a strong possibility that sorbed $\mathrm{Si}$, as particulate solids and/or colloids, was present on the quartz surfaces. During the Week 1 to Week 5 of the heated experiment, Si concentrations increase rapidly within the heating section and in down gradient locations, which could indicate surface release. However, these values gradually decrease at these locations and points to the 
removal of the sorbed Si fraction, which likely becomes increasingly less abundant over time. Further support of the surface bound $\mathrm{Si}$ is also evident during the unheated phase as quartz dissolution is known to be a relatively slow reaction, yet silica concentrations appear to reach near-equilibrium values.

An additional mechanism to consider in the heated system is the properties of different polymers of amorphous silica at downgradient locations in the column. The formation of silica polymers can be rationalized with the following reaction:

$$
\mathrm{Si}(\mathrm{OH})_{4}+\mathrm{OH}^{-} \rightarrow(\mathrm{OH})_{3} \mathrm{SiO}^{-}+\mathrm{H}_{2} \mathrm{O}
$$

In this case, $\mathrm{Si}(\mathrm{OH})_{4}$ undergoes anionic polymerization, which decreases $\mathrm{pH}$ while lowering the concentration of dissolved Si (Zuhl and Amjad, 2014). As this solution exits the heating section and flows through the last metre of the column at $25^{\circ} \mathrm{C}$, the dissolved and polymerized Si species move towards thermodynamic equilibrium with amorphous silica which has a solubility limit of $116 \mathrm{mg} / \mathrm{L}$ (Rimstidt, 1997). PHREEQC model results validate this concept as the $\mathrm{SI}$ of $\mathrm{SiO}_{2(\mathrm{am})}$ remains under saturated at conditions throughout Experiment 1 and demonstrate that is very unlikely for this mineral phase to precipitate (Figure 33). 


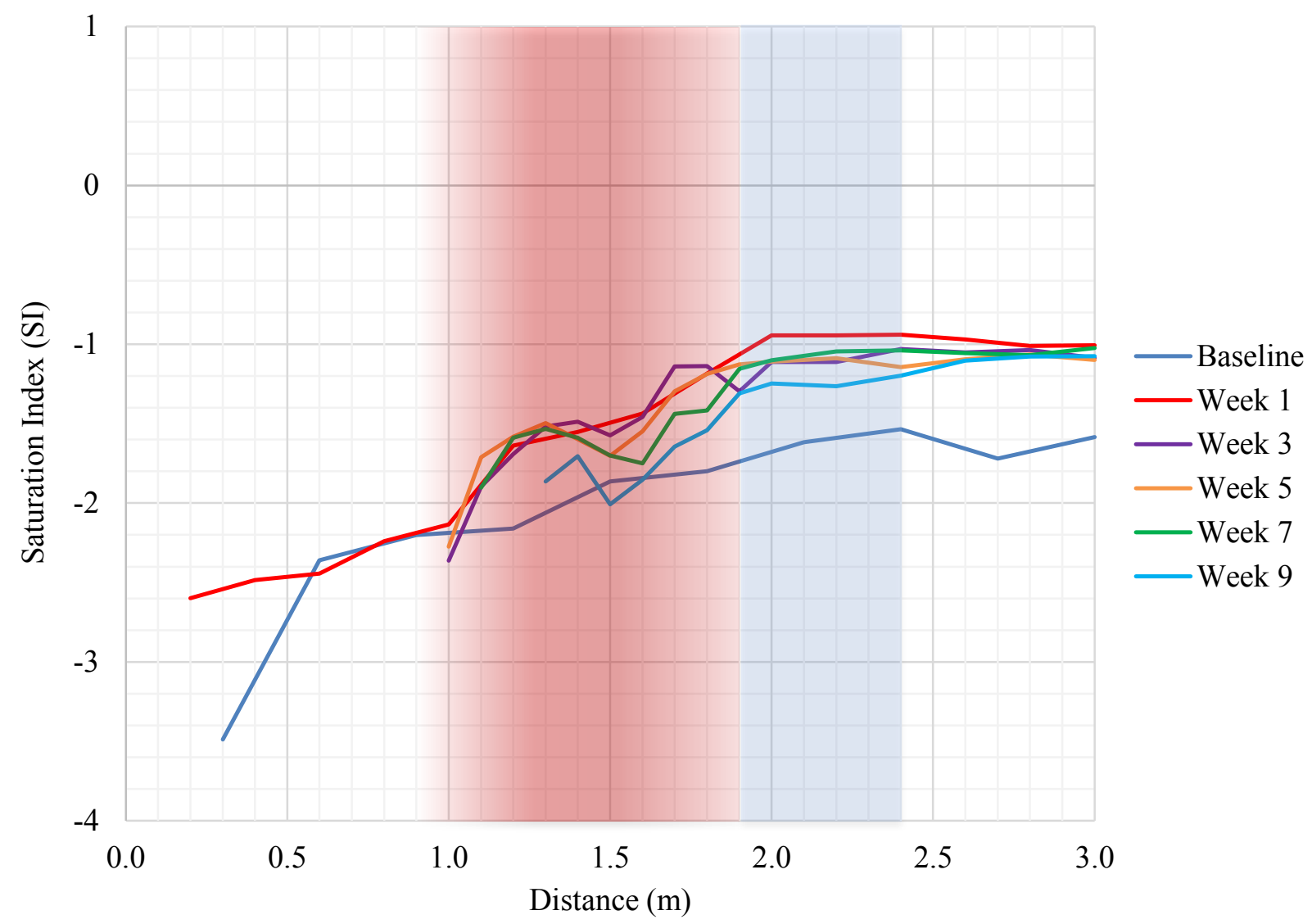

Figure 33. Modelled $\mathrm{SiO}_{2(\mathrm{am})}$ saturation indices over the length of the column during unheated ('Baseline') conditions and heated (Week 1 to Week 9) conditions of Experiment 1.

Although residence time of the solution increases in the column along with the concentration of $\mathrm{Si}$ and $\mathrm{pH}$, the data indicates that this period is not sufficient for the system to reach equilibrium with amorphous silica (Figure 10 and Figure 11). The overall geochemical evolution of $\mathrm{pH}$ and silica in this system is indicative of a shift from the initial input conditions that approaches steady state conditions with respect to quartz, and then later to amorphous silica as distance from the source and residence time increases.

Another important factor to note when assessing these results is to understand that the analytical method was only able to detect dissolved silica. As mentioned above, the silica polymers that 
have likely been formed in these heated experiments, along with possible colloidal and/or suspended silica complexes, are undetermined and therefore, higher concentrations of total silica cannot be ruled out.

\subsection{Experiment 2}

\section{Sediment Characterization}

Scanning electron microscopy (SEM) and laser ablation ICP-MS (LA-ICP-MS) analysis was conducted on the pyrite fragments used in Experiment 2 to better understand the surface condition and elemental composition of the pyrite, and allow for reasonable interpretations of the column results to be presented. SEM micrographs of the pyrite grains show that surfaces exhibit very minute signs of chemical weathering (i.e. surface pitting), which suggests that oxidation has only recently commenced. The rate of oxidation of the pyrite in an aerobic environment was likely influenced by bacterially mediated reactions as there was roughly four weeks between crushing the original crystal and conducting surface analysis. Similar findings by Murphy and Strongin (2008) and Chandra and Gerson (2010) have established that pyrite can undergo oxidation in subaerial environments after exposure to atmospheric conditions.

LA-ICP-MS results of the pyrite indicated that trace quantities of $\mathrm{Al}, \mathrm{As}, \mathrm{Cu}, \mathrm{Pb}, \mathrm{Mn}, \mathrm{Ti}, \mathrm{Se}, \mathrm{V}$ and $\mathrm{Zn}$ were present within the mineral structure. Data also shows a wide distribution of element concentrations, demonstrating spatial heterogeneity within the original cubic crystal sample. It is possible that a more consistent geochemical signature of the pyrite could be attained using acid digestion and ICP-MS analysis; however, the amount of pyrite and the dilution factor would need to be scrutinized beforehand in order to avoid possible instrument malfunction. 


\section{Aerobic Phase}

Results from the aerobic unheated (Baseline) conditions show that sulfate concentrations increase gradually over the length of the column and eventually reach $20 \mathrm{mg} / \mathrm{L}$ at $3.0 \mathrm{~m}$, which indicates that minor pyrite oxidation was occurring at temperatures of $25^{\circ} \mathrm{C}$ (Figure 15). These initial outcomes were generally expected as mineral grains had been left exposed to atmospheric conditions after being crushed and were subjected to high concentrations of dissolved oxygen (5 $-6 \mathrm{mg} / \mathrm{L}$ ) within the column porewater. In the presence of dissolved oxygen, the dissolution of pyrite is known to proceed from the following reaction:

$$
\mathrm{FeS}_{2(\mathrm{~s})}+\mathrm{H}_{2} \mathrm{O}+\frac{7}{2} \mathrm{O}_{2(\mathrm{aq})} \rightarrow \mathrm{Fe}^{2+}+2 \mathrm{SO}_{4}{ }^{2-}+2 \mathrm{H}^{+}
$$

This overall reaction is well documented in literature and has been studied extensively in research of the oxidation, dissolution and weathering mechanisms of sulfide minerals (Moses et al., 1987; Moses and Herman, 1991; Kamei and Ohmoto, 2000; Chandra and Gerson, 2010).

Additional support of pyrite oxidation is evident as low concentrations of ferrous iron $(<0.15$ $\mathrm{mg} / \mathrm{L})$ were present throughout the column while concentrations of total iron displayed a peak of $1.7 \mathrm{mg} / \mathrm{L}$ at $2.4 \mathrm{~m}$ (Figure 17 and Figure 18). Comparison between these two datasets points to oxidation of ferrous iron to ferric iron, which can be illustrated as:

$$
\mathrm{Fe}^{2+}+\frac{1}{4} \mathrm{O}_{2(\mathrm{aq})}+\mathrm{H}^{+} \rightarrow \mathrm{Fe}^{3+}+\frac{1}{2} \mathrm{H}_{2} \mathrm{O}
$$

Metals $\mathrm{Al}, \mathrm{Mn}$ and $\mathrm{Zn}$ also associated with the pyrite composition were observed above detection limits and provide further evidence that pyrite was undergoing dissolution.

Baseline concentrations of $\mathrm{Ca}$ and $\mathrm{Mg}$ displayed moderate increases within the column, likely due to minor $\mathrm{pH}$ buffering of the acidity generated from the oxidation reaction 5.4 (Figure 20). 
Although the presence of carbonates was not investigated as part of the sediment characterization study, baseline $\mathrm{pH}$ levels remained generally consistent at $\sim 5.8$ which also supports this buffering reaction. The source of the carbonates is thought to exist as minor surface coatings on the quartz grains.

Another possible component of the $\mathrm{pH}$ buffering in this system may be occurring due to the silicate dissolution, which was made evident by the moderately higher concentrations of Si. In comparison to Experiment 1, baseline concentrations of Si match relatively well to those from the unheated phase of Experiment 2 and reach $6 \mathrm{mg} / \mathrm{L}$ at $3.0 \mathrm{~m}$ while a peak of $8.8 \mathrm{mg} / \mathrm{L}$ was also noted at $1.2 \mathrm{~m}$ (Figure 21). PHREEQC modelling results indicate that the SI for quartz is between 0 and -1 for the length of the column, while the $\mathrm{SI}$ for $\mathrm{SiO}_{2(\mathrm{am})}$ remains between -1 and 2. Knowing the relationship between Si solubility, temperature and $\mathrm{pH}$, these results indicate that there is dissolution of quartz occurring due in part from the acidity generated during pyrite oxidation and are creating conditions where these silicate minerals are undersaturated.

Trends from Week 1 to Week 10 of the aerobic heated column experiment show that quartz sand and pyrite underwent temperature influenced dissolution reactions. These reactions were likely due to increased rates of water-rock interactions, which lead to the subsequent evolution of $\mathrm{pH}$ and $\mathrm{DO}$, as well as the release of constituents including $\mathrm{Al}, \mathrm{Ca}, \mathrm{Cu}, \mathrm{Fe}, \mathrm{Mg}, \mathrm{Mn}, \mathrm{Ni}, \mathrm{S}, \mathrm{Si}$, and $\mathrm{Zn}$.

As the concentration of DO was relatively high $(4-5 \mathrm{mg} / \mathrm{L})$ within the input column water, dissolution of pyrite proceeded rapidly over the duration of the aerobic experiment (Figure 14). Furthermore, the observed decrease in DO within the heating section can be attributed to the consumption of $\mathrm{O}_{2(\mathrm{aq})}$ by pyrite oxidation. Similarly, the decrease in $\mathrm{pH}$ is likely a result of oxidation and increasing $\mathrm{H}^{+}$concentration which is made evident in reaction 5.4. 
Reaction 5.4 also assumes that sulfoxy anions (sulfite and thiosulfate) generated from the pyrite dissolution rapidly oxidize to sulfate during the dissolution of pyrite. Observations from the aerobic experiment align with this reaction mechanism as $\mathrm{SO}_{4}$ is shown to account for approximately all the total S concentration while consistently low quantities $(<25 \mu \mathrm{g} / \mathrm{L})$ of $\mathrm{HS}^{-}$ were measured.

There has been indication that the first overall step in the dissolution of the pyrite mineral surface with respect to sulfur compounds, is the oxidation of sulfide to neutral sulfur $\left(S^{0}\right)$ - which can refer to products including elemental sulfur $\left(\mathrm{S}^{0}\right)$, polysulfides $\left(\mathrm{FeS}_{\mathrm{n}}\right)$ and metal-deficient sulfide $\left(\mathrm{Fe}_{1-\mathrm{x}} \mathrm{S}_{2}\right)$ (Nordstrom, 1982; Tao et al., 2003).

The results of electrochemical studies by Tao et al. (2003) suggest that the oxidation reaction with pyrite is likely to produce an initial hydrophobic sulfur species such as polysulfide or metaldeficient sulfide in alkaline solutions. Although the presence of microbial communities were not investigated as part of this research and cannot be entirely ruled out, it is believed that the inorganic mechanisms related to sulfide production lead to the observed sulfide concentrations within this system. Additional support for this conclusion is also based on the interpretations of Nesbit at al. (1988) who indicates that when pyrite is fractured, the S-S bonds are ruptured and subsequently produce $\mathrm{S}^{-1}$ species, which become reduced to monosulfide $\left(\mathrm{S}^{2-}\right)$ during relaxation through oxidation of surface $\mathrm{Fe}^{2+}$ ions.

The primary reduced species that is known to be a direct by-product of this pyrite dissolution is $\mathrm{Fe}^{2+}$ which undergoes further oxidation in aerobic conditions to $\mathrm{Fe}^{3+}$ according to reaction 5.5. Results of the heated experiment indicate that the concentration of $\mathrm{Fe}^{2+}$ was less than $0.15 \mathrm{mg} / \mathrm{L}$ while total Fe was greater $1.0 \mathrm{mg} / \mathrm{L}$ at both $1.5 \mathrm{~m}$ and $3.0 \mathrm{~m}$ by Week 8 , which strongly suggest that $\mathrm{Fe}^{3+}$ remains as the dominant $\mathrm{Fe}$ species (Figure 18). 
Overall concentrations of $\mathrm{Mn}$ in the pyrite were relatively low; however, the aqueous concentration exhibits a slight increase over the extent of the heated experiment and indicates that it was liberated as a result of pyrite oxidation (Figure 19). Although redox speciation was not performed, the subsequent oxidation of $\mathrm{Mn}^{2+}$ to $\mathrm{Mn}^{3+}$ was also expected to occur.

Precipitation of $\mathrm{Mn}^{3+}$ and $\mathrm{Fe}^{3+}$ as oxyhydroxide minerals in the aerobic system is likely due to their low solubility above pH 2.5 (Nordstrom, 2011; Karapinar, 2016). The hydrolysis reaction that produces the more abundant Fe-oxyhydroxide mineral can be expressed as:

$$
\mathrm{Fe}^{3+}+3 \mathrm{H}_{2} \mathrm{O} \rightarrow \mathrm{Fe}(\mathrm{OH})_{3(\mathrm{am})}+3 \mathrm{H}^{+}
$$

Visual observations of the column material after conducting Experiment 2 indicate that quartz grains were stained in a rust coloured precipitate which appeared to intensify after $\sim 1.0 \mathrm{~m}$. PHREEQC model results indicate that the SI for ferrihydrite $\left(\mathrm{FeOOH} \cdot 0.4 \mathrm{H}_{2} \mathrm{O}\right)$ was at saturation at $1.5 \mathrm{~m}$ during Week 1 and Week 5 of the heated experiment (Figure 34). Although Fe concentrations were highest during Week 10 and reached above $1.0 \mathrm{mg} / \mathrm{L}$ after $1.0 \mathrm{~m}$ in the column, the coincident decrease in $\mathrm{pH}$ resulted in ferrihydrite to become under saturated within the system. In this context, it appears that ferrihydrite underwent dissolution in the moderately acid conditions and caused the rapid increase in aqueous Fe concentration. This rationale is also supported by PHREEQC results which indicate that SI for this mineral was between -2.5 and 8.0 throughout the column during Week 10 . 


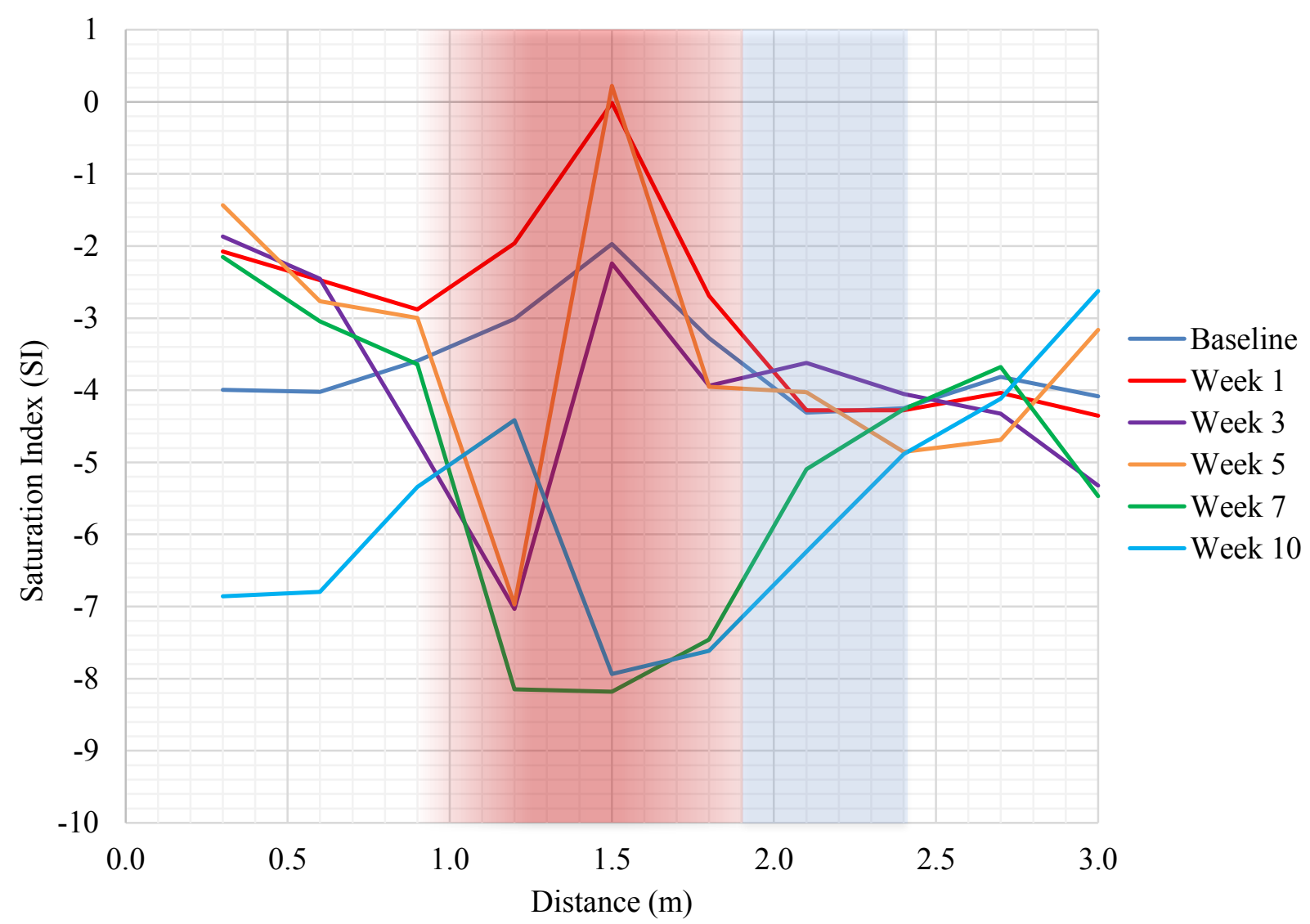

Figure 34. Modelled ferrihydrite saturation indices over the length of the column during aerobic unheated ('Baseline') conditions and heated (Week 1 to Week 10) conditions of Experiment 2.

The production of Fe-oxyhydroxide precipitates over time may have also contributed to the overall decreasing trend in $\mathrm{SO}_{4}$ concentration throughout the experiment. Similar studies by Grundle and Delwiche (1993), and Rose and Elliot (1998) have demonstrated the sorption ability of Fe-oxyhydroxide minerals to sorb oxyanions such as sulfate, and appears to provide a reasonable mechanism as visual and geochemical characteristics generally support their presence.

Increasing concentrations of dissolved $\mathrm{Al}, \mathrm{Cu}, \mathrm{Ni}$ and $\mathrm{Zn}$ over the course of the aerobic experiment were also attributed to pyrite dissolution as these constituents were generally found 
as part of the pyrite composition (Figure 18 and Figure 19). Although Ni was not reported as one of the primary trace elements, it was detected in some mineral grains and its release is consistent with the reaction mechanism. Trends throughout the experiment point to specific times at which pyrite underwent rapid oxidation and caused a surge in concentration of these elements. Interestingly, these elements reached the highest concentrations at $3.0 \mathrm{~m}$ from column input which suggests that they were relatively mobile within the substrate and were transported from the heating section. Peak concentrations also align well with similar spikes in S concentration and verifies that this was occurring as a result of pyrite dissolution.

Calcium and magnesium concentrations also showed moderate increases at times when peak $\mathrm{S}$ was produced and provide further support that there were likely carbonate minerals present within the system. The presence of these minerals could be due to minor carbonate coatings on the quartz sand grains and generally, these results signifies a minor amount of acid buffering capacity was generated from pyrite oxidation and Fe-oxyhydroxide precipitation. This can be rationalized further as the $\mathrm{pH}$ decrease within the heating section during Week 8 corresponds to an increase in concentration of $\mathrm{Ca}$ and $\mathrm{Mg}$ during Week 10 at $3.0 \mathrm{~m}$ within the column (Figure 20).

Generally, Si concentrations were shown to be lower than baseline conditions by roughly $2 \mathrm{mg} / \mathrm{L}$ to $7 \mathrm{mg} / \mathrm{L}$, and lower than the heated phase of Experiment 1 by approximately $10 \mathrm{mg} / \mathrm{L}$ to 20 $\mathrm{mg} / \mathrm{L}$. Some instances were noted where Si was higher during the heated phase than the unheated phase of Experiment 2; however, these primarily occurred during Week 1 and Week 5 (Figure 21). As these increases in Si were noted at similar times of increases to $\mathrm{S}$ and metals, this likely indicates that quartz is also providing $\mathrm{pH}$ buffering capacity. 
Based on the evidence of Si production at higher temperatures in Experiment 1, the dissolved concentrations were expected to be similar during Experiment 2. However, the observed differences for $\mathrm{Si}$ between each experiment can be likely attributed to changes in $\mathrm{pH}$, which is supported by the PHREEQC results. Additional control on Si concentrations may also include sorption by Fe oxyhydroxide minerals, which has been demonstrated as a primary mechanism where both components exist (Carlson and Schwertmann, 1981; Davis et al., 2001).

Another important aspect to consider with abundance of $\mathrm{Si}$ in this system is the co-precipitation reaction that can occur with $\mathrm{Fe}^{3+}$, which has been recognized in previous studies to favour the production of silica-ferrihydrite at neutral pH (Schwertmann and Thalmann, 1979; Pokrovski et al., 2003; Kinsela et al., 2016). Given that the presence of both of these aqueous constituents has been established as a component within this system, it is believed that silica-ferrihydrite was precipitated under aerobic conditions. Furthermore, silica-ferrihydrite has been shown to have a retarding effect on the oxidation rate of $\mathrm{Fe}^{2+}$, while at the same time, acting as a surface site for $\mathrm{Fe}^{2+}$ to sorb (Kinsela et al., 2016). Based on this information, it would provide insight as to the overall decrease in $\mathrm{Fe}^{2+}$ concentration in comparison to unheated results (Figure 17).

In the case of $\mathrm{As}, \mathrm{Pb}$ and $\mathrm{Se}$ that were found as trace elements in the pyrite, it was originally hypothesized that a small concentration would be present within the column. Although the detection limits of the ICP-OES analysis were not low enough to elucidate their actual concentrations within the column pore water, their complete absence cannot be ruled out. It is likely that low concentrations of these elements existed in solution and may have been coprecipitated and/or sorbed onto amorphous Fe and Mn-oxyhydroxide minerals. 


\section{Anaerobic Phase}

In contrast to the aerobic phase, primary trends from the anaerobic phase point to the production of $\mathrm{Fe}^{2+}$ and $\mathrm{HS}^{-}$species, as well as the sorption of trace metals. It is also of relevance to note that although the concentration of dissolved organic carbon (DOC) was not measured during both experiments, microbially mediated processes are an unlikely control within this system as the three known components include only quartz, pyrite and deionized water. Without a primary electron donor necessary for these biotic processes to take place, their influence on particular reactions cannot be reasonably assumed.

The increases observed in $\mathrm{Fe}^{2+}$ and $\mathrm{HS}^{-}$during the anaerobic phase can be explained by further dissolution of pyrite. Dissolved oxygen concentrations with the heating section appeared to fluctuate less than other sections of column which show an overall decline in DO by approximately $2 \mathrm{mg} / \mathrm{L}$ between Week $1(\sim 5 \mathrm{mg} / \mathrm{L})$ and Week $7(\sim 3 \mathrm{mg} / \mathrm{L})$. Trends from Week 3 and Week 7 show a subtle decrease in DO over the length of the column, and suggests that there was consumption within the heating section from pyrite oxidation (Figure 14).

With DO concentrations at $\sim 5 \mathrm{mg} / \mathrm{L}$ during Week 1 , this would still be able to cause oxidative dissolution of the pyrite as similar observations were noted for the aerobic phase. However, as DO decreases to $\sim 3 \mathrm{mg} / \mathrm{L}$ to Week 7 due to more effective removal, it is apparent that the rate of oxidation is also reduced, both with respect to pyrite as well as with reaction products, $\mathrm{Fe}^{2+}$ and $\mathrm{HS}^{-}$. Therefore, this decrease in available DO is likely responsible for the higher concentrations observed for these reduced species in comparison to the aerobic phase due to the lower redox potential. This rational is also supported by the overall decrease in sulfate concentration and increase in $\mathrm{pH}$, which aligns with the mechanisms of reaction 5.4. However, the adsorption 
effects of sulfate onto Fe-oxyhydroxide surfaces may also have a continued effect from the aerobic phase and could play a role in the fate of $\mathrm{SO}_{4}$ during transport.

Interestingly, trends in total $\mathrm{Fe}$ concentration indicate that there is a rapid increase in the heating section during Week 2 that surpasses concentrations from the aerobic phase by $\sim 2 \mathrm{mg} / \mathrm{L}$ (Figure 18). If we consider the Pourbaix diagram for Fe (Appendix I), it is possible to note that the decrease in $\mathrm{DO}$ results in a reduction in $\mathrm{pE}$, and subsequently favours $\mathrm{Fe}^{2+}$ as the most stable species. Observations are generally consistent with interpretations from Week 10 of the aerobic phase which suggest that Fe-oxyhydroxide undergoes dissolution from the moderately acidic $\mathrm{pH}$ $(<4)$ conditions. However, the rapid increase in Fe during Week 2 in the anaerobic phase is also likely due the cumulative effects of additional factors such as $\mathrm{Fe}^{2+}$ desorption from the silicaferrihydrite and minor pyrite oxidation. Although there is little support in the literature that addresses the dissolution and solubility of silica-rich ferrihydrite, it was assumed that the characteristics are similar to that of silica-deficient ferrihydrite and therefore would be stable at $\mathrm{pH}$ greater than 3. It should also be noted that the reductive dissolution of silica-ferrihydrite is not likely responsible for these observations since this reaction is generally known to occur in the presence of organic matter (Schwertmann, 1991).

This distinction of the abiotic system is important to consider when assessing the results of $\mathrm{Si}$ as there was an overall increase in concentration over the course of the anaerobic phase and not only in Week 2 when $\mathrm{pH}$ conditions were sub-neutral (Figure 21). Because it has been established that pyrite oxidation rates decreased under low DO conditions, the increase in Si was likely due to desorption from the Fe-oxyhydroxide. In addition, Si concentrations were likely influenced by the lower $\mathrm{Fe}^{2+}$ oxidation rate and subsequent discontinuation of silica-ferrihydrite coprecipitation. Bonte et al. (2014) indicate that sorption of Si also decreases with increasing 
temperature, and supports the observations made in the anaerobic phase of Experiment 2. Additionally, in comparison to Week 10 of the aerobic phase, PHREEQC model results for the SI of quartz and $\mathrm{SiO}_{2(\mathrm{am})}$ during Week 8 of the anaerobic phase indicate that the degree of saturation is relatively similar (Figure 35).

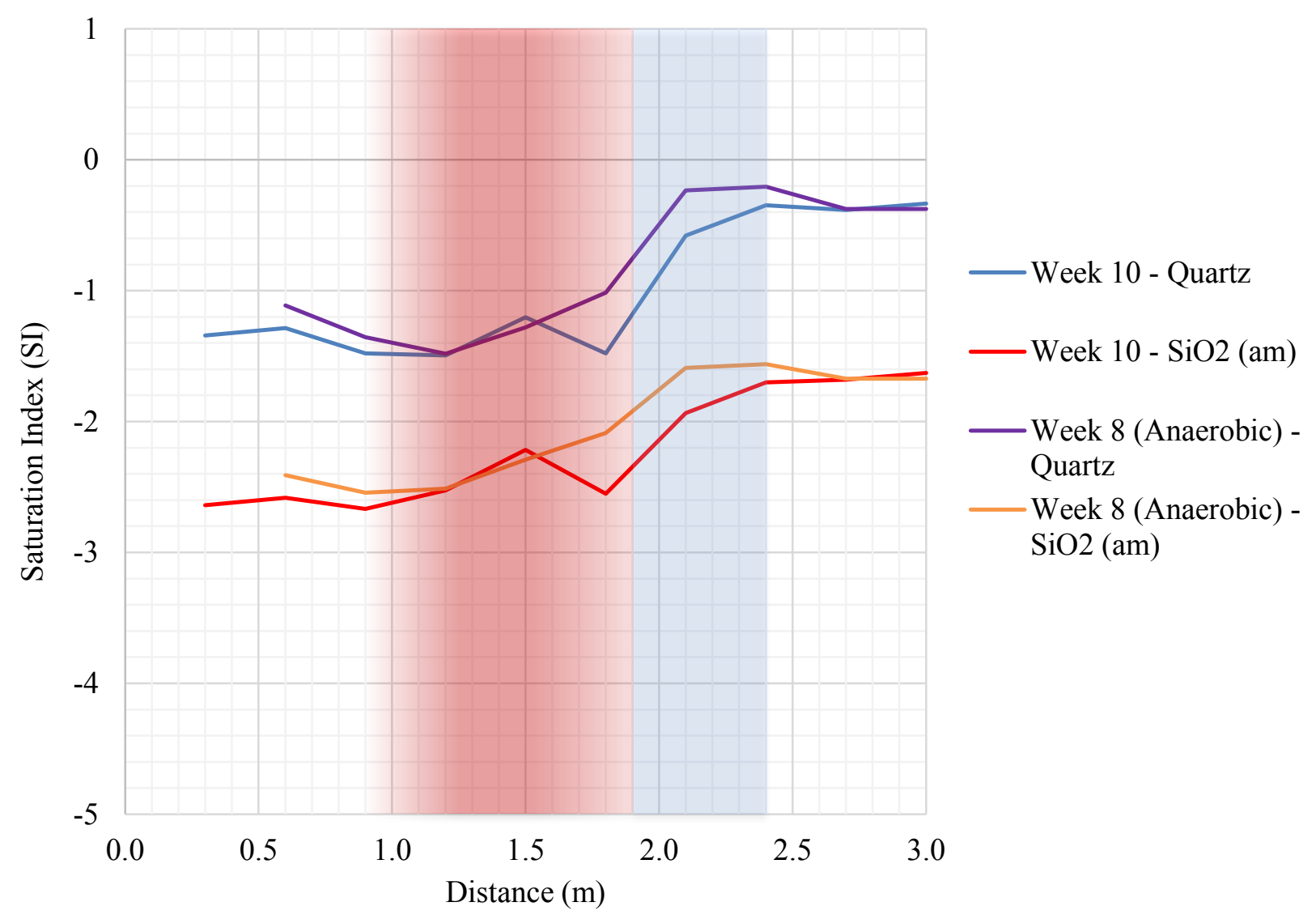

Figure 35. Modelled quartz and $\mathrm{SiO}_{2(\mathrm{am})}$ saturation indices over the length of the column during heated aerobic (Week 10) and anaerobic (Week 8) conditions of Experiment 2.

Mobilization of metals, primarily $\mathrm{Mn}, \mathrm{Ni}$ and $\mathrm{Zn}$, was also evident during the anaerobic experiment. Generally, the concentrations of these metals increased initially at locations within and downgradient from the heating section in Week 2 and remained above detection limits during Week 8 (Figure 19). These increases are generally consistent with the $\mathrm{Fe}$ and $\mathrm{Mn}$ 
oxyhydroxide dissolution. However, by the final week of the anaerobic experiment, these dissolved metals were slightly above or below detection limits indicating that only trace quantities were being liberated back into solution. It is suspected that continued pyrite dissolution is still able to produce these low concentrations of these metals even with decreased DO conditions.

Similarly to the observations made with dissolved metals, minor releases of $\mathrm{Ca}, \mathrm{K}, \mathrm{Mg}$ and $\mathrm{Na}$ were shown during Week 2 of the anaerobic experiment within and downgradient from the heating section, which were also attributed to desorption. Additionally, since the aerobic phase did not show any increases, it was hypothesized that detectable concentrations of $\mathrm{As}, \mathrm{Pb}$ and $\mathrm{Se}$ would also be encountered in the anaerobic phase. However, these elements were not detected which may be a result of the higher limits of detection associated with the ICP-OES analysis.

\subsection{Experiment 3}

\section{$\underline{\text { Sediment Characterization }}$}

Bulk mineralogy of the Cold Lake aquifer material generally supports the observations made by Fennel (2008), Javed et al. (2014), and Moncur et al. (2015b) in similar sediment characterization studies. Although Fennel (2008) and Javed et al. (2014) report that clay minerals (smectite and kaolinite) were detected in their sediment samples, none were found to be a component of the material in this study. Furthermore, all three studies indicated that sulfide minerals were present as a small portion; however, the analysis from the aquifer material used in this study did not reveal that sulfide minerals were present. It is possible that the XRD did not 
detect clay and/or sulfide minerals comprising $<1 \%$ of the total samples from this study, so their presence cannot be entirely ruled out.

ICP-OES results of the Cold Lake sediments used in this study indicate that values for As align reasonably well with Javed et al. (2016) who also looked at sediments of the Empress formation. In this case, two out of three samples contained concentrations less than detection limits $(5 \mu \mathrm{g} / \mathrm{g})$ and one sample contained $8 \mu \mathrm{g} / \mathrm{g}$, while Javed et al. (2016) reported average concentrations of $3.5 \pm 0.1 \mu \mathrm{g} / \mathrm{g}$. Furthermore, the results of this study are consistent with Moncur et al. (2015a) who reported average As concentrations of $6 \mu \mathrm{g} / \mathrm{g}$ from 216 Cold Lake sediment samples, as well as the average abundance of As in the upper continental crust, which ranges from $2 \mu \mathrm{g} / \mathrm{g}$ to $5.1 \mu \mathrm{g} / \mathrm{g}$ (Rudnick and Gao, 1995).

Interestingly, As bearing secondary precipitate was identified an on one of the grains from an SEM-EDX image of the Cold Lake sediments used in Experiment 3. Based on the quantitative results as well as description from previous reports by Fennel (2008), Javed et al. (2014) and Moncur et al. (2015b), the precipitate was very likely Fe oxyhydroxide. However, it should be noted that sulfide minerals are also a dominant carrier of As. Although sulfide and $\mathrm{Fe}$ oxyhydroxide minerals were not detected in the Cold Lake sediments from the analytical methods used in this study, there was an apparent relationship between As and $\mathrm{S}$ from the sediment Sample 1 (Table 8). Both of these constituents had the highest concentrations in the same sample, which demonstrates a distinct correlation in comparison to Sample 2 and Sample 3 where As was below detection limits and S concentrations were also lower than in Sample 1. Results from Sample 2 show that $\mathrm{Fe}$ and $\mathrm{Mn}$ are highest among the sample set and may point to more abundant $\mathrm{Fe}$ and Mn oxyhydroxides. 
The sequential extractions of $\mathrm{S}$ indicate that the most abundant phase was associated with the weakly adsorbed fraction. In contrast, the supernatant from Phase 1 and 2 showed relatively low concentrations of $\mathrm{Cu}, \mathrm{Fe}, \mathrm{Mn}$, and $\mathrm{Zn}$ (Table 10). In this case, adsorbed $\mathrm{S}$ is likely attributed to a surface bound fraction on amorphous Fe and Mn-oxyhydroxide minerals, along with minor amounts of $\mathrm{Cu}$ and $\mathrm{Zn}$. This higher proportion of adsorbed $\mathrm{S}$ is also reflected in the $\mathrm{SO}_{4}$ data from Experiment 3, which shows a rapid increase in concentration ( $>800 \mathrm{ppm}$ at $3.0 \mathrm{~m})$ during baseline conditions and early on in the heated experiment.

Sulfur within Phase $3 a$ (organic/carbonate fraction) and $3 b$ (amorphous sulfide mineral fraction) accounts for $9 \%$ and $6 \%$ of the average total $\mathrm{S}$, respectively. These fractions indicate that there is more $\mathrm{S}$ associated with carbonate minerals, which parallels the higher concentrations of $\mathrm{Ca}$ and Mg also found in this extraction phase.

In terms of $\mathrm{S}$ from the amorphous sulfide mineral fraction, there were none identified in the sediment characterization methods to validate their occurrence; however, Moncur et al. (2015b) noted that framboidal pyrite was present in sediments from aquifers in the CLBR basin. Framboidal pyrite is generally produced after crystallization from amorphous iron monosulfide (FeS), which could suggest the presence of similar minerals within the sediments from this study. Furthermore, the increased concentration of other metal(oid)s in the Phase 3a residual fraction including $\mathrm{Al}, \mathrm{As}, \mathrm{Cu}, \mathrm{Fe}, \mathrm{Mn}, \mathrm{Ni}$ and $\mathrm{Pb}$ provide support that these amorphous sulfide minerals may exist, in conjunction with more abundant amorphous Fe and Mn oxyhydroxides. In addition, the supernatant from Phase $3 \mathrm{~b}$ shows moderate concentrations of $\mathrm{Si}(1558 \pm 376 \mathrm{ppm})$ and $\mathrm{K}$ $(229 \pm 71 \mathrm{ppm})$, which is likely due to dissolution of silicate and phyllosilicate minerals, but is an unlikely source of $\mathrm{S}$ bearing minerals. 
The final $\mathrm{S}$ fraction in Phase $4 \mathrm{~b}$ indicates that there was pyritic $\mathrm{S}$ which comprised approximately $8 \%$ in Sample 2 and 3, and 27\% in Sample 1 (Table 9). Although no sulfide minerals were identified with the detection methods, these results indicate that they are likely present and potentially exist as framboidal pyrite, as described by Moncur et al. (2015b). Furthermore, notable concentrations of other constituents such as $\mathrm{As}, \mathrm{Cu}, \mathrm{Pb}$ and $\mathrm{Zn}$ from the pyrite are believed to reside in Phase 4a; however, due to analytical difficulty due to the addition of granular $\mathrm{Zn}$, this hypothesis could not be confirmed.

In comparison to the total $\mathrm{S}$ concentration obtained from the digested sediment samples, the cumulative $\mathrm{S}$ concentration from the sequential extraction is generally lower by roughly 100 to 1000 ppm (Table 8). Although direct comparisons between the samples can be made, overall trends suggest that all $\mathrm{S}$ components were not captured from the sequential extraction. The factors that could have caused this discrepancy could arise from the sediments in the sequential extractions being uncrushed, as well as oxidized sulfur species that could have been included in the residual Phase $4 \mathrm{~b}$. Sediments were left uncrushed to understand the sources of sulfur released in the column, so it is possible that crushed sediments would be able to access other $\mathrm{S}$ fractions from dissolved sulfur bearing minerals.

\section{Anaerobic Experiment}

Results from unheated anaerobic conditions in Experiment 3 indicate that $\mathrm{pH}$ was near-neutral $(\sim 7.2)$ while dissolved oxygen concentrations were consistently below $4 \mathrm{mg} / \mathrm{L}$ throughout the length of the column (Figure 25 and Figure 26). Calcium, $\mathrm{K}, \mathrm{Mg}, \mathrm{Na}$ and $\mathrm{S}$ concentrations were shown to increase with distance, and by $3.0 \mathrm{~m}$ were substantially higher than initial input 
quantities (Figure 31). In the case of S, speciation analysis demonstrates that sulfate is the most abundant species, while sulfide concentrations remained relatively low $(<0.025 \mathrm{mg} / \mathrm{L})$. Processes that were likely responsible for producing these effects are consistent with surface complex desorption, as well as minor carbonate mineral dissolution.

In comparison to the field tests conducted by Fennel (2008) and the thermal column experiments by Bonte et al. (2013b), baseline concentrations of $\mathrm{Ca}, \mathrm{K}, \mathrm{Mg}, \mathrm{Na}$ and $\mathrm{SO}_{4}$ during Experiment 3 are higher by approximately 1 to 2 orders of magnitude within the column at ambient temperature. The source of these high concentrations is believed to be a function of groundwater geochemistry and to some extent, water-rock interactions that had taken place during the 17-year sediment storage time. Since the sediments had been stored without being fully dried, it is possible that oxidation and/or dissolution reactions may have occurred due to the change in redox conditions. In addition, these reactions could have caused subsequent implications on $\mathrm{S}$ and Fe speciation as well as the stability of particular minerals such as framboidal pyrite, which had been identified as a component of the sediment mineralogy in previous studies by Fennell (2008), Moncur et al. (2015a) and Moncur et al. (2015b).

Data presented by Moncur et al. (2015a) provides clarification to this apparent discrepancy, and shows that groundwater parameters $\mathrm{pH}, \mathrm{DO}, \mathrm{Fe}, \mathrm{K}, \mathrm{Mg}, \mathrm{Na}, \mathrm{Si}$ and $\mathrm{SO}_{4}$ within the Empress Formation are quite similar to those of in the column. Moncur et al. (2015a) suggests that the generally high concentrations for most of the dissolved constituents was attributed to active weathering of surficial sediments in the shallow units and subsequent recharge to aquifers coupled with reductive dissolution of minerals in the deeper groundwater. In comparison to these field interpretations, the geochemical data from the column in Experiment 3 could suggest that there was a minor influence from reactions that occurred while the sample was being stored. 
However, after careful review of the data from this experiment, Experiment 1 and 2, and Moncur et al. (2015a), there is also a strong indication that carbonate and silicate minerals are a dominant control on the observed geochemical response through $\mathrm{pH}$ buffering reactions during sulfide mineral oxidation. Further insights from Al concentration could offer more support for this notion, though this parameter was not analyzed.

Differences between data presented by Moncur et al. (2015a) and Experiment 3 were evident for $\mathrm{Ca}$, which was higher by $\sim 300 \mathrm{mg} / \mathrm{L}$ in the column; and As, which was below detection limit $(0.01 \mathrm{mg} / \mathrm{L})$ in the column. Although it is possible that As concentrations could align with the 1 $\mu \mathrm{g} / \mathrm{L}$ to $60 \mu \mathrm{g} / \mathrm{L}$ range in values presented by Moncur et al. (2015a), the analytical detection limits used in this study were unable to provide this confirmation. Nevertheless, the results of this comparison demonstrate that the unheated column experiment provides a reasonable analogue for natural conditions.

Following the unheated experiment, there was a successive decrease in concentration for $\mathrm{Ca}, \mathrm{K}$, $\mathrm{Mg}, \mathrm{Na}$ and $\mathrm{S}$ from Week 1 to Week 7 of the heated experiment, which likely indicates depletion of the adsorbed constituents (Figure 31). In addition. concentrations of $\mathrm{Fe}$ and $\mathrm{Ni}$ remained below $0.04 \mathrm{mg} / \mathrm{L}$, while increases in concentrations were observed for $\mathrm{Mn}, \mathrm{Si}, \mathrm{Zn}$ and sulfide. The increase in $\mathrm{Si}$ is consistent with the influence of temperature on quartz solubility which resembles results obtained in Experiment 1. Influences from dissolution of additional silicate minerals such as albite and muscovite likely contributed to the observed differences between the two experiments. This rationale corresponds with the results of previous experiments which have demonstrated that the dissolution rate for both minerals increases with higher temperatures (Gruber et al., 2016; Lammers et al., 2017). 
The increases noted with respect to $\mathrm{Mn}, \mathrm{Zn}$ and sulfide could point the possible reactions involving sulfide mineral dissolution. The first increase for $\mathrm{Zn}$ and $\mathrm{HS}^{-}$during Week 1 could indicate minor oxidation and dissolution of sulfide minerals, or alternatively, could suggest desorption from grain surfaces within the heating section. The presence of sphalerite or amorphous $\mathrm{ZnS}$ was not eluded to in previous sediment characterization reports by Fennel (2008), Javed et al. (2014), and Moncur et al. (2015b), and therefore is an unlikely component in this study as well.

Based on the results from Experiment 2 where the abundance of pyrite was similar to the proportions reported by Javed et al. (2014), the Fe concentrations observed during the anaerobic phase were primarily attributed to the dissolution of Fe-oxyhydroxide precipitates due to low $\mathrm{pH}$ conditions. As the Fe concentrations in Experiment 3 remains consistently low, this suggests that such processes are not active and do not favour the desorption of $\mathrm{Zn}$ and $\mathrm{HS}^{-}$. As such, the release of these constituents is more likely a function of pyrite or amorphous sulfide dissolution.

If pyrite was oxidizing and dissolving in Experiment 3, it should also be expected that there would be some indication of increasing Fe concentration. Although data from ICP-OES shows that $\mathrm{Fe}$ concentrations remain low, the speciation analysis indicates that concentrations of $\mathrm{Fe}^{2+}$ are produced during baseline conditions and in Week 7 of the heated phase (Figure 28). Discrepancies between both reported Fe concentrations is likely due to the differences in the dissolved and total fractions.

Therefore, given that increases in sulfide and minor sulfate and metals ( $\mathrm{Fe}, \mathrm{Mn}, \mathrm{Ni}$ and $\mathrm{Zn}$ ) concentrations pointed to the occurrence of pyrite oxidation in aerobic phase of Experiment 2, it is believed that similar mechanisms are likely responsible for the generally comparable observations in Experiment 3. Additional support for this rationale is made evident by the subtle 
decrease in DO concentration within the heating section and corresponding decrease in $\mathrm{pH}$ during Week 1 which is characteristic of sulfide mineral oxidation (Figure 25 and Figure 26).

With respect to the increase observed for $\mathrm{Mn}$, there is a gradual increasing trend over the distance of the column, which suggests that it is also independent of the reactions involving sulfide and $\mathrm{Zn}$ as these constituents display obvious peaks in concentration (Figure 30). However, a spike in Mn was noted at $1.2 \mathrm{~m}$ during unheated conditions and the observed increase downgradient of this location could be due to transport, which is supported by the fact that $\mathrm{Mn}$ concentration at $3.0 \mathrm{~m}$ aligns with the concentration observed during the spike. Overall, Mn concentration remains below $1.0 \mathrm{ppm}$ and generally aligns with the adsorbed fraction observed from the sequential extraction. Based on these results, it is likely that the increase is Mn is due to desorption from sediment surfaces; however, the influence of sulfide oxidation and dissolution on the total Mn concentration should be considered as well.

Comparisons between results from Week 5 and Week 7 generally indicate that $\mathrm{Ca}, \mathrm{Fe}, \mathrm{K}, \mathrm{Mg}$, $\mathrm{Mn}, \mathrm{Na}, \mathrm{Ni}, \mathrm{S}$ and $\mathrm{Si}$ have all reached steady state conditions with respect to the heated system. Conversely, $\mathrm{Zn}$ shows noticeable changes between the same period that includes a spike in concentration at $3.0 \mathrm{~m}$ during Week 5 , and an increase in concentration within the heating section at $1.5 \mathrm{~m}$ in Week 7. Although no other constituents are shown to follow the same trend, there is a change between $\mathrm{pH}$ between Week 5 and Week 7 which is follows a decrease from 8.8 to 8.4 at $1.5 \mathrm{~m}$. Similarly, alkalinity between these two weeks decreases within the heating section at $1.2 \mathrm{~m}$ and $1.8 \mathrm{~m}$ (Figure 24). These fluctuations indicate that there are still acid buffering reactions occurring within the heating section, which is resulting in carbonate and silicate mineral consumption, a decline in $\mathrm{pH}$ and a subsequent release of $\mathrm{Zn}$. 
There was generally an expectation that an increase in As concentration within the pore-water would be observed as temperature increased; however, this constituent was below detection limits in all samples. Reasons why this might have occurred could be due to the combined absence of clay minerals, which Fennel (2008) noted to be dominant source of As within test sediments and undergo dissolution when subjected to high temperatures. Additionally, Moncur et al. (2016a) shows that the natural groundwater concentration of As within the Empress Formation aquifer was between $1 \mu \mathrm{g} / \mathrm{L}$ to $60 \mu \mathrm{g} / \mathrm{L}$; however, the detection limits used in this study $(0.01 \mathrm{mg} / \mathrm{L})$ would not be able to accurately determine if these were present on the lower end of this range.

Generally, the data from this experiment shows that temperatures of $25^{\circ} \mathrm{C}$ to $90^{\circ} \mathrm{C}$ are able to cause constituent leaching to occur in aquifer sediments from the Empress Formation. Furthermore, the column experiment provides insight into potential reactions and mechanisms that would take place in natural conditions and when exposed to higher temperature conditions. Although the constraints applied in Experiment 3 differ from those in similar thermal column experiments performed by Bonte et al. (2013), the overall behavior of constituent concentrations between both studies bare a close resemblance, particularly with respect to $\mathrm{pH}$, alkalinity, $\mathrm{SO}_{4}$, $\mathrm{Ca}, \mathrm{Mg}, \mathrm{K}$ and Si.

In contrast, the results from Experiment 3 were shown not to reflect the field observations made by Fennel (2008) for $\mathrm{Ca}, \mathrm{Mg}, \mathrm{K}, \mathrm{Na}, \mathrm{SO}_{4}, \mathrm{As}, \mathrm{Fe}$ and $\mathrm{Mn}$; however, some similarities were apparent for Si and HS. The discrepancies noted are likely a function of the differences between redox potential, the sediment composition and quality, as well as the overall groundwater geochemistry within the study site. The differences also highlight the need for further research on this subject through field and laboratory investigations. However, the similarities with respect 
to silica and sulfide may point to comparable reactions found in column Experiment 3 which were identified as sulfide mineral oxidation and $\mathrm{pH}$ buffering from silicate mineral dissolution. 


\section{Chapter 6 - Conclusions}

The heated column experiments and tracer tests conducted in this study were able to effectively show that hydrogeochemical changes occur in the porewater of different aquifer materials when exposed to temperatures between $80^{\circ} \mathrm{C}$ and $90^{\circ} \mathrm{C}$. Comparisons between anaerobic and aerobic systems were also able to demonstrate the different reactions that can occur in oxygen deprived and oxygen rich conditions.

Tracer tests indicate that flow within the column is directly influenced by the higher temperatures within heating section which caused increases in dispersion and dispersivity by approximately one to two orders of magnitude in each material type. Flow within the heating section appeared to undergo changes with respect to hydraulic conductivity, as this parameter is inherently linked to viscosity and density of the fluid. Calculations of a Reynolds number also show that flow continued to behave according to Darcy's law.

The results of the first experiment indicate that the geochemistry of the column porewater shifted from a state of quasi-equilibrium with quartz to amorphous $\mathrm{SiO}_{2}$ after heating. Concentrations of Si within the column were found to be a function of temperature, $\mathrm{pH}$, and residence time, which were determined to act as primary controls on mineral solubility of the quartz sand. Over the course of the heated experiment, Si concentrations and $\mathrm{pH}$ gradually decreased proportionately, as the surface bound fraction of $\mathrm{Si}$ was likely removed during heating.

In Experiment 2, $\mathrm{Ca}, \mathrm{Cu}, \mathrm{Fe}, \mathrm{Mg}, \mathrm{Mn}, \mathrm{Ni}, \mathrm{S}, \mathrm{Si}$ and $\mathrm{Zn}$ were liberated at temperatures of $90^{\circ} \mathrm{C}$ from the quartz sand and pyrite material under aerobic conditions. Overall decreasing trends for dissolved oxygen and $\mathrm{pH}$ were indicative of oxidative-dissolution of pyrite. Support of this mechanism was evident through the increase in $\mathrm{SO}_{4}$ concentration and observed $\mathrm{Fe}$ stained grain 
coatings, while minor concentrations of sulfide and ferrous iron were present. Particular increases in Si were also attributed to buffering reactions within the column and appeared to maintain the $\mathrm{pH}$ conditions of the column above 4. Results of the anaerobic phase of Experiment 2 indicate that both reduced $\mathrm{S}$ and $\mathrm{Fe}$ species, $\mathrm{Si}$, and $\mathrm{pH}$ show marked increases after approximately eight pore-volume flushes. Concentrations of $\mathrm{Al}, \mathrm{Ca}, \mathrm{Cu}, \mathrm{Fe}, \mathrm{Mg}, \mathrm{Mn}, \mathrm{Ni}$ and $\mathrm{Zn}$ were shown to decrease. Observations from the anaerobic heated column experiment suggest that dissolution of Fe-oxyhydroxide at acidic $\mathrm{pH}$, slowed rates of sulfide mineral oxidation, and quartz dissolution are likely the dominant mechanisms.

Geochemical characterization of the aquifer material from Cold Lake, Alberta revealed that sediments were primarily comprised of quartz, calcite, muscovite and minor enstatite and sericite, that are typical of a glacial deposit. Visual observation confirmed the presence of secondary Fe precipitates while SEM-EDX analysis revealed that As was contained in $\mathrm{Fe}$ minerals.

Sequential extractions of sulfur from the sediments demonstrated that the highest proportion of $\mathrm{S}$ was found in the weakly adsorbed/water soluble fraction followed by lesser amounts of pyritic, organic/carbonate bound, and amorphous sulfide fractions. Minor concentrations of $\mathrm{Fe}, \mathrm{Mn}$ and $\mathrm{Zn}$ were held within the adsorbed fraction while concentrations of $\mathrm{As}, \mathrm{Cu}, \mathrm{Ni}$ and $\mathrm{Pb}$ were associated with the organic and amorphous mineral fraction.

Results from Experiment 3 showed that $\mathrm{Ca}, \mathrm{K}, \mathrm{Mg}, \mathrm{Na}$ and $\mathrm{SO}_{4}$ increased by approximately one order of magnitude between $0.3 \mathrm{~m}$ to $3.0 \mathrm{~m}$ along the column during the anaerobic unheated phase at $25^{\circ} \mathrm{C}$. Based on the results of the sediment characterization results, Experiments 1 and 2, and previous field data, the increases in these constituents likely point to sulfide mineral oxidation and dissolution coupled with $\mathrm{pH}$ buffering from carbonate and silicate minerals. 
Between Week 1 and Week 7 of the anaerobic heated phase, concentrations of these constituents steadily declined and reached near steady state conditions. During this time, increases in concentration were noted for $\mathrm{Mn}, \mathrm{Si}, \mathrm{Zn}$ and $\mathrm{HS}^{-}$. Liberation of $\mathrm{Mn}, \mathrm{Zn}$ and sulfide is believed to be a product of minor sulfide mineral oxidation in conjunction with low DO concentrations while the increases for $\mathrm{Si}$ were shown to resemble the dissolution of quartz as well as additional silicate minerals at higher temperatures.

Although no increases in As concentration were observed within this heated column experiments, important mechanisms of other constituents were revealed. In addition, the sequential extractions of sulfur provide detailed information on the different fractions that are associated with components of the sediments. In particular, trends for $\mathrm{Zn}$ showed that it continued to be liberated from locations within the heating section during multiple weeks of the experiment.

Insights into the controlling mechanisms of As release from these sediments could be complimented by extending the length of the experiment time, performing grain analysis, and developing a reactive transport model. Additionally, further column experiments could be conducted using higher temperatures as well as using fresh sediment samples from different aquifer units within the CLBR. Ultimately, once a better understanding of these processes is attained, a field monitoring program can be conducted to clearly identify and explain how heat, transport, and hydrogeochemistry interact dynamically in these systems. 


\section{References}

Allison, J.D., Brown, D.S., Novo-Gradac, K.J. (1991). MINTEQA2, a geochemical assessment data base and test cases for environmental systems. Report EPA/600/3-91/-21.US EPA, Athens, GA.

Alvarez, J., and Han, S. (2013). Current Overview of Cyclic Steam Injection Process. Journal of Petroleum Science Research, 2(3): pp.116-127.

Andriashek, L.D., and Fenton, M.M. (1989). Quaternary stratigraphy and surficial geology of the Sand River area 73L. Alberta Research Council, Alberta Geological Survey and Terrain Sciences Department.

Andriashek, L.D. (2000). Geochemistry of Selected Glacial and Bedrock Geologic Units, Cold Lake Area, Alberta. Alberta Energy and Utilities Board, Alberta Geological Survey.

Andriashek, L.D. (2003). Quaternary Geological Setting of the Athabasca Oil Sands (In Situ) Area, Northeast Alberta. Alberta Energy and Utilities Board, Alberta Geological Survey.

Appelo, C.A.J., and Postma, D. (2005). Geochemistry, groundwater and pollution. $2^{\text {nd }}$ ed. A.A. Balkema, Leinden, ISBN 04-1536-428-0.

Argun, M.E., Dursun, S., Ozdemir, C., Karatas, M. (2007). Heavy metal adsorption by modified oak sawdust: Thermodynamics and kinetics. Journal of Hazardous Materials, 141: pp.77-85.

Blake, R.E. and Walter, L.M. (1999). Kinetics of feldspar and quartz dissolution at $70-80^{\circ} \mathrm{C}$ and near-neutral pH: Effects of organic acids and $\mathrm{NaCl}$. Geochimica et Cosmochimica Acta, 63: pp.2043-2059.

Bonte, M., Stuyfzand, P.J., Hulsmann, A., Van Beelen, P. (2011). Underground thermal energy storage: environmental risks and policy developments in the Netherlands and European Union. Ecology and Society, 16(1). URL: http://www.ecologyandsociety.org/vol16/iss1/art22/

Bonte, M., van Breukelen, B.M., Stuyfzand. P.J. (2103a). Environmental impacts of aquifer thermal energy storage investigated by field and laboratory experiments. Journal of Water and Climate Change, 4(2): pp.77-89.

Bonte, M., van Breukelen, B.M., Stuyfzand, P.J. (2013b). Temperature-induced impacts on groundwater quality and arsenic mobility in anoxic aquifer sediments used for both drinking water and shallow geothermal energy production. Water Research, 47: pp.5088-5100.

Bonte, M., Röling, W.F.M., Zaura, E., van der Wielen, P.W.J.J., Stuyfzand, P.J., van Breukelen, B.M. (2013c). Impacts of Shallow Geothermal Energy Production on Redox Processes and Microbial Communities. Environmental Science and Technology, 47: pp.14476-14484.

Bonte, M., Stuyfzand, P.J., van Breukelen, B.M. (2014). Reactive Transport Modeling of Thermal Column Experiments to Investigate the Impacts of Aquifer Thermal Energy Storage on Groundwater Quality. Environmental Science and Technology, 48: pp.12099-12107. 
Brady, P.V., and Walther, J.V. (1989). Controls on silicate dissolution rates in neutral and basic pH solutions at $25^{\circ} \mathrm{C}$. Geochimica et Cosmochimica Acta, 53(11): pp.2823-2830.

Brady, P.V., and Walther, J.V. (1990). Kinetics of quartz dissolution at low temperatures. Chemical Geology, 82: pp.253-264.

Butler, I.B., Schoonen, M.A., Rickard, D.T. (1994). Removal of dissolved oxygen from water: $a$ comparison of four common techniques. Talanta, 41(2): pp.211-215.

Carlson, L. and Schwertmann, U. (1981). Natural ferrihydrites in surface deposits from Finland and their association with silica. Geochimica et Cosmochimica Acta, 45(3): pp.421-425,427429.

Chandra, A.P. and Gerson, A.R. (2010). Review, The mechanisms of pyrite oxidation and leaching: A fundamental perspective. Surface Science Reports, 65: pp.293-315.

Chaudhary, K., Cardenas, M.B., Deng, W., Bennett, P.C. (2011). The role of eddies inside pores in transition from Darcy to Forchheimer flows. Geophysical Research Letters. 38(24): pp.1-6.

Chen, B., Xiao-quan, S., Dong-qing, S., Shi-fen, M. (1997). Nature of the HCl-soluble sulfate in the sequential extraction for sulfur speciation in soils. Journal of Analytical Chemistry, 357: pp.941-945.

Cho, W.J., Lee, J.O., Chun, K.S. (1999). The temperature effects on hydraulic conductivity of compacted bentonite. Applied Clay Science, 14(1-3): pp.47-58.

Chopra, S., Lines, L., Schmitt, D.R., Batzle, M. (2010). Chapter 1. Heavy-oil Reservoirs: Their Characterization and Production. Heavy Oils: Reservoir Characterization and Production Monitoring, Society of Exploration Geophysicists: pp.1-68.

Clark, I. (2015). Groundwater Geochemistry and Isotopes. CRC Press, Taylor \& Francis Group, ISBN 978-1-4665-9174-5.

CNRL (Canadian Natural Resources Limited), (2006). Primrose, Wolf Lake and Burnt Lake Annual Presentation to the EUB. Alberta Energy Regulator.

Davis, C.C., Knocke, W.R., Edwards, M. (2001). Implications of Aqueous Silica Sorption to Iron Hydroxide: Mobilization of Iron Colloids and Interference with Sorption of Arsenate and Humic Substances. Environmental Science and Technology, 35(15): pp.3158-3162.

Dhar, R.K., Zheng, Y., Stute, M., van Geen, A., Cheng, Z., Shanewaz, M., Shamsudduha, M., Hoque, M.A., Rahman, M.W., Ahmed, K.M. (2008). Temporal variability of groundwater chemistry in shallow and deep aquifers of Araihazar, Bangladesh. Journal of Contaminant Hydrology, 99: pp.97-111.

Domenico, P.A., and Schwartz, F.W. (1990). Physical and Chemical Hydrogeology. John Wiley \& Sons, Inc., ISBN 0-471-50744-X.

Drahota, P., and Filippi, M. (2009). Secondary arsenic minerals in the environment: A review. Environment International, 35(8): pp.1243-1255. 
Dusseault, M.B. (2001). Comparing Venezuelan and Canadian Heavy Oil and Tar Sands. Canadian International Petroleum Conference, Petroleum Society, Calgary, Alberta, Canada.

Færgestad, I.M. (2016). Heavy Oil. The Defining Series, Oilfield Review, Schlumberger.

Fennel, J.W. (2008). Effects of Aquifer Heating on Groundwater Geochemistry with a Review of Arsenic and its Mobility. Unpublished Ph.D. Thesis, University of Calgary, Calgary, Alberta.

Fennel, J.W. (2011). Groundwater in Alberta - An assessment of source, use and change. Alberta Water Research Institute.

Freeze, R.A., and Cherry, J.A. (1979). Groundwater. Prentice Hall Inc., Englewood Cliffs, New Jersey, ISBN 0-13-365312-9.

Giraldo, N.M., and MacMillan, G. (2016). Temperature Plume Migration in Aquifers: The necessary first step to geochemical evaluation of thermally-mobilized constituents. GeoConvention 2016, Calgary, Alberta, Canada.

Government of Alberta, (2014a). Domestic Well Water Quality in Alberta: 2002 - 2008 Characterization. Alberta Health, Health Protection Branch.

Government of Alberta (2014b). Domestic Well Water Quality in the Beaver River Basin: Drinking Water Quality and Human Health Assessment. Alberta Health, Health Protection Branch.

Government of Alberta (2017). Oil Sands Operations Map: Alberta's Oil Sands Projects and Upgraders. Resource Mapping and Analysis, Alberta Energy, February 2017.

Gruber, C., Kutuzov, I., Ganor, J. (2016). The combined effect of temperature and pH on albite dissolution rate under far-from-equilibrium conditions. Geochimica et Cosmochimica Acta, 186: pp. 154-167.

Grundle, T. and Delwiche, J. (1993). Kinetics of ferric oxyhydroxide precipitation. Journal of Contaminant Hydrology, 14: pp.71-97.

Hall, G.E.M., Gauthier, G., Pelchat, J-C., Pelchat, P., Vaive, J.E. (1996). Application of a sequential extraction scheme to ten geological certified reference materials for the determination of 20 elements. Journal of Analytical Atomic Spectrometry, 11: pp.787-796.

Health Canada (2006). Guidelines for Canadian Drinking Water Quality: Guidelines Technical Document - Arsenic. Water Quality and Health Bureau, Healthy Environments and Consumer Safety Branch, Health Canada, Ottawa, Ontario.

Holly, C., Mader, M., Soni, S., Toor, J. (2016). Oil Sands Production Profile: 2004 - 2014. Alberta Energy, Energy Technical Services, Resource Development Policy Division. Thakur N.K., and Rajput, S. (2011). Exploration of Gas Hydrates. Springer-Verlag Berlin Heidelberg. 
Ilgen, A.G., Rychagov, S.N., Trainor, T.P. (2011). Arsenic speciation and transport associated with the release of spent geothermal fluids in Mutnovsky field (Kamchatka, Russia). Chemical Geology, 288: pp.115-132.

Imperial Oil Resource Limited (Imperial Oil), (2017). Volume 6 - Supplemental Information Request 3: Environmental Impact Assessment Report and Environmental Protection and Enhancement Act, Health Risk Assessment. Alberta Energy Regulator.

International Energy Agency (2012). World Energy Outlook 2012. IEA Publications, Paris, France.

Javed, M.B., Kachanoski, G., Siddique, T. (2014). Arsenic fractionation and mineralogical characterization of sediments in the Cold Lake area of Alberta, Canada. Science of the Total Environment, 500-501: pp.181-190.

Javed, M.B., and Siddique, T. (2016). Thermally Released Arsenic in Porewater from Sediments in the Cold Lake Area of Alberta, Canada. Environmental Science and Technology, 50: pp.2191-2199.

Johnsen, T., Haluska, A., McLean, M. (2015). Thermal Effects and Quaternary Hydrogeology: Making Good Decisions in a Complex Geological Setting. GeoConvention 2015, Calgary, Alberta, Canada.

Kamei, G. and Ohmoto, H. (2000). The kinetics of reactions between pyrite and $\mathrm{O}_{2}$-bearing water revealed from in-situ monitoring of $\mathrm{DO}$, Eh and $\mathrm{pH}$ in a closed system. Geochimica et Cosmochimica Acta, 64(15): pp.2585-2601.

Karapinar, N. (2016). Removal of Heavy Metal Ions by Ferrihydrite: an Opportunity to the Treatment of Acid Mine Drainage. Water, Air and Soil Pollution, 227(193): pp.1-8.

Kim, M. (2014). A study on the adsorption characteristics of cadmium and zinc onto acidic and alkaline soils. Environmental Earth Sciences, 72(10): pp.3981-3990.

Kinsela, A.S., Jones, A.M., Bligh, M.W., Pham, A.N., Collins, R.N., Harrison, J.J., Wilsher, K.L., Payne, T.E., Waite, T.D. (2016). Influence of Dissolved Silicate on Rates of Fe(II) Oxidation. Environmental Science and Technology, 50: pp.11663-11671.

Knauss, K.G., and Wolery, T.J. (1988). The dissolution kinetics of quartz as a function of pH and time at $70^{\circ} \mathrm{C}$. Geochimica et Cosmochimica Acta, 52: pp.43-53.

Knudson, H.W., Juday, C., Meloche, V.W. (1940). Silicomolybdate method for silica. Industrial and Engineering Chemistry Analytical Edition, 12(5): pp.270-273.

Kocaman, A.T., Cemek, M., Edwards, K.J. (2016). Kinetics of pyrite, pyrrhotite, and chalcopyrite dissolution by Acidothiobacillus ferrooxidans. Canadian Journal of Microbiology, 62(8): pp.629-642.

Lammers, K., Smith, M.M., Carroll, S.A. (2017). Muscovite dissolution kinetics as a function of pH at elevated temperatures. Chemical Geology, 466: pp.149-158. 
Langmuir, D. (1997). Aqueous Environmental Geochemistry. Prentice Hall, New Jersey, ISBN 0-02-367412-1.

Lemay, T., Parks, K., Andriashek, L.D., Michael, K., Jean, G., Kempin, E., Stewart, S. (2005). Regional Groundwater Quality Appraisal, Cold Lake-Beaver River Drainage Basin, Alberta. Alberta Energy and Utilities Board, Alberta Geological Survey, Special Report 73.

Levy, G.J., Smith, H.J.C., Agassi, M. (1989). Water temperature effect on hydraulic conductivity and infiltration rate of soils. South African Journal of Plant and Soil, 6(4): pp.240-244.

Lines, L. (2008). Petroleum Geophysics - The Heavy Future. The Leading Edge, Society of Exploration Geophysicists.

McGlade, C.E. (2012). A review of the uncertainties in estimates of global oil resources. Energy, 47(1): pp.262-270.

Moncur, M.C., Paktunc, D., Birks, S.J., Ptacek, C.J., Welsh, B., Thibault, Y. (2015a). Source and distribution of naturally occurring arsenic in groundwater from Alberta's Southern Oil Sands Regions. Applied Geochemistry, 62: pp.171-185.

Moncur, M.C., Birks, S.J., Gibson, J.J., Yi, Y., Paktunc, D. (2015b). Predicting the mobilization of dissolved metals, organics and gas generation from aquifer sediments prior to in situ operations. GeoConvention 2015, Calgary, Alberta, Canada.

Moncur, M.C., Birks, S.J., Taylor, E., Gibson, J.J., Paktunc, D., Welsh, B., Ptacek, C.J. (2016). Occurrence and source of geogenic arsenic in groundwater from the Cold Lake-Beaver River Basin, Alberta. GeoConvention 2016, Calgary, Alberta, Canada.

Morey, G.W., Fournier, R.O., Rowe, J.J. (1962). The solubility of quartz in water in the temperature interval from $25^{\circ}$ to $300^{\circ} \mathrm{C}$. Geochimica et Cosmochimica Acta, 26(10): pp.10291040.

Moses, C.O., Nordstrom, D.K., Herman, J.S., Mills, A.L. (1987). Aqueous pyrite oxidation by dissolved oxygen and by ferric iron. Geochimica et Cosmochimica Acta, 15: pp.1561-1571.

Moses, C.O. and Herman, J.S. (1990). Pyrite oxidation at circumneutral pH. Geochimica et Cosmochimica Acta, 55: pp.471-482.

Muloin, T., and Dudas, M.J. (2005). Aqueous phase arsenic in weathered shale enriched in native arsenic. Journal of Environmental Engineering and Science, 4(6): pp.461-468.

Murphy, R., Strongin, D.R. (2008). Surface reactivity of pyrite and related sulfides. Surface Science Reports, 64: pp.1-45.

Nath, B., Stüben, D., Mallik, S.B., Chatterjee, D., Charlet, L. (2008). Mobility of arsenic in West Bengal aquifers conducting low and high groundwater arsenic. Part I: Comparative hydrochemical and hydrogeological characteristics. Applied Geochemistry, 23: pp.977-995.

Nesbitt, H.W., Bancroft, G.M., Pratt, A.R., Scaini, M.J. (1998). Sulfur and iron surface states on fractured pyrite surfaces. American Mineralogist, 83(9-10): pp.1067-1076. 
Nickson, R.T., McArthur, J.M., Ravenscroft, P., Burgess, W.G., Ahmed, K.M. (2000). Mechanism of arsenic release to groundwater, Bangladesh and West Bengal. Applied Geochemistry, 15: pp.403-413.

Nordstrom, D.K. (1982). Chapter 3 -Aqueous Pyrite Oxidation and the Consequent Formation of Secondary Iron Minerals. Soil Science of America, Acid Sulfate Weathering, Special Publication 10: pp.37-56.

Nordstrom, D.K. (2011). Mine Water: Acidic to Circumneutral. Elements, 7: pp.393-398.

Parkhurst, D.L. and Appelo, C.A.J. (2013). Description of input and examples for PHREEQC version 3 - A Computer Program for Speciation, Batch-reaction, One-Dimensional Transport, and Inverse Geochemical Calculations. U.S. Geological Survey, Water-Resources Investigation Report 99-4259.

Parks, K., Andrashek, L.D., Michael, K., Lemay, T., Stewart, S., Jean, G., Kempin, E. (2005). Regional Groundwater Resource Appraisal, Cold Lake-Beaver River Drainage Basin, Alberta. Alberta Energy and Utilities Board, Alberta Geological Survey, Special Report 74.

Payne, K.B. and Abdel-Fattah, T.M. (2005). Adsorption of Arsenate and Arsenite by IronTreated Activated Carbon and Zeolites: Effects of $\mathrm{pH}$, Temperature, and Ionic Strength. Journal of Environmental Science and Health, Part A, 40(4): pp.723-749.

Pokrovski, G.S., Schott, J., Farges, F., Hazemann, J.L. (2003). Iron(III)-silica interations in aqueous solution: Insights from X-ray adsorption fine structure spectroscopy. Geochimica et Cosmochimica Acta, 67(19): pp.3559-3573.

Rimstidt, J.D., and Barnes, H.L. (1980). The kinetics of silica-water reactions. Geochimica et Cosmochimica Acta, 44: pp.1683-1699.

Rimstidt, J.D. (1997). Quartz solubility at low temperatures. Geochimica et Cosmochimica Acta, 61(13): pp.2553-2558.

Rose, S. and Elliot, W.C. (2000). The effects of pH regulation upon the release of sulfate from ferric precipitates formed in acid mine drainage. Applied Geochemistry, 15(1): pp.27-34.

Rudnick, R.L., and Gao, S. (2003). 3.01 - Composition of the Continental Crust. Treatise on Geochemistry, 3: pp.1-64.

Scheekel, K.G., and Sparks, D.L. (2001). Temperature Effects on Nickel Sorption Kinetics at the Mineral-Water Interface. Soil Science Society of America Journal, 65: pp.719-728.

Schwertmann, U. and Thalmann, H. (1976). The influence of [Fe(II)], [Si], and $\mathrm{pH}$ on the formation of lepidocrocite and ferrihydrite during oxidation of aqueous $\mathrm{FeCl}_{2}$ solutions. Clay Miner, 11(3): pp.189-200.

Schwertmann, U. (1991). Solubility and dissolution of iron oxides. Plant and Soil, 130: pp.1-25. 
Sequeira, L.A. (2014). The Effects of Entrapped Gas Bubbles on Physical Flow and Dissolved Gas Transport - A Sand Tank Experiment. Unpublished M.Sc. Thesis, University of Waterloo, Waterloo, Ontario.

Sjöberg, S. (1996). Silica in aqueous environments. Journal of Non-Crystalline Solids, 196: pp.51-57.

Stüben, D., Berner, Z., Chandrasekharam, D., Karmakar, J. (2003). Arsenic enrichment in groundwater of West Bengal, India: geochemical evidence for mobilization of As under reducing conditions. Applied Geochemistry, 18: pp.1417-1434.

Tao, D.P., Richardson, P.E., Luttrell, G.H., Yoon, R.H. (2003). Electrochemical studies of pyrite oxidation and reduction using freshly-fractured electrodes and rotating ring-disc electrodes. Geochimica et Cosmochimica Acta, 48(24): pp.3615-3623.

Van Breukelen, B.M. and Bonte, M. (2016). Comment on "Thermally Released Arsenic in Porewater from Sediments in the Cold Lake Area of Alberta, Canada". Environmental Science and Technology, 50: pp.7263-7264.

Webster, J.G., and Nordstrom, D.K. (2003). Chapter 4 - Geothermal Arsenic. Arsenic in Groundwater, edited by Welch, A.H. and Stollenwerk, K.G., Kluwer Academic Publishers, ISBN 1-40207-317-8.

White, A.F., Blum, A.E., Bullen, T.D., Vivit, D.V., Shulz, M.S., Fitzpatrick, J. (1999). The effect of temperature on experimental and natural chemical weathering rates of granitoid rocks. Geochimica et Cosmochimica Acta, 63(19/20): pp.3277-3291.

Williams, M.D., and Oostrum, M. (2000). Oxygenation of anoxic water in a fluctuating water table system: an experimental and numerical study. Journal of Hydrology, 230: pp.70-85.

Wood, J.R., and Hewett, T.A. (1982). Fluid convection and mass transfer in porous sandstones a theoretical model. Geochimica et Cosmochimica Acta, 66: pp.1707-1713.

World Health Organization (WHO) (2011). Arsenic in Drinking-water. Guidelines for Drinkingwater Quality, WHO Press, Geneva, Switzerland.

Xiao-quan, S., Bin, C., Long-zhu, J., Yan, Z., Xiao-ping, H., Shi-fen, M. (1992). Determination of sulfur fractions in soils by sequential extraction, inductively coupled plasma-optical emission spectroscopy and ion chromatography. Chemical Speciation and Bioavailability, 4(3): pp.97-103.

You, C.F., Spivak, A.J., Gieskes, J.M, Rosenbauer, R., Bishoff, J.L. (1995). Experimental study of boron geochemistry: implications for fluid processes in subduction zones. Geochimica et Cosmochimica Acta, 59: pp.2435-2442.

Zheng, Y., Stute, M., van Geen, A., Gavrieli, I., Dhar, R., Simpson, H.J., Schlosser, P., Ahmed, K.M. (2004). Redox control of arsenic mobilization in Bangladesh groundwater. Applied Geochemistry, 19: pp.201-214. 
Zuhl, R.W. and Amjad, Z. (2014). Mineral Scales in Biological and Industrial Systems, Chapter 10. Taylor \& Francis Group, Boca Raton, Florida. ISBN: 978-4665-6868-6. 


\section{Appendix I}

\section{Experiment 1}

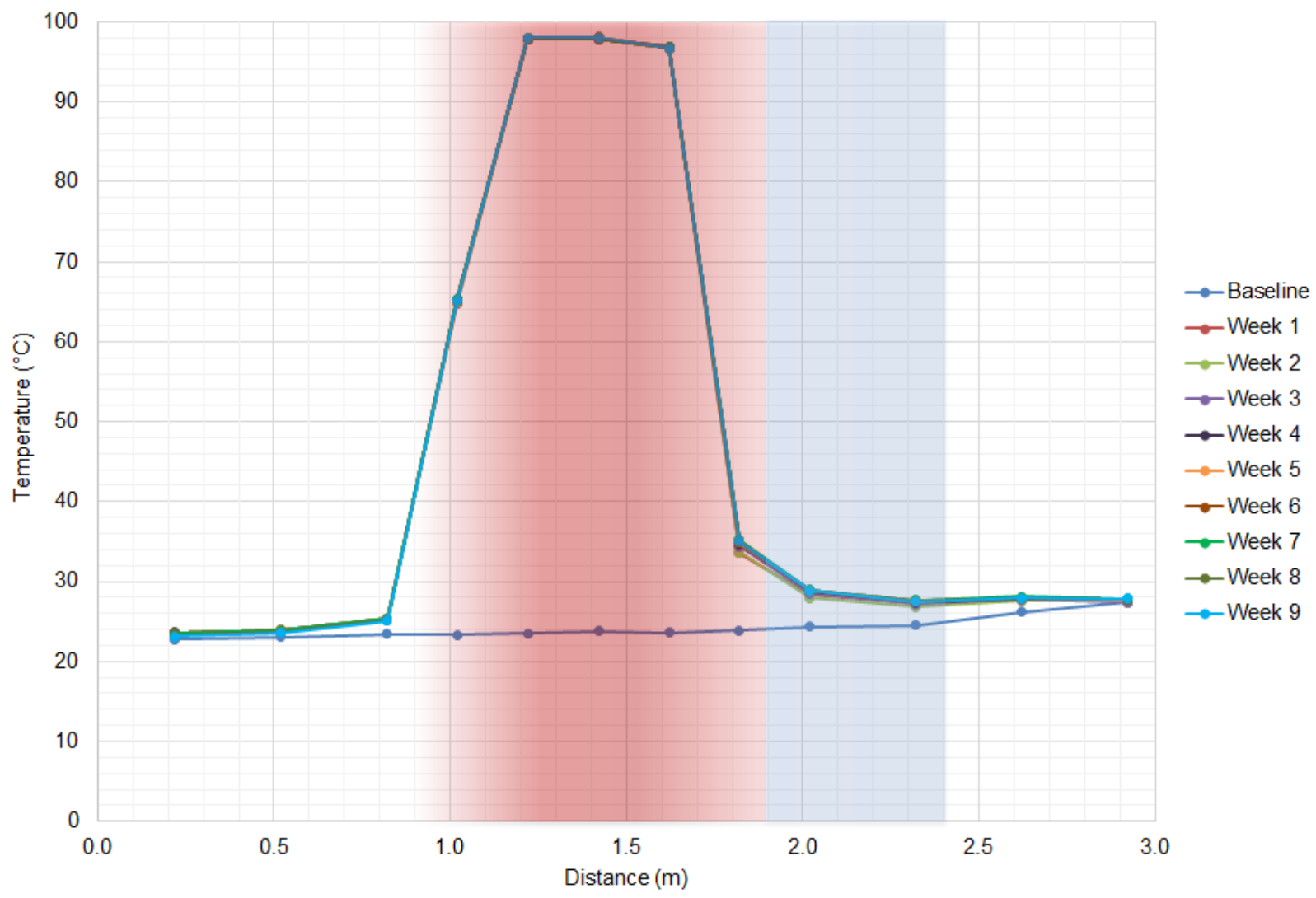

Figure A1.1. Column profile of average weekly temperatures over the duration of unheated (Baseline) and heated conditions (Weeks 1 to 9) from Experiment 1. The red shaded area from $1.0 \mathrm{~m}$ to $1.9 \mathrm{~m}$ represents the heating section, as well as the area where downgradient temperatures were elevated in comparison to ambient conditions. The blue shaded area from 1.9 $\mathrm{m}$ to $2.4 \mathrm{~m}$ indicates where the cooling section is located. 


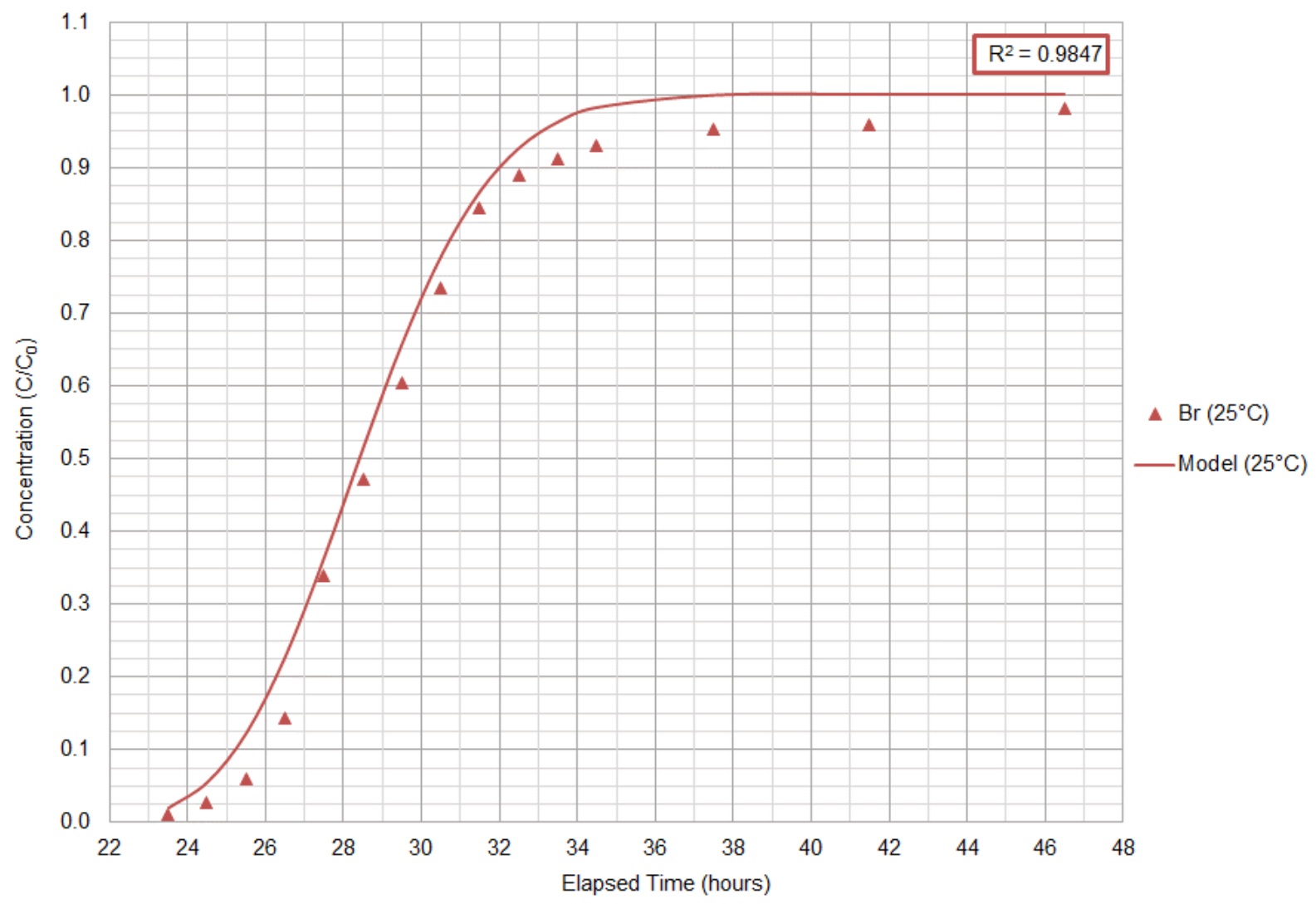

Figure A1.2. Bromide tracer breakthrough data and modeled curve at $25^{\circ} \mathrm{C}$ from the $0.5 \mathrm{~m}$ sampling port on the column in Experiment 1. 


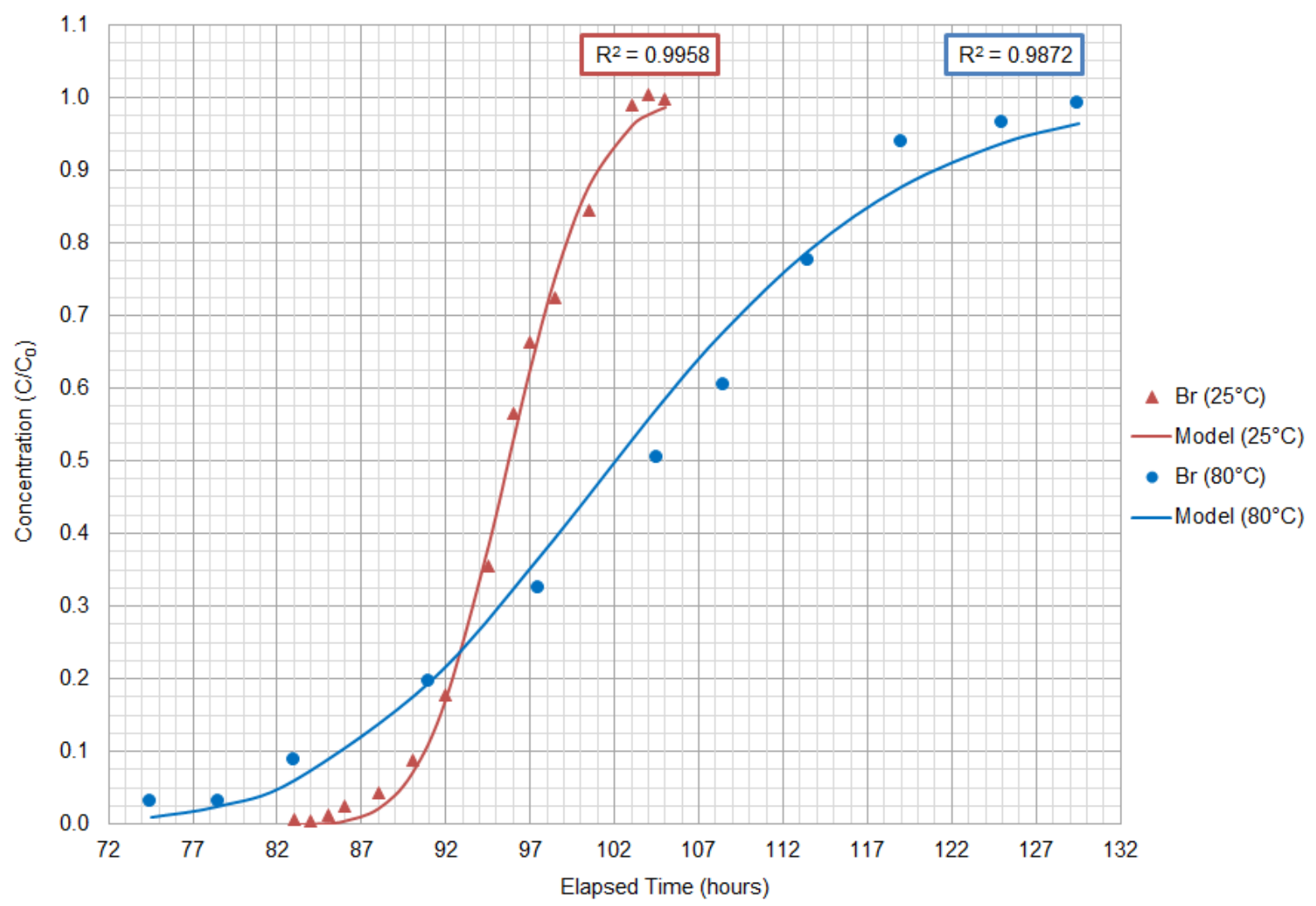

Figure A1.3. Bromide tracer breakthrough data and modeled curve at $25^{\circ} \mathrm{C}$ and $80^{\circ} \mathrm{C}$ from the $1.7 \mathrm{~m}$ sampling port on the column in Experiment 1. 


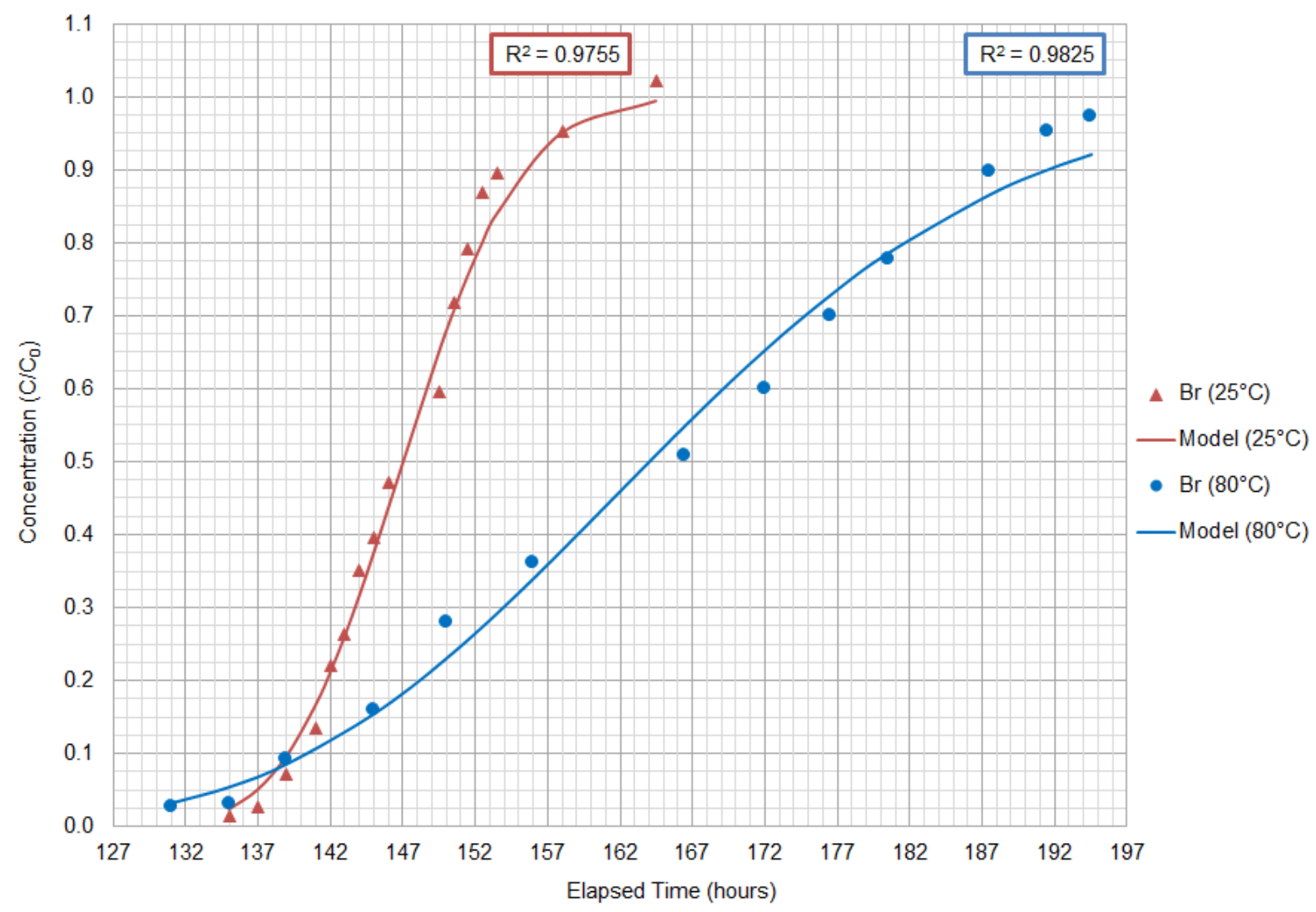

Figure A1.4. Bromide tracer breakthrough data and modeled curve at $25^{\circ} \mathrm{C}$ and $80^{\circ} \mathrm{C}$ from the $2.5 \mathrm{~m}$ sampling port on the column in Experiment 1. 


\section{Experiment 2}

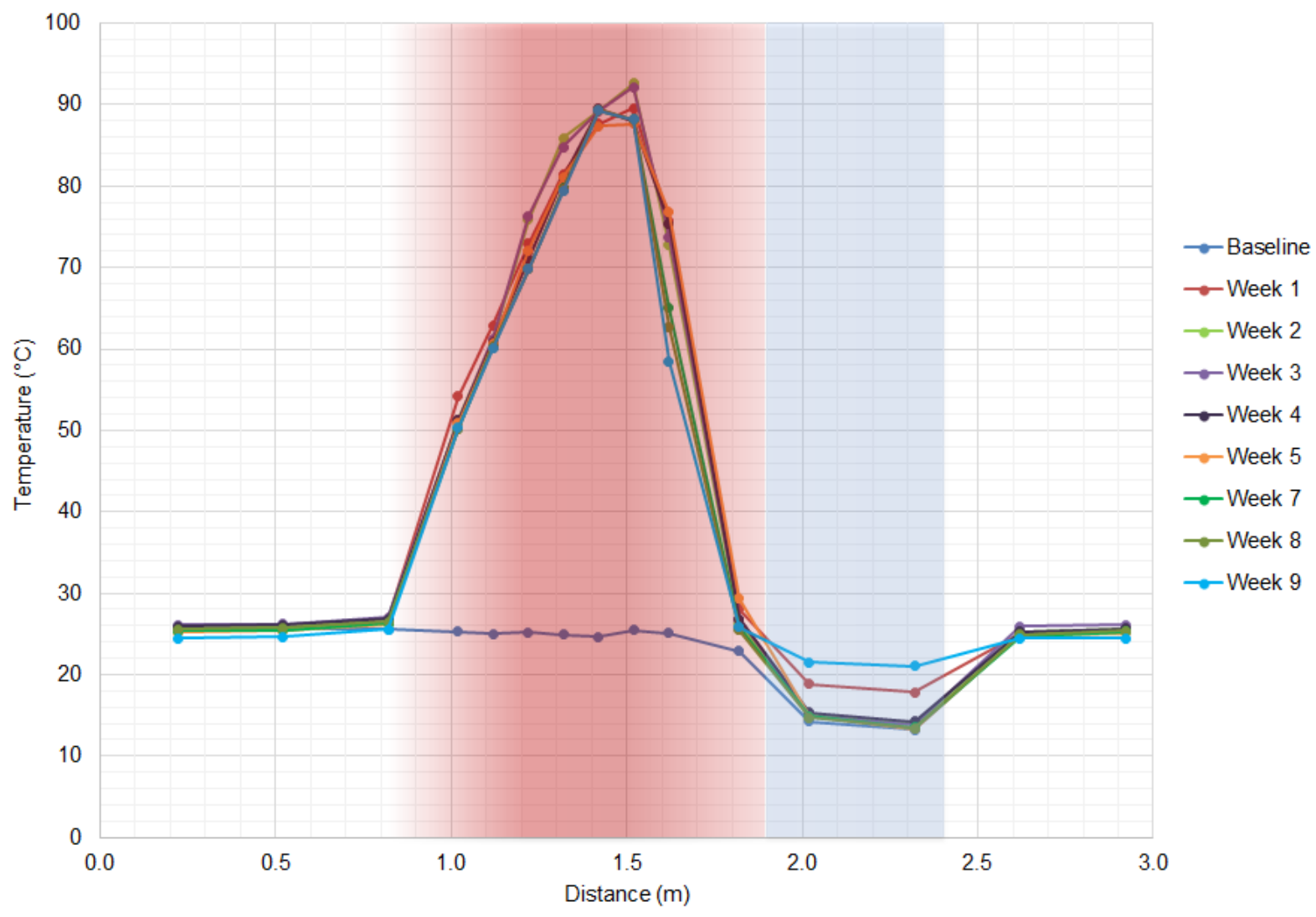

Figure A1.5. Temperature profile of the column during the aerobic unheated (baseline) and heated phase of Experiment 2. 


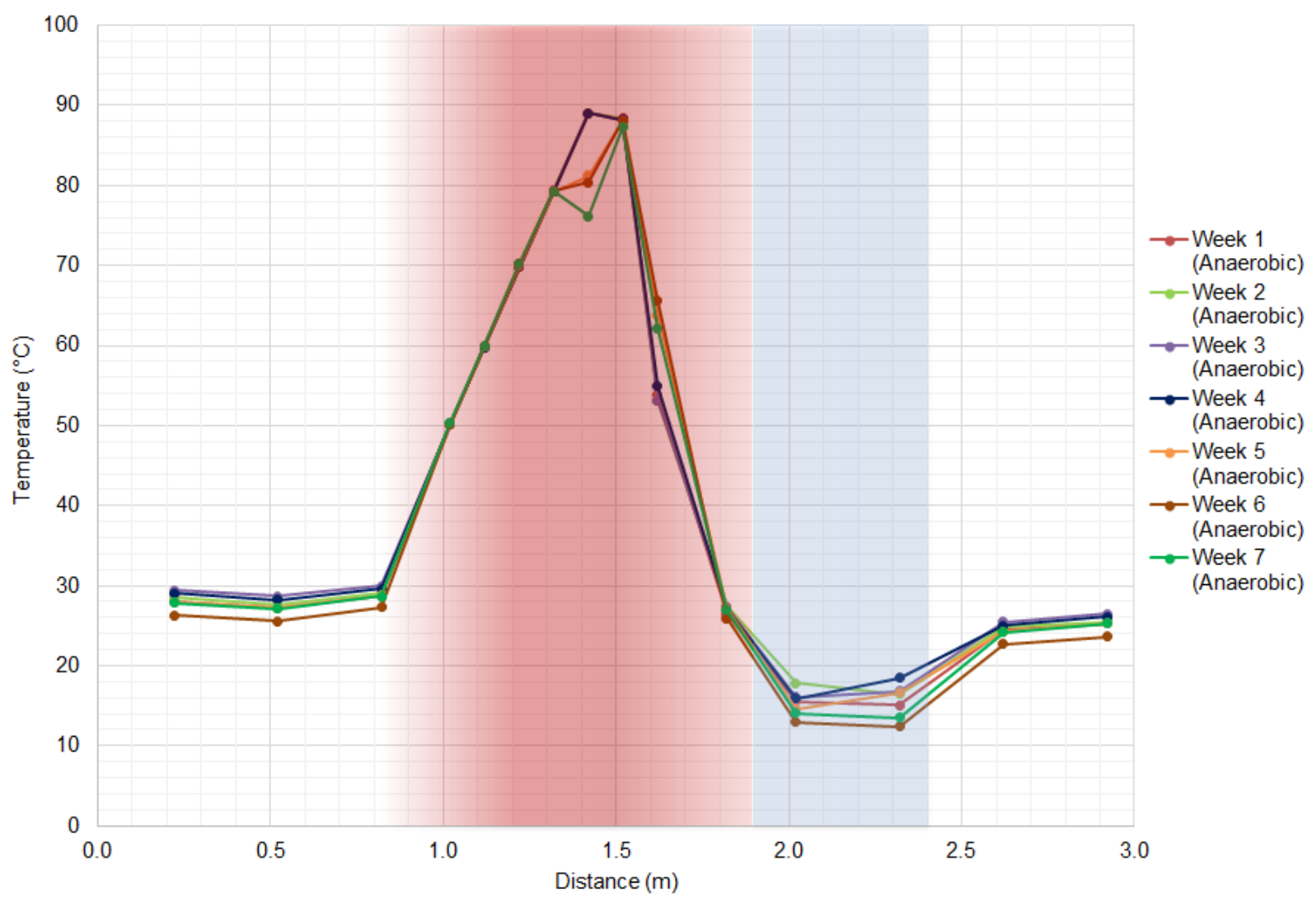

Figure A1.6. Temperature profile of the column over the duration of the heated anaerobic conditions from Experiment 2. 


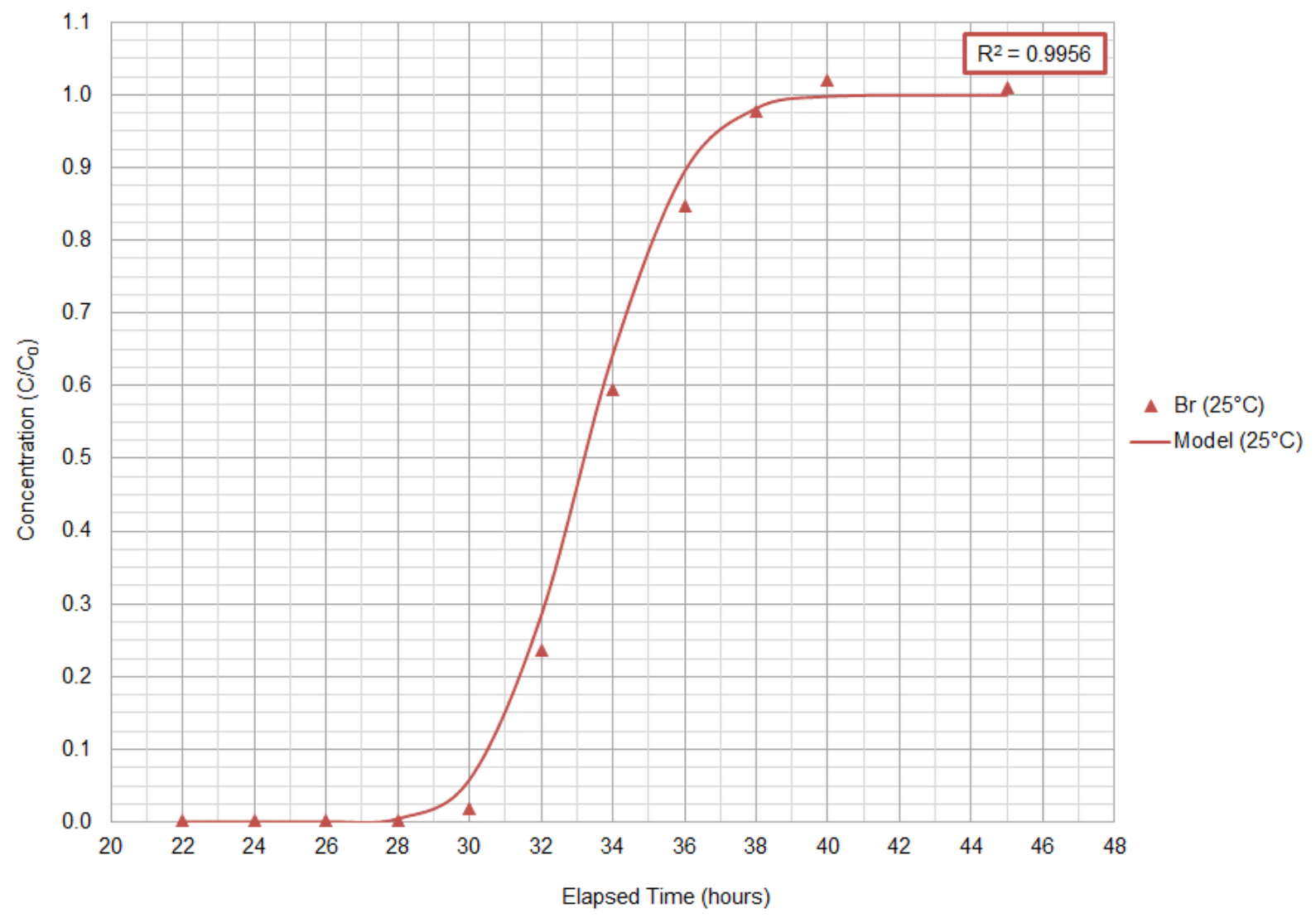

Figure A1.7. Bromide tracer breakthrough data and modeled curve at $25^{\circ} \mathrm{C}$ from the sampling port located at $0.5 \mathrm{~m}$ in Experiment 2 . 


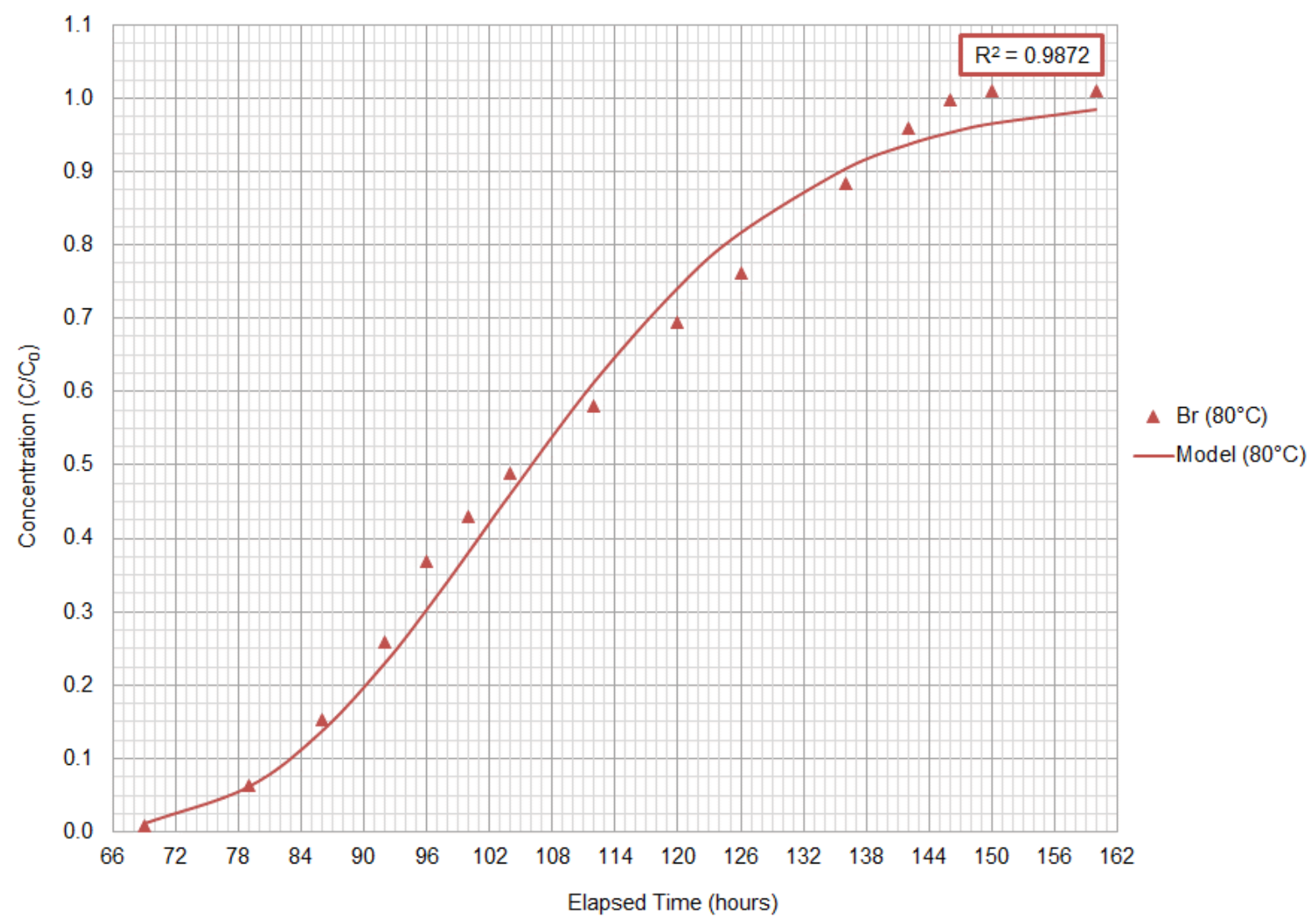

Figure A1.8. Bromide tracer breakthrough data and modeled curve at $80^{\circ} \mathrm{C}$ from the sampling port at $1.7 \mathrm{~m}$ in Experiment 2. 


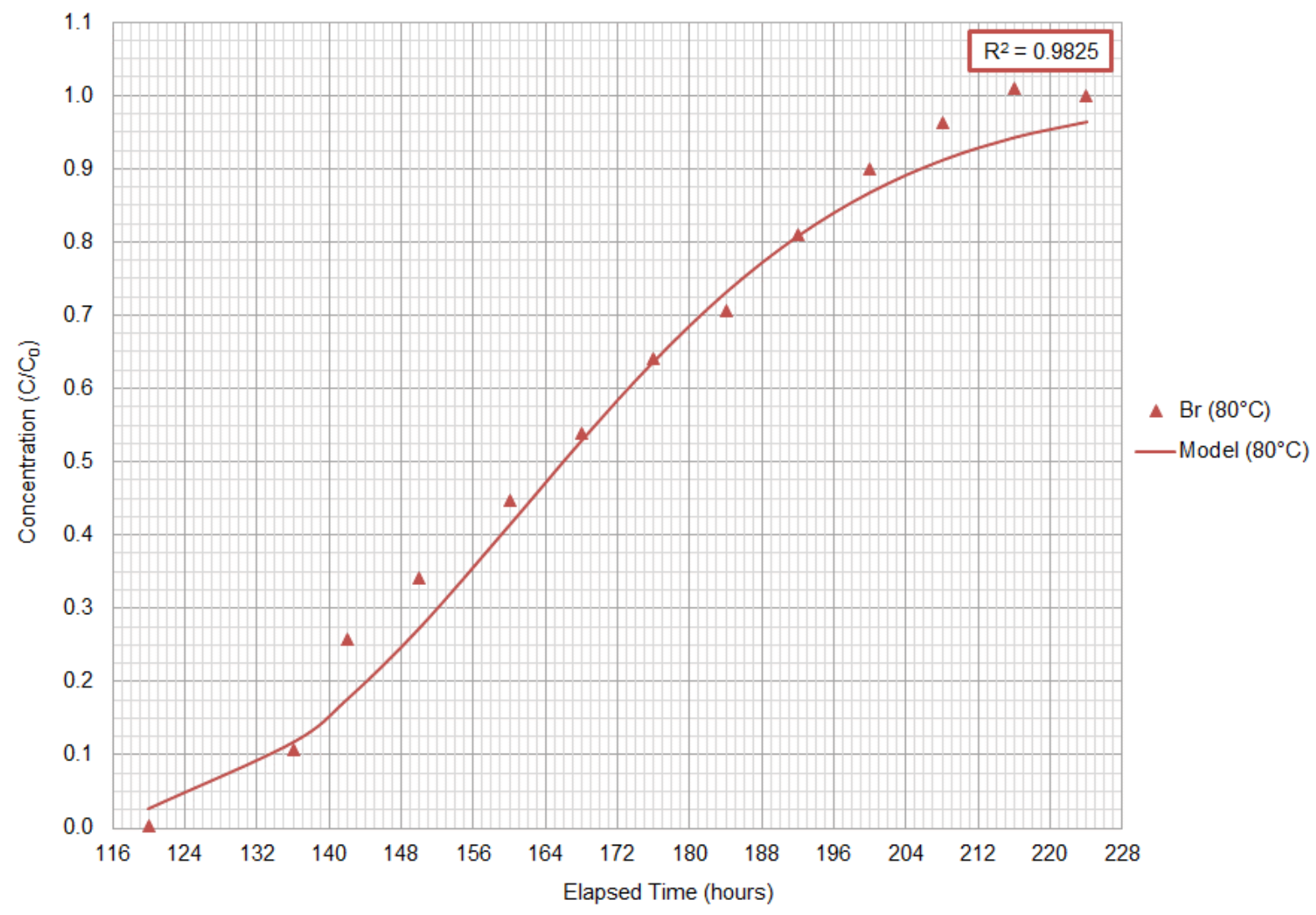

Figure A1.9. Bromide tracer breakthrough data and modeled curve at $80^{\circ} \mathrm{C}$ from the sampling port located at $2.5 \mathrm{~m}$ in Experiment 2. 


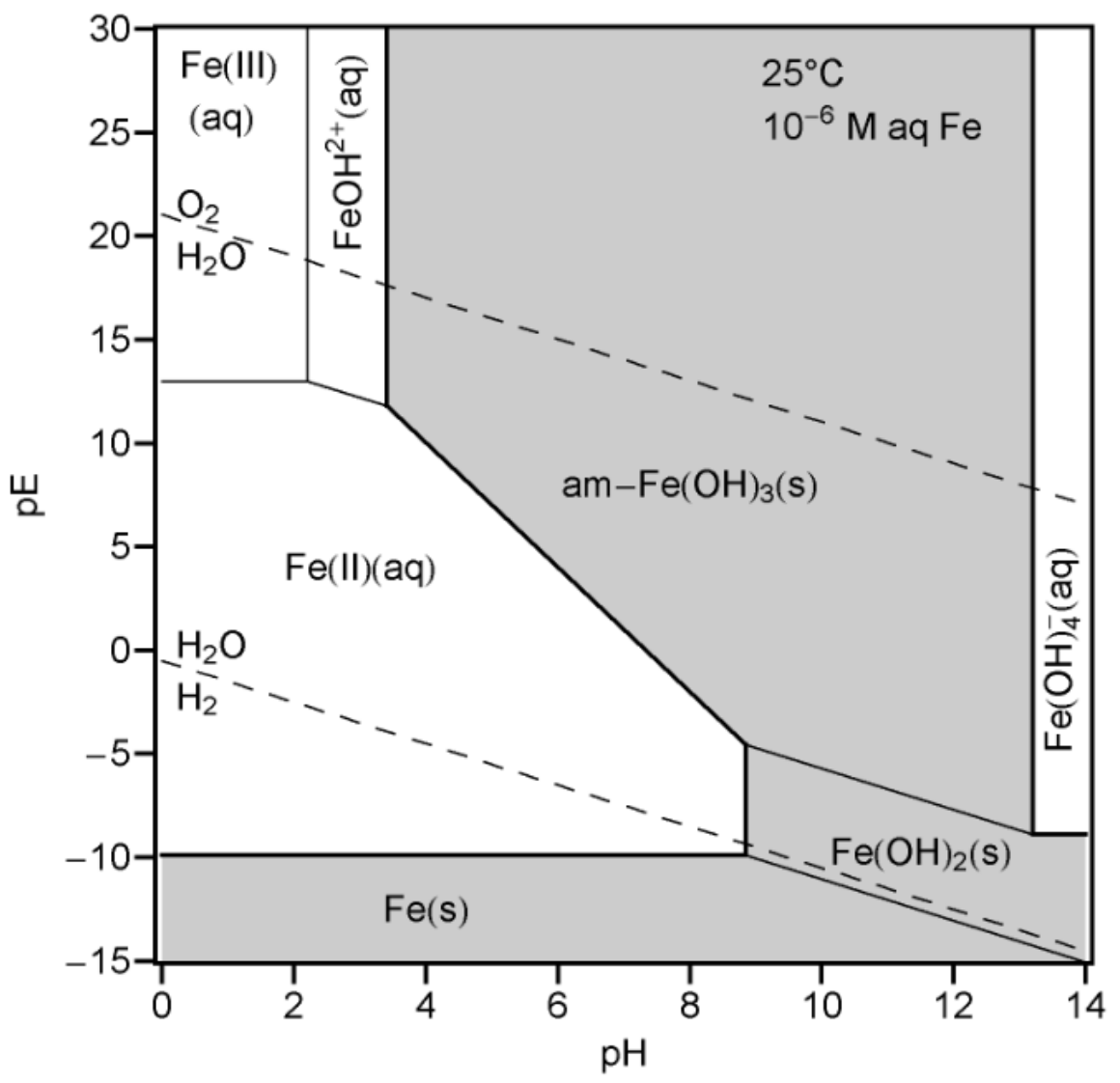

Figure A1.10. Pourbaix diagram for iron. 


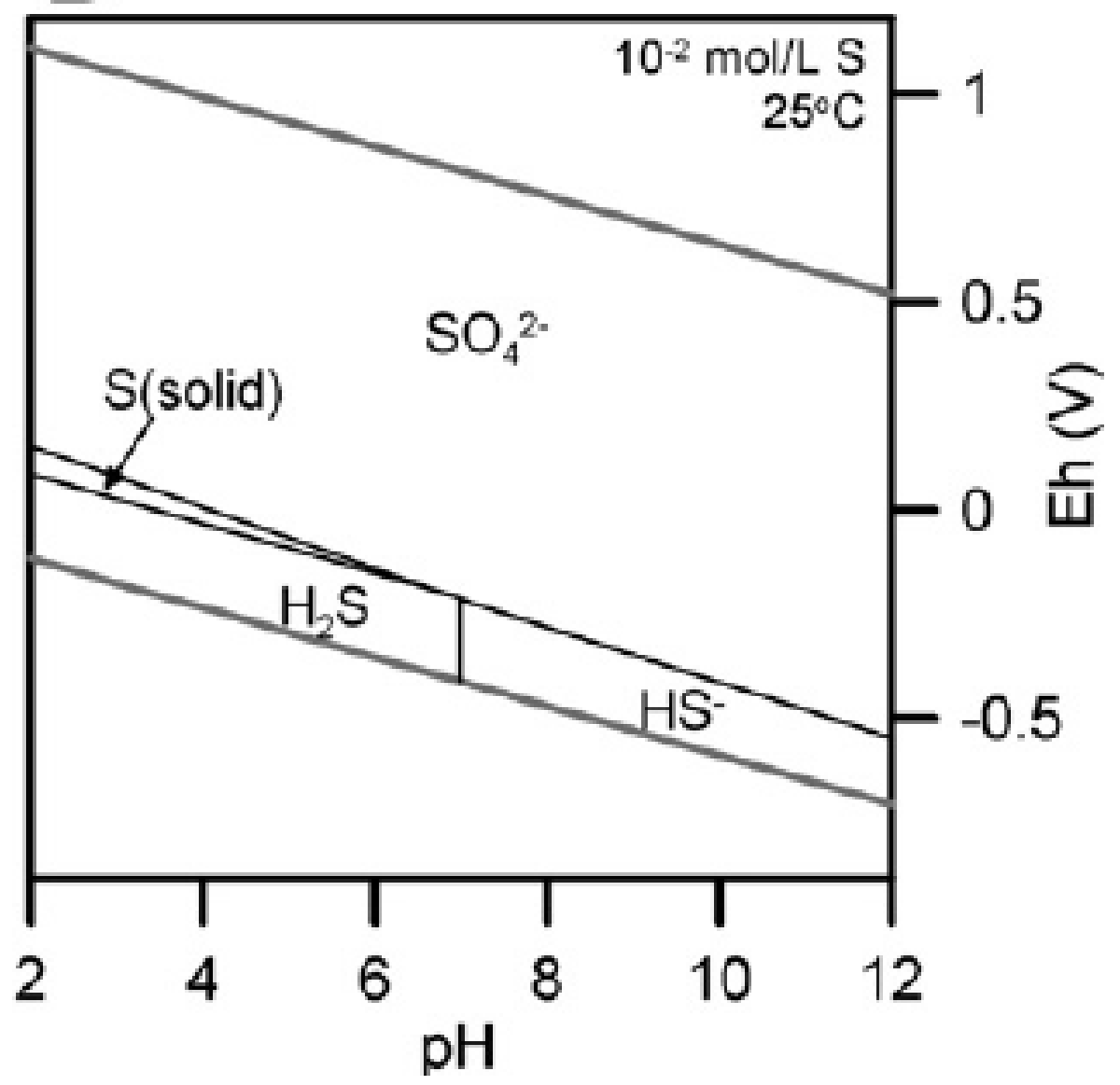

Figure A1.11. Pourbaix diagram for sulfur. 


\section{Experiment 3}

Table A1.1. Quantitative data for SEM-EDS micrograph shown in Figure 39.

\begin{tabular}{|c|c|c|}
\hline Element & Weight\% & Atomic\% \\
\hline $\mathrm{C} \mathrm{K}$ & 3.66 & 13.99 \\
\hline $\mathrm{O} \mathrm{K}$ & 19.74 & 56.64 \\
\hline $\mathrm{Al} \mathrm{K}$ & 1.03 & 1.76 \\
\hline $\mathrm{Si} \mathrm{K}$ & 3.49 & 5.71 \\
\hline $\mathrm{P} \mathrm{K}$ & 0.81 & 1.20 \\
\hline $\mathrm{K} \mathrm{K}$ & 0.27 & 0.32 \\
\hline $\mathrm{Ca} \mathrm{K}$ & 1.39 & 1.59 \\
\hline Fe K & 20.78 & 17.08 \\
\hline As L & 0.90 & 0.55 \\
\hline Au M & 4.93 & 1.15 \\
\hline Totals & 57.02 & \\
\hline
\end{tabular}

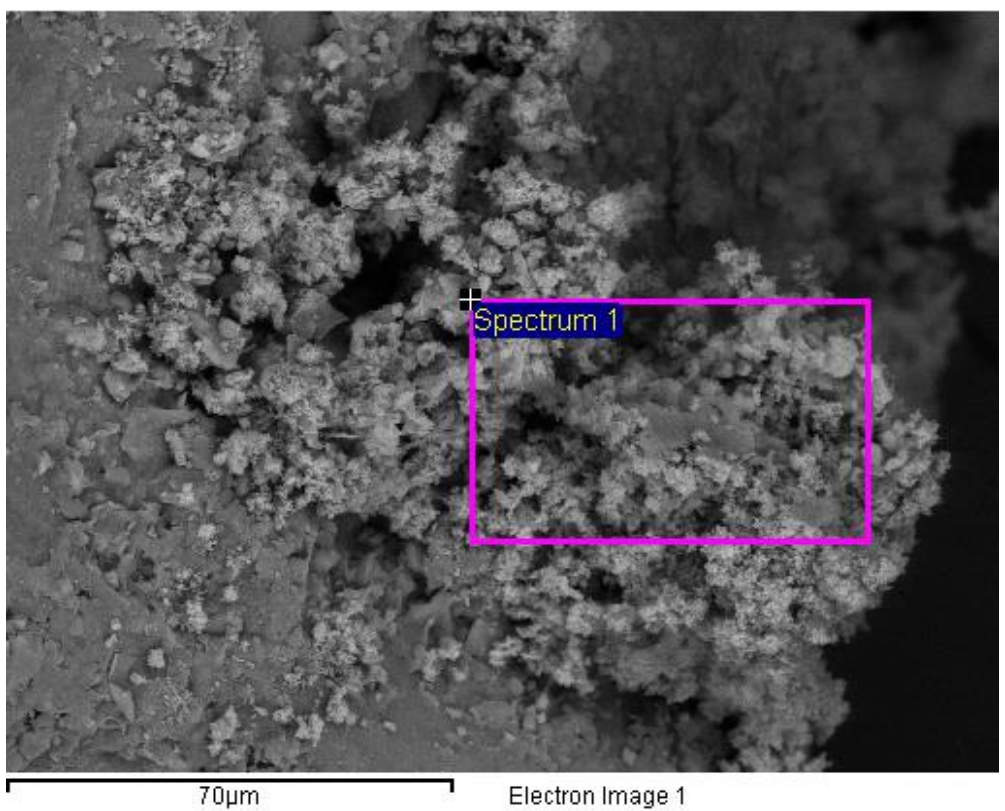

Figure A1.12. The area of SEM-EDS analysis for the micrograph shown in Figure 39. 


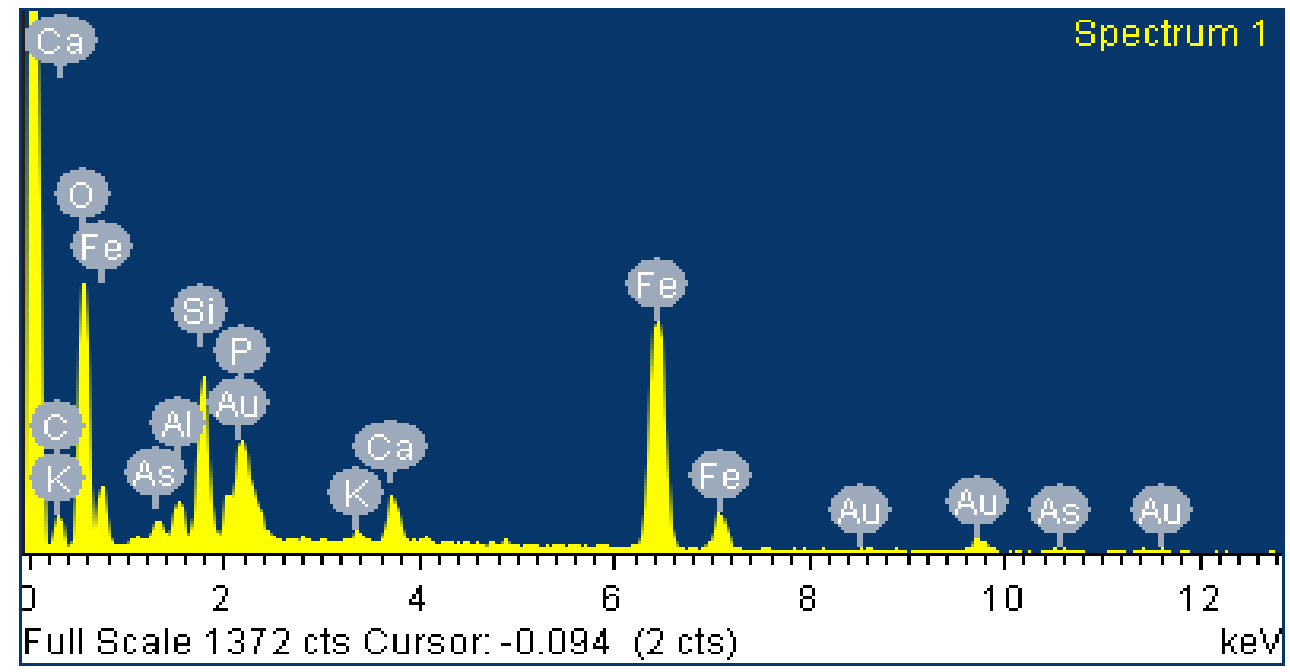

Figure A1.13. The spectrometry signal produced from the SEM-EDS analysis for the micrograph shown in Figure 39. 
Table A1.2. Summary of XRF data from Alberta sediment samples.

\begin{tabular}{|c|c|c|c|}
\hline Element & $\begin{array}{c}\text { Bulk Sample } 1 \\
(\text { ppm) }\end{array}$ & $\begin{array}{l}\text { Bulk Sample } 2 \\
\text { (ppm) }\end{array}$ & $\begin{array}{l}\text { Mean (ppm) } \\
\quad \mathrm{n}=\mathbf{2}\end{array}$ \\
\hline $\mathrm{Al}$ & 150,650 & 65,910 & $108,280 \pm 42,370$ \\
\hline $\mathrm{Ba}$ & 1053 & 1548 & $1300.5 \pm 247.5$ \\
\hline $\mathrm{Ca}$ & 22,410 & 28,090 & $25,250 \pm 2,840$ \\
\hline $\mathrm{Co}$ & 28 & 21 & $24.5 \pm 3.5$ \\
\hline $\mathrm{Cr}$ & 95 & 8 & $51.5 \pm 43.5$ \\
\hline $\mathrm{Cu}$ & 80 & 189 & $134.5 \pm 54.5$ \\
\hline $\mathrm{Fe}$ & 59,370 & 32,140 & $45,755 \pm 13,615$ \\
\hline K & 26,670 & 11,150 & $18,910 \pm 7,760$ \\
\hline $\mathrm{La}$ & 36 & 34 & $35 \pm 1$ \\
\hline $\mathrm{Mg}$ & 16,530 & 6,230 & $11,380 \pm 5150$ \\
\hline $\mathrm{Mn}$ & 930 & 1,460 & $1,195 \pm 265$ \\
\hline $\mathrm{Na}$ & 10,920 & 8,270 & $9,595 \pm 1,325$ \\
\hline $\mathrm{Nb}$ & 11 & 12 & $11.5 \pm 0.5$ \\
\hline $\mathrm{Ni}$ & 80 & 67 & $73.5 \pm 6.5$ \\
\hline $\mathrm{P}$ & 1,060 & 1,310 & $1,185 \pm 125$ \\
\hline $\mathrm{Pb}$ & 46 & 9 & $27.5 \pm 18.5$ \\
\hline $\mathrm{Rb}$ & 224 & 104 & $164 \pm 60$ \\
\hline $\mathrm{S}$ & 1155 & 1156 & $1,155.5 \pm 0.5$ \\
\hline $\mathrm{Si}$ & 695,770 & 833,210 & $764,490 \pm 68,720$ \\
\hline $\mathrm{Sr}$ & 212 & 144 & $178 \pm 34$ \\
\hline $\mathrm{Ti}$ & 6,160 & 2,660 & $4,410 \pm 1,750$ \\
\hline Th & 28 & 10 & $19 \pm 9$ \\
\hline $\mathrm{U}$ & 17 & 0 & $8.5 \pm 8.5$ \\
\hline V & 92 & 13 & $52.5 \pm 39.5$ \\
\hline $\mathrm{Y}$ & 0 & 22 & $11 \pm 11$ \\
\hline $\mathrm{Zn}$ & 112 & 62 & $87 \pm 25$ \\
\hline
\end{tabular}




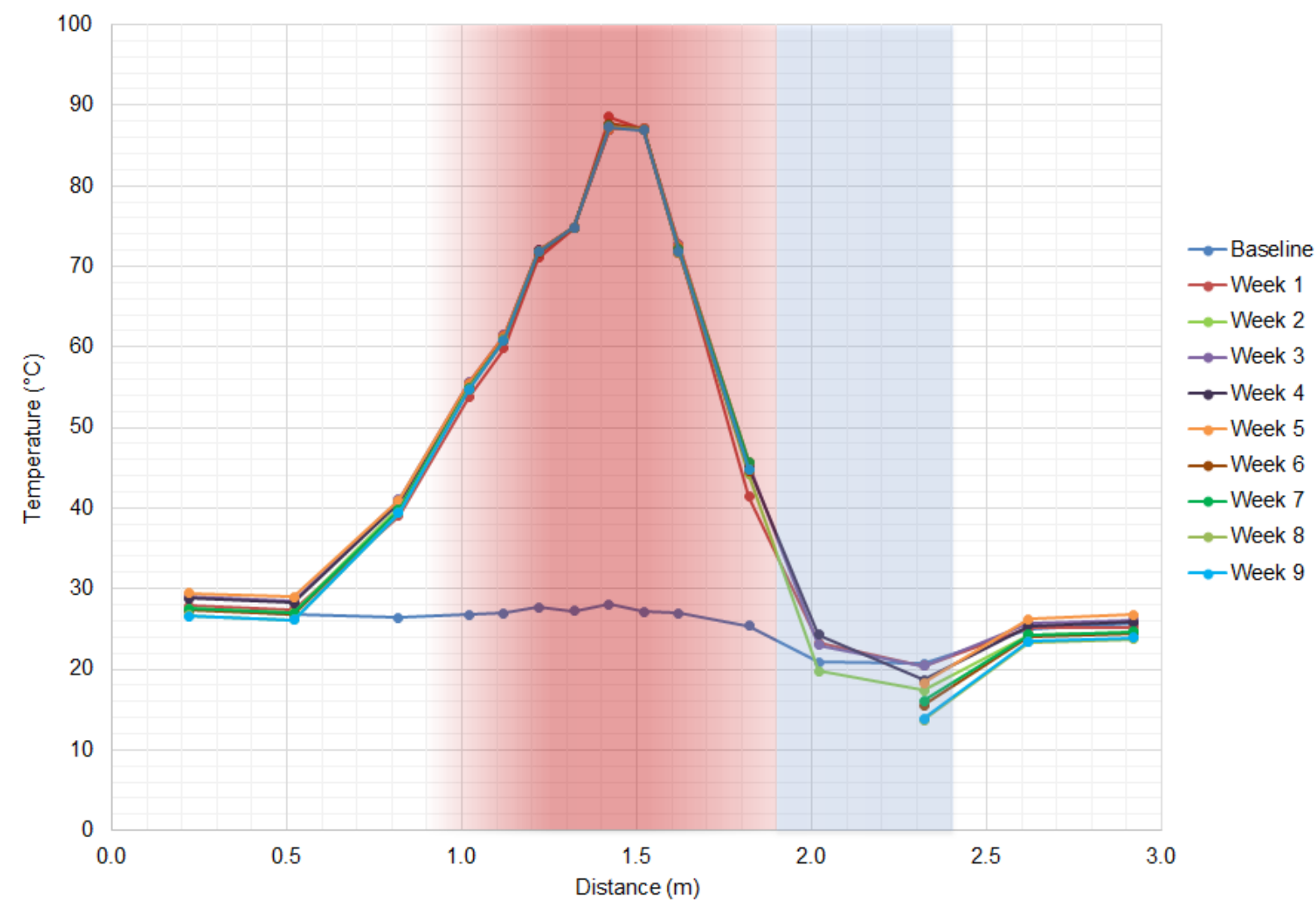

Figure A1.14. Temperature profile of the column over the duration of the unheated (baseline) and heated phase of Experiment 3. 


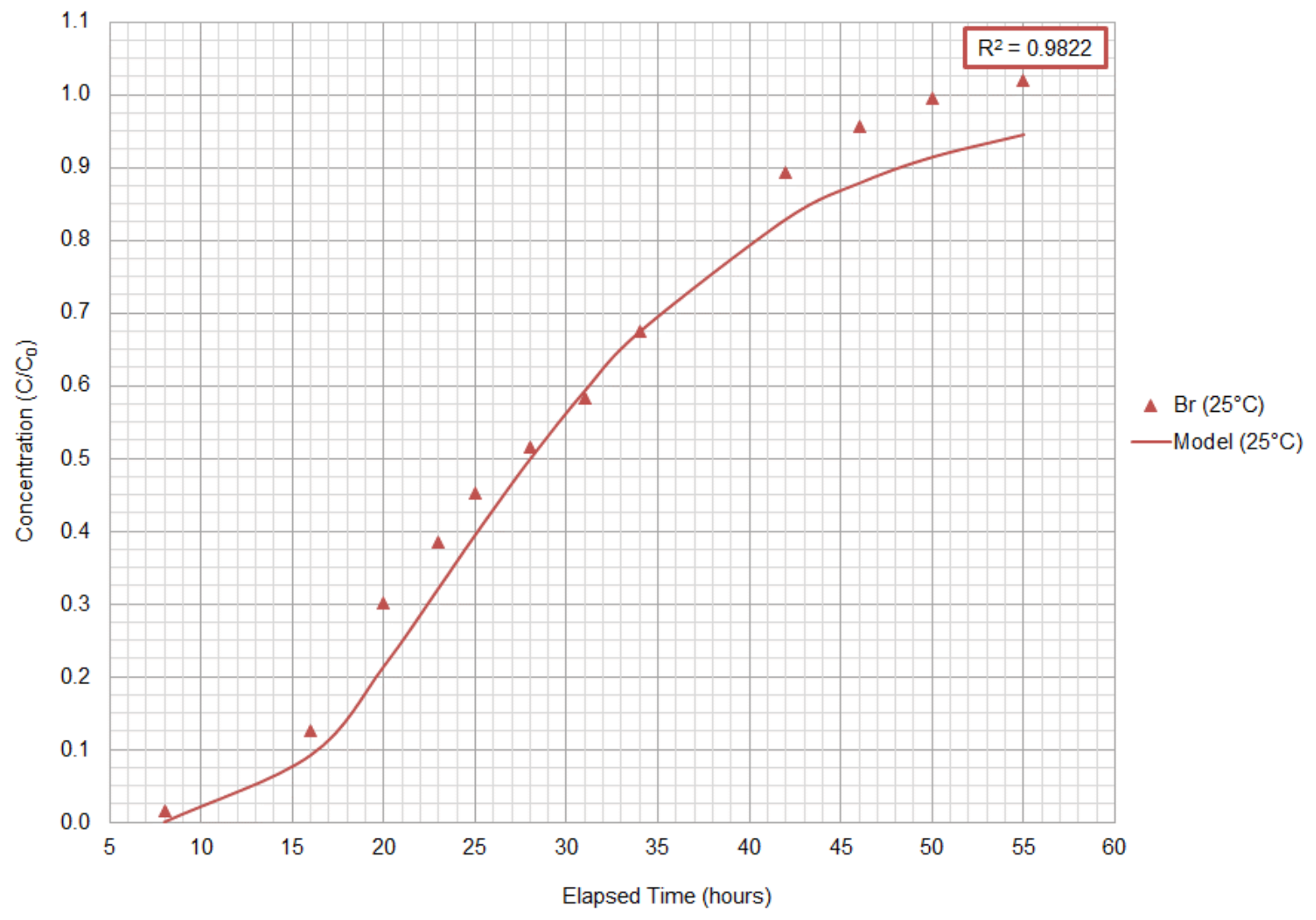

Figure A1.15. Bromide tracer breakthrough data and modeled curve at $25^{\circ} \mathrm{C}$ from the $0.5 \mathrm{~m}$ sampling port on the column for Experiment 3. 


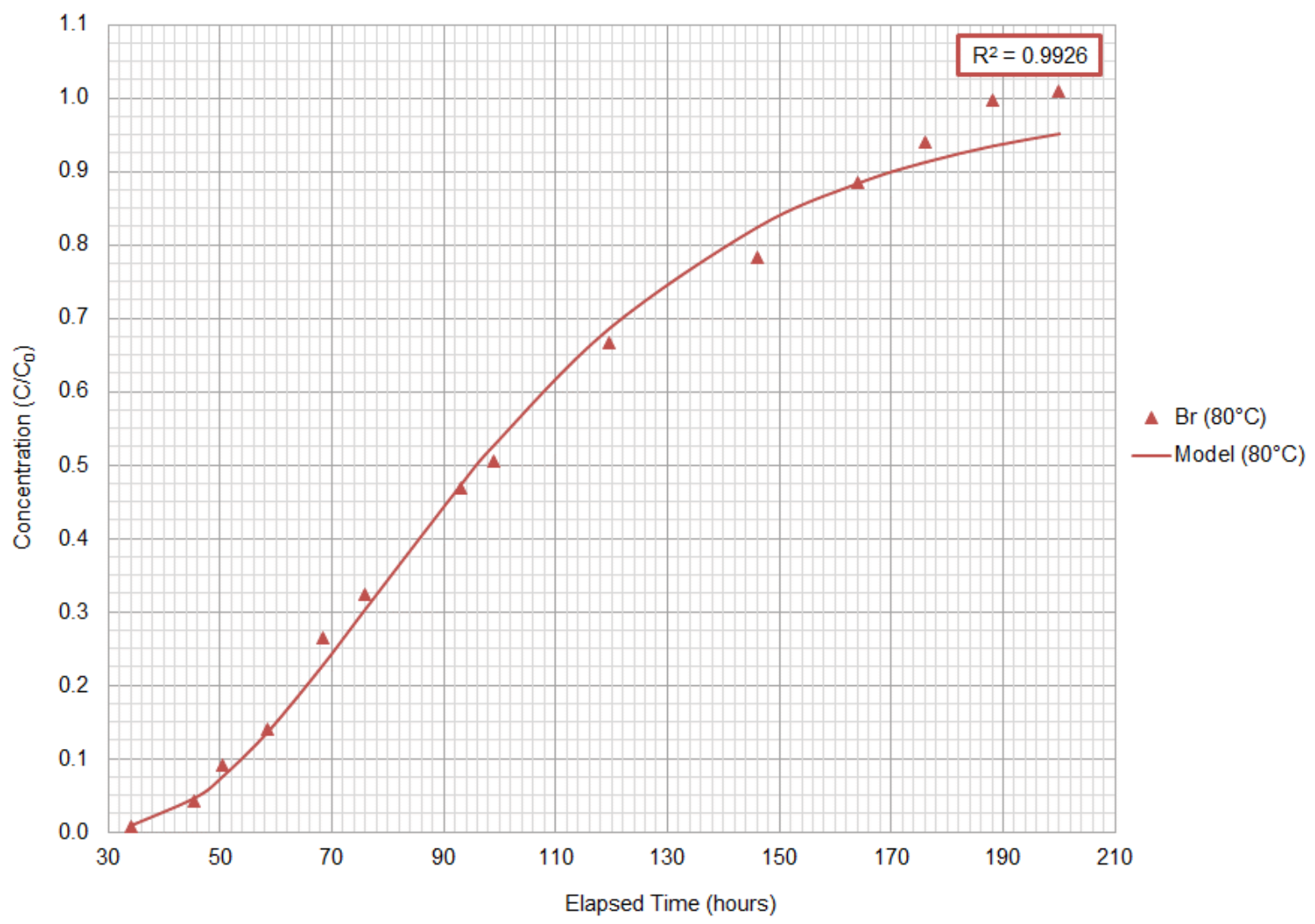

Figure A1.16. Bromide tracer breakthrough data and modeled curve at $80^{\circ} \mathrm{C}$ from the $1.7 \mathrm{~m}$ sampling port on the column for Experiment 3. 


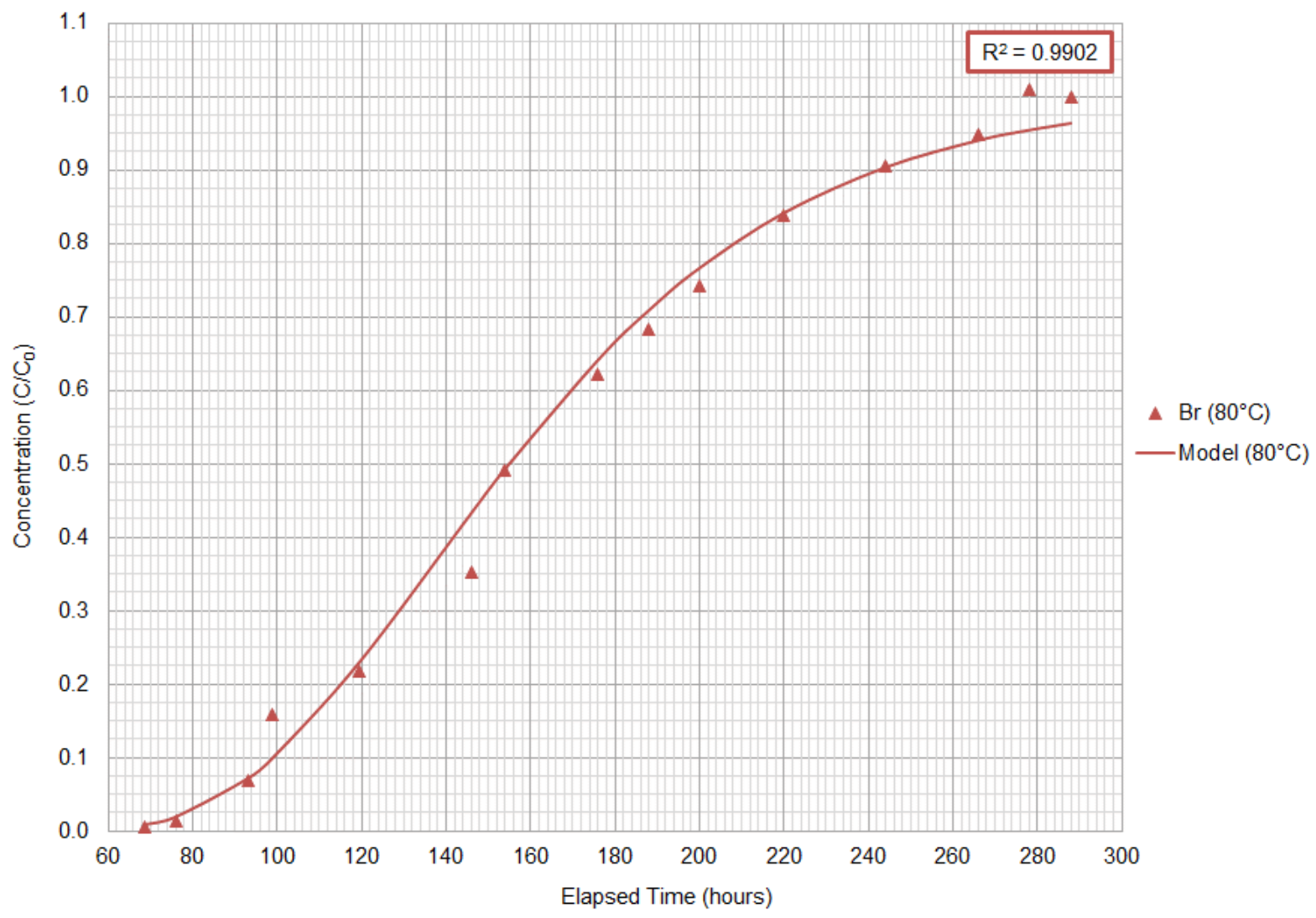

Figure A1.17. Bromide tracer breakthrough data and modeled curve at $80^{\circ} \mathrm{C}$ from the $2.5 \mathrm{~m}$ sampling port on the column for Experiment 3. 